UNIVERSIDADE DE SÃO PAULO

FACULDADE DE ECONOMIA, ADMINISTRAÇÃO E CONTABILIDADE DEPARTAMENTO DE ADMINISTRAÇÃO PROGRAMA DE PÓS-GRADUAÇÃO EM ADMINISTRAÇÃo

ESTUDO DA CONTRIBUIÇÃO DOS PARCEIROS ESTABELECIDOS EM REDES DE INOVAÇÃO PARA O DESEMPENHO INOVADOR DE EMPRESAS DA INDÚSTRIA ELÉTRICA ELETRÔNICA

Silvye Ane Massaini

Orientador: Prof. Dr. Fábio Lotti Oliva 
Prof. Dr. João Grandino Rodas

Reitor da Universidade de São Paulo

Prof. Dr. Reinaldo Guerreiro

Diretor da Faculdade de Economia, Administração e Contabilidade

Prof. Dr. Adalberto Américo Fischmann

Chefe do Departamento de Administração

Prof. Dr. Lindolfo Galvão de Albuquerque Coordenador do Programa de Pós-Graduação em Administração 


\section{ESTUDO DA CONTRIBUIÇÃO DOS PARCEIROS ESTABELECIDOS EM REDES DE INOVAÇÃO PARA O DESEMPENHO INOVADOR DE EMPRESAS DA INDÚSTRIA ELÉTRICA ELETRÔNICA}

Dissertação apresentada ao Programa de PósGraduação em Administração da Faculdade de Economia, Administração e Contabilidade da Universidade de São Paulo, para obtenção do título de Mestre em Ciências.

Orientador: Prof. Dr. Fábio Lotti Oliva

Versão Corrigida

(versão original disponível na Faculdade de Economia, Administração e Contabilidade)

\section{SÃO PAULO}


FICHA CATALOGRÁFICA

Elaborada pela Seção de Processamento Técnico do SBD/FEA/USP

Massaini, Silvye Ane

Estudo da contribuição dos parceiros estabelecidos em redes de inovação para o desempenho inovador de empresas da indústria elétrica eletrônica / Silvye Ane Massaini. - São Paulo, 2013.

$216 \mathrm{p}$.

Dissertação (Mestrado) - Universidade de São Paulo, 2013.

Orientador: Fábio Lotti Oliva.

1. Inovações tecnológicas - Administração 2. Relações interorganizacionais 3. Avaliação de desempenho 4. Redes de inovações I. Universidade de São Paulo. Faculdade de Economia, Administração e Contabilidade II. Título.

$$
\text { CDD }-658.514
$$


Dedico este trabalho aos meus pais e à minha avó que, com sabedoria, amor e dedicação, forneceram um exemplo de caráter, luta e determinação. 


\section{AGRADECIMENTOS}

É com imensa satisfação que agradeço a todos aqueles que, de alguma forma, contribuíram para a realização deste trabalho.

Primeiramente, agradeço aos meus pais, que sempre me apoiaram em minhas decisões. À minha mãe, por todo amor e por me dar forças para prosseguir.

Ao Prof. Dr. Fábio Lotti Oliva, meu orientador, que acreditou no meu trabalho e que, com dedicação e paciência, esteve presente em todas as etapas desta jornada.

Ao Prof. Dr. Silvio Aparecido dos Santos, por sua atenção e sugestões para a concretização desta dissertação.

À Profa. Dra. Maria Aparecida Gouvêa, por todo apoio e pelos ensinamentos, que contribuíram enormemente para o desenvolvimento desta pesquisa.

À Associação Brasileira de Indústria Elétrica e Eletrônica (ABINEE), especialmente ao Sr. Fabián Yaksic e ao Sr. Wesley Giachini, pela colaboração e auxílio no processo de coleta de dados.

Aos Professores Paulo de Tarso Muzy, Luiz Eduardo de Abreu da Cunha e Armando Terribili Filho por gentilmente compartilharem seus conhecimentos.

Ao Prof. José Maria Rodriguez Ramos, pela leitura atenciosa e contribuição indispensável para o aprimoramento deste trabalho.

Aos meus queridos amigos e colegas de trabalho, por serem ótimos ouvintes e críticos.

A todos os professores do Programa de Pós-graduação em Administração da FEA-USP, que contribuíram para a minha formação e agregaram vivências tão significativas.

Aos meus colegas do curso, que tornaram essa experiência muito mais interessante e agradável. 
"O que nos torna imediatamente felizes é a alegria do pensamento, pois essa boa qualidade se recompensa logo, por si mesma." 


\section{RESUMO}

As redes de inovação têm sido frequentemente referenciadas na literatura como forma de complementar as atividades inovadoras das empresas, tendo em vista seu importante papel na transferência de conhecimentos. Considerando-se que, cada vez mais, a inovação pode ser fruto de um processo de interação entre diferentes atores, do que de um esforço isolado, o presente estudo teve por objetivo verificar qual a contribuição dos parceiros estabelecidos em redes de inovação para o desempenho inovador das empresas. Pretendeu-se, mais especificamente, realizar uma análise sob o ponto de vista das empresas da Indústria Elétrica Eletrônica, que, por pertencerem a um setor de tecnologia intensiva, cuja competitividade é global, são altamente dependentes da atividade inovativa. Visando ao alcance desse objetivo, realizou-se uma pesquisa descritiva e exploratória, de caráter quantitativo. Para o exame dos fundamentos teóricos, foram abordados conceitos relacionados aos tipos de inovação, às redes de inovações e suas tipologias, à transferência de conhecimento na rede, à utilização de estratégias de exploração e explotação, à capacidade de absorção do conhecimento e aos tipos de parceiros estabelecidos nas redes e suas possíveis contribuições. Complementarmente, realizou-se um levantamento por meio da aplicação de questionários, totalizando uma amostra de 185 empresas. A análise dos dados da pesquisa foi feita com base na estatística descritiva e multivariada, por meio da aplicação da modelagem de equações estruturais e da análise multivariada de variância. Dentre os principais resultados, foi observado que o estabelecimento de relações de colaboração com clientes e consumidores, competidores e universidades e institutos de pesquisa pode corroborar com os resultados em inovação de processo e organizacional. Ressalta-se também que, apesar da obtenção de alguns resultados significativos acerca da contribuição de diferentes parceiros na rede, as empresas da Indústria Elétrica Eletrônica ainda atribuem maior importância às atividades internas para inovar. Em outras palavras, apesar do alto número de relações com clientes, consumidores e fornecedores, ainda se nota uma centralização do processo de desenvolvimento das inovações.

Palavras-chave: Redes de inovação. Colaboração interorganizacional. Desempenho em Inovação. 


\begin{abstract}
Innovation networks have been frequently referenced in literature as a way to complement the firm's innovative activities, in view of its important role in knowledge transfer. Considering that, currently, innovation may be the result of a process of interaction between different actors, rather than an isolated effort, this study aims to verify the contribution of partners established in innovation networks for company's innovative performance. It was intended, more specifically, to perform an analysis from the point of view of Electrical Electronic Industry firms, which, for belonging to a technology-intensive industry, are highly dependent on innovative activity. As a way of reaching this purpose, a descriptive and exploratory research was applied, based on the quantitative method. In the theoretical research, concepts related to innovation types, innovation networks and their typologies, the transfer of knowledge in the network, the use of exploration and exploitation strategies, the absorptive capacity, the types of partners established in the networks and their possible contributions have been addressed. In addition, a survey was applied to a total sample of 185 companies. The data examination was performed using descriptive and multivariate statistics, by applying the structural equation modeling and multivariate analysis of variance. As the main findings, it was observed that the establishment of collaborative relationships with clients and customers, competitors and universities and research institutes can corroborate to process and organizational innovation. It also emphasized that, despite getting some significant results concerning the contribution of different partners in the network, Industry Electrical Electronics' companies also attach more importance to internal activities to develop their innovations. In other words, despite of the high number of relationships with customers, suppliers and consumers, it still noticed a centralization of developing innovations' processes.
\end{abstract}

Keywords: Innovation networks. Interorganizational collaboration. Innovative performance. 


\section{SUMÁRIO}

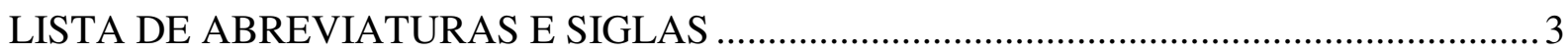

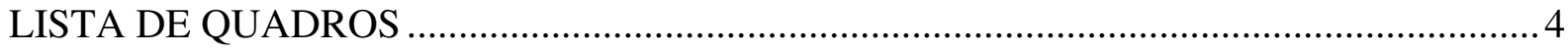

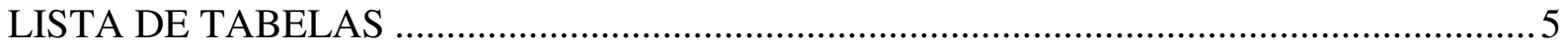

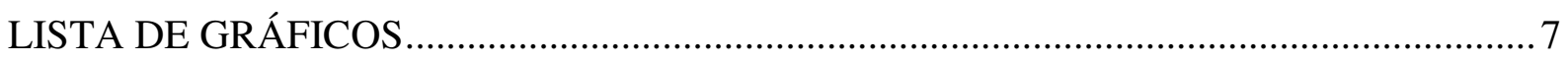

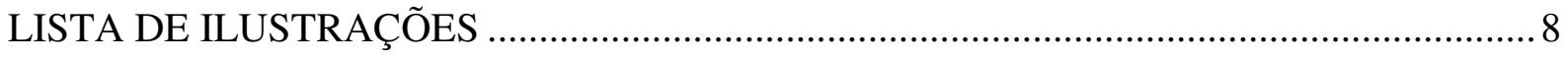

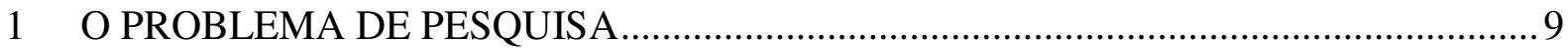

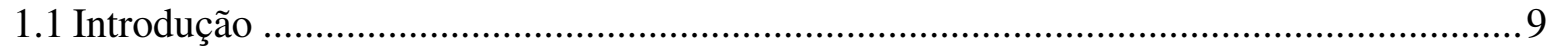

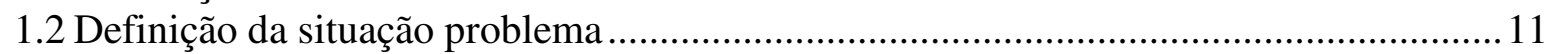

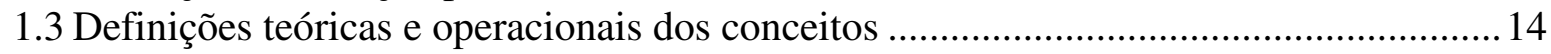

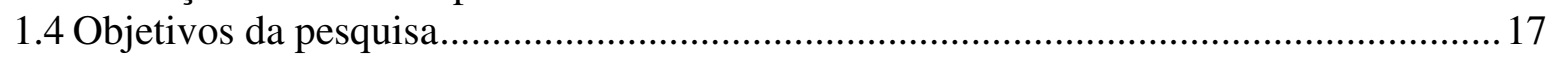

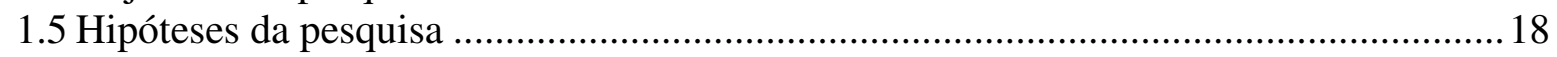

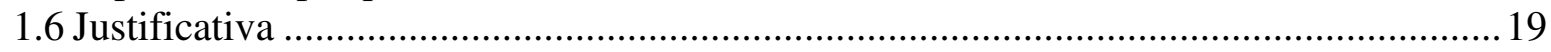

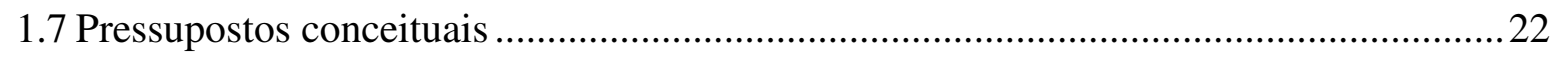

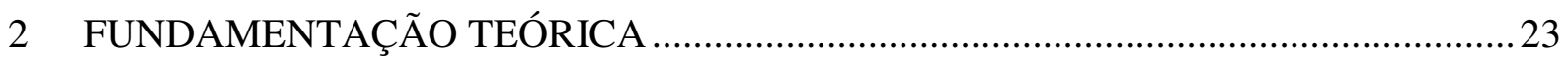

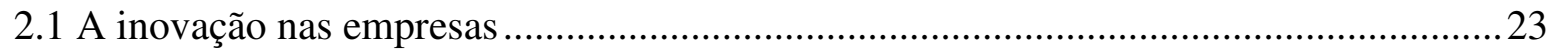

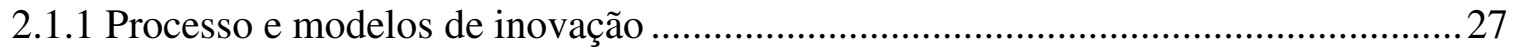

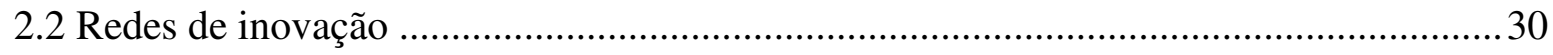

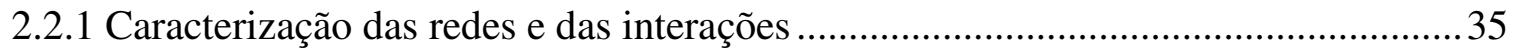

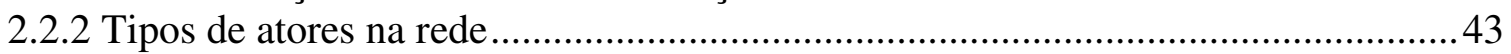

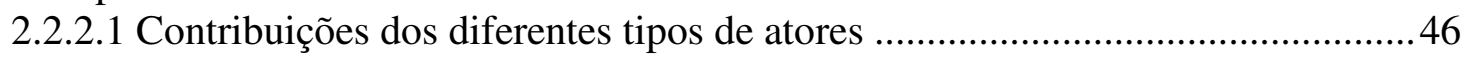

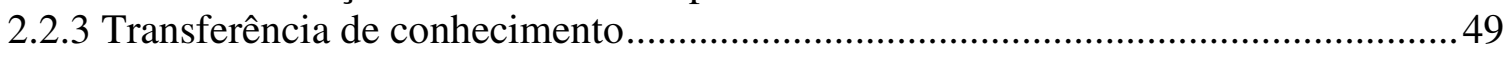

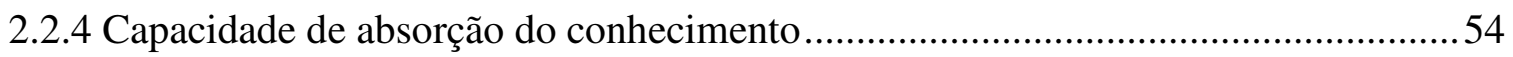

2.2.5 Estratégias de exploração e explotação do conhecimento .......................................55

2.2.6 Fatores motivadores para a formação de redes de inovação .....................................58

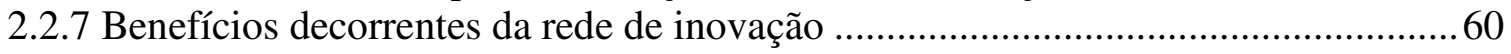

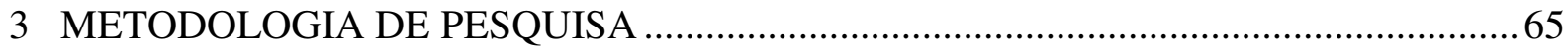

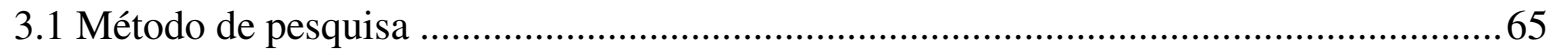

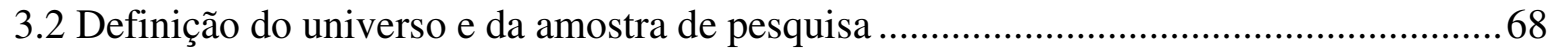

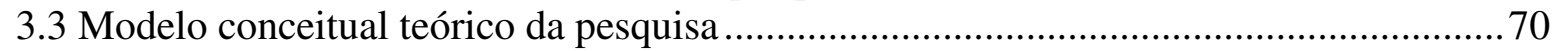

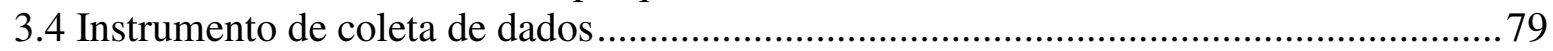

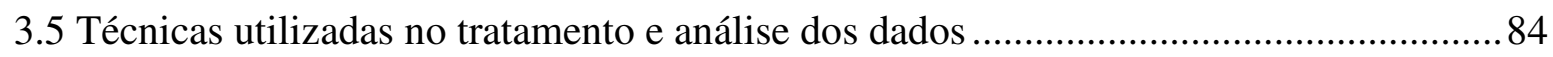

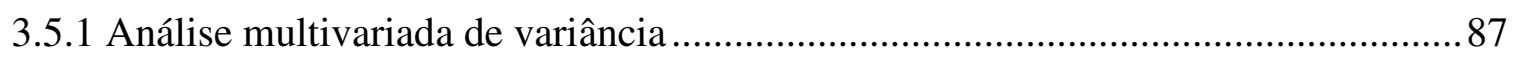

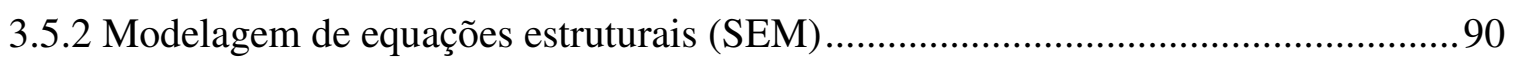

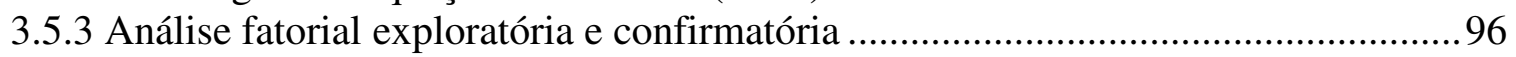

3.5.4 Considerações sobre a utilização da SEM neste trabalho ....................................... 99

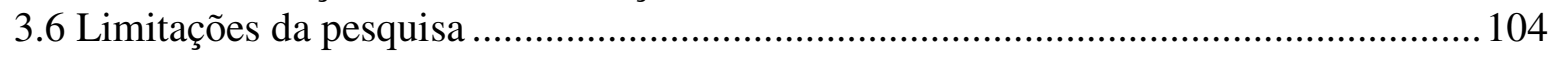

4 APRESENTAÇÃO E ANÁLISE DOS RESULTADOS DA PESQUISA ........................ 107

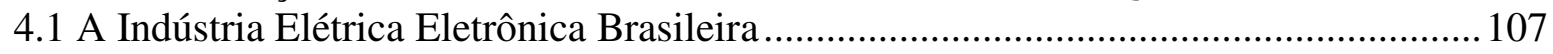

4.1.1 Inovação na Indústria Elétrica Eletrônica ............................................................. 114

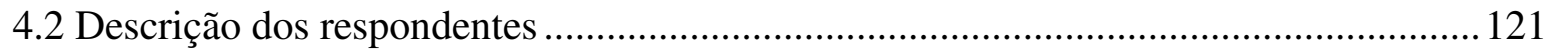

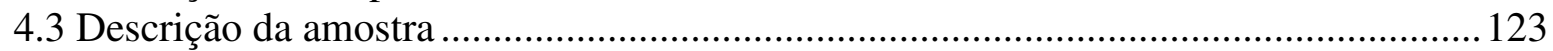

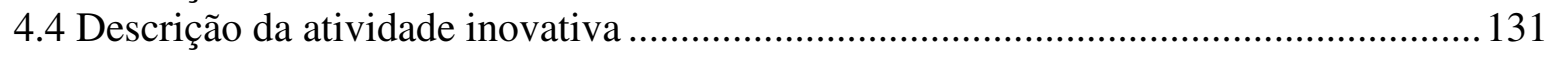

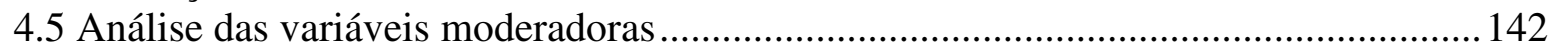




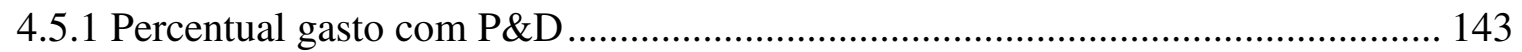

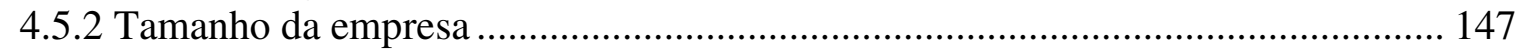

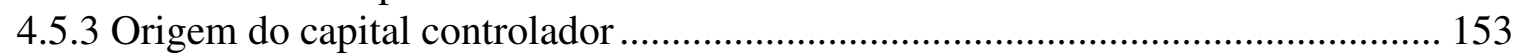

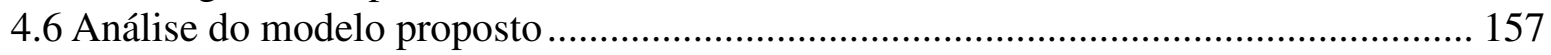

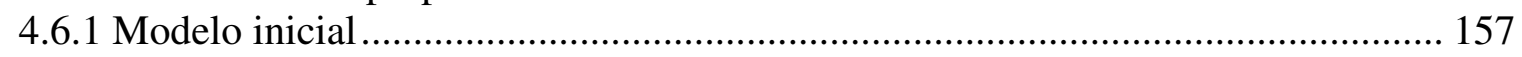

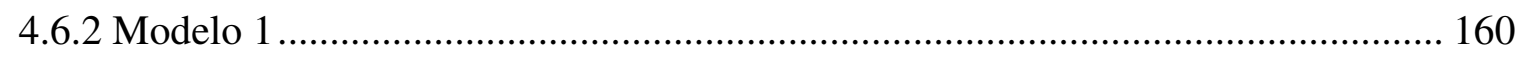

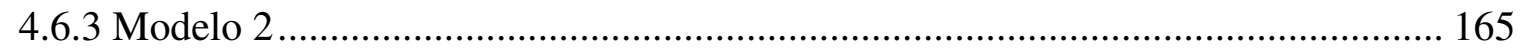

4.7 Análise das hipóteses testadas e resumo dos resultados da pesquisa ......................... 171

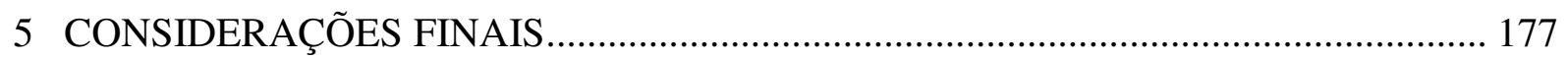

5.1 Limitações do estudo e recomendações para futuras pesquisas ................................. 182

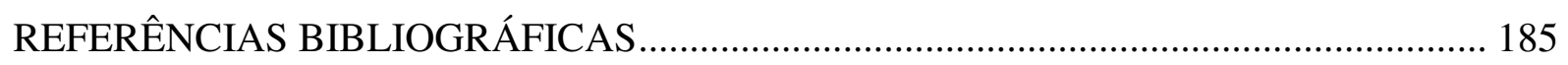

APÊNDICE 1 - INSTRUMENTO DE COLETA DE DADOS ............................................. 197

APÊNDICE 2 - SOLICITAÇÃO DE APOIO À PESQUISA .............................................. 205

APÊNDICE 3 - COMUNICADO AOS ASSOCIADOS DA ABINEE ................................. 206 


\section{LISTA DE ABREVIATURAS E SIGLAS}

ABINEE: Associação Brasileira da Indústria Elétrica e Eletrônica

ADF: Asymptotically Distribution-Free

AMOS: Análise de Estruturas de Momento

ANOVA: Análise de Variância

ASV: Average Shared Squared Variance

AVE: Average Variance Extracted

BRICS: Brasil, Rússia, Índia, China e África do Sul

CFA: Confirmatory Factor Analysis

CFI: Comparative Fit Index

CIS: Community Innovation Survey

CR: Composite Reliability

EFA: Exploratory Factor Analysis

EQS: Equações

GFI: Goodness of Fit Index

GLS: Generalized Least Squares

GOF: Goodness of fit

GTD: Geração, Transmissão e Distribuição

IBGE: Instituto Brasileiro de Geografia e Estatística

IFI: Incremental Fit Index

INSEAD: Institut Européen d'administration des Affaires

LISREL: Linear Structural Relations

MANOVA: Análise Multivariada de Variância

MLE: Maximum Likelihood Estimation

MSV: Maximum Shared Squared Variance

OCDE: Organização para Cooperação e Desenvolvimento Econômico

P\&D\&I: Pesquisa, desenvolvimento e inovação

P\&D: Pesquisa e desenvolvimento

PADIC: Programa de Apoio ao Desenvolvimento Tecnológico da Indústria de Componentes

PINTEC: Pesquisa de Inovação Tecnológica

PME's: Pequenas e médias empresas

RMSEA: Root Mean Square Error of Approximation

SEM: Structural equation modeling

SPSS: Statistical Package for the Social Sciences

SRMR: Standardized Root Mean Residuals

TI: Tecnologia da informação

TIC: Tecnologias da Informação e Comunicação

VE: Variância extraída

WIPO: World Intellectual Property Organization 


\section{LISTA DE QUADROS}

Quadro 1 - Tipos de inovação....

Quadro 2 - Relação entre resultados em inovação de produto e processo e colaboração com fornecedores

Quadro 3 - Relação entre resultados em inovação de produto e processo e colaboração com clientes

Quadro 4 - Formas de compartilhamento do conhecimento.....

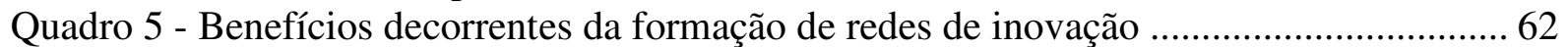

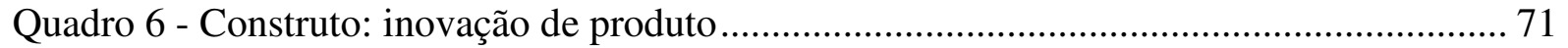

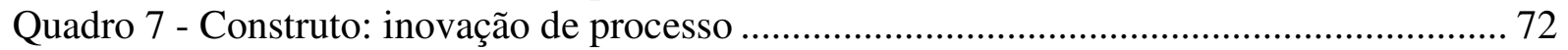

Quadro 8 - Construto: inovação de marketing ........................................................................ 72

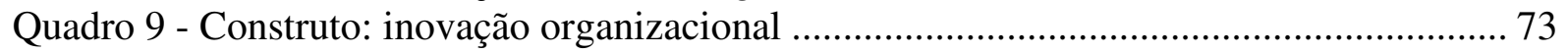

Quadro 10 - Construto: estratégia de exploração do conhecimento ........................................ 74

Quadro 11 - Construto: estratégia de explotação do conhecimento......................................... 74

Quadro 12 - Construto: capacidade de absorção do conhecimento ......................................... 75

Quadro 13 - Variáveis e escalas de mensuração do instrumento de coleta de dados ............... 80

Quadro 14 - Variáveis e escalas de mensuração do instrumento de coleta de dados (cont.)... 81

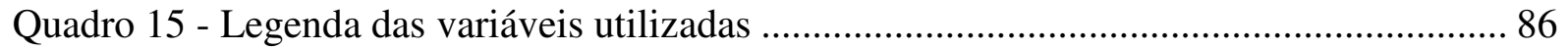

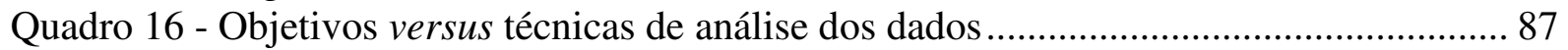

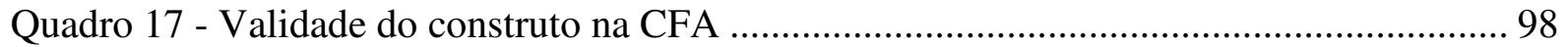

Quadro 18 - Formação dos novos construtos ......................................................................... 100

Quadro 19 - Medidas de qualidade de ajuste e valores recomendados.................................. 103

Quadro 20 - Síntese das hipóteses e resultados................................................................. 172 


\section{LISTA DE TABELAS}

Tabela 1 - Grau de concordância com relação às afirmações do questionário .........................82

Tabela 2 - Faturamento total por segmentos da Indústria Elétrica Eletrônica........................ 108

Tabela 3 - Principais indicadores da Indústria Elétrica Eletrônica ...................................... 109

Tabela 4 - Proporção de empresas que implementaram inovações ....................................... 115

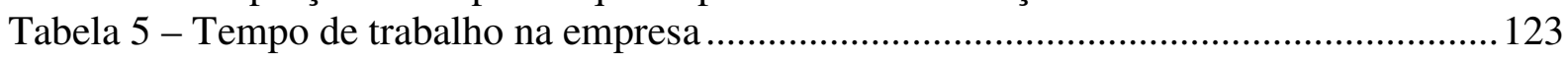

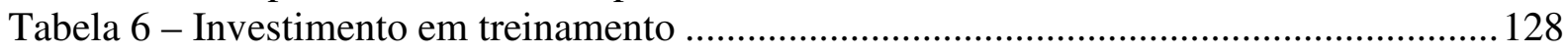

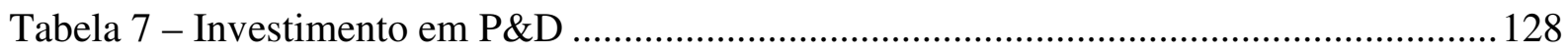

Tabela 8 - Percentis observados para o percentual da receita operacional bruta gasto com treinamento e P\&D

Tabela 9 - Cruzamento entre receita operacional bruta anual e porcentagem gasta com

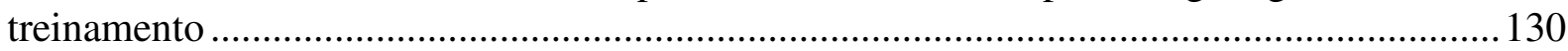

Tabela 10 - Cruzamento entre receita operacional bruta anual e porcentagem gasta com P\&D

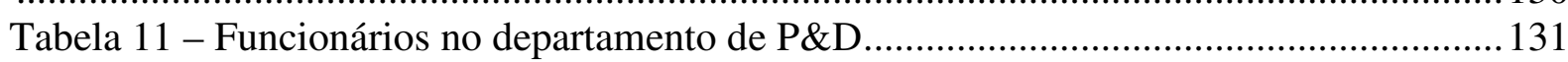

Tabela 12 - Inovação de produto ....................................................................................... 131

Tabela 13 - Média e desvio padrão das variáveis do construto inovação de produto de acordo

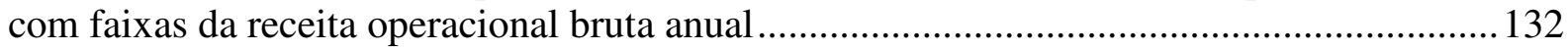

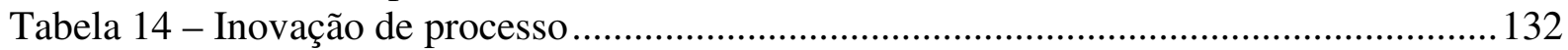

Tabela 15 - Média e desvio padrão das variáveis do construto inovação de processo de acordo

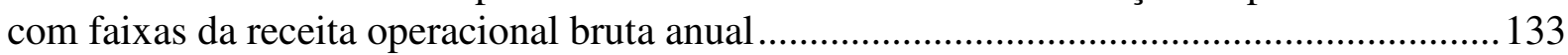

Tabela 16 - Inovação de marketing ............................................................................... 134

Tabela 17 - Média e desvio padrão das variáveis do construto inovação de marketing de acordo com faixas da receita operacional bruta anual........................................................... 134

Tabela 18 - Inovação organizacional ................................................................................ 135

Tabela 19 - Média e desvio padrão das variáveis do construto inovação organizacional de acordo com faixas da receita operacional bruta anual ......................................................... 136

Tabela 20 - Grau de importância dos parceiros de inovação ................................................ 139

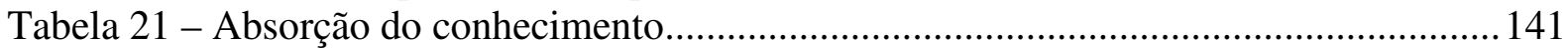

Tabela 22 - Estratégia de exploração e explotação …........................................................... 142

Tabela 23 - Teste M de Box para inovação de produto e gasto com P\&D ............................ 143

Tabela 24 - MANOVA para inovação de produto e gasto com P\&D .................................... 143

Tabela 25 - Teste de comparações múltiplas entre o percentual gasto com P\&D e variáveis do

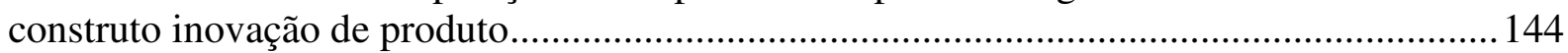

Tabela 26 - Teste M de Box para inovação de processo e gasto com P\&D .......................... 145

Tabela 27 - MANOVA para inovação de processo e gasto com P\&D .................................. 145

Tabela 28 - Teste M de Box para inovação de marketing e gasto com P\&D ........................ 145

Tabela 29 - MANOVA para inovação de marketing e gasto com P\&D................................. 146

Tabela 30 - Teste M de Box para inovação organizacional e gasto com P\&D ..................... 146

Tabela 31 - MANOVA para inovação organizacional e gasto com P\&D .............................. 146

Tabela 32 - Teste M de Box para inovação de produto e tamanho da empresa ................... 147

Tabela 33 - MANOVA para inovação de produto e tamanho da empresa ............................ 148

Tabela 34 - Teste de comparações múltiplas entre o tamanho da empresa e variáveis do

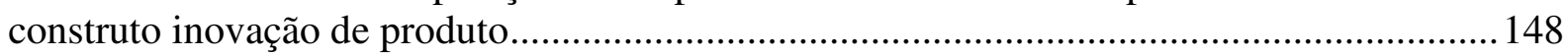

Tabela 35 - Teste M de Box para inovação de processo e tamanho da empresa ..................... 149

Tabela 36 - MANOVA para inovação de processo e tamanho da empresa............................ 149

Tabela 37 - Teste de comparações múltiplas entre o tamanho da empresa e variáveis do

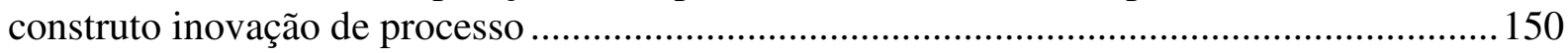


Tabela 38 - Teste M de Box para inovação de marketing e tamanho da empresa ................ 151

Tabela 39 - MANOVA para inovação de marketing e tamanho da empresa......................... 151

Tabela 40 - Teste M de Box para inovação organizacional e tamanho da empresa.............. 151

Tabela 41 - MANOVA para inovação organizacional e tamanho da empresa ..................... 152

Tabela 42 - Teste de comparações múltiplas entre o tamanho da empresa e variáveis do

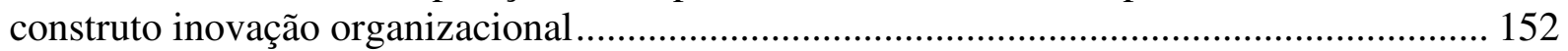

Tabela 43 - Teste M de Box para inovação de produto e origem do capital ......................... 153

Tabela 44 - MANOVA para inovação de produto e origem do capital ................................. 154

Tabela 45 - Teste de comparações múltiplas entre a origem do capital e variáveis do construto

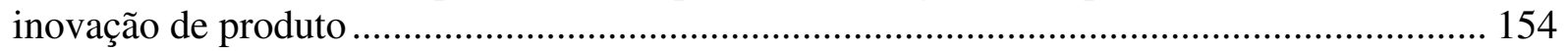

Tabela 46 - Teste $M$ de Box para inovação de processo e origem do capital ........................ 155

Tabela 47 - MANOVA para inovação de processo e origem do capital ................................ 155

Tabela 48 - Teste de comparações múltiplas entre a origem do capital e variáveis do construto

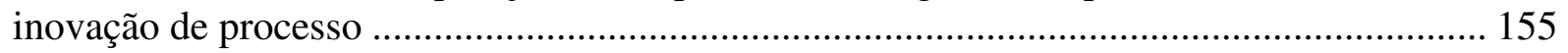

Tabela 49 - Teste M de Box para inovação de marketing e origem do capital ..................... 156

Tabela 50 - MANOVA para inovação de marketing e origem do capital............................. 156

Tabela 51 - Teste M de Box para inovação organizacional e origem do capital .................. 157

Tabela 52 - MANOVA para inovação organizacional e origem do capital ......................... 157

Tabela 53 - Alfa de Cronbach (variáveis padronizadas) para cada construto ........................ 158

Tabela 54 - Validação dos construtos por meio da CFA.................................................... 158

Tabela 55 - Alfa de Cronbach (variáveis padronizadas) para cada construto no Modelo 1.. 161

Tabela 56 - Cargas fatoriais apresentadas pelas variáveis de cada construto no Modelo 1 .. 161

Tabela 57 - Validação dos construtos do Modelo 1 por meio da CFA ................................. 162

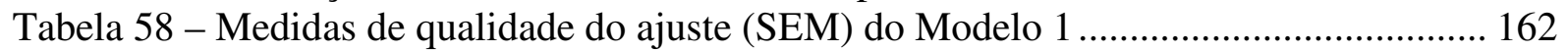

Tabela 59 - Testes de hipótese realizados (SEM) para o Modelo 1 ...................................... 163

Tabela 60 - Alfa de Cronbach (variáveis padronizadas) para cada construto no Modelo 2.. 166

Tabela 61 - Cargas fatoriais apresentadas pelas variáveis de cada construto no Modelo 2 .. 166

Tabela 62 - Validação dos construtos no Modelo 2 por meio da CFA ................................. 167

Tabela 63 - Medidas de qualidade do ajuste (SEM) do Modelo 2 ........................................ 167

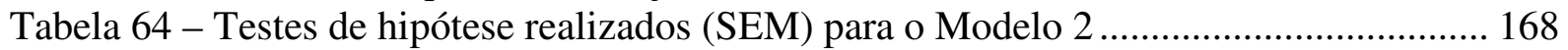




\section{LISTA DE GRÁFICOS}

Gráfico 1 - Distribuição geográfica das organizações do Setor Elétrico Eletrônico 108

Gráfico 2 - Principal responsável pelo desenvolvimento de inovações em produto 115

Gráfico 3 - Grau de importância das atividades no desenvolvimento de inovação

Gráfico 4 - Grau de importância do impacto causado pela inovação ...

Gráfico 5 - Grau de importância atribuído aos obstáculos à inovação

Gráfico 6 - Grau de importância atribuído às fontes de informação.

Gráfico 7 - Grau de importância atribuído às fontes de cooperação.

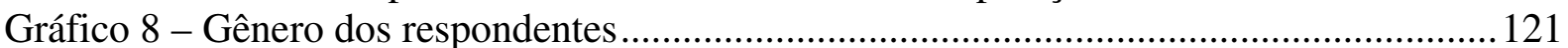

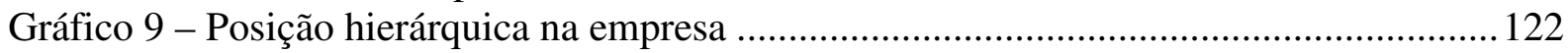

Gráfico 10 - Grau de escolaridade dos respondentes......................................................... 122

Gráfico 11 - Localização das empresas ............................................................................. 123

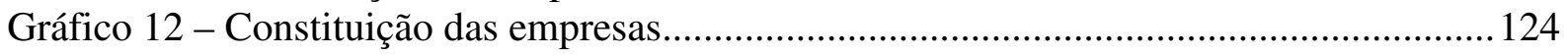

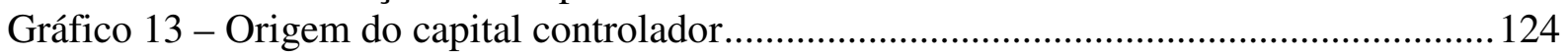

Gráfico 14 - Principal segmento de atuação .................................................................... 125

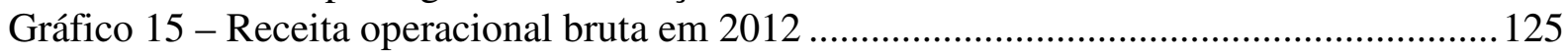

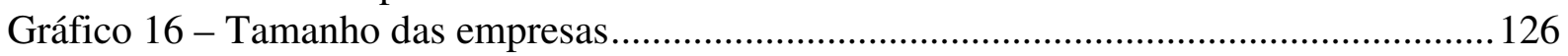

Gráfico 17 - Percentual médio de funcionários com cursos de Especialização, Mestrado e

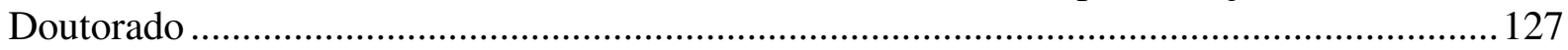

Gráfico 18 - Principais áreas de formação dos profissionais ............................................. 127

Gráfico 19 - Contratação de profissionais estrangeiros ......................................................... 128

Gráfico 20 - Principal responsável pelo desenvolvimento de inovações............................... 137

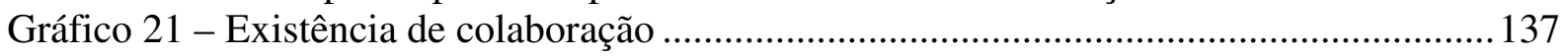

Gráfico 22 - Parceiros para inovação por tamanho da empresa.............................................. 139

Gráfico 23 - Razões para o estabelecimento de redes de inovação ...................................... 140 


\section{LISTA DE ILUSTRAÇÕES}

Ilustração 1 - Modelo linear de inovação ............................................................................ 28

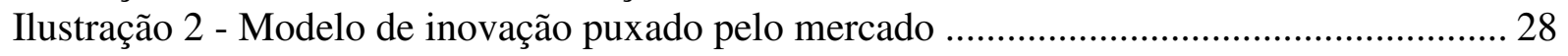

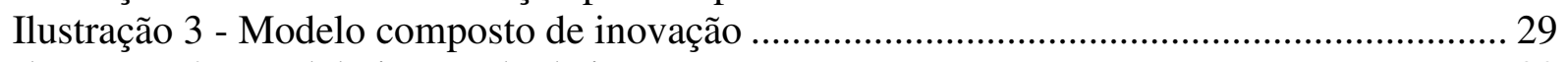

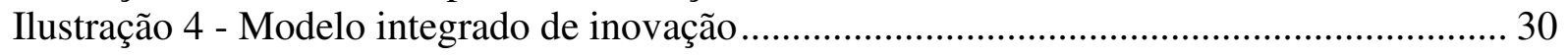

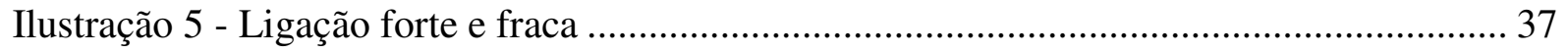

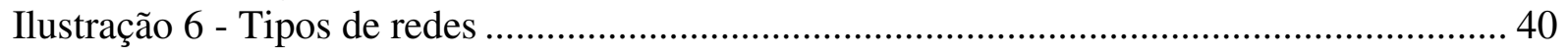

Ilustração 7 - Mapa de orientação conceitual.......................................................................... 41

Ilustração 8 - Parceiros no processo de inovação e suas contribuições ...................................... 44

Ilustração 9 - Nível de colaboração externa por tipo de parceiro ......................................... 45

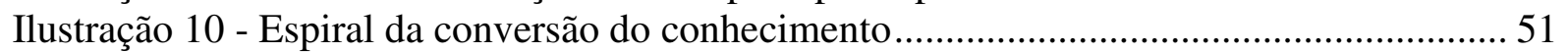

Ilustração 11 - Codificação do conhecimento e inovação....................................................... 53

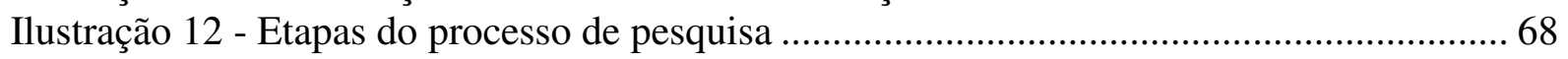

Ilustração 13 - Modelo conceitual da pesquisa .................................................................. 70

Ilustração 14 - Processo de seis estágios para a Modelagem de Equações Estruturais ........... 92

Ilustração 15 - Políticas estruturantes e complementares para a Indústria Elétrica Eletrônica

Ilustração 16 - Modelo de equações estruturais para inovação em produto e marketing ...... 165 Ilustração 17 - Modelo de equações estruturais para inovação em processo e organizacional

Ilustração 18 - Modelo final da pesquisa ......................................................................... 175

Ilustração 19 - Resumo dos resultados para as variáveis moderadoras ................................ 176 


\section{O PROBLEMA DE PESQUISA}

\subsection{Introdução}

O processo de globalização e a revolução da tecnologia da informação provocaram significativas alterações no ambiente empresarial, instaurando novos padrões de competitividade como consequência da abertura e interconexão dos mercados. O processo de globalização, dotado de um caráter transformador capaz de reorientar o princípio de interdependência global, resultou na ampliação, aceleração e intensificação das dinâmicas estabelecidas. De forma semelhante, as mudanças decorrentes da revolução tecnológica implicaram transformações relevantes no âmbito produtivo, nos sistemas de armazenamento e no processamento da informação, convergindo para a diminuição de custos, a alteração da relação entre oferta e demanda e a modernização da vida cotidiana das famílias.

Essas mudanças de ordem macroeconômica, regulatória, competitiva e mercadológica criaram uma nova realidade empresarial, diante da qual a inovação tornou-se um imperativo. Não obstante, vários autores têm ressaltado a importância da inovação como elemento fundamental para a competitividade e mesmo para a sobrevivência das organizações (DRUCKER, 1996; PORTER, 1999; BAUMOL, 2002, BARBIERI; ÁLVARES, 2003). Estudos revelaram que as empresas que se sobressaem e crescem além da média do seu segmento possuem a inovação como elemento comum. Inovar, neste contexto, é uma ação percebida como essencial, sendo resultado do acesso a novos conhecimentos, parcerias, modelos de gestão, mercados e oportunidades, fato que favorece o estabelecimento de vantagens competitivas a médio e longo prazo (BAUTZER, 2009).

No entanto, o desenvolvimento de inovações não é uma tarefa fácil a ser realizada, sobretudo em decorrência do ritmo acelerado das transformações na sociedade (CHESBROUGH, 2003). Considerando-se que, para inovar, as empresas dependem da habilidade de criar, reconhecer, reter, transmitir e utilizar o conhecimento (HALLIKAS et al., 2009), está cada vez mais difícil desenvolver individualmente todas as competências necessárias para conceber as inovações. Em outras palavras, há um ponto no qual a empresa se depara com um limite de sua capacidade, no qual os custos envolvidos no processo de inovação ultrapassam o seu próprio benefício. 
Como uma alternativa para superar as limitações internas, as organizações têm expandido suas fronteiras visando integrar recursos e capacidades por meio da constituição de redes de cooperação voltadas à inovação (AHUJA, 2000). Freel e Harrison (2006) definem estas redes como um conjunto de atores que desenvolvem vínculos com o objetivo de superar as incertezas do processo de inovação.

Segundo o Manual de Oslo (OCDE, 2005), uma rede de inovação pode propiciar o envolvimento de clientes e fornecedores no desenvolvimento conjunto de novos produtos, processos ou outras inovações. Para Tidd et al. (2005), as razões que podem levar as empresas a estabelecer alguma relação de cooperação para inovação podem derivar do volume de informações necessárias, do tempo de desenvolvimento de novos produtos e sua comercialização, do aumento dos custos e dos riscos do desenvolvimento tecnológico e de mercado.

Exemplos claros dessa questão são encontrados em empresas como a IBM e a Procter \& Gamble, que adotaram, com sucesso, uma abordagem mais aberta com relação ao desenvolvimento de suas inovações. No caso da IBM, isso ocorreu por meio do estabelecimento de relações interorganizacionais, resultando na ampliação do uso de tecnologias de terceiros em seus negócios. Já no caso da Procter \& Gamble (P\&G), a abertura do processo de inovação foi resultado da ampliação de seu processo de Pesquisa e Desenvolvimento $(\mathrm{P} \& \mathrm{D})$, que enfatizou a necessidade da empresa recorrer a terceiros em busca de ideias inovadoras. "A lógica da companhia é simples: no âmbito da P\&G existem mais de 8.600 cientistas aperfeiçoando o conhecimento industrial que habilita novos produtos da P\&G; fora da companhia, esses cientistas são 1,5 milhão. Então, por que inventar tudo internamente?” (CHESBROUGH, p.11, 2012). Ao ampliar sua rede, a $\mathrm{P} \& \mathrm{G}$ consegue não somente atingir aos seus objetivos de inovação, como também consegue movimentar suas ideias para outros negócios. Isso porque as ideias que não são aproveitadas em seus laboratórios são disponibilizadas, três anos depois, para outras empresas, inclusive para seus concorrentes diretos (CHESBROUGH, 2012).

Nesse sentido, nota-se que a colaboração propiciada pela formação de redes tem se tornado cada vez mais relevante, utilizada como forma de complementar as atividades internas inovadoras das empresas (HAGEDOORN, 2002; HILL; ROTHAERMEL, 2003). Tal fato tem 
despertado o interesse de pesquisadores e estudiosos, destacando-se como uma importante linha de pesquisa no campo da administração de empresas.

\subsection{Definição da situação problema}

O eixo da competitividade mundial está se voltando para o conhecimento e para a inovação. De fato, segundo o relatório do Banco Mundial (2008), diversos economistas que se debruçaram sobre a questão do desenvolvimento a partir da segunda metade do século XX convergem para um ponto comum: o conhecimento e a inovação são bastante relevantes para o crescimento econômico, fazendo com que a competitividade esteja cada vez mais assentada na capacidade de adaptação a mudanças tecnológicas e nos avanços organizacionais (BANCO MUNDIAL, 2008).

No entanto, estudos realizados pela INSEAD e pela WIPO (2012) mostraram que, de 2011 para 2012, o Brasil perdeu 32 posições na lista de eficiência do Índice Global de Inovação, ocupando atualmente a $39^{\text {a }}$ colocação. Para realizar essa classificação, o estudo considerou a produção de inovações nos países a partir de estímulos provenientes do governo, da indústria e do meio acadêmico. Por meio da análise dos fatores que sustentam o ambiente de inovação, tais como educação, solidez das instituições econômicas e infraestrutura, o levantamento revelou que o Brasil foi o país que mais caiu no ranking entre os BRICS, apresentando obstáculos principalmente com relação à qualidade do ensino superior e às condições de investimento em ciência (INSEAD; WIPO, 2012).

Além disso, dados da Pesquisa de Inovação Tecnológica de 2008 (IBGE, 2010) indicaram um aumento de 14,6\% no percentual de empresas que enfrentaram obstáculos para inovar. Dentre os maiores problemas evidenciados pelas indústrias estão os elevados custos da inovação (73,2\%), seguidos pelos riscos econômicos excessivos $(65,9 \%)$, a falta de pessoal qualificado $(57,8 \%)$ e a escassez de fontes de financiamento $(51,6 \%)$.

Tratando-se especificamente da Indústria Elétrica Eletrônica - foco do presente estudo - notase que, por pertencerem a um setor de tecnologia intensiva, cuja competitividade é global, as empresas dessa indústria são altamente dependentes da atividade inovativa. 
De acordo com a Associação da Indústria Elétrica Eletrônica (ABINEE, 2012), essas empresas enfrentam uma concorrência internacional, além de estarem expostas à fatores macroambientais, como as taxas de juros e a taxa cambial para exportação e importação, fato que tende a influenciar a competitividade do setor. Neste sentido, a realização de inovações se faz necessária para, em um primeiro momento, garantir a sobrevivência e, num segundo momento, proporcionar melhores patamares de competitividade para as empresas.

Vale ressaltar que a Indústria ocupa um lugar proeminente na malha produtiva nacional, por condicionar as operações e a eficiência de outros segmentos, acarretando em um intenso efeito multiplicador sobre o conjunto da economia (MACEDO et al., 2009). Por conseguinte, o setor eletroeletrônico é um dos mais priorizados pela política de desenvolvimento industrial brasileira, que visa incentivar a modernização das empresas, de forma a propiciar a inovação e a melhoria da competitividade.

A forte dependência do progresso tecnológico impõe à Indústria a necessidade de realizar altos investimentos em pesquisa e desenvolvimento, além de assumir riscos inerentes ao processo de inovação. No entanto, apesar dos avanços obtidos com as novas linhas de financiamento, o Brasil ainda não dispõe de um ambiente favorável para a expansão das atividades de P\&D dentro das empresas (ABINEE, 2010). É necessário aprimorar:

a qualidade dos recursos humanos, aperfeiçoar e fortalecer o relacionamento entre universidades e empresas, desonerar integralmente os investimentos em P\&D\&I, ampliar os canais de informação sobre recursos e iniciativas de instituições de fomento, como também demarcar as trajetórias tecnológicas do setor e acompanhar os avanços realizados no exterior (ABINEE, 2010, p.11).

Diante deste contexto e, visando fazer frente aos desafios e obstáculos contemporâneos decorrentes do processo de inovação, constata-se que a constituição de redes de inovação tem sido bastante referenciada pela possibilidade de compartilhamento de conhecimento e recursos, de modo a ampliar as capacidades isoladas de cada membro da rede, aumentando assim a eficiência coletiva (MELO; AGOSTINHO, 2007).

De acordo com Chesbrough (2003), os principais benefícios decorrentes da organização em redes para a inovação decorrem da possibilidade de compartilhamento de diferentes conhecimentos, habilidades e recursos, sendo os agentes externos à empresa uma importante fonte adicional ao processo de inovação. 
Segundo Powell et al. (1996), o conhecimento inovador não é fruto apenas do setor de Pesquisa e Desenvolvimento (P\&D) de uma única empresa, mas sim de um conjunto de alianças e parcerias entre diferentes agentes, de modo a aumentar as fontes de conhecimento. Em consonância aos autores, pesquisas desenvolvidas pela Forfás (2004) sugeriram que, no caso das indústrias orientadas para a inovação, a aquisição e manutenção das capacidades tecnológicas da organização dependem do contato com fontes externas de conhecimento que, dentre outras formas, pode ser estabelecido por meio das redes de inovação (FORFÁS, 2004).

Por esse motivo, a dispersão das fontes de conhecimento tende a tornar as redes, ao invés de empresas individuais, o locus da inovação, por permitir o acesso a conhecimentos e recursos que, de outra forma, estariam indisponíveis (POWELL et al., 1996). Tal fato, no entanto, não reduz a importância da base de conhecimentos e das capacidades internas desenvolvidas pela da empresa, uma vez que estas não são substituíveis, mas sim complementares (POWELL et al., 1996).

Apesar de todo o interesse em torno da temática, o conhecimento produzido sobre redes de inovação, tendo como foco a própria estrutura de rede, ainda é modesto, principalmente devido à complexidade inerente à observação dos fenômenos nas redes (PROVAN et al., 2007).

Além disso, aponta-se para o fato de que nem todas as colaborações voltadas para a inovação são bem-sucedidas. A falta de flexibilidade e adaptabilidade, a difusão de conhecimentos de maneira não intencional e a má interpretação dos benefícios pretendidos a partir da constituição das redes são comumente citados como razões para o mau desempenho das parcerias (FAEMS et al., 2005).

Faems et al. (2005) ainda advertem que, na literatura acerca da inovação, a colaboração interorganizacional é referida como um instrumento para melhorar o desempenho inovador das empresas. Ao mesmo tempo, a evidência empírica para tal relação ainda é escassa.

Ademais, a falta de consenso acadêmico sobre os postulados teóricos e de definições formais também traz impactos à área de pesquisa (BELL et al., 2006). De acordo com Tsai (2009), a falta de concordância sobre os possíveis benefícios em inovação, decorrentes da colaboração 
com diferentes atores na rede, pode indicar a necessidade de estudo de outras variáveis que possam influenciar tais resultados.

Sendo assim, como forma de aprofundar o conhecimento acadêmico no que se refere às redes de inovação e suas possíveis contribuições em termos de inovação, este estudo apresenta o seguinte problema de pesquisa:

Qual a contribuição dos parceiros estabelecidos em redes de inovação para o desempenho inovador das empresas?

A análise desta questão foi feita considerando-se fatores pertinentes à rede de inovação, como a capacidade de absorção do conhecimento da empresa e as estratégias de exploração e explotação ${ }^{1}$ do conhecimento.

\subsection{Definições teóricas e operacionais dos conceitos}

Os itens subsequentes apresentam as definições teóricas e operacionais dos principais termos a serem abordados na pesquisa.

\section{a) Parceiros estabelecidos}

Por meio da revisão teórica foi possível identificar quatro tipos principais de parceiros com os quais as empresas estabelecem relações visando à inovação: clientes/consumidores, universidades/institutos de pesquisas, fornecedores e competidores (GEMÜDEN et al., 1996; OCDE, 2005; DOZ et al., 2006; TSAI, 2009; CARVALHO, 2010).

Em termos operacionais, a determinação dos tipos de parceiros estabelecidos foi realizada a partir de dois aspectos: (1) a existência de relações com clientes/consumidores, universidades/institutos de pesquisas, fornecedores ou competidores para desenvolvimento de

\footnotetext{
${ }^{1}$ A estratégia de exploração refere-se à pesquisa e experimentação com o objetivo de constituir novos conhecimentos; enquanto a estratégia de explotação está associada ao refinamento, seleção, produção e execução de ideias e informações já existentes na organização (DITTRICH; DUYSTERS, 2003).
} 
pelo menos uma inovação nos últimos três anos; e (2) o grau de importância relativa de cada um destes atores no processo de inovação da organização.

\section{b) Redes de inovação}

As redes de inovação são definidas na literatura como um conjunto de relações estabelecidas de modo colaborativo entre empresas e outras organizações, instituições e/ou indivíduos, nas quais todos os intervenientes assumem um papel ativo visando a obtenção ou compartilhamento de conhecimentos e outros recursos necessários ao processo de inovação de produto, processo, de marketing ou organizacional (FORFÁS, 2004; OCDE, 2005).

O estabelecimento das relações supracitadas pode ocorrer por meio de contratos formalizados, como também de maneira informal, tanto no curto quanto no longo prazo, em qualquer localização geográfica. Vale ressaltar que, para caracterização da rede de inovação, não serão consideradas as relações estabelecidas por contratos de aquisição de conhecimento e tecnologia, uma vez que uma simples contratação não se configura como uma relação de colaboração ou cooperação entre as partes (OCDE, 2005).

Operacionalmente, ressalta-se que o exame das redes de inovação foi realizado sob a perspectiva do ator principal, ou seja, a análise se deu a partir do ponto de vista das empresas pesquisadas acerca das relações estabelecidas com outras organizações, indivíduos, universidades e centros de pesquisa.

\section{c) Desempenho inovador}

O desempenho inovador refere-se ao desenvolvimento e implementação de inovações - sejam elas de produto, de processo, de marketing e/ou organizacional - sob o ponto de vista da organização pesquisada.

Uma inovação refere-se à implementação de um produto (bem ou serviço), um processo, um método de marketing e/ou um método organizacional novo ou significativamente melhorado por parte da organização. O requisito mínimo para se definir uma inovação é que o produto, o processo, o método de marketing ou organizacional sejam novos (ou significativamente melhorados) para a empresa, não sendo necessariamente novos para o mercado. Isso inclui 
produtos, processos e métodos que as empresas são as pioneiras a desenvolver e àqueles que foram adotados de outras empresas ou organizações (OCDE, 2005).

Quanto aos quatro tipos de inovação propostas, têm-se as seguintes definições teóricas:

- Inovações de produto envolvem mudanças significativas nas potencialidades de produtos e serviços. Incluem-se bens e serviços totalmente novos e aperfeiçoamentos importantes para produtos existentes.

- Inovações de processo representam mudanças significativas nos métodos de produção e de distribuição.

- As inovações organizacionais referem-se à implementação de novos métodos organizacionais, tais como mudanças em práticas de negócios, na organização do local de trabalho ou nas relações externas da empresa.

- As inovações de marketing envolvem a implementação de novos métodos de marketing, incluindo mudanças no design do produto e na embalagem, na promoção do produto e sua colocação, e em métodos de estabelecimento de preços de bens e de serviços (OCDE, 2005).

Tendo por base o Manual de Oslo (OCDE, 2005) e outras importantes fontes consultadas (NEELY; HII, 1998; FAEMS et al., 2005; IBGE, 2010), o desempenho inovador da empresa foi mensurado primordialmente por meio de construtos que consideram:

- a introdução no mercado de produtos/serviços novos ou significativamente melhorados nos últimos 3 anos e o percentual de vendas atribuído aos novos produtos;

- a introdução de processos novos ou significativamente melhorados nos últimos 3 anos, incluindo-se métodos de fabricação, sistemas logísticos, equipamentos e softwares;

- a implementação de novas estratégias, conceitos de marketing ou mudança na estética ou desenho dos produtos nos últimos 3 anos;

- a introdução de novas técnicas de gestão e novos métodos de organização do trabalho nos últimos 3 anos, como também a implementação de mudanças nas relações com outras instituições visando constituir uma novidade organizacional neste mesmo período de análise. 
Outro fator relevante refere-se aos efeitos resultantes da implementação de inovações nas organizações nos últimos três anos, que também foram mensurados e fazem parte da análise do desempenho inovador da mesma. Dessa forma, foi computado na pesquisa o grau de intensidade de efeitos percebidos nas empresas, relacionados ao desenvolvimento de inovações, como a ampliação e criação de novos mercados, o aumento da qualidade e diversidade de produtos oferecidos, o aumento da flexibilidade e redução de custos na produção, a melhoria no compartilhamento do conhecimento e na comunicação entre as áreas de negócios e o enquadramento em regulações e normas no mercado.

Oliva et al. (2011) também ofereceram importantes contribuições ao mensurarem a probabilidade de realização de inovações em empresas de base-tecnológica. O modelo proposto pelos autores considera o número de congressos e feiras nos quais as empresas participaram como expositores como um fator que contribui positivamente para o resultado em inovação. Além disso, a média de competidores por serviço ou produto que a empresa possui foi apontada como variável que influencia negativamente este mesmo resultado. Estas variáveis fizeram parte do presente estudo, sendo utilizadas adicionalmente para mensuração do desempenho inovador das organizações.

\section{d) Empresas}

O estudo teve como foco de análise as empresas participantes da Indústria Elétrica Eletrônica. Tratam-se, portanto, de empresas localizadas em várias regiões do Brasil, de pequeno, médio e grande porte, cujo capital controlador é nacional, estrangeiro ou misto.

\subsection{Objetivos da pesquisa}

Tendo por base o problema de pesquisa apresentado, este estudo possui como objetivo geral verificar qual a contribuição dos parceiros estabelecidos em redes de inovação para o desempenho inovador de empresas da Indústria Elétrica Eletrônica. 
Visando atingir ao propósito geral de estudo, foram estabelecidos os seguintes objetivos específicos:

1) Identificar as razões primordiais pelas quais as empresas constituem redes de inovação;

2) Hierarquizar os principais parceiros estabelecidos nas redes, segundo seu grau de importância;

3) Mensurar os resultados das empresas em termos de inovação de produto, processo, marketing e organizacional;

4) Verificar qual a influência das variáveis moderadoras (tamanho da organização, gasto com $\mathrm{P} \& \mathrm{D}$ e origem do capital controlador) no desempenho inovador;

\subsection{Hipóteses da pesquisa}

Considerando-se os objetivos da pesquisa, estabeleceram-se as seguintes hipóteses alternativas, que foram submetidas a teste. Estas hipóteses estão justificadas no item 3.3 deste estudo.

H1.1 A colaboração com clientes/consumidores está relacionada positivamente com o resultado em inovação da empresa.

H1.2 A colaboração com fornecedores está relacionada positivamente com o resultado em inovação da empresa.

H1.3 A colaboração com competidores está relacionada positivamente com o resultado em inovação da empresa.

H1.4 A colaboração com universidades e institutos de pesquisa está relacionada positivamente com o resultado em inovação da empresa.

H1.5 A utilização de estratégias de explotação do conhecimento está relacionada positivamente com o desenvolvimento de colaborações com clientes/consumidores. 
H1.6 A utilização de estratégias de explotação do conhecimento está relacionada positivamente com o desenvolvimento de colaborações com fornecedores.

H1.7 A utilização de estratégias de exploração do conhecimento está relacionada positivamente com o desenvolvimento de colaborações com universidades e institutos pesquisa.

H1.8 Quanto maior a capacidade de absorção do conhecimento apresentada pela empresa, maior seu resultado em inovação.

H1.9 Quanto maior o gasto com P\&D na empresa, maior seu resultado em inovação.

H1.10 Quanto maior o tamanho da empresa, maior seu resultado em inovação.

H1.11 As empresas cuja origem do capital controlador é estrangeira apresentam um maior resultado em inovação.

\subsection{Justificativa}

Tendo em vista que, cada vez mais, a inovação pode ser fruto de um processo de interação entre diferentes atores do que de um esforço isolado (FAEMS et al., 2005); e que a capacidade de inovar pode depender da capacidade da empresa de formar redes (NEELY; HII, 1998), o tema mostra-se relevante, tanto do ponto de vista da academia, quanto do ponto de vista das organizações e demais interessados.

Com relação à academia, observa-se que o tema relativo às redes de cooperação entre organizações tem evoluído constantemente, sendo foco de renomados periódicos internacionais, como a revista Organization Studies (1998), o Academy of Management Journal (2004) e o Journal of International Management (2007), que já realizaram edições especiais dedicadas ao assunto. Outro exemplo claro do aumento do interesse na temática foi demonstrado pelo Fórum Econômico Mundial, ao definir o poder da inovação colaborativa como tema central do encontro de 2008 (BALESTRIN et al., 2010). 
$\mathrm{Na}$ literatura, o tema tem sido abordado por diversos autores, tais como Prahalad e Ramaswamy (2004), Surowiecki (2006), Tapscott e Williams (2007) e Chesbrough (2012), que destacam em seus livros a importância da colaboração em rede como uma das condições fundamentais para a competitividade organizacional.

No entanto, as pesquisas que têm como foco as redes de inovação ainda sofrem algumas críticas devido à diversidade de explicações e entendimentos. A variedade de abordagens teóricas, decorrente das contribuições de diversas áreas de estudo, ajudou a produzir explicações complementares e, por vezes, concorrentes, implicando diferentes definições e interpretações do conceito (BALESTRIN et al., 2010).

Ademais, a relevância das redes de inovação evidenciada na literatura deflagra a necessidade de pesquisas que enfoquem e analisem seu potencial no que diz respeito aos resultados em inovação das organizações. Desafortunadamente, os estudos a esse respeito, apesar de ponderar as contribuições de outras áreas do conhecimento, ainda são fragmentados e não consideram a natureza colaborativa e dinâmica das redes (MERCY, 2008).

Não obstante, o atual ambiente econômico no qual as empresas estão inseridas instauram novos desafios às organizações, principalmente no que diz respeito à inovação. Isso porque o modelo tradicional linear de pesquisa e desenvolvimento com base na inovação está sendo substituído por um modelo baseado em redes, de alcance global. Portanto, para lidar com este novo contexto, as organizações necessitam adaptar sua forma de trabalho e desenvolver competências necessárias para formação e desenvolvimento de redes (RITTER, GERMUNDEN, 2003).

Segundo um estudo desenvolvido pela Booz Allen Hamilton, juntamente com o INSEAD em 2006, os maiores desafios a serem enfrentados pelas empresas, considerando-se um ambiente global de inovação, estão relacionados ao conhecimento. Em outras palavras, a inovação global apresenta oportunidades para que as empresas ampliem sua rede e acesso a novos conhecimentos, tecnologias e clientes. No entanto, gerenciar e integrar essas atividades exige novas estruturas organizacionais, processos e capacidades, fatores com os quais a maioria das empresas ainda apresenta dificuldades. Neste sentido, a constituição de uma rede de inovação parece representar uma oportunidade interessante às empresas, sobretudo do ponto de vista do compartilhamento dos conhecimentos (DOZ et al., 2006). 
Além disso, as redes tornaram-se um importante foco de interesse da política, não só porque permitem que pequenas e médias empresas ganhem em escala, mas, por desempenhar um importante papel como um canal de compartilhamento de conhecimentos, podendo ser consideradas uma fonte significativa aos processos de inovação (FORFÁS, 2004).

Portanto, o presente estudo pretende contribuir para o avanço da discussão no que se refere às redes de inovação por tentar relacionar sua constituição aos resultados em inovação das empresas, sendo de interesse tanto de acadêmicos das áreas de tecnologia, sociais e estratégia, como também de profissionais da área pública e privada.

Vale salientar que a pesquisa possui como foco de análise as empresas da Indústria Elétrica e Eletrônica. De fato, esta indústria ocupa lugar proeminente na malha produtiva nacional. Seu faturamento em 2012 correspondeu a R \$ 145,5 bilhões, representando 3,3\% do PIB nacional (ABINEE, 2013).

Com relação às inovações, trata-se de um setor que irradia tecnologia, tornando-se base para a realização de avanços tecnológicos, como mudanças radicais nos processos de produção e/ou desenvolvimento de novos produtos, inclusive em outros setores. Isso porque, devido ao tamanho e, especialmente, à intensidade do desenvolvimento tecnológico, esta indústria possui efeito multiplicador em diversos outros segmentos da economia: as plantas industriais em geral dependem de equipamentos (como motores), materiais elétricos de instalação e sistemas de automação, e todas as empresas de bens e serviços demandam equipamentos de telecomunicações e de informática (ABINEE, 2010).

Além disso, o país todo depende de equipamentos de geração, transmissão e distribuição de energia elétrica. Portanto, a qualidade e a magnitude da oferta de produtos elétricos e eletrônicos acabam condicionando as operações e a eficiência de outros segmentos da economia sendo, por esse motivo, considerada uma indústria estratégica para o desenvolvimento nacional, cujo estudo é justificado (ABINEE, 2010). 


\subsection{Pressupostos conceituais}

Para a realização da presente pesquisa são assumidos como pressupostos conceituais os seguintes aspectos:

- o desenvolvimento de inovações propicia efeitos benéficos às organizações;

- a associação de duas ou mais empresas, organizações ou instituições, que atuam de forma ativa e colaborativa, visando desenvolver ou ampliar os resultados em inovação, pode ser considerada rede de inovação;

- a exigência mínima para que uma mudança nos produtos ou funções da empresa seja considerada uma inovação é que ela seja nova (ou significativamente melhorada) para a empresa, mesmo que já exista no mercado. 


\section{FUNDAMENTAÇÃO TEÓRICA}

Este capítulo apresenta os conceitos teóricos relacionados às redes de inovação. Procura-se, através da revisão da bibliografia, levantar as principais características e fatores pertinentes às redes de inovação. Para tanto, as diretrizes teóricas da pesquisa estão baseadas no conceito de inovação e de redes de inovação, suas tipologias, além de aspectos relacionados à transferência de conhecimento na rede, aos tipos de atores/parceiros e suas contribuições, aos fatores indutores para a formação das redes de inovação e aos possíveis benefícios decorrentes de sua constituição.

\subsection{A inovação nas empresas}

Os conceitos de inovação estão baseados nos princípios da destruição criativa e do ciclo econômico, desenvolvidos por Joseph Schumpeter, na primeira metade do século XX. Segundo Schumpeter (1939), o desenvolvimento econômico é conduzido pela inovação por meio de um processo dinâmico de evolução, capaz de destruir os velhos modelos, substituindo-os por novos. Os líderes do mercado, portanto, passam a ser aqueles que conseguem lidar com essa evolução por meio de processos de inovação.

Peter Drucker também ofereceu contribuições importantes à temática, propondo que uma das funções básicas da empresa é a inovação. Para o autor, "não é necessário que o negócio se torne maior, mas é necessário que nunca deixe de se tornar melhor" (1962, p.64). Drucker também desenvolveu o conceito de organização inovadora, caracterizada não pelo volume de investimento em pesquisa, mas sim por uma atitude voltada à inovação. Em suas palavras,

a organização inovadora compreende que a inovação começa com uma ideia, e estimula e orienta os esforços para transformar uma ideia num produto, num processo, numa empresa ou numa tecnologia. Ela mede as inovações não por sua importância científica ou tecnológica, mas pelo que contribuem para o mercado e para o cliente (DRUCKER, 1989, p.256).

O termo inovação pode ser utilizado de diversas formas, geralmente estando associado a novos produtos e processos decorrentes da aplicação de alta tecnologia. No entanto, esse entendimento é limitado por não considerar que a tecnologia deve estar vinculada a outros 
fatores para representar uma inovação. Em outras palavras, novos produtos, processos, serviços e sistemas organizacionais somente poderão ser entendidos como inovações a partir de sua implementação no mercado ou na organização (RADEMAKERS, 2005).

Segundo Tidd et al. (2008), a inovação é um processo que visa desenvolver o uso prático de uma invenção previamente concebida, representando assim a difusão e efetivação de uma ideia. Ressalta-se, dessa forma, a diferença entre invenção e inovação, uma vez que "nem toda invenção se transforma em inovação, pois esta só se efetiva se for implementada e o mercado aceitá-la" (BARBIERI; ÁLVARES, 2003, p.44).

De acordo com o Manual de Oslo (OCDE, 2005), uma inovação corresponde à implementação de uma solução nova ou significativamente melhorada do ponto de vista da empresa, podendo ser classificada em quatro tipos: de produto, de processo, de marketing e organizacional.

A inovação de produto está relacionada à introdução de melhoramentos significativos nas especificações técnicas, nos componentes, materiais, softwares incorporados, na facilidade de uso ou outras características funcionais, tanto de bens quanto de serviços. Este tipo de inovação pode ser proveniente da utilização de novos conhecimentos ou tecnologias, como também de novos usos ou combinações de conhecimentos ou tecnologias já existentes (OCDE, 2005).

A inovação de processo, por sua vez, refere-se à introdução de um método de produção ou distribuição novo ou significativamente melhorado, envolvendo mudanças significativas em técnicas, equipamentos e softwares com o objetivo de reduzir custos de produção ou distribuição, melhorar a qualidade, ou ainda de produzir e distribuir produtos novos ou melhorados (OCDE, 2005).

Já a inovação de marketing está relacionada à utilização de um novo método de marketing, envolvendo "mudanças significativas na concepção do produto ou em sua embalagem, no posicionamento do produto, em sua promoção ou na fixação de preços" (OCDE, 2005, p. 59). Objetiva-se, por meio deste tipo de inovação, a melhora no atendimento das necessidades dos consumidores, a abertura de novos mercados, ou o reposicionamento do produto de uma empresa no mercado, com o objetivo de aumentar as vendas. 
Por fim, a inovação organizacional compreende a implementação de novas práticas de negócios, rotinas e procedimentos, bem como a adoção de novas formas de organização do trabalho ou das relações externas, visando à redução de custos administrativos ou de transação, o estímulo à satisfação no trabalho e o acesso a ativos não transacionáveis (OCDE, 2005).

O Quadro 1 apresenta de forma sucinta os principais tipos de inovação, classificados segundo a área do negócio sobre a qual incidem.

Quadro 1 - Tipos de inovação

\begin{tabular}{|c|c|c|}
\hline \multicolumn{2}{|c|}{ TIPO DE INOVAÇÃO } & CARACTERÍSTICAS \\
\hline \multirow{2}{*}{$\begin{array}{l}\text { Inovações } \\
\text { tecnológicas }\end{array}$} & Inovação do produto & $\begin{array}{l}\text { Desenvolvimento de um novo produto, serviço ou a } \\
\text { combinação destes. }\end{array}$ \\
\hline & Inovação do processo & $\begin{array}{l}\text { Novos métodos para executar atividades que agregam valor } \\
\text { (ex. produção, distribuição) de forma melhor ou mais barata. }\end{array}$ \\
\hline \multirow{2}{*}{$\begin{array}{l}\text { Inovações não } \\
\text { tecnológicas }\end{array}$} & Inovação de marketing & $\begin{array}{l}\text { Novos métodos de marketing relacionados ao produto, } \\
\text { embalagem, posicionamento do produto ou da marca, } \\
\text { promoção ou fixação de preços. }\end{array}$ \\
\hline & Inovação organizacional & $\begin{array}{l}\text { Novos métodos de organizar, coordenar e controlar } \\
\text { funcionários, tarefas e responsabilidades. }\end{array}$ \\
\hline
\end{tabular}

Fonte: RADEMAKERS, 2005; OCDE, 2005.

As inovações tecnológicas podem ser entendidas como um processo realizado pela empresa para introduzir "produtos e processos que incorporem novas soluções técnicas, funcionais ou estéticas”, visando alcançar algum resultado específico (BARBIERI; ÁLVARES, 2003, p.46). Essas soluções podem ser representadas pela introdução de novos processos produtivos ou pela alteração dos processos já existentes, com o objetivo de reduzir custos, melhorar a qualidade ou aumentar a capacidade de produção; como também pela modificação ou substituição de produtos; pela introdução de novos produtos integrados verticalmente com os existentes (fabricados a partir de um processo comum ou afim); e/ou pela introdução de novos produtos que exijam novas tecnologias (BARBIERI; ÁLVARES, 2003).

Já as inovações não tecnológicas são resultantes de modificações nos processos administrativos, na maneira como as decisões são tomadas, na alocação de recursos e atribuições de responsabilidades, nas combinações de produtos, processos e sistemas organizacionais referentes ao modelo de negócios, dentre outros. Essas inovações incluem mudanças significativas na estrutura da empresa, implementação de técnicas de gestão 
avançadas, bem como a modificação da orientação estratégica corporativa (BARBIERI; ÁLVARES, 2003).

A revisão da literatura acerca do tema revelou que as definições e tipificações das inovações são bastante diversas. A própria categorização das inovações pode ser feita de diferentes formas, como, por exemplo, segundo o grau de novidade (inovação incremental ou radical), segundo o grau de controle que a empresa detém sobre elas (inovação aberta ou inovação fechada), dentre outras.

Em relação ao grau de novidade, as inovações podem ser classificadas como radicais ou incrementais. As inovações radicais são mais revolucionárias, pois pressupõem investimentos de longo prazo visando à criação de algo novo em um mercado atual. Já as inovações incrementais são realizadas a partir da utilização de tecnologias e conhecimentos atuais para melhorar algo já existente no mercado, tornando-se relevantes pelo efeito cumulativo das mudanças proporcionadas, como também pela geração de versatilidade (ABERNATHY; CLARK, 1985). Vale ressaltar que, segundo o Manual de Oslo (OCDE, 2005), o requisito mínimo para se considerar algo como uma inovação é que a mudança introduzida tenha sido nova para a empresa. No entanto, outros dois conceitos podem ser considerados: a criação de algo novo para o mercado ou novo para o mundo.

Há ainda as inovações disruptivas, que se referem àquelas que geralmente se iniciam em mercados pouco atrativos e/ou limitados e que, após aprimoramentos e substituição das tecnologias existentes, causam um impacto significativo no mercado e na atividade econômica das empresas do setor. Este impacto pode, por exemplo, alterar a estrutura do mercado, criar novos mercados ou tornar produtos existentes obsoletos (CHRISTENSEN, 1997). Esta classificação propõe uma abordagem baseada no grau de impacto da inovação e não em seu grau de novidade.

Já em relação ao grau de controle que a empresa detém sobre o processo, as inovações podem ser classificadas em abertas ou fechadas. O modelo de inovação aberta contrasta com o modelo tradicional de inovação que prevaleceu durante o século XX, denominado inovação fechada. No modelo tido como tradicional, as empresas apoiavam-se nos processos de P\&D, que ocorria nos seus laboratórios internos, para deterem uma vantagem competitiva sustentada (CHESBROUGH, 2003). Diferentemente dessa abordagem, a inovação aberta está 
baseada na premissa de que, em um mundo onde o conhecimento está amplamente disponível e disperso, as empresas não podem se valer apenas de seu conhecimento e capacidades internas para inovar. Um dos princípios básicos da inovação aberta é o reconhecimento de que nem todos os componentes para uma inovação são originados por meio de fontes internas da organização e que o conhecimento proveniente de fontes externas pode tornar mais efetivos ou amplos seus próprios esforços direcionados à inovação (WITZEMAN et al., 2006). Deste modo, observa-se uma transição de um modelo fechado de P\&D para um modelo aberto e interativo de busca de soluções provenientes de dentro e fora da organização, no qual as interações entre organizações assumem papel relevante e despertam o interesse para a inovação que nasce de parcerias, alianças, joint-ventures e organizações em rede (CHESBROUGH, 2003).

\subsubsection{Processo e modelos de inovação}

O processo básico de inovação nas empresas é constituído por três atividades principais: geração e seleção de ideias; desenvolvimento e implementação das ideias selecionadas; e obtenção ou sustentação dos resultados. O processo só se completa quando novos conhecimentos estiverem definitivamente incorporados nos produtos/serviços, nos processos ou na gestão, atendendo aos objetivos específicos da organização. No entanto, na prática, o processo de inovação na empresa não é necessariamente linear. Tal fato decorre da existência de processos incrementais de mudança, que dificulta a determinação de quando a inovação está completa e quando se iniciam os aperfeiçoamentos. No caso das inovações tecnológicas, por exemplo, o processo se inicia desde a percepção de um problema/oportunidade, estendendo-se até a aceitação comercial do produto/serviço ou processo que incorporem as soluções encontradas. Já nas inovações organizacionais, o processo só se completa após a aceitação dos stakeholders (BARBIERI; ÁLVARES, 2003).

A literatura acerca dos processos de inovação apresenta diversos modelos que tentam explicálos. Uma das contribuições mais relevantes é apresentada por Roy Rothwell (1994), que classificou os modelos de processo de inovação em cinco gerações:

$1^{a}$ Geração - Inovação empurrada pela tecnologia ou modelo linear: o modelo da primeira geração demonstra o processo adotado nas décadas de 1950 e 1960, situação na qual a demanda era maior do que a capacidade de produção das empresas, fazendo com que a 
maioria das inovações fosse aceita pelo mercado. Neste modelo, a inovação é vista como um processo linear que se inicia na pesquisa científica básica, sendo procedida pelas etapas de desenvolvimento, fabricação e comercialização, resultando em um fluxo de novos produtos no mercado [Ilustração 1].

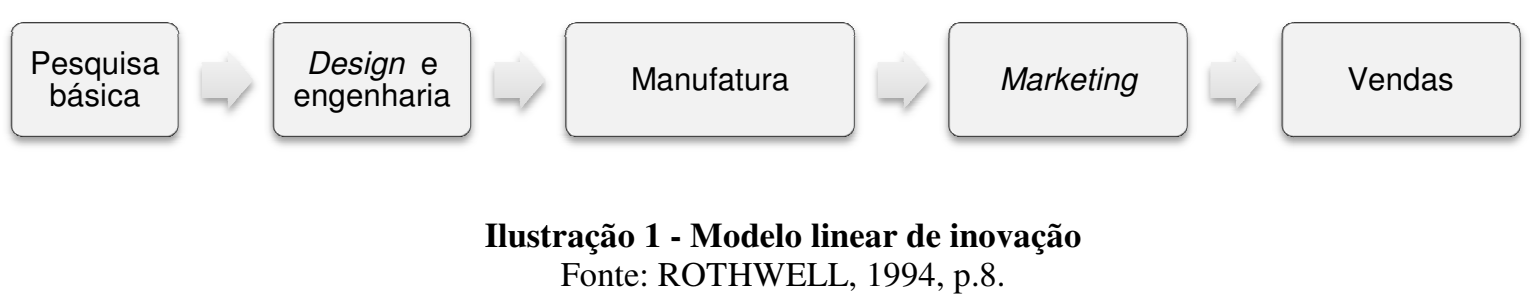

Neely e Hii (1998) reconheceram, no entanto, que este modelo é inadequado para descrever o processo de inovação atualmente. Os autores justificam que, no modelo, o processo de inovação é retratado como uma série de etapas estanques ao invés de um processo cíclico e de interação. Além disso, o modelo considera que o mercado irá aceitar e absorver todos os outputs do processo, situação que pode não ocorrer de fato.

$2^{a}$ Geração - Inovação puxada pelo mercado ou modelo linear reverso: a segunda geração retrata o modelo de processo de inovação adotado nos anos 1960 e 1970, expresso na Ilustração 2. Este momento é caracterizado pela diversificação das ofertas de produtos por parte das empresas com o objetivo de atender à crescente concorrência. $\mathrm{O}$ elemento fundamental considerado nesta segunda geração são as necessidades dos clientes. Há, portanto, uma ênfase crescente no papel do mercado para o processo de inovação, uma vez que este passa a ser visto como uma fonte direcionadora das atividades de P\&D. Porém, Neely e Hii (1998) afirmaram que, assim como no modelo linear, este modelo negligencia os outros insumos necessários às inovações bem sucedidas, além de sugerir um processo de inovação linear e sequencial que, na prática, dificilmente existiria.

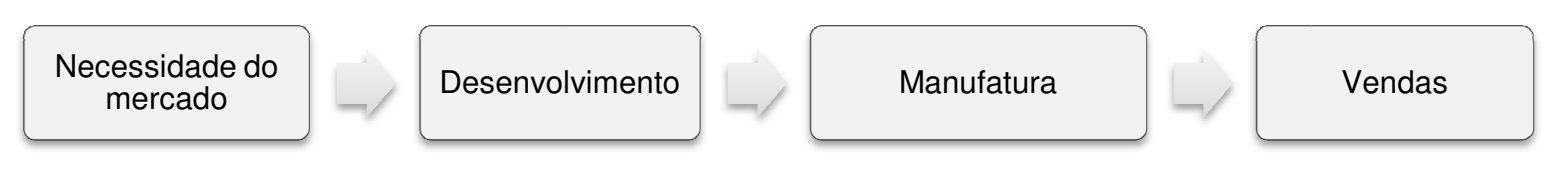

Ilustração 2 - Modelo de inovação puxado pelo mercado Fonte: ROTHWELL, 1994, p.9.

$3^{\text {a }}$ Geração - Modelo Composto: Rothwell (1994) ainda apresentou um terceiro modelo de processo de inovação [Ilustração 3] que busca incorporar ambas as concepções do processo 
linear e reverso, demonstrando que a inovação pode ser resultante tanto do avanço dos conhecimentos científicos e tecnológicos quanto da demanda da própria sociedade e organização, havendo assim um inter-relacionamento entre estes aspectos. O modelo adotado nos anos de 1970 e 1980 caracteriza os processos de inovação por meio de caminhos complexos de comunicação, interligando os agentes internos e externos de modo a permitir o acesso a conhecimentos científicos e do mercado.

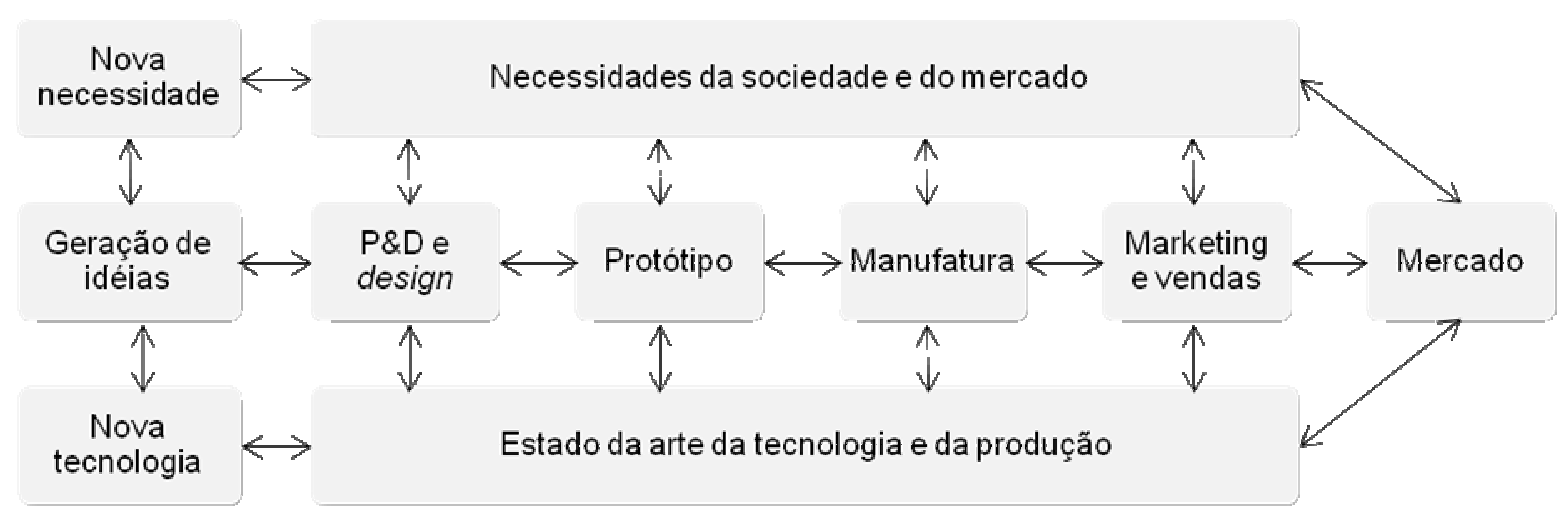

Ilustração 3 - Modelo composto de inovação Fonte: ROTHWELL, 1994, p.10.

O modelo expresso na Ilustração 3 propõe uma visão mais sistêmica à inovação na medida em que considera as diferentes interações entre os agentes ao longo do processo, possibilitando um maior espectro de mudanças.

$4^{\text {a }}$ Geração - Modelo Integrado: este modelo surgiu em meados dos anos de 1980 em decorrência de estudos sobre processo de inovação no setor automobilístico e de eletrônicos no Japão. Os estudos detectaram que a abordagem japonesa ao processo de desenvolvimento de produtos era caracterizada por um elevado nível de integração funcional e pela partilha de informação. Considerando-se que o processo de inovação é complexo, não-linear e requer uma retroalimentação, o modelo da quarta geração [Ilustração 4] propõe o que o processo de inovação seja desenvolvido de forma paralela entre os departamentos e parceiros, por meio de processos integrados, resultando em uma maior eficiência de processamento de informação e na redução do tempo de desenvolvimento de produtos (NEELY; HII, 1998). 


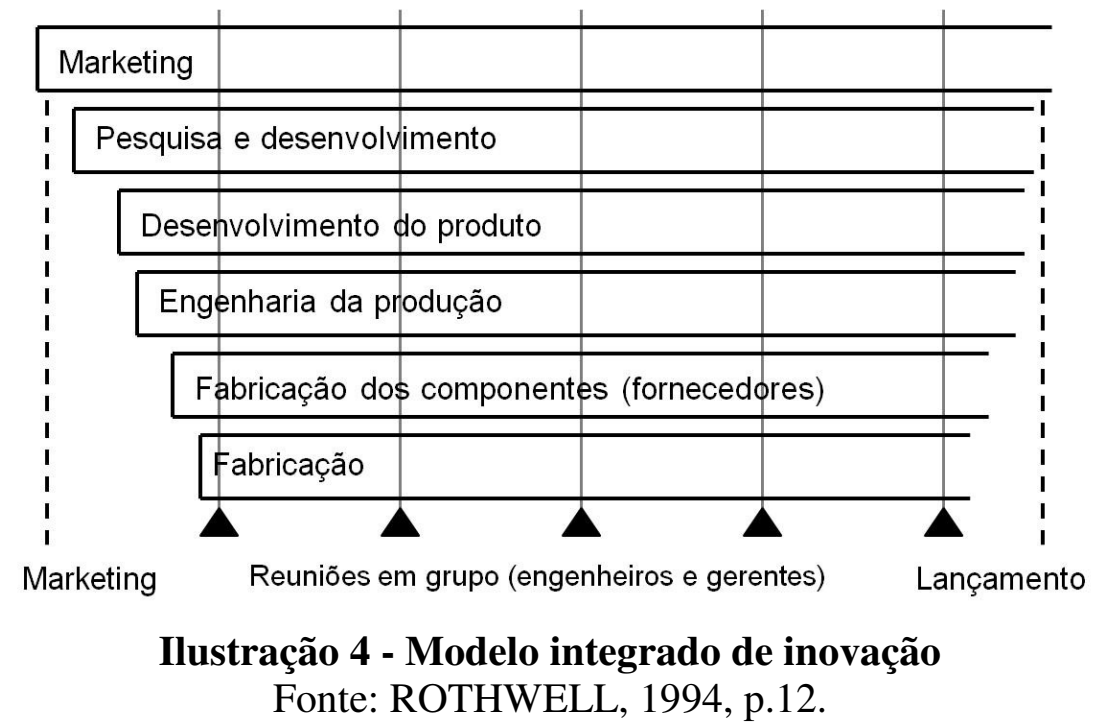

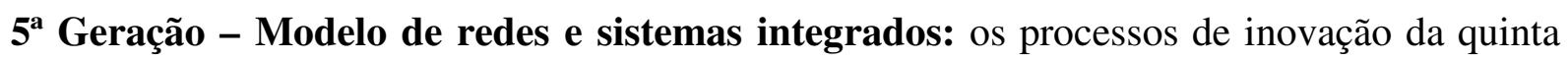
geração se assemelham aos processos em rede. O surgimento deste modelo, a partir da década de 1990, é decorrente do aumento do número de alianças estratégicas, do desenvolvimento das relações de colaboração para $\mathrm{P} \& \mathrm{D}$, da crescente importância dada à gestão da cadeia de suprimentos, bem como do aumento das redes estabelecias entre PME's e empresas de grande porte. O modelo de inovação da quinta geração é caracterizado pela integração de sistemas e pela associação em redes, possível principalmente devido à utilização da tecnologia da informação (TI) para integrar as várias funções dentro e fora da empresa. A formação em rede permite a conexão da empresa com o ambiente externo de forma rápida e eficaz, fato que tem se mostrado importante para a troca de conhecimentos e para as atividades de inovação na empresa (NEELY; HII, 1998).

Como se pôde observar, o processo de inovação nas empresas evoluiu concomitantemente às mudanças em seu ambiente, assumindo um caráter mais interativo e inter-relacionado. A partir desta concepção, os processos em rede puderam ser entendidos como mecanismos importantes para a otimização dos recursos organizacionais e para o aumento da capacidade de geração de inovações.

\subsection{Redes de inovação}

O termo 'rede' é utilizado em diversas áreas do conhecimento, apresentando diferentes significados e aplicações. Segundo Smith-Doerr e Powell (2005), o estudo das redes se 
iniciou nos primeiros anos da década de 1970, a partir de pesquisas antropológicas e sociológicas, que tinham por objetivo compreender como os indivíduos se conectavam uns aos outros e como essas conexões influenciavam o significado da vida social. Apesar de importantes, a ênfase desses estudos não era pautada sobre a ação econômica, fato que ocorreu a partir da década de 1980.

Na definição clássica, uma rede pode ser entendida como um conjunto de nós interconectados (CASTELLS, 1999). No contexto organizacional, o conceito de rede tem sido empregado para caracterizar um conjunto de fluxos de recursos entre um conjunto de nós, representados por indivíduos, grupos, organizações e sistemas de informações (FOMBRUN; 1997). Contudo, devido à abrangência do tema, há uma série de outras definições possíveis, de acordo com a abordagem pretendida.

Jarillo (1988), por exemplo, a partir de uma visão estratégica, defendeu que as redes são acordos de longo prazo instituídos entre diferentes organizações, visando a propósitos específicos. Já para Guarau (2005) uma rede consiste em relações entre atores (indivíduos ou empresas) que cooperam entre si para adquirir ou compartilhar recursos. Para Porter (1998), as redes são uma forma de organização de atividades econômicas, ocorrida por meio da coordenação e/ou cooperação entre firmas. Sua definição leva em consideração que as redes são constituídas de forma a regular a interdependência de sistemas complementares, o que é diferente de agregá-los em uma única empresa. Dessa forma, as competências e atribuições de uma rede estão relacionadas aos processos de coordenação das interações entre as organizações (AMATO NETO, 2000).

Essa coordenação pode ser realizada por um dos membros da rede, por um agente que difere de seus membros ou por um organismo estabelecido pelos membros coletivamente. As redes empresariais podem envolver empresas do mesmo ramo ou empresas que fornecem bens ou serviços complementares. Além disso, as relações estabelecidas na rede podem ser formais e de longo prazo, como também direcionada à cooperação de curto prazo apenas para o desenvolvimento de certas atividades (FORFÁS, 2004).

A revisão da literatura revelou que os conceitos de "redes" e "clusters" são utilizados, por algumas vezes, indistintamente. No entanto, apesar de estarem intimamente ligados, os termos apresentam algumas diferenças importantes. 
Segundo O'Doherty (1998), as principais diferenças entre as redes e clusters são:

- as redes geralmente possuem uma participação mais restrita e um conjunto específico de objetivos, enquanto os clusters são mais abertos, tanto em termos de composição quanto de objetivos;

- as redes geralmente envolvem arranjos contratuais formais, fato que não ocorre na formação dos clusters;

- os clusters estão relacionados a um espaço geográfico, possuindo geralmente um foco setorial, enquanto as redes normalmente não dependem da localização ou setor.

Para Rosenfeld (1995), as redes geralmente se referem à formação de um grupo de empresas e outras instituições em torno de objetivos comuns, cujo propósito é gerar ganhos mútuos. Os membros da rede possuem participação restrita e específica e, por esse motivo, podem escolher uns ao outros e concordar explicitamente a cooperar de alguma forma. De acordo com o autor, as redes podem se desenvolver a partir dos clusters, especialmente em situações nas quais haja uma ampla gama de transações de negócios, realizadas ao longo do tempo, que resulte na construção de relações de confiança entre os parceiros, fortalecendo seus desejos de trocarem conhecimentos e estabelecerem redes. O autor ainda ressaltou que os clusters se diferenciam das redes por possuir uma delimitação geográfica, caracterizando-se por concentrações de empresas similares, conexas ou complementares, que compartilham uma infra-estrutura especializada, assim como oportunidades e ameaças comuns. Além disso, os clusters se configuram de forma mais aberta, por meio de relações de cooperação baseadas na confiança entre as empresas em torno de uma visão compartilhada, ao invés de objetivos comuns.

Amato Neto (2000) enfatizou que a formação de redes interempresariais pode viabilizar uma série de necessidades das empresas, que provavelmente não poderiam ser atendidas caso estas atuassem isoladamente. Dentre as principais necessidades abordadas pelo autor destacam-se:

- a combinação de competências e utilização de know-how de outras empresas;

- a divisão do ônus para realização de pesquisas tecnológicas, compartilhando o desenvolvimento e os conhecimentos adquiridos; 
- a partilha dos riscos e custos inerentes da exploração de novas oportunidades;

- o exercício de uma pressão maior no mercado, aumentando a força competitiva em benefício do cliente;

- o compartilhamento de recursos, em especial aos que estão sendo subutilizados, dentre outros.

De acordo com os estudos desenvolvidos por Powell (1987), Oliver (1990) e Grandori e Soda (1995), a noção de rede pode ser aplicada a uma ampla variedade de relações interorganizacionais, como, por exemplo, no caso de joint ventures, alianças estratégicas, complexos industriais, consórcios, redes sociais, redes de cooperação, como também redes inovação.

Dentre as diferentes manifestações de rede na literatura, as redes de inovação apresentam-se como uma entidade formada por diversas instituições autônomas, geograficamente distribuídas e heterogêneas, que colaboram entre si para atingir a objetivos comuns (PLISSON et al., 2007).

Freel e Harrison (2006), em consonância com os conceitos do Manual de Oslo (OCDE, 2005), definiram as redes de inovação como um conjunto de instituições que desenvolvem vínculos de parceria com o objetivo superar as incertezas do processo de inovação.

De acordo com Beckman e Haunschild (2002), as redes interorganizacionais são os meios pelos quais as organizações podem agregar ou trocar recursos e desenvolver novas ideias e habilidades de forma conjunta. De acordo com as autoras, a heterogeneidade de colaboradores permite que empresas em setores de rápido desenvolvimento aprendam a partir de um amplo espectro de conhecimentos. Em outras palavras, as organizações com redes mais amplas estão expostas a diferentes experiências, atividades, colaboradores, competências e oportunidades, corroborando para a criação de um ambiente favorável às inovações.

Segundo Dyer e Nobeoka (2000), as redes de inovação entre empresas, outras organizações e instituições promovem interações de modo colaborativo, e dependem primordialmente do compartilhamento de conhecimento. Powell et al. (2005) afirmaram que o desenvolvimento de parcerias múltiplas, seja por meio da promoção de colaborações ou por meio da expansão de uma parceria de P\&D já existente, acarreta no aumento dos pontos de contato entre as 
empresas. Quando os relacionamentos são aprofundados, o compromisso e a partilha de conhecimento tornam-se mais fortes e é por isso que as organizações com laços múltiplos são mais suscetíveis a desenvolver melhores relações de troca de informações. Corroborando com este pensamento, Küppers e Pyka (2002) ressaltaram que as estruturas em rede permitem a veiculação de conhecimentos provenientes de produtores, fornecedores e usuários localizados em diferentes organizações, tendendo a facilitar a rápida troca de informação.

A partir do estudo de diversas cadeias de suprimentos, Bovet e Martha (2000) ofereceram importantes contribuições sobre o que pode ser denominada uma 'rede de valor'. Segundo os autores, a rede de valor consiste em uma rede dinâmica estabelecida entre clientes e fornecedores para facilitar o fluxo de informações. A criação de valor ocorre quando seus participantes - empresa, fornecedores e consumidores - podem se beneficiar de sua formação, operando por meio de uma integração colaborativa, de forma a permitir um fluxo de informação em escala e de forma ágil.

Pode-se notar que, de fato, os fatores que impulsionam as empresas a estabelecerem vínculos colaborativos por meio de redes com outros parceiros referem-se à necessidade de agilidade na resposta às oportunidades de negócios e aos estímulos de um ambiente cada vez mais turbulento em profunda transformação (HALLIKAS et al., 2008).

Segundo Pellegrin et al. (2007), há dois principais fatores fortemente entrelaçados que corroboram para a criação de redes de inovação: (1) o crescimento de maneira substancial associada à complexidade do conhecimento e dos demais recursos necessários aos processos de inovação; e (2) a necessidade de desenvolvimento de novos produtos (time to market) de forma cada vez mais rápida, a baixo custo. Em suas palavras:

\footnotetext{
a exigência de capacidade para desenvolver tecnologias em tempo e custo menores faz com que a opção de formar todas as competências necessárias dentro da empresa seja cada vez menos viável. A própria noção de competência central (core competence), tão disseminada no meio empresarial, é resultado desses dois fatos que caracterizam o ambiente competitivo e aumentam a associação entre cooperação entre as organizações (sejam elas firmas ou não) e o processo de inovação (PELLEGRIN et al., 2007, p. 314).
}

Para Tidd et al. (2005), as razões que podem levar as empresas a estabelecer alguma relação de cooperação para inovação podem derivar do volume de informações necessárias, do tempo 
de desenvolvimento de novos produtos e sua comercialização, do aumento dos custos e dos riscos do desenvolvimento tecnológico e de mercado.

Powell e Grodal (2006) observaram que a formação de redes pode facilitar a difusão de informação, o compartilhamento de recursos, o acesso a ativos específicos, bem como a aprendizagem. Neste sentido, percebe-se que a constituição de redes está relacionada à necessidade de insumos para os processos de inovação, considerando-se especialmente a complexidade da base de conhecimentos necessários para inovar.

Küppers e Pyka (2002) afirmaram que as redes de inovação possuem três implicações fundamentais: (1) constituem um dispositivo de coordenação que possibilita e apoia a aprendizagem interempresarial; (2) permitem a exploração de complementaridades entre os atores, essenciais para o domínio das tecnologias caracterizadas pela complexidade e diversidade das diversas áreas de conhecimento; e (3) constituem um ambiente que abre a possibilidade da exploração de sinergias pela junção de diferentes competências tecnológicas.

Outros fatores motivadores para a formação das redes de inovação dizem respeito à redução da incerteza e da complexidade inerentes ao processo de inovação. As redes podem constituir uma resposta para reduzir a incerteza e grau de irreversibilidade do processo de inovação, reduzindo os investimentos individuais e os riscos das organizações no desenvolvimento de um novo campo do conhecimento, aumentando a flexibilidade e reversibilidade dos comprometimentos e reduzindo a assimetria de informações sobre o mercado (PELLEGRIN et al., 2007).

\subsubsection{Caracterização das redes e das interações}

A cooperação por meio de redes voltadas para a inovação pode assumir uma série de formas, desde acordos de transferência de tecnologia, acordos com universidades para desenvolvimento ou exploração conjunta de uma patente, até o desenvolvimento conjunto de produtos a serem comercializados em parceria (PELLEGRIN et al., 2007).

Além disso, os estudos sobre tipologias de redes apontam para uma grande diversidade de conceitos que inclui desde redes baseadas em relações formais contratuais, tais como alianças 
estratégicas ou a participação em um consórcio de pesquisa, até as relações informais, com base na participação comum ou associação comercial entre empresas.

A diversidade de tipologias de redes interorganizacionais provoca certa ambiguidade no próprio entendimento do termo. Esta questão foi objeto da análise de Castells (1999), com base no argumento de que as redes interorganizacionais podem figurar de diferentes formas e contextos, como, por exemplo, as redes familiares, as redes tecnológicas, as redes hierárquicas, as redes horizontais de cooperação, as redes internacionais resultantes de alianças estratégicas, dentre outras.

Segundo Powell e Grodal (2006) as redes podem ser classificadas segundo a sua duração e estabilidade, bem como com base no objetivo pelo qual elas são criadas (p.e. para realizar uma tarefa específica ou para se desenvolver além dos laços de associação pré-existentes). As redes também podem se desenvolver a partir de projetos de curto prazo, tornando-se relacionamentos de longo prazo. Algumas redes são hierárquicas, monitoradas por uma autoridade central, enquanto outras são mais heterárquicas, com a autoridade distribuída e sistemas de auto-organização.

Iacob et al. (2001) sugeriram que as redes podem ser classificadas segundo quatro critérios principais: dinâmica, coordenação, interdependência das organizações e estrutura. A dinâmica se refere ao padrão de cooperação na rede, ou seja, se as relações são estáveis ou instáveis, persistentes ou transitórias. A coordenação representa a forma pela qual as empresas são gerenciadas, seja por meio de uma hierarquia, por meio de forças do mercado ou de forma híbrida. A interdependência das organizações engloba fatores como a perspectiva temporal (longo ou curto prazo), o objetivo da rede (ganhos individuais ou ganhos conjuntos), além da distribuição do poder entre as organizações participantes (balanceado ou desbalanceado). Por fim, a estrutura envolve a topologia (características geométricas da rede, p. e. cadeia, estrela, rede completa), a modularidade (como os diferentes componentes formam as redes) e a estratificação das diversas relações existentes.

A partir destas características, os autores propuseram três tipologias principais das redes de empresas: 
- Redes permanentes: formadas por organizações em uma rede bem estruturada e estável, cujas relações são de longo prazo.

- Redes baseadas em projetos: composta por organizações em cooperação, que se juntam por algum objetivo específico, de forma temporária.

- Redes baseadas no mercado: outro tipo de rede de caráter temporário, cuja configuração está baseada em demandas do mercado e em comportamentos mais oportunistas.

Fundamentando suas análises nas redes interpessoais, Granovetter (1973) ofereceu uma importante contribuição para a caracterização da estrutura das redes, baseada na força das ligações entre seus atores. Segundo o autor (1973, p. 1361), a força de uma ligação é definida como "uma combinação, provavelmente linear, de tempo, intensidade emocional, intimidade e serviços recíprocos". Em geral, costuma-se dar grande importância às ligações fortes, representadas por interações regulares, fundamentadas em interesses comuns. No entanto, o autor sugere que as ligações fracas possuem características importantes e podem ser mais interessantes nos processos de difusão de informação, pela possibilidade de reduzir a redundância e trazer informações novas aos agentes. Dessa forma, as ligações fracas possuem um alcance mais longo, mas uma largura de banda muito mais estreita do que as ligações fortes que, por serem mais coesas, muitas vezes provam ser mais eficazes para a troca de informações complexas. A Ilustração 5 apresenta a diferença entre as ligações fortes e fracas sugeridas pelo autor.

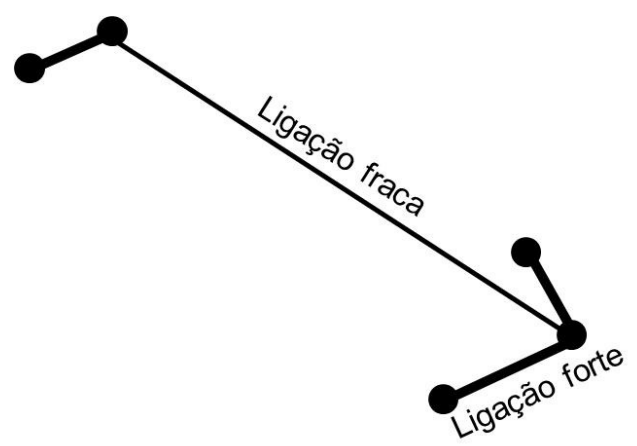

Ilustração 5 - Ligação forte e fraca

Fonte: Adaptado de Granovetter, 1973.

Ainda segundo Granovetter (1973), conceitos como a densidade da rede, a distância entre os atores e a frequência de relações são igualmente fundamentais para sua classificação. A 
densidade é definida pelo número de ligações existentes sobre o número de ligações possíveis, ou seja, quanto maior o número de ligações, mais densa é a rede.

Já a análise da distância entre os atores numa rede é importante por possibilitar o entendimento dos padrões de difusão das informações, os custos de transação e as estruturas de governança. As ligações fracas conseguem atravessar maior distância e difundir as informações mais rapidamente e com menor redundância do que as ligações fortes (GRANOVETTER, 1973). Dessa forma, agentes com várias ligações fracas estão mais bem posicionados na rede para difundir uma inovação. Ou seja, as ligações fracas podem ser entendidas como estimuladoras da inovação, pois trazem informações novas e não redundantes às redes, embora não sejam muito ricas em detalhes. Corroborando com os pensamentos de Granovetter (1973), Powell e Grodal (2006) argumentaram que uma ligação forte entre as partes pode restringir a coleta de informações em termos de amplitude, apesar de permitir um melhor detalhamento. Por outro lado, as ligações fracas são menos densas e duráveis, apesar de proporcionar um melhor acesso à informação não redundante.

O último atributo importante para a análise das ligações é a frequência, que indica a quantidade de encontros entre os agentes por um período de tempo. Sua função é permitir o estreitamento do relacionamento ao longo do tempo, criando confiança mútua e enriquecendo o fluxo de informações. Segundo Cortes et al. (2005), é razoável assumir que quanto maiores os recursos envolvidos numa troca, maior a frequência de ligações entre os agentes da rede.

Outro conceito relevante foi apresentado por Burt (1992) ao examinar o papel das diferentes estruturas de redes. Burt ampliou as considerações de Granovetter sobre as ligações fracas, concebendo um modelo de competição econômica baseado na estrutura do relacionamento social e no conceito de "buracos estruturais". O termo se refere a uma lacuna que se forma entre dois atores (individuais ou coletivos), situados em grupos sociais ou redes distintas, sem conexão entre si, que detêm recursos complementares. Para o autor, as lacunas podem ser importantes por fornecer oportunidades de alavancagem e realização de intermediações entre os agentes.

Apoiado nos estudos de Granovetter (1973) e Burt (1992), Ahuja (2000) desenvolveu pesquisas com o objetivo de entender como os aspectos caracterizadores da estrutura em rede podem influenciar a performance da empresas em termos de inovação. $\mathrm{O}$ autor constatou que 
as redes fechadas, ou seja, redes com relacionamentos de compromisso de longo prazo entre os agentes, são propícias para a criação de um ambiente colaborativo e para a superação do oportunismo. Por outro lado, redes com buracos estruturais, que possuem contatos com diversos parceiros que não interagem entre si, facilitam o rápido acesso a informações diversificadas. No entanto, os buracos estruturais dificultam a inovação, por prejudicarem a relação de confiança entre os agentes parceiros (AHUJA, 2000).

Ahuja (2000) também observou um efeito positivo das ligações diretas e indiretas na rede com relação ao desempenho em inovações. Uma ligação direta refere-se ao acesso de determinada empresa a outras por meio do estabelecimento de uma parceria sem a intermediação de terceiros. Por outro lado, ligações indiretas são os relacionamentos nos quais a empresa desenvolve algum tipo de acesso indireto a várias empresas, por intermédio de uma parceria direta. Ahuja (2000) demonstra que as ligações diretas entre empresas proporcionam compartilhamento de recursos e conhecimento, enquanto as ligações indiretas, proporcionam apenas o compartilhamento de informações para a empresa focal.

Outro ponto relevante para a caracterização das redes refere-se ao motivo pela qual elas são constituídas e como elas se desenvolvem. Powell e Grodal (2006) evidenciaram a existência de redes formadas intencionalmente por meio de uma conexão com o mercado para realização de determinada tarefa, bem como de redes emergentes que crescem a partir das relações em curso. Para os autores, a primeira pode ser considerada uma relação instrumental ou estratégica, enquanto a segunda decorre de relações mais primordiais, como a etnia comum, a cooperação, ou localização. No entanto, independentemente do ponto de partida para sua formação, as redes podem se desenvolver de diferentes formas. Em outras palavras, as relações na rede podem evoluir para uma colaboração profunda, com parceiros mutuamente dependentes, como também para uma parceria oportunista; indicando que as redes não são estáticas e podem se desenvolver de acordo com o contexto no qual as empresas estão inseridas.

Partindo dessa concepção, Powell e Grodal (2006) apresentaram quatro tipologias de redes [Ilustração 6], baseados no grau de formalidade e no grau de densidade da relação. As setas indicam as possíveis evoluções decorrentes de cada tipo de rede. 


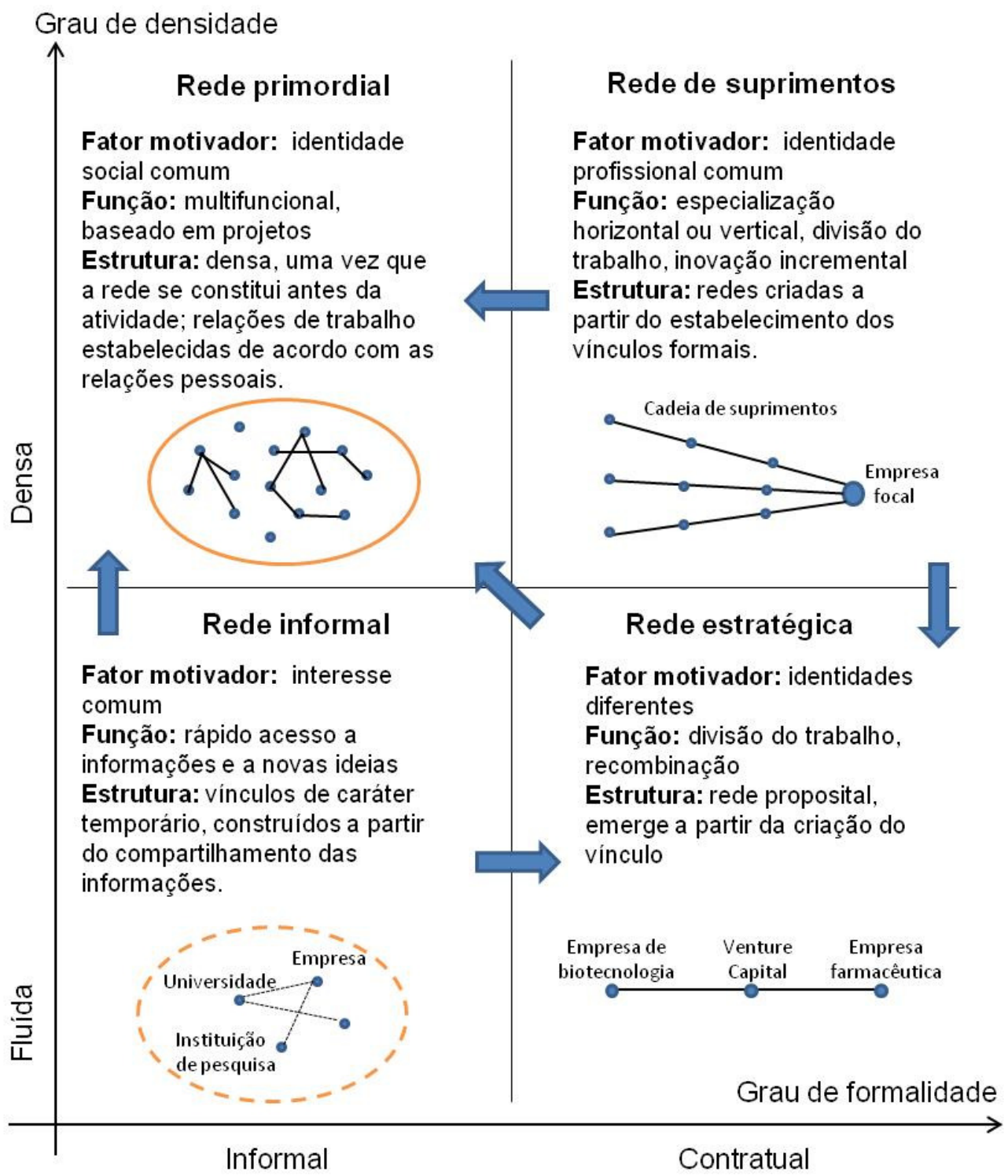

Ilustração 6 - Tipos de redes

Fonte: POWELL; GRODAL, 2006, p. 64.

Na Ilustração 6, o quadrante inferior esquerdo se refere às redes informais, que emergem da experiência compartilhada ou de algum interesse comum. Embora essas relações tendam a ser temporárias e de curta duração, elas podem evoluir para alianças de negócios formais ou para relações mais duradouras, nas quais a participação é mais constante e menos fluída.

A rede primordial, no quadrante superior esquerdo, é constituída a partir de uma identidade social comum, caracterizando-se pela participação contínua dos parceiros na rede e no desenvolvimento de relações estreitas. Tais características são frequentemente encontradas em redes profissionais e setores industriais. 
A rede de suprimentos, no quadrante superior direito, é caracterizada pelo envolvimento em um projeto comum. A filiação em uma rede desse tipo normalmente é restrita e, por muitas vezes, regida por uma empresa focal. As setas neste quadrante indicam que esta relação pode evoluir tanto para as redes primordiais quanto para alianças estratégicas de negócios.

Por fim, o tipo mais intencional de rede é a estratégica, representada pelo quadrante inferior direito. Este tipo de rede é representado por uma relação contratual, como, por exemplo, uma aliança estratégica, propiciando o intercâmbio mútuo de informações, tecnologias e outros recursos.

A caracterização apresentada na Ilustração 6 assemelha-se muito às tipologias desenvolvidas em estudos anteriores de Grabher e Powell (2004), que atentam para a existência de quatro tipos de redes: (1) redes informais, que surgem com base na experiência partilhada; (2) redes de projetos, baseadas em projetos de curto prazo ou combinações para a realização de tarefas específicas; (3) redes regionais, na qual proximidade espacial ajuda a sustentar uma relação comum; e (4) redes de negócios, cuja relação é proposital, baseada em alianças estratégicas.

Na tentativa de oferecer uma melhor compreensão acerca da diversidade de tipologias de redes interorganizacionais, Marcon e Moinet (2000) criaram um modelo que indica, a partir de quatro quadrantes, as principais dimensões sobre as quais as redes são estruturadas [Ilustração 7].

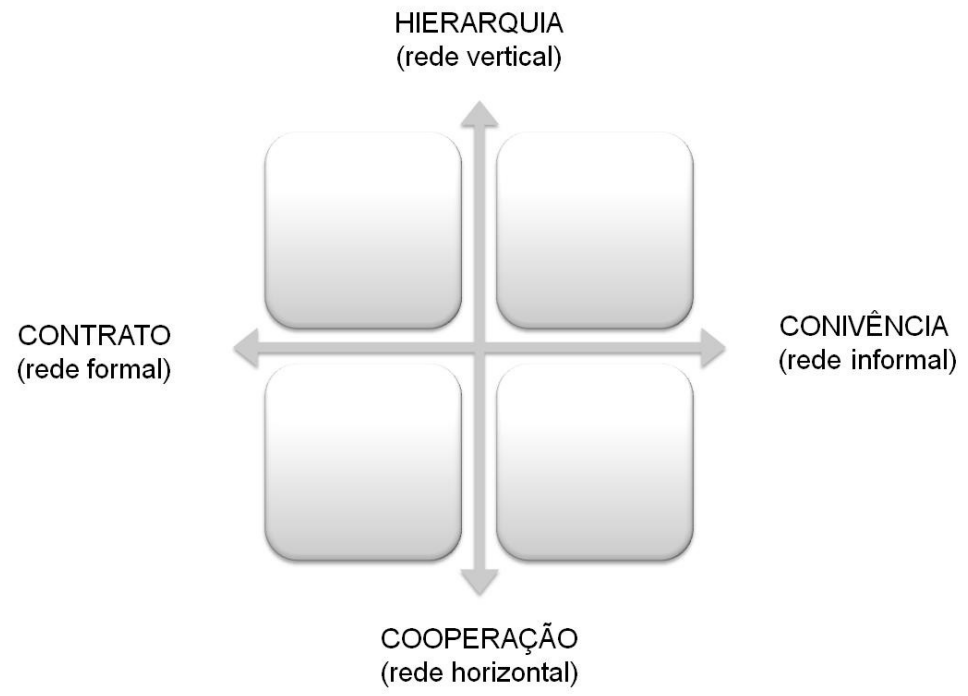

Ilustração 7 - Mapa de orientação conceitual

Fonte: adaptado de Marcon e Moinet, 2000. 
Observa-se, na Ilustração 7, que o eixo vertical está relacionado com a natureza dos elos estabelecidos entre os atores da rede. Tais elos podem representar uma atividade de cooperação, no caso de uma rede horizontal, ou uma ligação hierárquica, no caso de uma rede vertical, como uma rede do tipo matriz/filial. As redes horizontais baseadas na cooperação são constituídas por empresas independentes, que optam por realizar certas atividades específicas de forma conjunta, visando à criação de novos mercados e o compartilhamento de custos e riscos em atividades como pesquisas de desenvolvimento de produtos/serviços, gestão da informação e de tecnologias, dentre outras. Esse tipo de configuração de rede favorece a concentração de esforços, sem privar seus membros de sua liberdade de ação estratégica, contribuindo para a formação de um ambiente de aprendizagem por meio da cooperação (MARCON; MOINET, 2000). As redes verticais, por sua vez, são caracterizadas, em geral, pela existência de relações semelhantes às estabelecidas entre matriz e filial, em que as filiais possuem pouca autonomia jurídica e administrativa. São formadas, por exemplo, por grandes redes de distribuição que adotam a estratégia de redes verticais para estarem mais próximas do cliente (MARCON; MOINET, 2000).

Já o eixo horizontal da Ilustração 7 representa o grau de formalização estabelecido nas relações entre os atores, que pode ser informal, como no caso de associações, clubes e redes de amigos, variando até as relações formalmente estabelecidas por contratos entre as partes, como ocorre na formação de joint-ventures. As redes informais permitem a troca de experiência e de informação por meio do estabelecimento de uma cultura geralmente de cooperação. Nessa dimensão, as redes são formadas sem o uso de contratos formais para o estabelecimento das regras, uma vez que a ação dos agentes é pautada, sobretudo, na confiança e na conformidade com os interesses mútuos de cooperação (MARCON; MOINET, 2000). Diferentemente, as redes formais são estabelecidas por meio de termos contratuais, que estabelecem regras de conduta entre os atores. Redes como as alianças estratégicas, os consórcios de exportação, as joint-ventures e as franquias são exemplos de redes fortemente formalizadas. Destaca-se, a partir da análise do modelo, que cada um dos quadrantes estabelecidos no mapa da Ilustração 7 evidencia um tipo específico de configuração de rede, elucidando, assim, a ampla diversidade de tipologias de redes interorganizacionais existentes.

Em síntese, a literatura acerca do tema revelou que, devido à existência de diversas abordagens acerca da tipificação de redes, dificilmente existirão duas estruturas de redes totalmente idênticas. Dessa forma, qualquer esforço no sentido de abranger todas as 
possibilidades de redes interorganizacionais constitui apenas uma simplificação em categorias pré-determinadas.

\subsubsection{Tipos de atores na rede}

O levantamento dos possíveis parceiros com os quais as empresas podem desenvolver relações visando melhorar suas atividades inovativas por meio de redes de inovações é de extrema relevância. Isso porque, para que os processos da rede de inovação possam ser desenvolvidos de forma satisfatória, "os papéis e os interesses dos diversos tipos de atores devem ser coordenados e articulados de forma sinérgica" (PELLEGRIN et al., 2007, p. 318). Para tanto, deve-se levar em consideração a relatividade dos papéis de cada um dos atores, ou seja, que cada ator possui um papel diferente na rede, bem como a necessidade de interação, o grau de dependência, o nível de especialização e complementaridade entre cada um dos agentes (HOFFMANN et al., 2007).

A análise da literatura indicou que as empresas podem complementar as suas capacidades inovadoras através do desenvolvimento de colaborações interorganizacionais com uma ampla variedade de parceiros, como, por exemplo, fornecedores e clientes (SHAW, 1994; VON HIPPEL, 1988; PRAHALAD; RAMASWAMY, 2004), potenciais usuários (QUINN, 1985; VON HIPPEL et al., 1999), universidades e centros de pesquisa (GERWIN et al., 1992; TIDD et al., 2002) e, até mesmo, concorrentes (HAMEL, 1991; DODGSON, 1993).

Considerando-se que as empresas diferem em relação a suas necessidades na rede, Gemüden et al. (1996) argumentaram que é plausível supor que as empresas também difiram em relação aos tipos de parceiros externos com os quais procuram estabelecer relações de colaboração. Para algumas empresas, por exemplo, as universidades podem constituir a fonte de recursos externos mais importante, enquanto, para outras empresas, pode ser mais interessante desenvolver relações de colaboração com clientes e fornecedores. Os autores constataram que a importância relativa de cada parceiro em comparação à importância global da rede pode diferir significativamente de empresa para empresa, uma vez que as diferentes configurações na rede podem servir ao alcance de objetivos distintos em termos de inovação. 
A Ilustração 8 apresenta os mais importantes tipos de parceiros em uma rede de inovação e suas contribuições segundo a concepção de Gemüden et al. (1996):

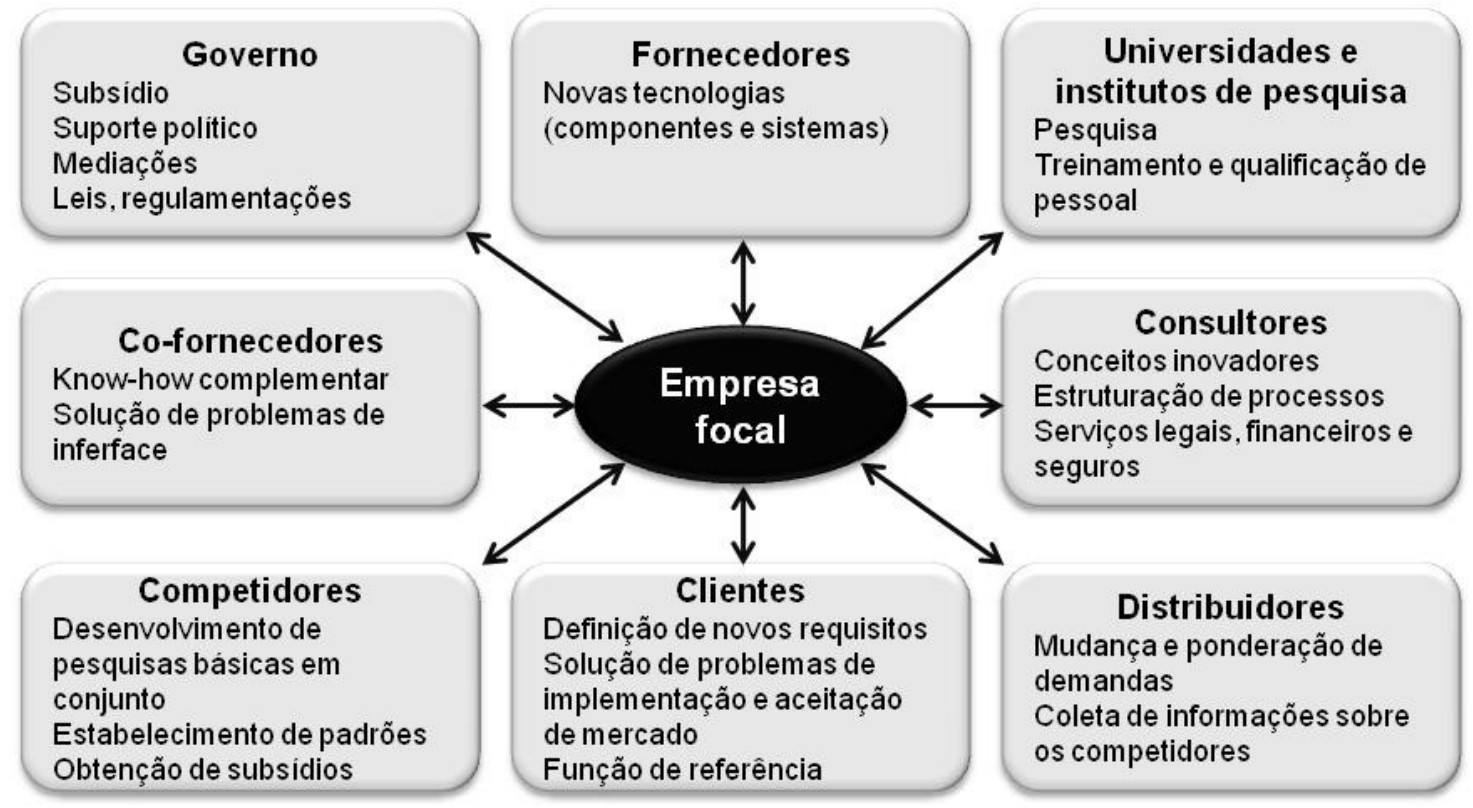

Ilustração 8 - Parceiros no processo de inovação e suas contribuições Fonte: GEMÜDEN et al., 1996, p. 450.

Observa-se, na Ilustração 8, que os diferentes tipos de parceiros podem contribuir para as atividades inovativas da empresa, apesar de cada um deles oferecer um conjunto distinto de recursos.

Outro aspecto relevante na relação desenvolvida na rede é que algumas empresas interagem intensamente com muitos parceiros externos, enquanto outras quase não mantêm relações estreitas com parceiros externos. Isto se deve a diferenças significativas na experiência das empresas e em sua capacidade de interagir em rede. Além disso, algumas empresas estão mais dispostas a investir em uma posição de rede mais vantajosa do que outros. Isto significa que as empresas não diferem apenas em relação ao padrão por meio do qual cooperam, como também na intensidade das relações desenvolvidas (GEMÜDEN et al.,1996).

Em seu estudo sobre a relação entre a configuração das redes e sua contribuição para o sucesso em inovação, Gemüden et al. (1996) constataram que a sinergia com o fornecedor e a interação com o cliente pode proporcionar melhores resultados em inovações no que se refere à melhoria de produtos da organização. Além disso, a universidade desempenha um papel importante nos resultados da empresa em termos de desenvolvimento de novos produtos, 
principalmente em indústrias de alta tecnologia. Seus resultados ainda mostraram que, para a obtenção de sucesso em termos de inovação de processo, é necessário que a empresa desenvolva uma cooperação em rede com múltiplos atores, seja por meio de uma interação intensa com universidades e consultores, seja por meio de interações de intensidade e padrões mais equilibrados entre outros agentes.

Em 2006, o INSEAD, juntamente com a consultoria Booz Allen Hamilton, apresentou os resultados de sua pesquisa realizada com 186 organizações, de 17 setores, em 19 países acerca da configuração e gerenciamento de redes de inovação globais (DOZ et al., 2006). A pesquisa apontou que as empresas estão utilizando uma ampla gama de parceiros na formação de sua rede de inovação, em especial institutos de pesquisas, universidades e consumidores [Ilustração 9]. No entanto, os níveis de colaboração com fornecedores não foram significativos estatisticamente.

Apontou-se ainda que a dispersão geográfica das empresas também possui relação com os níveis de colaboração e com os tipos de parceiros. As organizações globais, por exemplo, tendem a apresentar um maior nível de colaboração com institutos de pesquisa e universidades, além de desenvolver mais relações de joint-venture com empresas locais (DOZ et al., 2006).

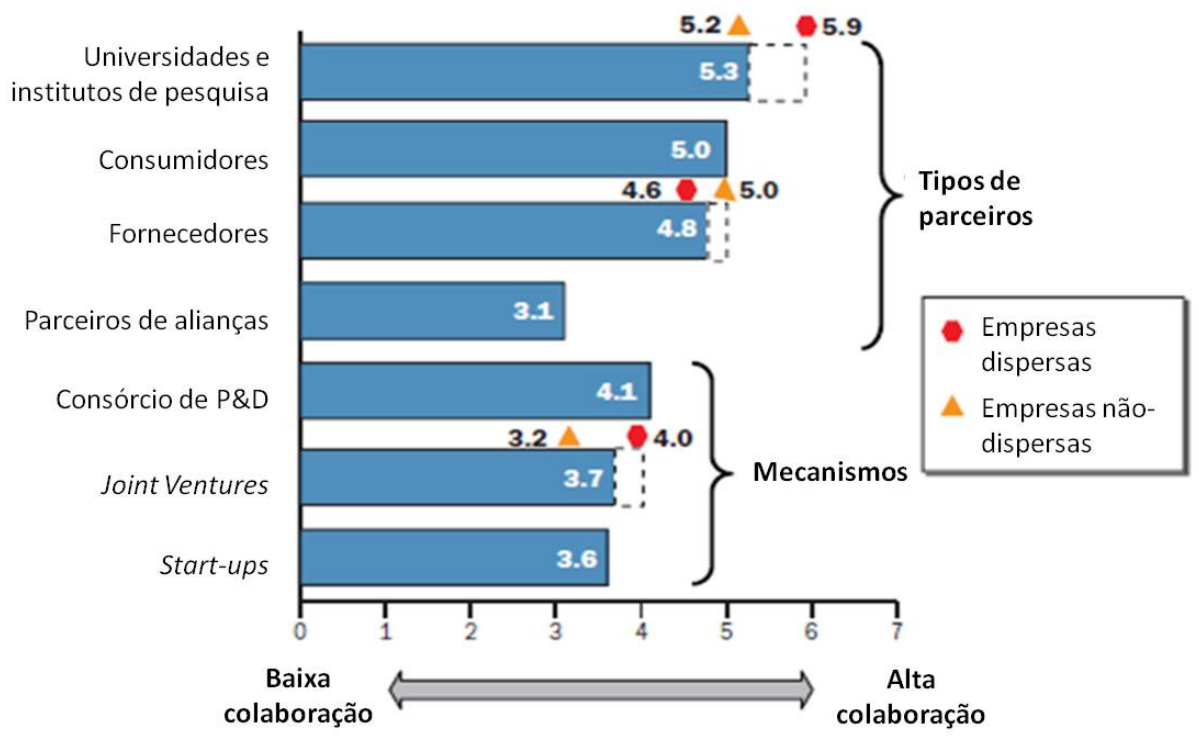

Ilustração 9 - Nível de colaboração externa por tipo de parceiro Fonte: DOZ et al., 2006, p.8. 
A análise do tipo de colaboração por setor pesquisado revelou alguns padrões de comportamento que diferem da média. Os setores de eletrônicos, engenharia elétrica, químico, farmacêutico e de saúde apresentaram níveis de colaboração com consumidores abaixo da média. No entanto, os setores de eletrônicos e engenharia elétrica estão mais inclinados à colaboração com os fornecedores, como também ao estabelecimento de alianças estratégicas. Tal fato é justificado possivelmente pela alta taxa de desenvolvimento tecnológico, combinado aos altos níveis de convergência do setor, criando um ambiente no qual as colaborações mais aprofundadas e de longo-prazo são mais necessárias para a sobrevivência das empresas (DOZ et al., 2006).

A pesquisa também revelou que o número de empresas que regularmente reavaliam o que seus parceiros externos necessitam, visando contribuir com as atividades de inovação, não são significativos. Com relação ao tipo de relação com os colabores externos, presume-se que, para a maioria, a colaboração se resume em lidar com o conhecimento modular e codificado. Há baixos níveis de alocação temporária de trabalhadores nas organizações, apesar do setor automotivo, de eletrônicos e de engenharia elétrica ser mais suscetível ao envio de seus funcionários às organizações parceiras. Nesses setores, a convergência e a complexidade do produto e do serviço faz com que haja a necessidade de alocações temporárias, como um mecanismo de transferência de conhecimento complexo (DOZ et al., 2006).

\subsubsection{Contribuições dos diferentes tipos de atores}

Pesquisas anteriores sugerem que uma empresa pode alavancar suas atividades inovativas por meio da interação em rede com diferentes colaboradores, principalmente com fornecedores, clientes, concorrentes e institutos de pesquisa (TSAI, 2009).

Os fornecedores costumam ter maior experiência e um conhecimento mais abrangente com relação às peças e componentes que podem ser fundamentais para o desenvolvimento de novos produtos, por exemplo, permitindo que as empresas incorporem a experiência e a perspectiva do fornecedor no processo de inovação (EISENHARDT; TABRIZI, 1995). Além disso, o desenvolvimento de uma relação com os fornecedores também auxilia as empresas a identificarem potenciais problemas técnicos, acelerando assim o desenvolvimento de novos produtos e as respostas às demandas do mercado (KESSLER; CHAKRABATRI, 1996). O 
Quadro 2 apresenta um resumo dos estudos acerca da contribuição dos fornecedores para o desempenho em inovação da empresa.

Quadro 2 - Relação entre resultados em inovação de produto e processo e colaboração com fornecedores

\begin{tabular}{|l|l|}
\hline $\begin{array}{l}\text { Miotti e Sachwald } \\
(2003)\end{array}$ & $\begin{array}{l}\text { Identificaram um efeito positivo sobre a venda de produtos inovadores, resultante da } \\
\text { colaboração com fornecedores na França. }\end{array}$ \\
\hline $\begin{array}{l}\text { Sánchez e Pérez } \\
(2003)\end{array}$ & $\begin{array}{l}\text { Analisaram empresas manufatureiras espanholas e concluíram que a colaboração com } \\
\text { os fornecedores não melhora o desempenho proveniente de novos produtos. }\end{array}$ \\
\hline Freel (2003) & $\begin{array}{l}\text { Analisaram pequenas e médias empresas do Reino Unido e descobriram que a } \\
\text { colaboração com fornecedores não representa um impacto significativo sobre o } \\
\text { desempenho em termos de novos produtos. }\end{array}$ \\
\hline $\begin{array}{l}\text { Belderbos } \text { et al. } \\
(2004)\end{array}$ & $\begin{array}{l}\text { Estudaram empresas de fabricação holandesa e encontraram uma relação negativa, } \\
\text { porém insignificante, entre a colaboração com fornecedores e o desempenho em } \\
\text { inovação de produto. }\end{array}$ \\
\hline Faems et al. (2005) & $\begin{array}{l}\text { Analisaram empresas de fabricação belga e encontraram uma associação positiva entre } \\
\text { a colaboração com fornecedores e o volume de negócios atribuídos aos produtos } \\
\text { melhorados. }\end{array}$ \\
\hline $\begin{array}{l}\text { Ledwith e } \\
\text { Coughlan (2005) }\end{array}$ & $\begin{array}{l}\text { Utilizaram uma amostra de empresas de eletrônicos na Irlanda e no Reino Unido e } \\
\text { encontraram uma correlação insignificante entre a colaboração com fornecedores e o } \\
\text { desempenho em inovação de produto. }\end{array}$ \\
\hline $\begin{array}{l}\text { Nieto e Santamaría } \\
(2007)\end{array}$ & $\begin{array}{l}\text { Em uma pesquisa com empresas industriais espanholas, os autores encontraram uma } \\
\text { relação positiva entre a colaboração com fornecedores e o grau de inovação em } \\
\text { produto. }\end{array}$ \\
\hline Tsai (2009) & $\begin{array}{l}\text { Por meio da modelagem de equações estruturais, o autor identificou que o resultado } \\
\text { em inovação de produto melhora em decorrência da colaboração com fornecedores, } \\
\text { porém apenas para as empresas com alta capacidade de absorção do conhecimento. }\end{array}$ \\
\hline $\begin{array}{l}\text { Fitjar e Rodríguez- } \\
\text { Pose (2013) }\end{array}$ & $\begin{array}{l}\text { Com base em estudos realizados na Noruega, os autores identificaram uma ligação } \\
\text { significativa entre a colaboração com os fornecedores e a realização de inovações de } \\
\text { produto e processo, tanto incrementais quanto marginais. }\end{array}$ \\
\hline
\end{tabular}

Fonte: Adaptado de Tsai (2009) e Fitjar e Rodríguez-Pose (2013).

Os estudos apresentados evidenciaram que ainda há uma falta de consenso acerca das principais contribuições do fornecedores em relação aos resultados em inovação.

A colaboração com clientes também pode ser considerada outra fonte relevante ao processo inovativo (GUPTA et al., 2000;. FRITSCH; LUKAS, 2001; BROCKHOFF, 2003), por facilitar a identificação de oportunidades de mercado para o desenvolvimento tecnológico, por exemplo, como também por reduzir a probabilidade de má concepção nas fases iniciais de desenvolvimento de produtos. Além disso, compreender as necessidades dos clientes pode ajudar as empresas a obter novas ideias sobre soluções (VON HIPPEL et al., 1999) e identificar tendências de mercado rapidamente, aumentando assim as chances de sucesso. O Quadro 3 apresenta um resumo dos estudos acerca da contribuição dos clientes para o desempenho em inovação da empresa. 
Quadro 3 - Relação entre resultados em inovação de produto e processo e colaboração com clientes

\begin{tabular}{|l|l|}
\hline Loof e Heshmati (2002) & $\begin{array}{l}\text { Identificaram uma relação negativa entre a colaboração do cliente e os } \\
\text { resultados em inovação. }\end{array}$ \\
\hline Miotti e Sachwald (2003) & $\begin{array}{l}\text { Descobriram que a colaboração com clientes tem um impacto positivo } \\
\text { no desempenho em inovação de produtos }\end{array}$ \\
\hline Freel (2003) & $\begin{array}{l}\text { Identificou uma relação positiva entre a colaboração com os clientes e o } \\
\text { desempenho em inovação de produtos }\end{array}$ \\
\hline Monjon e Waelbroeck (2003) & $\begin{array}{l}\text { Analisaram empresas industriais francesas e constataram que a } \\
\text { colaboração do cliente tem um impacto insignificante na inovação em } \\
\text { produtos. }\end{array}$ \\
\hline Belderbos et al. (2004) & $\begin{array}{l}\text { Revelaram uma associação insignificante entre a colaboração com } \\
\text { clientes e mudanças na venda de novos produtos. }\end{array}$ \\
\hline Faems et al. (2005) & $\begin{array}{l}\text { Encontraram uma relação positiva entre a colaboração com clientes e os } \\
\text { resultados em inovação de produtos. }\end{array}$ \\
\hline Nieto e Santamaría (2007) & $\begin{array}{l}\text { Descobriram que a colaboração do cliente tem um impacto positivo } \\
\text { apenas em casos de inovações de produtos com alterações marginais. }\end{array}$ \\
\hline $\begin{array}{l}\text { Fitjar e Rodríguez-Pose } \\
\text { (2013) }\end{array}$ & $\begin{array}{l}\text { Os autores identificaram que a colaboração com clientes está } \\
\text { relacionada com a inovação em produto, porém não impacta } \\
\text { significativamente na inovação em processo. }\end{array}$ \\
\hline
\end{tabular}

Fonte: Adaptado de Tsai (2009) e Fitjar e Rodríguez-Pose (2013).

De acordo com Tsai (2009), os agentes menos frequentes em uma rede de inovação parecem ser os concorrentes. No entanto, este tipo de colaboração oferece algumas vantagens, como o compartilhamento de conhecimentos e habilidades, bem como a obtenção de um efeito sinérgico na resolução de problemas comuns fora da área de influência do concorrente (TETHER, 2002). Em seu estudo de caso, Inkpen e Pien (2006) sugerem que as empresas que colaboram com os concorrentes podem ter um melhor desempenho em inovação se comparadas à utilização de outras fontes de colaboração. Além disso, a colaboração com os concorrentes permite às empresas conhecê-los melhor, favorecendo sua capacidade de diferenciação (LINN, 1994). Apesar do exposto, pesquisas desenvolvidas por Monjon e Waelbroeck (2003), Miotti e Sachwald (2003), Belderbos et al. (2004) e Fitjar e RodríguezPose (2013) constataram que a colaboração com concorrentes não impacta de forma positiva ou significativa no desempenho em inovação de produto e processo.

No que se refere à colaboração com universidades e institutos de pesquisa, Tsai (2009) apontou que ela têm crescido bastante, principalmente devido aos incentivos governamentais. As universidades e institutos de pesquisa são importantes centros para a criação e disseminação do conhecimento científico (HEMMERT, 2004). Dessa forma, as empresas podem interagir, formalmente e informalmente com universidades e institutos de pesquisa para adquirir novos conhecimentos científicos úteis ao seu processo de inovação (CALOGHIROU et al., 2004). Belderbos et al. (2004), Faems et al. (2005), Nieto e 
Santamaría (2007), Clifton et al. (2010), Varis e Littunen (2010) e Fitjar e Rodríguez-Pose (2013) verificaram que a colaboração com institutos de pesquisa e universidades afeta positivamente o desempenho em inovação. No entanto, contradizendo esses resultados, Monjon e Waelbroeck (2003), Caloghirou et al. (2004), e Ledwith e Coughlan (2005) encontraram que a colaboração com universidades e institutos de pesquisa tem um efeito negativo sobre o desempenho em inovação de produtos.

Em resumo, os estudos empíricos analisados mostram que ainda há uma ausência de consenso sobre os benefícios em inovação decorrentes da colaboração com os diferentes parceiros. Segundo Tsai (2009), a discórdia apresentada pelos autores pode evidenciar a necessidade de inclusão de outras variáveis no estudo das redes de inovação.

\subsubsection{Transferência de conhecimento}

O papel da transferência de conhecimento é, claramente, essencial para o processo de inovação. Henderson e Clark (1990) frisaram em seus estudos que cada tipo de inovação requer um tipo específico de conhecimento, que varia de acordo com a complexidade da inovação desejada. Esta constatação sugere que as naturezas destes conhecimentos também sejam distintas, podendo ser de ordem técnica ou baseada em alguma experiência, como também proveniente de recursos internos ou externos à empresa.

Segundo Powell e Grodal (2006), o processo de transferência de conhecimento pode ocorrer de duas formas principais em uma rede de inovação. A primeira acontece quando duas ou mais empresas utilizam recursos complementares, fato que pode incitar o desenvolvimento de uma relação de colaboração para produção conjunta, permitindo assim o reforço mútuo de suas capacidades. A segunda forma de compartilhamento de conhecimento se verifica quando as informações existentes dentro de uma rede é recombinada em novas formas. Como consequência de tais transposições, as empresas podem gerar algo que não foram capazes de criar por conta própria. Os autores sustentam, no entanto, que ambas as formas de transferência de conhecimento dependem de algum tipo de intercâmbio bem sucedido de informações. 
Para entender melhor como esse intercâmbio de conhecimentos tem lugar no ambiente da inovação é necessário, sobretudo, fazer uma distinção entre o conhecimento tácito e explícito. $\mathrm{O}$ entendimento da natureza distinta dos conhecimentos gerados por uma empresa oferece elementos para avaliar o seu modo de transmissão entre os demais atores, que não partilham das mesmas fontes de informação.

De acordo com Nonaka et al. (2001), os conhecimentos podem ser classificados segundo sua natureza em dois tipos:

- tácito: conhecimento profundamente enraizado à ação, implicando em sua dificuldade de transmissão aos outros; e

- explícito: conhecimento que pode ser expresso em linguagem formal e sistematizada, cuja principal característica é a possibilidade de ser armazenado e transmitido com maior facilidade.

O conhecimento tácito, por estar ligado ao indivíduo, é mais difícil de ser articulado. Sua transferência ocorre por meio da observação ou tentativa e erro. Já o conhecimento explícito, por ser mais objetivo, pode ser expresso em palavras e/ou números, fato que facilita seu compartilhamento (NONAKA; TAKEUCHI, 1997).

A tipificação apresentada pelos autores não implica que as naturezas do conhecimento sejam imutáveis e que estas não possam ser modificadas por meio do processo de aprendizado organizacional. Neste sentido, Nonaka e Takeuchi (1997) constataram que a criação do conhecimento dentro de uma organização acontece por meio da interação destes dois tipos de conhecimento. A Ilustração 10 representa como os conhecimentos, em suas diferentes naturezas, fluem em ambas as direções, formando fluxos ininterruptos. Estes fluxos sugerem que o conhecimento é socializado e compartilhado, de modo dinâmico, por meio de quatro diferentes modos de conversão.

O modelo da Ilustração 10 apresenta o tipo de conhecimento compartilhado pelos membros (tácito e explícito), o nível em que a interação acontece (individual, grupal ou organizacional); bem como a forma de conversão dos conhecimentos produzidos. 


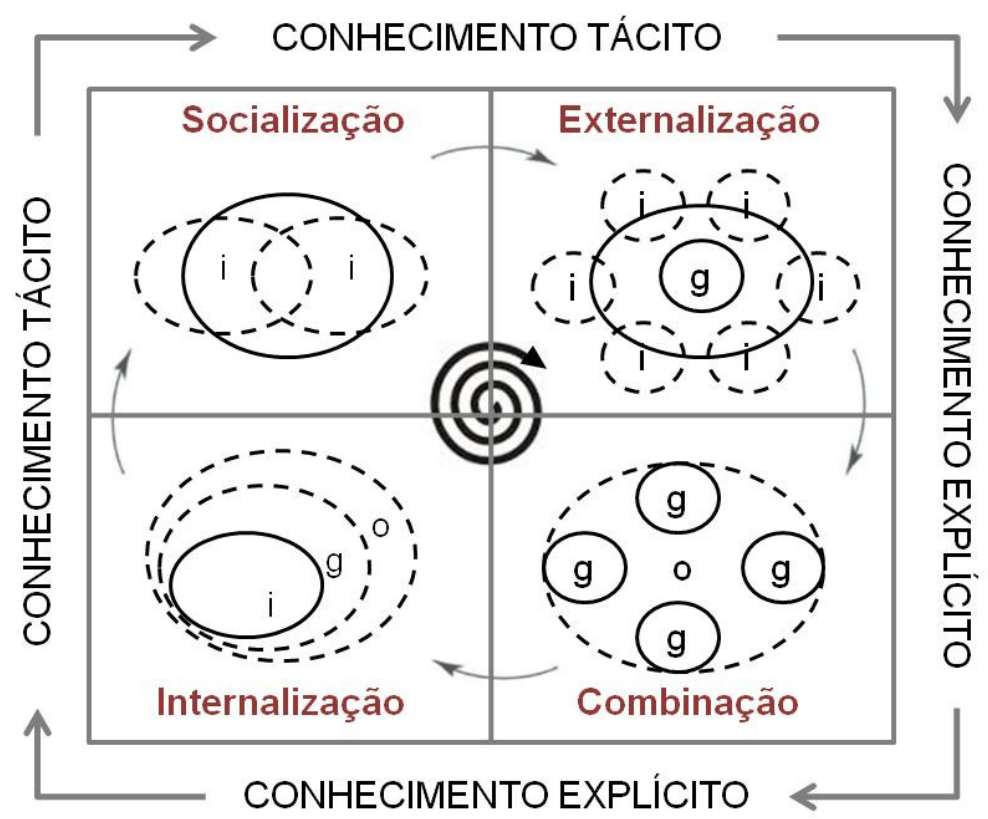

Ilustração 10 - Espiral da conversão do conhecimento

Fonte: adaptado de Nonaka et al., 2001.

Nota: i (indivíduo), g (grupo), o (organização).

Quanto aos tipos de conhecimento compartilhados entre os membros, Nonaka et al. (2001) afirmaram que eles podem ser do tipo tácito-tácito, tácito-explícito, explícito tácito e explícito-explícito. A descrição das formas de conversão dos conhecimentos supracitados está expressa no Quadro 4.

Quadro 4 - Formas de compartilhamento do conhecimento

\begin{tabular}{|c|l|}
$\begin{array}{c}\text { Formas de } \\
\text { compartilhamento } \\
\text { do conhecimento }\end{array}$ & \multicolumn{1}{c|}{ Descrição } \\
\hline $\begin{array}{c}\text { Tácito-tácito } \\
\text { (socialização) }\end{array}$ & $\begin{array}{l}\text { O processo de socialização envolve a realização de interpretações do ambiente, bem como } \\
\text { a aquisição de experiências por meio de interações face-a-face. O compartilhamento deste } \\
\text { tipo de conhecimento depende do grau de relação entre os indivíduos possuidores deste } \\
\text { tipo de conhecimento. }\end{array}$ \\
\hline $\begin{array}{c}\text { Tácito-explícito } \\
\text { (externalização) }\end{array}$ & $\begin{array}{l}\text { O processo de externalização consiste na articulação do conhecimento tácito em explícito } \\
\text { através de ações que possam ser entendidas pelos outros. }\end{array}$ \\
\hline $\begin{array}{c}\text { Explícito-explícito } \\
\text { (combinação) }\end{array}$ & $\begin{array}{l}\text { A combinação refere-se ao processo de sistematização do conhecimento explícito em um } \\
\text { sistema de conhecimento. O conhecimento explícito pode ser coletado de dentro ou de } \\
\text { fora da organização para então ser combinado, editado ou processado como uma nova } \\
\text { forma de conhecimento. Nesta modalidade encontram-se as redes, os agrupamentos } \\
\text { virtuais, os bancos de dados e os demais ambientes colaborativos para criação e } \\
\text { sistematização do conhecimento. }\end{array}$ \\
\hline $\begin{array}{c}\text { Explícito-tácito } \\
\text { (internalização) }\end{array}$ & $\begin{array}{l}\text { A internalização consiste na incorporação do conhecimento explicito sob a forma de } \\
\text { conhecimento tácito. Este processo ocorre principalmente através da prática e da criação } \\
\text { de modelos mentais. Quando a maioria dos membros da organização compartilha do novo } \\
\text { modelo mental, o conhecimento passa a fazer parte da cultura organizacional. A cada } \\
\text { internalização bem sucedida, o ciclo se reinicia, levando ao aperfeiçoamento ou à } \\
\text { inovação. }\end{array}$ \\
\hline
\end{tabular}


Vale ressaltar que a conversão dos conhecimentos ocorre em uma espiral, que passa por todos os tipos de conhecimento. Além disso, o aprendizado e a internalização dependem do desenho da estrutura organizacional, que deve ser favorável a sua transferência e possível reutilização (GRANT, 2001).

É interessante notar que o conhecimento, muitas vezes, exige um esforço considerável para ser adquirido. $\mathrm{O}$ conhecimento de tecnologias de produção, por exemplo, raramente é obtido de forma direta, fazendo com que sua compreensão fique condicionada à prática. Sendo assim, a distinção dos conhecimentos referenciada por Nonaka e Takeushi (1997) é fundamental por evidenciar que a troca de conhecimentos tácitos exige um esforço maior entre os agentes da rede para serem compartilhados, implicando, muitas vezes, no aprendizado por tentativa e erro. Outros estudos nesse sentido sugerem, inclusive, uma maior facilidade de transferência de conhecimentos explícitos em contraste aos conhecimentos tácitos (POWELL; GRODAL, 2006).

Von Hippel (1998) salientou que quando o conhecimento contém um grande componente tácito, o grau de dificuldade e os custos de transferência se elevam. Conseqüentemente, os ganhos esperados a partir dessas informações são incertas, já que o custo de obtenção de informações pode exceder o valor proporcionado pela inovação. Tal fato sugere que, quando o conhecimento envolve um nível moderado de complexidade, os benefícios derivados de sua transferência pode ser maior, contudo, a incerteza inerente ao processo também é maior.

Segundo Powell e Grodal (2006), a transferência de conhecimentos em redes mais consolidadas e de longa duração parece ser facilitada em decorrência do desenvolvimento de uma linguagem comum e do compartilhamento de modelos mentais entre os parceiros, fato que sugere a existência de uma curva de aprendizado. Em outras palavras, à medida que as relações amadurecem, os participantes da rede passam a desenvolver uma maior compreensão entre si, fazendo com que as informações sejam transmitidas de forma mais eficaz.

A Ilustração 11 expressa a relação entre o valor da inovação em decorrência da codificação do conhecimento, considerando-se os custos de transferência do mesmo. 


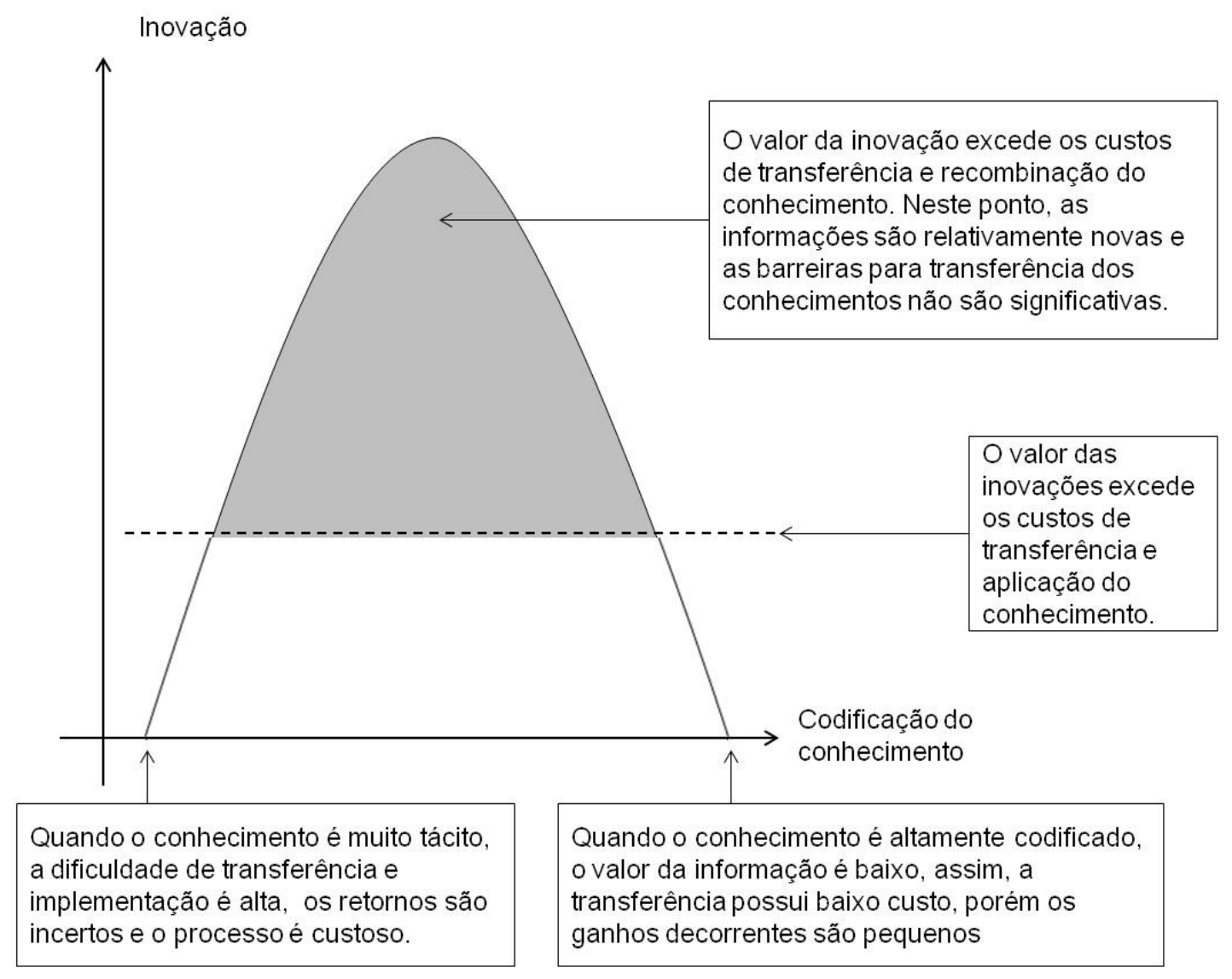

Ilustração 11 - Codificação do conhecimento e inovação Fonte: POWELL; GRODAL, 2006, p.76.

Além de elucidar a dificuldade de compartilhamento do conhecimento em função de sua codificação, Powell e Grodal (2006) ainda salientaram outra dificuldade decorrente da existência de diferentes níveis ou capacidades de absorção do conhecimento entre os agentes da rede. Ou seja, a capacidade inovadora da rede está associada às formas pelas quais os atores reconhecem valor, assimilam e aplicam as novas informações para fins comerciais.

Outro fator central para o sucesso das redes de inovação se refere à ampliação do fluxo de informações entre os participantes atuais, ao mesmo tempo em que se procura desenvolver novos parceiros. No entanto, Powell e Grodal (2006) argumentam que, aumentar a coesão dentro da rede e, simultaneamente, estar apto a reconhecer fontes promissoras de novas ideias não é uma tarefa fácil às empresas. Como alternativa, os autores sugerem o estabelecimento tanto de vínculos fortes quanto fracos entre os agentes, permitindo assim uma medida adequada de confiabilidade e novidade. 


\subsubsection{Capacidade de absorção do conhecimento}

Teece (2000) e Tsai (2009) consideram que a capacidade de absorção do conhecimento pela empresa pode determinar a extensão pela qual é possível utilizar os conhecimentos advindos de fora. Sendo assim, em uma rede de inovação, a capacidade que a empresa possui para absorver os conhecimentos externos pode influenciar os tipos de relação por ela desenvolvidos, bem como seus resultados em termos de inovação.

A capacidade de absorção refere-se a capacidade de uma empresa em utilizar o seu próprio conhecimento, como também em reconhecer, assimilar e utilizar o conhecimento externo para fins comerciais (COHEN; LEVINTHAL, 1990). Segundo Todorova e Durisin (2007), a absorção envolve um conjunto de cinco capacidades: o reconhecimento, a aquisição, a assimilação, a transformação e a exploração do conhecimento.

Nota-se que uma empresa com um alto nível de capacidade de absorção é capaz de criar e explorar melhor as ligações com outras empresas (CALOGHIROU et al., 2004). Vários estudos salientaram que a capacidade de absorção é necessária para a aprendizagem eficaz em colaborações interorganizacionais (KIM, 1998; LANE; LUBATKIN, 1998; LANE et al., 2001; SCHMIDT, 2005).

Segundo Kim (2001), a capacidade de absorção de uma empresa dependente de seu nível atual de conhecimento tecnológico, que por sua vez é derivado de esforços internos anteriores e atuais em P\&D. De acordo com Tsai (2009), as organizações com maior capacidade de absorção normalmente têm uma base tecnológica suficientemente desenvolvida que lhes permite ter comunicações ricas e detalhadas com seus fornecedores durante a troca de conhecimentos. Além disso, essas empresas são mais propensas a reconhecer o valor de novas ideias e integrá-las efetivamente em seus esforços de desenvolvimento de inovações. Em contraste, uma organização com uma menor capacidade de absorção pode apresentar dificuldades para reconhecer valor em novas ideias que surgem a partir de interações com a rede, ou até mesmo dificuldades para integrar tais ideias, transformando-as em inovações.

A capacidade de absorção pode também aumentar o uso de conhecimentos provenientes da colaboração com clientes, visando inovar. Para Atuahene-Gima et al. (2005), ao trabalhar em estreita colaboração com clientes, particularmente com os mais influentes, uma empresa pode 
descobrir suas necessidades latentes, fato que pode melhorar o desempenho em inovação de uma empresa. Por outro lado, uma organização que não possua uma capacidade suficiente de absorção não será capaz de integrar as necessidades dos clientes no processo dedesenvolvimento de novos produtos. Neste caso, a estreita colaboração com os clientes pode não contribuir para o aumento do desempenho da empresa em inovação de produtos (TSAI, 2009).

A capacidade de absorção de conhecimento também é bastante relevante nas relações estabelecidas com concorrentes. Isso porque, neste tipo de relação, a organização pode acessar conhecimentos bastante especializados, que geralmente são tácitos e não podem ser facilmente copiados por simples observação. Sobre o tema, Kim e Song (2007) sugeriram que a capacidade de absorção pode facilitar a criação de novas tecnologias através da colaboração com outras empresas. Assim, uma empresa com maior capacidade de absorção possui uma base de conhecimentos mais desenvolvida, fato que lhe permite compreender e explorar os conhecimentos e habilidades dos concorrentes, resultando no desenvolvimento de inovações.

De forma semelhante, as universidades e institutos de pesquisa também são uma importante fonte para novos conhecimentos científicos, permitindo à empresa o acesso ao conhecimento científico anteriormente inexplorado. Para Ahuja e Lampert (2001), o processo de combinação de novos conhecimento com conhecimentos existentes pode promover insights, oferecendo um potencial significativamente maior para inovações mais radicais.

Em resumo, os autores abordados assinalam que o desenvolvimento da capacidade de absorção das empresas pode facilitar a internalização dos conhecimentos obtidos por meio de fontes externas, contribuindo para os resultados em inovação das organizações.

\subsubsection{Estratégias de exploração e explotação do conhecimento}

Por meio da constituição de redes, as empresas podem adquirir conhecimentos necessários para realizar seus processos de inovação. No entanto, dependendo da capacidade de aprendizagem da organização, as parcerias estabelecidas com agentes externos podem ser mais ou menos bem sucedidas. Nesse sentido, o estudo das estratégias de utilização do conhecimento adotadas pelas empresas é de extrema importância, podendo, inclusive, afetar 
os resultados obtidos pela organização por meio da rede de inovação. Aponta-se na literatura para a existência de duas principais estratégias: a estratégia de exploração e estratégia de explotação (MARCH, 1991).

A estratégia de exploração do conhecimento está associada com a pesquisa, a experimentação, a assunção de riscos e a inovação, podendo ser vista como um instrumento de criação de novas competências organizacionais. Uma estratégia de exploração pode ser extremamente poderosa em redes de inovação, pois a inovação é, por muitas vezes, dependente de novas combinações de conhecimento, principalmente tácito (MARCH, 1991). Segundo Dittrich e Duysters (2003), as novas ideias provêm principalmente de parceiros que não estejam atrelados a atividade da empresa, uma vez que esses parceiros permitirão o acesso a uma base de conhecimento diferente daquela dominada pela empresa. Geralmente, as colaborações desenvolvidas com universidades e institutos de pesquisa, são orientadas pela estratégia de exploração. Esses tipos de colaboração têm por objetivo a criação de know-how e know-why de novas tecnologias que, eventualmente, podem ser traduzidas no desenvolvimento de inovações (WHEELWRIGHT; CLARK, 1992).

As empresas que adotam a estratégia de exploração tendem a estabelecer relações baseadas em ligações fracas (GRANOVETTER, 1973). No entanto, a falta de confiança e compromisso em tais tipos de parcerias podem prejudicar a troca de informações entre os parceiros. Além disso, a capacidade de uma empresa para absorver conhecimentos provenientes de parceiros de atividades distintas é amplamente dependente de um mínimo conhecimento compartilhado em um campo específico. Ou seja, embora as empresas que desenvolvem uma estratégia de exploração estejam mais propensas a aprender a partir de alianças com parceiros de um segmento diferente, algumas semelhanças entre os parceiros são necessárias para que a troca de conhecimentos possa ocorrer (COHEN, LEVINTHAL, 1990). Outro aspecto importante é que a estratégia de exploração é caracterizada por um comportamento oportunista, permitindo inclusive que uma empresa faça parte de duas redes distintas de empresas, beneficiando-se dos recursos de ambas as redes (DITTRICH; DUYSTERS, 2003).

Por outro lado, a estratégia de explotação dos conhecimentos e capacidades já existentes está associada com o refinamento, seleção, produção e execução de ideias e informações. Este tipo de estratégia se destina ao reforço e ampliação dos conhecimentos organizacionais já estabelecidos (DITTRICH; DUYSTERS, 2003). Na rede de inovação, isto pode ser feito por 
meio do reforço das ligações existentes e da constituição de novas parcerias diretas, com relações de ligações fortes (GRANOVETTER, 1973). O estabelecimento desse tipo de relação, juntamente com a utilização de uma estratégia de explotação do conhecimento, pode ser considerado uma importante fonte para o processo de inovação incremental. Tal fato se justifica uma vez que as empresas que adotam uma estratégia de explotação podem reforçar a sua base de conhecimento por meio de relações com organizações que possuam atividades semelhantes. O resultado será uma rede de empresas relacionadas, na qual os vínculos de longo prazo serão mantidos por meio de ligações fortes, estabelecidas, geralmente, entre fornecedores e clientes (DITTRICH; DUYSTERS, 2003). Isso porque, da mesma forma que a colaboração com os fornecedores pode melhorar significativamente a eficiência operacional dos processos de produção existentes, a colaboração com os clientes faz com que as necessidades do mercado se tornem o foco do processo de inovação (VON HIPPEL, 1988). Nesta linha de pensamento, Christensen e Overdorf (2000) argumentaram que a colaboração com fornecedores e clientes não são úteis para a realização de projetos de inovação de natureza mais radical, enfatizando que o tipo de colaboração desenvolvida geralmente com clientes e fornecedores são úteis apenas para reforçar os recursos já existentes na organização.

As duas estratégias de aprendizagem abordadas podem levar a diferentes resultados na rede de inovação. Rothaermel (2001) chegou à conclusão de que as empresas que se concentram em uma rede baseada na estratégia de explotação superam àquelas que tem uma rede orientada pela estratégia de exploração do conhecimento. Contradizendo esta assertiva, Dittrich e Duysters (2003) argumentaram que a estratégia de exploração, por meio das ligações fracas, pode ser extremamente útil às redes de inovação porque esta é, muitas vezes, dependente de novas combinações de conhecimento. No entanto, a falta de confiança e compromisso em tais tipos de parcerias podem prejudicar gravemente a troca de informações entre os parceiros. Ao mesmo tempo, a absorção do conhecimento proveniente de parceiros de campos distintos, em relações de ligações fracas, parece ser extremamente difícil, uma vez que a capacidade de absorção de uma empresa depende, em grande medida, de um conhecimento compartilhado mínimo, em um campo específico (COHEN; LEVINTHAL, 1990). Dessa forma, as empresas devem possuir alguma experiência ou habilidades comuns, a fim de serem capazes de trocar informações sobre novas tecnologias. Caso contrário, a absorção do conhecimento tecnológico adquirido pelas fontes externas será dificultada. 
Portanto, a relação baseada em ligações fracas não favorece muito o fortalecimento da base de conhecimentos existentes das empresas, porém pode ser considerada uma ótima fonte para o aprendizado exploratório. Por outro lado, a relação baseada em ligações fortes e na estratégia de explotação é mais eficaz na consolidação e fortalecimento de uma base de conhecimento já existente. Isto implica que, apesar de as inovações radicais estarem mais propensas a surgir a partir de relações com parceiros baseadas em ligações fracas, as ligações fortes são provavelmente mais capazes de reforçar e alargar a base de conhecimento existente na empresa, fato que pode facilitar a transferência de conhecimento necessário para a inovação. Consequentemente, as empresas devem procurar desenvolver um equilíbrio entre a estratégia de exploração e explotação de conhecimento, a fim de sobreviver e prosperar em um ambiente em mudança (MARCH, 1991).

\subsubsection{Fatores motivadores para a formação de redes de inovação}

Os motivos pelos quais as empresas desenvolvem relações de colaboração em rede visando à eficácia e a eficiência de uma estratégia de inovação são numerosos, dentre eles o acesso a ativos complementares (TEECE, 1986), a necessidade de transferência de conhecimento tácito e explícito (AHUJA, 2000; EISENHARDT; SCHOONHOVEN, 1996), a familiarização com novas competências que estão surgindo dentro ou fora do setor (ROBERTS; BERRY, 1985), a criação e desenvolvimento de recursos que, de outra forma, dificilmente seriam mobilizados, imitados ou substituídos (DAS; TENG, 2000), a distribuição de custos de P\&D (HAGEDOORN, 2002; VEUGELERS, 1998), a redução de riscos associados à P\&D e a projetos de inovação (FAEMS et al., 2005), dentre outros.

Cairnarca et al. (1992) argumentaram que as razões para o estabelecimento de colaborações variam em função dos diferentes estágios do ciclo de vida das tecnologias do setor. Antes da maturidade tecnológica ser alcançada, as organizações implantam atividades de colaboração com a finalidade de obter acesso rápido a conhecimentos especializados. Por outro lado, quando há certa maturidade tecnológica, as inovações de processos e da cadeia de suprimentos se tornam dominantes. Nestas circunstâncias, as organizações tendem a favorecer os acordos de colaboração e de produção com clientes e fornecedores, principalmente para otimizar a tecnologia existente, para explorar a tecnologia existente nos mercados periféricos ou para melhorar as possibilidades comerciais e de fabricação da tecnologia envolvida. 
Para Hagedoorn (2002), os principais fatores que influenciam a formação de associações são o custo e a estratégia. O motivo pelo qual a partilha de custos se tornou interessante é o fato de estes terem crescido dramaticamente com o desenvolvimento industrial e tecnológico dos últimos 20 anos, o que não somente aumentou o valor dos projetos, como também antecipou a velocidade com que a tecnologia se desatualiza. Da mesma forma, o autor apontou que a estratégia tem bastante influência na constituição de redes, já que diferentes tipos de colaboração podem servir a objetivos estratégicos e de inovação distintos. Assim, as organizações tendem a utilizar as associações voltadas para a tecnologia, por meio de joint ventures, colaborações com institutos de pesquisa e acordos de $\mathrm{P} \& \mathrm{D}$ para apoiar estratégias de longo prazo. Acordos de intercâmbio de tecnologia com os clientes ou fornecedores, por outro lado, podem ser vistos como estratégias de curto prazo (HAGEDOORN, 1993). Além disso, o fator estratégico na formação de redes tem grande importância quando se trata de atividades que vão além do domínio tecnológico da empresa, envolvendo atividades de maior risco. As parcerias voltadas para a inovação tornaram-se, portanto, uma forma de compartilhar os riscos inerentes à atividade inovadora, de resultados incertos.

Para Cassiman e Veugelers (2006) a busca por conhecimento e sua complementaridade são fatores ainda mais relevantes do que a redução de custos para as empresas que decidem em cooperar, especialmente nos acordos verticais ou com institutos de pesquisa. A cooperação com foco no acúmulo e avanço do conhecimento tem como importantes parceiras as instituições geradoras de conhecimento, ou seja, institutos de pesquisa públicos e privados, além de universidades. Por esse motivo, universidades e institutos de pesquisa são relevantes fontes de conhecimento e parceiros bastante requisitados por empresas, principalmente nos países desenvolvidos.

Segundo Carvalho (2010), outros fatores podem afetar a participação das empresas em redes de inovação, como o tamanho da empresa, a intensidade tecnológica do setor, a velocidade com que o conhecimento evolui, o grau de competição do mercado, dentre outros. Nota-se que a cooperação entre parceiros torna-se mais frequente quanto maior a necessidade por tecnologias de elevado componente tácito. Para Tether (2002), empresas maiores investem mais em P\&D, assim como as de setores intensivos em conhecimento, implicando em uma maior propensão das organizações a participarem de arranjos cooperativos. 
Com relação à influência do tipo de setor na formação de redes, notou-se que o setor farmacêutico e o de tecnologias da informação e comunicação, por exemplo, lideram em quantidade de acordos cooperativos, segundo pesquisas realizadas por Hagedoorn (2002).

Outros estudos, porém, encontraram evidências de que o setor influencia a quantidade de cooperações que a empresa toma parte, mas em geral não tem impacto sobre a participação em acordos voltados para a inovação (FRITSCH; LUKAS, 2001).

\subsubsection{Benefícios decorrentes da rede de inovação}

Os estudos empíricos parecem confirmar que, por meio da formação das redes de inovação, as organizações podem potencialmente acessar conhecimentos que de outro modo exigiria anos de experiência (AHUJA, 2000; EISENHARDT; SCHOONHOVEN, 1996; GULATI, 1998; NOHRIA, GARCIA-PONT, 1991; TEECE, 1986). Além disso, se geridas com sucesso, as redes parecem contribuir para a eficácia das atividades de inovação das empresas envolvidas.

Tether (2002), por exemplo, observou que as organizações que introduziram pelo menos uma inovação no mercado cooperaram mais significativamente com fornecedores, clientes e concorrentes em comparação às organizações que não haviam introduzido inovações. Do mesmo modo, Shan et al. (1994) descobriram que o número de acordos com empresas comerciais tem uma influência positiva e significativa na quantidade de patentes concedidas por start-ups do ramo biofarmacêutico.

Visando relacionar a ocorrência de cooperação voltada para a inovação e os possíveis efeitos sobre o desempenho das empresas, Belderbos et al.(2004) testaram o impacto da participação em cooperações para P\&D sobre o crescimento da produtividade de empresas holandesas. Os autores encontraram um resultado positivo, com diferentes níveis de importância, conforme o tipo de parceiro. As parcerias com universidades, por exemplo, revelaram resultados mais significativos na geração de inovações radicais.

Além disso, Baum et al. (2000), ao estudarem o desempenho da start ups no setor de biotecnologia canadense, monstraram que a composição da rede tem um efeito positivo sobre o desempenho em inovação dessas start ups. No entanto, os autores também reconheceram a 
existência de limitações quanto aos benefícios oferecidos pela rede. Especificamente, quanto maior o número de relações estabelecidas pela empresa, maior o risco de redundância, ou seja, o risco de que diferentes parceiros forneçam acesso às mesmas informações ou conhecimentos complementares (BURT, 1992). Portanto, Baum et al. (2000), chegaram à conclusão de que não é somente a quantidade de relações estabelecidas na rede que pode influenciar o desempenho inovador da empresa, mas também a diversidade de parceiros presentes na rede.

Em seus estudos, Cincera et al. (2005) reconheceram ganhos relacionados à difusão do conhecimento provenientes da cooperação entre parceiros. Isso porque a maior proximidade entre os agentes potencializa o fluxo de conhecimento já existente entre empresas que cooperam, sobretudo com produtores e consumidores. Assim, a difusão de conhecimento em acordos cooperativos seria, também, mais bem controlada entre os parceiros, ampliando os resultados das atividades de $\mathrm{P} \& \mathrm{D}$.

Buscando dar um passo adiante no estudo da cooperação para inovação e seus potenciais efeitos sobre o desempenho das empresas brasileiras, Carvalho (2010) utilizou dados da Pesquisa de Inovação Tecnológica (PINTEC) de 2005 e identificou que a cooperação nos processos de inovação resultou em efeitos positivos para as organizações, principalmente no que se refere à criação de novos mercados, tanto em inovações de produto quanto de processo.

Utilizando os dados da Community Innovation Survey (CIS II) de 1997 para estudar o papel das redes de inovação na indústria de manufatura belga, Faems et al. (2005) chegaram à conclusão de que as empresas que possuem uma rede heterogênea de parceiros colaborativos, no âmbito de suas estratégias de inovação, apresentam um melhor desempenho, tanto em termos de novos produtos, quanto de produtos melhorados. Os autores também comprovaram que as colaborações orientadas para a estratégia de explotação são bastante úteis para a melhoria e desenvolvimento de tecnologias de produtos já existentes, enquanto as colaborações orientadas para a exploração tem efeito benéfico para as atividades de inovação que visem a criação de novas tecnologias e produtos. Corroborando com estudos anteriores, Faems et al. (2005) ainda afirmaram que a colaboração com clientes e fornecedores, rotulada como de caráter de explotação, está associada positivamente com um maior volume de inovações, resultante da melhoria incremental dos produtos. Por outro lado, as colaborações com universidades e instituições de pesquisa, rotulados como de caráter de exploração, estão 
associadas com um alto volume inovações baseadas em novos produtos. Os resultados obtidos pelos autores sugerem que as empresas devem desenvolver parcerias de forma diversificada, com o objetivo de serem eficazes tanto em termos de inovações incrementais quanto de inovações mais radicais. Isso porque ambas as estratégias de exploração e de explotação do conhecimento, desenvolvidas por meio de relações com diferentes atores da rede, mostram-se influentes na melhora do desempenho em inovação da empresa (FAEMS et al., 2005).

Belderbos et al. (2004) salientaram que os diferentes objetivos perseguidos pelas empresas que cooperam entre si podem influenciar a ocorrência de resultados favoráveis ou não. Em outras palavras, objetivos distintos levam a diferentes tipos de parcerias e, consequentemente à obtenção de diferentes resultados.

A pesquisa desenvolvida pela Forfás (2004), elencou, de forma sintetizada, os principais benefícios decorrentes da constituição de redes, que estão expressos no [Quadro 5].

Quadro 5 - Benefícios decorrentes da formação de redes de inovação

\begin{tabular}{|c|c|}
\hline BENEFÍCIO & DESCRIÇÃO \\
\hline $\begin{array}{l}\text { Aumento de escala } \\
\text { e escopo das } \\
\text { atividades }\end{array}$ & $\begin{array}{l}\text { O desempenho de empresas que fazem parte de redes de inovação pode ser } \\
\text { consideravelmente alargado por meio de sinergias entre organizações que } \\
\text { possuam diferentes competências tecnológicas. }\end{array}$ \\
\hline $\begin{array}{l}\text { Compartilhamento } \\
\text { de custos e riscos }\end{array}$ & $\begin{array}{l}\text { Os custos envolvidos no desenvolvimento de inovações, principalmente as mais } \\
\text { radicais, são muito elevados, dificultando a atuação da organização de forma } \\
\text { individual. Portanto, por meio da colaboração, as empresa podem compartilhar os } \\
\text { custos elevados desse processo e, consequentemente, os riscos inerentes à } \\
\text { atividade de inovação. }\end{array}$ \\
\hline $\begin{array}{l}\text { Melhora da } \\
\text { capacidade em lidar } \\
\text { com a } \\
\text { complexidade }\end{array}$ & $\begin{array}{l}\text { O processo de inovação é complexo e depende de uma ampla gama de } \\
\text { conhecimentos científicos e comerciais. Isso reforça a necessidade de cooperação } \\
\text { entre participantes de diferentes áreas de especialização, além de uma maior } \\
\text { integração estratégica e tecnológica entre as empresas. }\end{array}$ \\
\hline $\begin{array}{l}\text { Aumento da } \\
\text { aprendizagem }\end{array}$ & $\begin{array}{l}\text { A colaboração em rede pode oferecer diversos aprendizados às organizações, não } \\
\text { somente no sentido tecnológico, como também com relação a novas formas de } \\
\text { fazer as coisas e gerir os negócios. }\end{array}$ \\
\hline $\begin{array}{l}\text { Efeito positivo no } \\
\text { processo de P\&D }\end{array}$ & $\begin{array}{l}\text { A internalização dos efeitos positivos provocados pela rede de colaboração pode } \\
\text { resultar no aumento da eficiência dos processos de P\&D. }\end{array}$ \\
\hline Flexibilidade & $\begin{array}{l}\text { As redes propiciam flexibilidade no que se refere à utilização e realocação de } \\
\text { recursos. Isso permite que pequenas empresas aproveitem os recursos de grandes } \\
\text { empresas e vice-versa. }\end{array}$ \\
\hline Eficiência & $\begin{array}{l}\text { O aumento da eficiência das redes está relacionado à natureza tácita do } \\
\text { conhecimento tecnológico, que é de difícil transferência. Sendo assim, a } \\
\text { colaboração fornece um mecanismo pelo qual esse tipo de transferência pode ser } \\
\text { facilitada, baseando-se na confiança entre os parceiros. }\end{array}$ \\
\hline Velocidade & $\begin{array}{l}\text { A velocidade pode ser necessária para que as empresas consigam aproveitar as } \\
\text { oportunidades do mercado. Nesse sentido, uma rede existente pode fornecer um } \\
\text { pacote de recursos, capacidades e conhecimentos externos para que as } \\
\text { organizações consigam agir de forma rápida. }\end{array}$ \\
\hline
\end{tabular}


O'Doherty (1998) também apontou alguns benefícios propiciados pela formação da rede, dividindo-os em três fatores principais:

- Benefícios materiais: as empresas podem aumentar as vendas e baixar os custos de produção por meio da cooperação.

- Benefícios psicológicos: ao deixar de atuar de forma totalmente isolada, a empresa pode descobrir que seus problemas são compartilhados por outras empresas.

- Benefícios para o desenvolvimento: ao promover a interação com outras empresas, a rede pode proporcionar o aumento da aprendizagem e da capacidade das empresas de se adaptar às mudanças do ambiente econômico.

De forma semelhante, Camarinha-Matos e Abreu (2007) também reforçaram os benefícios provenientes da colaboração em redes, apontando para os seguintes aspectos:

- Compartilhamento de custos

- Compartilhamento de riscos

- Diminuição do nível de dependência em relação a terceiros

- Aumento da capacidade de inovação

- Manutenção ou aumento de uma posição no mercado

- Aumento da flexibilidade

- Aumento da agilidade

- Aumento da especialização

- Estabelecimento de normas adequadas

- Compartilhamento de responsabilidades sociais

A partir das diversas discussões apresentadas neste capítulo, pode-se inferir que as redes de inovação têm sido, cada vez mais, foco de estudos, principalmente em decorrência de seu importante papel como um canal na transferência de conhecimentos tão necessários ao processo de inovação. A revisão da literatura indicou que as redes podem trazer benefícios significativos para as organizações membros, como o compartilhamento de custos e riscos, além do acesso a ativos que, individualmente, dificilmente poderiam ser alcançados. No entanto, tais benefícios não devem ser generalizados, uma vez que o estabelecimento de uma 
rede pode ser um processo difícil e demorado, cujo sucesso ainda não é consensual na literatura. 


\section{METODOLOGIA DE PESQUISA}

Neste capítulo são apresentados os procedimentos metodológicos utilizados no desenvolvimento da pesquisa. Após a caracterização da abordagem metodológica, são feitas considerações acerca da amostragem, da elaboração do instrumento de pesquisa, do procedimento de coleta, tratamento e análise dos dados, além do modelo conceitual e das limitações da pesquisa.

\subsection{Método de pesquisa}

Tendo em vista o problema de estudo proposto, "verificar qual a contribuição dos parceiros estabelecidos em redes de inovação para o desempenho inovador das empresas" a pesquisa pode ser classificada como de natureza exploratória e descritiva.

A pesquisa exploratória constitui-se como um passo inicial no processo de pesquisa, tendo por objetivo a familiarização com o fenômeno a ser estudado, bem como a obtenção de uma nova percepção acerca do problema em análise (CERVO et al., 2007). Este tipo de estudo permite ao pesquisador a obtenção de informações sobre determinado contexto particular ou ainda a identificação de conceitos ou variáveis promissoras para o entendimento das causas dos fenômenos observados (SAMPIERI et al., 2006).

De forma complementar, a pesquisa descritiva apresenta como principal objetivo descrever as características de determinado fenômeno, permitir o estabelecimento de relações entre variáveis, além de contribuir para o esclarecimento dos fatores que corroboram para sua ocorrência (GIL, 1996). Segundo Sampieri et al. (2006, p. 102), os estudos descritivos têm como objetivo "especificar propriedades e características importantes de qualquer fenômeno que se analise", contribuindo inclusive para o estabelecimento de previsões ainda que de forma primária.

Quanto a sua estratégia, o estudo baseou-se na pesquisa bibliográfica e no levantamento de dados. Segundo Cervo et al. (2007), a pesquisa bibliográfica constitui-se como um procedimento básico para qualquer estudo, podendo ser utilizada para explicar um problema a 
partir das informações e conhecimentos prévios já publicados. Marconi e Lakatos (2010) destacaram a importância da pesquisa bibliográfica, afirmando que sua finalidade é colocar o pesquisador em contato direto com o que foi dito ou escrito acerca do tema em estudo.

A pesquisa bibliográfica foi utilizada com o intuito de embasar e definir os conceitos a serem tratados na pesquisa de campo. Para tanto, foram utilizados dados secundários como artigos acadêmicos nacionais e internacionais, livros, dissertações e teses, além de outras pesquisas que tratavam sobre inovação e redes de inovação.

O levantamento, por sua vez, foi realizado por meio da aplicação de um questionário, visando promover uma investigação empírica acerca do tema. De acordo com Martins e Theóphilo (2009), os levantamentos são indicados quando se deseja responder a questões relacionadas à distribuição de uma variável, como também para entender as relações existentes entre características de pessoas ou grupos. Para Gil (1999), as pesquisas de levantamento geralmente são utilizadas em estudos descritivos, por possibilitar uma grande abrangência de pesquisa.

Segundo Marconi e Lakatos (2010), o levantamento é utilizado para levantar informações acerca de um problema para o qual se procura uma resposta, de uma hipótese que se queira comprovar ou, ainda, para descobrir novos fenômenos ou as relações entre eles. Ainda segundo as autoras, o levantamento requer, primeiramente, a realização de uma pesquisa bibliográfica sobre o tema em questão, para verificar em que estado se encontra o problema atualmente, bem como quais foram os trabalhos já realizados a esse respeito. Essa primeira etapa do processo permite o estabelecimento de um modelo teórico inicial de referência, auxiliando na determinação das variáveis e elaboração do plano geral de pesquisa.

Para desenvolvimento do estudo, considerou-se como premissa metodológica que o objeto a ser estudado pode ser conhecido por meio da medição e quantificação. Portanto, as etapas da pesquisa seguiram-se conforme o exposto por Sampieri et al. (2006):

- a partir da fundamentação teórica, foi desenvolvida a questão de pesquisa e as hipóteses a serem testadas;

- as hipóteses foram submetidas à prova, a partir de um modelo de pesquisa e um instrumento de medição padronizado; 
- as medições obtidas foram analisadas por meio de métodos estatísticos na busca de explicações acerca do problema em estudo.

Sendo assim, com relação à abordagem ou enfoque utilizado, a pesquisa pode ser classificada como quantitativa. De acordo com Sampieri et al. (2006), o enfoque quantitativo baseia-se na utilização de dados organizados de forma estruturada (matricial) e na análise estatística visando responder às questões de pesquisa e testar as hipóteses estabelecidas previamente. Em outras palavras, a abordagem quantitativa tem por objetivo conhecer determinado fenômeno utilizando-se da medição e descrição dos dados, buscando relatar fatos que forneçam informações acerca da realidade (SAMPIERI et al., 2006).

Segundo Creswell (2007), essa busca pelo conhecimento se dá através do raciocínio de causa e efeito, da redução de variáveis específicas, da formulação de hipóteses e questões, da mensuração de variáveis, da observação e do teste de teorias. Marconi e Lakatos (2010) complementam essa concepção constatando que, na abordagem quantitativa, a análise do conteúdo deve ser feita de forma objetiva e sistemática, possibilitando a descrição, compreensão e explicação dos fenômenos a partir da quantificação de seus ingredientes.

Nos estudos em administração, a pesquisa quantitativa permite enumerar ou medir eventos, opiniões, hábitos, reações e atitudes de determinada amostra, possibilitando, por meio de uma amostra estatisticamente representativa, a generalização dos resultados (ZOUAIN, 2006).

O estudo também pode ser definido como transversal, já que os dados foram coletados em um único momento. Esse tipo de estudo pode ser comparável a uma fotografia, que representa o que está ocorrendo no exato momento em que ela é tirada (SAMPIERI et al., 2006). Além disso, o modelo de pesquisa pode ser caracterizado como não-experimental, já que parte da observação de situações já existentes, não provocadas intencionalmente pelo pesquisador (SAMPIERI et al., 2006). A Ilustração 12 detalha as etapas metodológicas desenvolvidas no processo de pesquisa. 


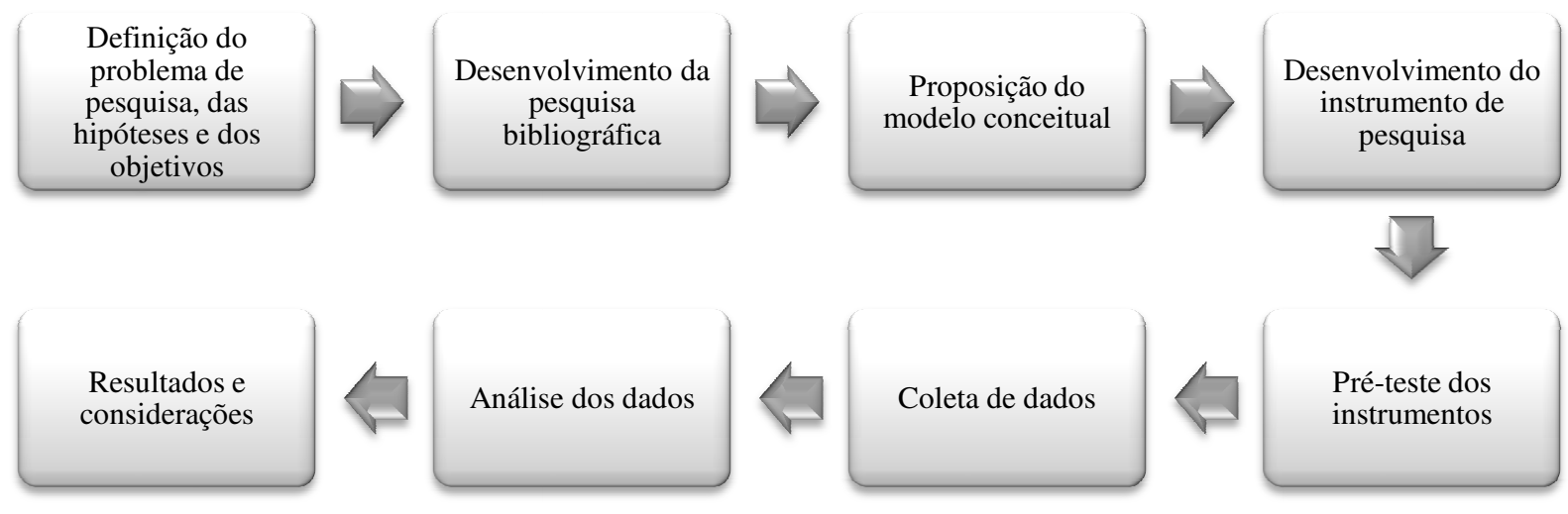

Ilustração 12 - Etapas do processo de pesquisa

Fonte: Elaborado pela autora

\subsection{Definição do universo e da amostra de pesquisa}

O universo de referência da pesquisa é composto por empresas da Indústria Elétrica Eletrônica, de pequeno, médio e grande porte, localizadas em todo território nacional, cujo capital controlador seja nacional, estrangeiro ou misto.

De acordo com as diretrizes estabelecidas pelo Manual de Oslo (OCDE, 2005), a populaçãoalvo para as pesquisas sobre inovação deve considerar, como unidades estatísticas, empresas de todos os portes. No caso de empresas pequenas, a população-alvo deve inserir, no mínimo, unidades com pelo menos dez empregados.

Ainda segundo o Manual (OCDE, 2005), a empresa é, em geral, a unidade estatística mais apropriada para a realização de pesquisas sobre inovação. Considera-se, dessa forma, que as unidades estatísticas em estudo incluam empresas legalmente constituídas e que estejam engajadas primordialmente em um tipo de atividade econômica; ou empresas legalmente constituídas que façam parte de um grupo de unidades legais, incluindo: unidades legais que são integradas vertical ou horizontalmente na empresa ou unidades legais individuais que desempenhem funções auxiliares, inclusive $P \& D$.

Vale ressaltar que o estudo examinou a rede de inovação a partir da perspectiva do ator principal (nível micro), verificando sua relação diante dos outros atores como, por exemplo, fornecedores, clientes, competidores, universidades e centros de pesquisa (PELLEGRIN, et al., 2007). 
A amostra da pesquisa foi selecionada a partir do critério de acessibilidade, configurando-se como uma amostragem não probabilística. Essa escolha foi motivada pela dificuldade de obtenção de listagens completas e atualizadas da população, pelos custos e tempo envolvidos no processo, pela dificuldade de seleção aleatória das empresas, bem como pela dificuldade de coleta de dados, uma vez que o índice médio de respostas no setor costuma ser bastante baixo, situando-se aproximadamente em 5\%, fato que inviabilizaria as análises multivariadas dos dados (KUNIYOSHI, 2008).

A amostragem não probabilística refere-se ao procedimento no qual a probabilidade de seleção de todos os elementos de uma população é desconhecida de antemão (HAIR et al., 2009). Embora só a amostragem probabilística permita extrapolar os resultados da amostra para a população alvo com uma margem de erro e uma confiabilidade, Mattar (1996, p.57) defende que,

\begin{abstract}
uma razão para o uso de amostragem não probabilística pode ser a de não haver outra alternativa viável porque a população não está disponível para ser sorteada. Outra razão é que apesar da amostragem probabilística ser tecnicamente superior na teoria, ocorrem problemas em sua aplicação na prática o que enfraquece essa superioridade. $\mathrm{O}$ resultado de um processo de amostragem probabilístico a priori pode resultar em um estudo não probabilístico devido a erros que os entrevistadores podem cometer quando não seguem corretamente as instruções. Outro motivo pode ser o de que a obtenção de uma amostra de dados que reflitam precisamente a população não seja o propósito principal da pesquisa. Se não houver intenção de generalizar os dados obtidos na amostra para a população, então não haverá preocupações quanto à amostra ser mais ou menos representativa da população. A última razão para usar amostragem não probabilística se refere às limitações de tempo, recursos financeiros, materiais e "pessoas" necessários para a realização de uma pesquisa com amostragem probabilística.
\end{abstract}

Conforme sustentado por Sampieri et al. (2006, p. 271), as amostras não probabilísticas são “de grande valor", por permitir uma cuidadosa e profunda imersão do pesquisador no tema de estudo, possibilitando a coleta de dados valiosos para a análise. Cabe ressaltar, no entanto, que os dados obtidos por meio da amostra não probabilística não podem ser objeto de alguns cálculos estatísticos, tal como a estimativa do erro amostral (MARCONI; LAKATOS, 2006), impossibilitando a inferência dos resultados para a população de interesse originalmente.

Por se tratar de um processo não probabilístico, o cálculo da amostra não pôde ser feito com base estatística. Mesmo assim, foram considerados os pressupostos das técnicas multivariadas utilizadas na análise dos dados para obter uma indicação de tamanho de amostra. Considerando-se tais critérios, definiu-se um número mínimo de 150 observações, sem 
definição de limite máximo. Vale ressaltar que a pesquisadora contou com o apoio do Instituto de Pesquisa e Desenvolvimento Tecnológico do Complexo Eletroeletrônico e Tecnologia da Informação (IPD Eletron) para divulgação do questionário. O órgão, responsável pelas pesquisas da ABINEE, enviou o questionário on-line para cerca de 1.000 associados. Complementarmente, foram encaminhados e-mails com o link da pesquisa direcionado às empresas pertencentes ao setor em estudo. No total, foram obtidas 185 questionários válidos, coletadas no período de 18/02/2013 a 14/04/2013.

\subsection{Modelo conceitual teórico da pesquisa}

Segundo Sampieri et al. (2006), o modelo teórico da pesquisa pode ser definido como um plano concebido para obter a informação que se deseja. Tendo por base os objetivos propostos ao estudo e, à luz das informações obtidas por meio da fundamentação teórica do tema, foi possível estabelecer o modelo conceitual da pesquisa, expresso na Ilustração 13.

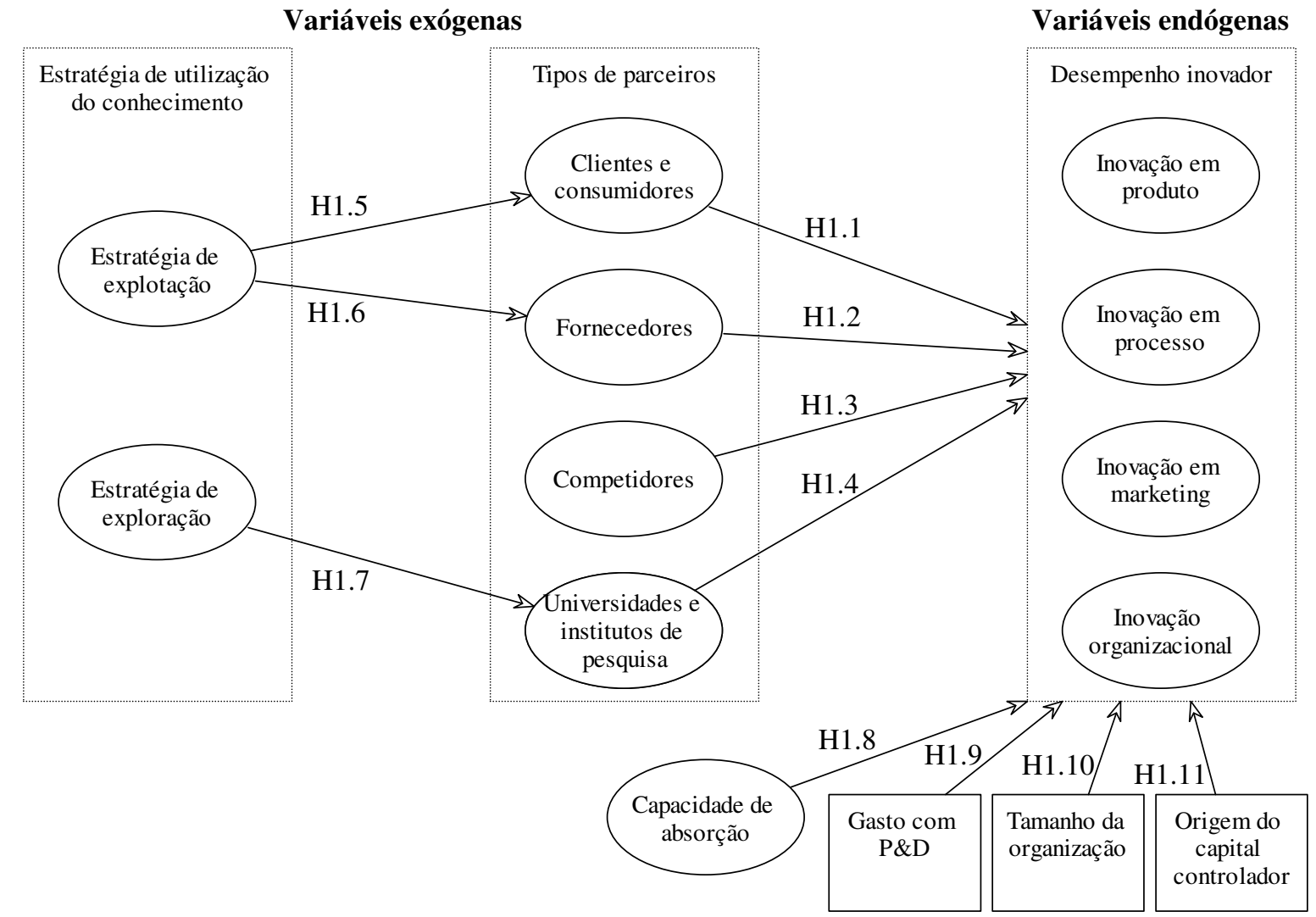

Variáveis Moderadoras

Ilustração 13 - Modelo conceitual da pesquisa

Fonte: Elaborado pela autora 
O modelo considera quatro tipos principais de parceiros com os quais as organizações estabelecem relações visando à inovação: clientes/consumidores, universidades/institutos de pesquisas, fornecedores e competidores (GEMÜDEN et al., 1996; OCDE, 2005; DOZ et al., 2006; TSAI, 2009; CARVALHO, 2010). Foram utilizados no modelo os atores com maior preponderância nas pesquisas analisadas.

Operacionalmente, a determinação dos tipos de parceiros estabelecidos pelas organizações foi realizada a partir de dois aspectos: (1) a existência de relações com clientes/consumidores, universidades/institutos de pesquisas, fornecedores ou competidores no desenvolvimento de pelo menos uma inovação nos últimos três anos (variável binária); e (2) o grau de importância relativa de cada um destes atores no processo de inovação da organização.

Sugere-se, no modelo, que o estabelecimento de relações com os atores propostos pode estar associado ao desempenho inovador da organização, em termos de inovação de produto, de processo, de marketing e/ou organizacional, sob o ponto de vista da empresa pesquisada.

Sendo assim, foram desenvolvidos construtos, com base na literatura, para aferir os resultados nos últimos três anos da empresa relacionados a cada tipo específico de inovação. Os construtos utilizados na elaboração do modelo estão expressos nos Quadros 6, 7, 8 e 9 e foram mensurados por meio do grau de concordância com relação às afirmações.

\section{Quadro 6 - Construto: inovação de produto}

\begin{tabular}{|c|c|c|}
\hline Cód. & Inovação de produto & Adaptado de: \\
\hline PROD1 & $\begin{array}{l}\text { A empresa introduziu pelo menos um produto (bem ou serviço) novo ou } \\
\text { significativamente melhorado no mercado. }\end{array}$ & $\begin{array}{l}\text { Neely e Hii (1998) } \\
\text { Faems } \text { et al. }(2005) \\
\text { OCDE (2005) } \\
\text { Tsai (2009) }\end{array}$ \\
\hline PROD2 & $\begin{array}{l}\text { Grande parte do percentual de vendas da empresa é proveniente de produtos } \\
\text { (bens ou serviços) novos ou significativamente melhorados. }\end{array}$ & $\begin{array}{l}\text { Neely e Hii (1998) } \\
\text { Tsai (2009) } \\
\text { Carvalho (2010) }\end{array}$ \\
\hline PROD3 & $\begin{array}{l}\text { A empresa participa frequentemente de congressos e feiras como } \\
\text { expositor/palestrante. }\end{array}$ & Oliva et al. (2011) \\
\hline PROD4 & A empresa possui poucos competidores por produto ou serviço prestado. & Oliva et al. (2011) \\
\hline PROD5 & Observou-se a melhoria na qualidade dos bens ou serviços da empresa. & $\begin{array}{l}\text { OCDE (2005) } \\
\text { IBGE (2010) }\end{array}$ \\
\hline PROD6 & A empresa ampliou a gama de bens ou serviços ofertados. & $\begin{array}{l}\text { OCDE (2005) } \\
\text { IBGE (2010) }\end{array}$ \\
\hline
\end{tabular}


Quadro 7 - Construto: inovação de processo

\begin{tabular}{|c|l|l|}
\hline Cód. & \multicolumn{1}{|c|}{ Inovação de processo } & \multicolumn{1}{|c|}{ Adaptado de: } \\
\hline PROC1 & $\begin{array}{l}\text { A empresa introduziu pelo menos um novo método de fabricação de bens ou } \\
\text { serviços }\end{array}$ & $\begin{array}{l}\text { Neely e Hii (1998) } \\
\text { OCDE (2005) } \\
\text { IBGE (2010) }\end{array}$ \\
\hline PROC2 & $\begin{array}{l}\text { A empresa introduziu pelo menos um sistema logístico ou método de entrega } \\
\text { para seus insumos, bens ou serviços }\end{array}$ & $\begin{array}{l}\text { A empresa introduziu equipamentos, softwares e técnicas em atividades de } \\
\text { apoio à produção (como por exemplo: planejamento e controle da produção, } \\
\text { medição de desempenho, controle da qualidade, compra, manutenção ou } \\
\text { infraestrutura de TI) }\end{array}$ \\
\hline PROC4 & $\begin{array}{l}\text { Houve aumento da capacidade e flexibilidade de produção ou de prestação de } \\
\text { serviços. }\end{array}$ & $\begin{array}{l}\text { OCDE (2005) } \\
\text { IBGE (2010) }\end{array}$ \\
\hline PROC5 & Observou-se uma redução de custos de produção/serviços prestados. & $\begin{array}{l}\text { OCDE (2005) } \\
\text { IBGE (2010) }\end{array}$ \\
\hline PROC6 & Observou-se uma redução do consumo de matérias-primas e energia. & $\begin{array}{l}\text { OCDE (2005) } \\
\text { IBGE (2010) }\end{array}$ \\
\hline
\end{tabular}

Fonte: Elaborado pela autora

\section{Quadro 8 - Construto: inovação de marketing}

\begin{tabular}{|c|c|c|}
\hline Cód. & Inovação de marketing & Adaptado de: \\
\hline MKT1 & $\begin{array}{l}\text { A empresa implementou mudanças significativas nos conceitos/estratégias de } \\
\text { marketing (como por exemplo: novas mídias ou técnicas para a promoção de } \\
\text { produtos; novas formas para colocação de produtos no mercado ou canais de } \\
\text { venda; ou novos métodos de fixação de preços para a comercialização de bens } \\
\text { e serviços) }\end{array}$ & $\begin{array}{l}\text { OCDE (2005) } \\
\text { IBGE (2010) }\end{array}$ \\
\hline MKT2 & $\begin{array}{l}\text { Foram implementadas grandes mudanças na estética ou desenho em pelo } \\
\text { menos um dos produtos }\end{array}$ & IBGE (2010) \\
\hline MKT3 & Houve a abertura de novos mercados. & $\begin{array}{l}\text { OCDE (2005) } \\
\text { IBGE (2010) }\end{array}$ \\
\hline MKT4 & Observou-se um aumento da visibilidade ou da exposição dos produtos. & $\begin{array}{l}\text { OCDE (2005) } \\
\text { IBGE (2010) }\end{array}$ \\
\hline MKT5 & $\begin{array}{l}\text { Houve uma melhoria da capacidade de adaptação às diferentes demandas dos } \\
\text { clientes. }\end{array}$ & $\begin{array}{l}\text { OCDE (2005) } \\
\text { IBGE (2010) }\end{array}$ \\
\hline
\end{tabular}

Fonte: Elaborado pela autora 
Quadro 9 - Construto: inovação organizacional

\begin{tabular}{|c|c|c|}
\hline Cód. & Inovação Organizacional & Adaptado de: \\
\hline ORG1 & $\begin{array}{l}\text { A empresa implementou novas técnicas de gestão para melhorar rotinas e } \\
\text { práticas de trabalho [como por exemplo: reengenharia dos processos de } \\
\text { negócio, gestão do conhecimento, controle da qualidade total, sistemas de } \\
\text { formação/treinamento, SIG (sistemas de informações gerenciais) e ERP } \\
\text { (planejamento dos recursos do negócio)] }\end{array}$ & $\begin{array}{l}\text { OCDE (2005) } \\
\text { IBGE (2010) }\end{array}$ \\
\hline ORG2 & $\begin{array}{l}\text { A empresa implementou novos métodos de organização do trabalho para } \\
\text { melhor distribuir responsabilidades e poder de decisão (como por exemplo o } \\
\text { estabelecimento do trabalho em equipe, a descentralização ou integração de } \\
\text { departamentos) }\end{array}$ & IBGE (2010) \\
\hline ORG3 & $\begin{array}{l}\text { A empresa implementou mudanças nas relações com outras empresas ou } \\
\text { instituições públicas visando constituir uma novidade organizacional (tais } \\
\text { como o estabelecimento pela primeira vez de alianças, parcerias, terceirização } \\
\text { ou subcontratação de atividades) }\end{array}$ & IBGE (2010) \\
\hline ORG4 & $\begin{array}{l}\text { Observou-se uma melhoria na comunicação e a interação entre as diferentes } \\
\text { áreas de negócios. }\end{array}$ & $\begin{array}{l}\text { OCDE (2005) } \\
\text { IBGE (2010) }\end{array}$ \\
\hline ORG5 & $\begin{array}{l}\text { Observou-se uma melhoria no compartilhamento e a transferência de } \\
\text { conhecimentos com outras organizações. }\end{array}$ & $\begin{array}{l}\text { OCDE (2005) } \\
\text { IBGE (2010) }\end{array}$ \\
\hline ORG6 & $\begin{array}{l}\text { Houve o enquadramento da empresa em regulações e normas relativas ao } \\
\text { mercado interno ou externo. }\end{array}$ & $\begin{array}{l}\text { OCDE (2005) } \\
\text { IBGE (2010) }\end{array}$ \\
\hline
\end{tabular}

Fonte: Elaborado pela autora

Outro aspecto analisado na pesquisa refere-se à estratégia de utilização do conhecimento empregada pela empresa para acessar as informações de seus parceiros. O levantamento teórico acerca do tema apontou para a existência de dois tipos de estratégias: a de explotação e a de exploração (MARCH, 1991).

O acréscimo destas variáveis no modelo de pesquisa é importante devido à possível existência de uma relação entre a estratégia de explotação e exploração adotada, os tipos de parceiros estabelecidos e os resultados da empresa em termos de inovação, conforme os estudos propostos por Dittrich e Duyters (2003), Faems et al. (2005) e Westerlund e Rajala (2010).

Sendo assim, foram formulados dois construtos, com base na literatura, para averiguar a estratégia utilizada pelas organizações pesquisadas, bem como sua possível associação com os parceiros estabelecidos. A identificação da estratégia foi feita com base no grau de concordância com relação às afirmações apresentadas nos Quadros 10 e 11. 
Quadro 10 - Construto: estratégia de exploração do conhecimento

\begin{tabular}{|c|c|c|}
\hline Cód. & Exploração & Adaptado de: \\
\hline EXPR1 & $\begin{array}{l}\text { A empresa desenvolve relações com parceiros que permitam a implementação } \\
\text { de inovações mais radicais. }\end{array}$ & \multirow{4}{*}{$\begin{array}{l}\text { March (1991) } \\
\text { Dittrich e Duysters } \\
\text { (2003) } \\
\text { Faems et al. }(2005) \\
\text { Westerlund e Rajala } \\
(2010)\end{array}$} \\
\hline EXPR2 & $\begin{array}{l}\text { A empresa visa o desenvolvimento de relações que lhe proporcionem a } \\
\text { geração de novas ideias e conhecimentos organizacionais. }\end{array}$ & \\
\hline EXPR3 & $\begin{array}{l}\text { O desenvolvimento de ligações mais fracas com os parceiros de inovação é } \\
\text { preferível, por possibilitar a difusão de novas informações. }\end{array}$ & \\
\hline EXPR4 & $\begin{array}{l}\text { A empresa possui como foco o desenvolvimento de novos produtos, } \\
\text { processos e métodos. }\end{array}$ & \\
\hline
\end{tabular}

Fonte: Elaborado pela autora

Quadro 11 - Construto: estratégia de explotação do conhecimento

\begin{tabular}{|c|c|c|}
\hline Cód. & Explotação & Adaptado de: \\
\hline EXPT1 & $\begin{array}{l}\text { A empresa desenvolve relações com parceiros que permitam a realização de } \\
\text { inovações incrementais. }\end{array}$ & \multirow{4}{*}{$\begin{array}{l}\text { March (1991) } \\
\text { Dittrich e Duysters } \\
(2003) \\
\text { Faems et al. }(2005) \\
\text { Westerlund e Rajala } \\
(2010)\end{array}$} \\
\hline EXPT2 & $\begin{array}{l}\text { A empresa visa o desenvolvimento de relações que lhe proporcionem o } \\
\text { reforço e aprimoramento dos conhecimentos organizacionais já estabelecidos. }\end{array}$ & \\
\hline EXPT3 & $\begin{array}{l}\text { O desenvolvimento de ligações fortes com os parceiros de inovação é } \\
\text { preferível, por estarem baseadas em interações regulares, fundamentadas na } \\
\text { confiança entre as organizações. }\end{array}$ & \\
\hline EXPT4 & $\begin{array}{l}\text { A empresa possui como foco a melhoria dos produtos, métodos e processos } \\
\text { existentes. }\end{array}$ & \\
\hline
\end{tabular}

Fonte: Elaborado pela autora

Considera-se, no modelo proposto, que a relação estabelecida entre as variáveis é moderada pela capacidade de absorção do conhecimento da empresa. Em outros termos, sugere-se que o desempenho em inovação de produto, processo, marketing e organizacional possa ser influenciado pela capacidade de absorção de conhecimento que a empresa possui.

Segundo Marconi e Lakatos (1990, p. 143), a variável moderadora pode ser entendida como "um estímulo determinante para que ocorra certo resultado" situando-se, porém, em nível secundário às variáveis independentes.

Para medição da capacidade de absorção do conhecimento, foi desenvolvido o construto demonstrado no Quadro 12. 
Quadro 12 - Construto: capacidade de absorção do conhecimento

\begin{tabular}{|c|l|l|}
\hline Cód. & \multicolumn{1}{|c|}{ Capacidade de absorção do conhecimento } & \multicolumn{1}{|c|}{ Adaptado de: } \\
\hline ABS1 & $\begin{array}{l}\text { Intensidade da área de P\&D (porcentagem da receita operacional bruta gasta } \\
\text { com P\&D e treinamento em 2012 sobre o total de funcionários na empresa) }\end{array}$ & $\begin{array}{l}\text { Tsai (2009) e } \\
\text { Schmidt (2005) }\end{array}$ \\
\hline ABS2 & Número de funcionários na área de P\&D em relação ao total & Faems et al. (2005) \\
\hline ABS3 & $\begin{array}{l}\text { A área de P\&D é bastante relevante para o desenvolvimento de inovações na } \\
\text { empresa (importância da área de P\&D) }\end{array}$ & $\begin{array}{l}\text { Faems } \text { et al. }(2005) \\
\text { IBGE (2010) }\end{array}$ \\
\hline ABS4 & $\begin{array}{l}\text { Percentual de funcionários da empresa que possui cursos de Especialização, } \\
\text { Mestrado e Doutorado (média ponderada com os pesos: 1 - Esp; 2 - Mest.; 3 - } \\
\text { Dout.) }\end{array}$ & Schmidt (2005) \\
\hline ABS5 & $\begin{array}{l}\text { Diversidade de formações dos profissionais da empresa (quantidade de áreas de } \\
\text { formação detectada na empresa sobre o total de funcionários) }\end{array}$ & Schmidt (2005) \\
\hline ABS6 & $\begin{array}{l}\text { Pelos menos uma inovação na empresa foi desenvolvida a partir de relações } \\
\text { com clientes, fornecedores, competidores, universidades ou institutos de } \\
\text { pesquisa nos últimos 3 anos }\end{array}$ & Schmidt (2005) \\
\hline
\end{tabular}

Fonte: Elaborado pela autora

Com base na pesquisa bibliográfica, o tamanho da empresa (FAEMS et al., 2005; TSAI, 2009), os gastos com P\&D (NEELY; HII, 1998; FAEMS et al., 2005; CARVALHO, 2010; IBGE, 2010) e a origem do capital controlador da empresa (FAEMS et al., 2005; IBGE, 2010) podem ser consideradas como variáveis que influenciam o desempenho inovador das empresas e, por esse motivo, foram classificadas como variáveis moderadoras.

O modelo conceitual apresenta ainda as hipóteses a serem testadas na pesquisa. A primeira hipótese refere-se à possível relação existente entre as colaborações com clientes/consumidores e o resultado em inovação da empresa:

\section{H1.1 A colaboração com clientes/consumidores está relacionada positivamente com o resultado em inovação da empresa.}

A colaboração com clientes e consumidores pode ser considerada uma fonte relevante ao processo inovativo, uma vez que pode facilitar a identificação de oportunidades do mercado para o desenvolvimento tecnológico, como também reduzir a probabilidade de má concepção nas fases iniciais de desenvolvimento de produtos (GUPTA et al., 2000; FRITSCH; LUKAS, 2001; BROCKHOFF, 2003). Além disso, compreender as necessidades dos clientes pode ajudar as empresas a obter novas ideias (VON HIPPEL et al., 1999), favorecendo a identificação de tendências de mercado rapidamente. 
A segunda hipótese procura estabelecer uma relação entre as colaborações com fornecedores e o resultado em inovação:

\section{H1.2 A colaboração com fornecedores está relacionada positivamente com o resultado em inovação da empresa.}

Gemüden et al. (1996) constataram que a sinergia com o fornecedor pode proporcionar resultados em inovações, principalmente no que se refere à melhoria de produtos da organização. Os fornecedores costumam ter maior experiência e um conhecimento mais abrangente com relação às peças e componentes que podem ser fundamentais para o desenvolvimento de novos produtos, permitindo que as empresas incorporem a experiência e a perspectiva do fornecedor no processo de inovação (EISENHARDT; TABRIZI, 1995). Além disso, o desenvolvimento de uma relação com os fornecedores também auxilia as empresas na identificação de potenciais problemas técnicos, podendo contribuir para os processos de desenvolvimento de novos produtos (KESSLER; CHAKRABATRI, 1996).

A terceira hipótese se refere à relação entre as colaborações com competidores e o resultado em inovação na organização:

\section{H1.3 A colaboração com competidores está relacionada positivamente com o resultado em inovação da empresa.}

De acordo com Tsai (2009), os agentes menos frequentes em uma rede de inovação parecem ser os concorrentes. No entanto, este tipo de colaboração pode permitir às empresas conhecer seus competidores melhor, o que pode favorecer sua capacidade de diferenciação (LINN, 1994). Para Lawson e Samson (2001), a aplicação do conhecimento proveniente dos competidores permite a realização de benchmarking e a internalização das qualidades dos mesmos, por meio da imitação ou do aperfeiçoamento.

A quarta hipótese procura estabelecer uma relação entre as colaborações com universidades/institutos de pesquisa e o resultado em inovação da empresa:

\section{H1.4 A colaboração com universidades e institutos de pesquisa está relacionada positivamente com o resultado em inovação da empresa.}


Segundo Gemünden et al. (1996), Hemmert (2004) e Caloghirou et al. (2004), as universidades e institutos de pesquisa são importantes centros para a criação e disseminação do conhecimento científico. Por esse motivo, podem desempenhar um papel importante nos resultados da empresa, principalmente dentro indústrias de alta tecnologia. De forma semelhante, por permitirem o acesso à informações não redundantes, as universidades e institutos de pesquisa podem contribuir também para a inovação organizacional (RUEF, 2002).

A quinta, sexta e sétima hipóteses da pesquisa propõem a verificação da relação existente entre a estratégia de utilização do conhecimento e o tipo de parceiro estabelecido pela empresa:

H1.5 A utilização de estratégias de explotação do conhecimento está relacionada positivamente com o desenvolvimento de colaborações com clientes/consumidores.

H1.6 A utilização de estratégias de explotação do conhecimento está relacionada positivamente com o desenvolvimento de colaborações com fornecedores.

H1.7 A utilização de estratégias de exploração do conhecimento está relacionada positivamente com o desenvolvimento de colaborações com universidades e institutos pesquisa.

A estratégia de exploração de conhecimentos está associada com a pesquisa, a experimentação, a assunção de riscos e a inovação (MARCH, 1991). Por esse motivo, as colaborações desenvolvidas com universidades e institutos de pesquisa, tendem a ser orientadas por essa estratégia, tendo por objetivo a criação de know-how e know-why de novas tecnologias que podem ser traduzidas no desenvolvimento de inovações (WHEELWRIGHT; CLARK, 1992; FAEMS et al., 2005).

A estratégia de explotação dos conhecimentos está associada com o refinamento, seleção, produção e execução de ideias e informações. Este tipo de estratégia se destina ao reforço e ampliação dos conhecimentos organizacionais já estabelecidos (DITTRICH; DUYSTERS, 2003), estando relacionada principalmente às colaborações com clientes e fornecedores (FAEMS et al., 2005). 
A oitava hipótese tem por objetivo verificar a existência de relação entre a capacidade de absorção do conhecimento da empresa e seu desempenho em termos de inovação de produto, processo, de marketing e organizacional:

H1.8 Quanto maior a capacidade de absorção do conhecimento apresentada pela empresa, maior seu resultado em inovação.

Teece (2000) e Tsai (2009) consideram que a capacidade de absorção do conhecimento da empresa pode determinar a extensão pela qual é possível utilizar os conhecimentos advindos de parceiros externos. Dessa forma, em uma rede de inovação, a capacidade que a empresa possui para absorver os conhecimentos pode influenciar seus resultados em termos de inovação.

Por fim, a nona, décima e décima primeira hipóteses visam verificar a influência do tamanho da organização, do gasto com $P \& D$ e da origem do capital controlador da empresa nos resultados em inovação de produto, processo, marketing e organizacional.

\section{H1.9 Quanto maior o gasto com P\&D na empresa, maior seu resultado em inovação.}

\section{H1.10 Quanto maior o tamanho da empresa, maior seu resultado em inovação.}

\section{H1.11 As empresas cuja origem do capital controlador é estrangeira apresentam um maior resultado em inovação.}

Considera-se que o desempenho inovador da empresa sofra a influência direta e positiva em relação ao tamanho da organização (FAEMS et al., 2005; TSAI, 2009) e aos gastos com P\&D (NEELY; HII, 1998; FAEMS et al., 2005; CARVALHO, 2010; IBGE, 2010). Além disso, a origem do capital controlador da empresa pode ser considerada como uma variável influente neste resultado. Estudos anteriores mostraram que, dentre as empresas mais inovadoras, predominam às de capital estrangeiro (FAEMS et al., 2005; IBGE, 2010).

De forma geral, a elaboração do modelo conceitual permitiu determinação das principais relações a serem analisadas na pesquisa, fornecendo bases para a construção do instrumento de coleta de dados. 


\subsection{Instrumento de coleta de dados}

De acordo com Marconi e Lakatos (2006), os procedimentos de coleta de dados têm como objetivo o levantamento das informações relevantes para resolução do problema de pesquisa. Trata-se, portanto, de uma etapa delicada, na qual se fazem necessários procedimentos de coleta de dados coerentes, em termos de sua estrutura, forma e conteúdo, com o problema e objetivos do estudo.

Tendo em vista a natureza descritiva e exploratória da pesquisa, optou-se por utilizar um questionário como instrumento de coleta de dados. O questionário é constituído por perguntas ordenadas, que devem ser respondidas sem a presença do entrevistador. Sua principal vantagem consiste na possibilidade de atingir um número maior de pessoas simultaneamente, fazendo com que o pesquisador economize tempo e obtenha um grande número de dados, sem restrição geográfica. Além disso, por não haver a influência de um pesquisador na aplicação dessa ferramenta, há um menor risco de distorção nas respostas (MARCONI; LAKATOS, 2006).

Em cumprimento ao Manual de Oslo, o questionário utilizado para coleta de dados sobre inovação deve ser estruturado, simples e apresentar definições e instruções claras, visando evitar altas taxas de não resposta. Além disso, o questionário deve ser formulado de tal forma que as organizações que não realizaram atividades de inovação possam responder as questões consideradas relevantes para elas (OCDE, 2005).

Os Quadros 13 e 14 apresentam de forma detalhada as variáveis do estudo, a escala de mensuração, o número da questão de referência no questionário e os objetivos/hipóteses da pesquisa relacionados. 
Quadro 13 - Variáveis e escalas de mensuração do instrumento de coleta de dados

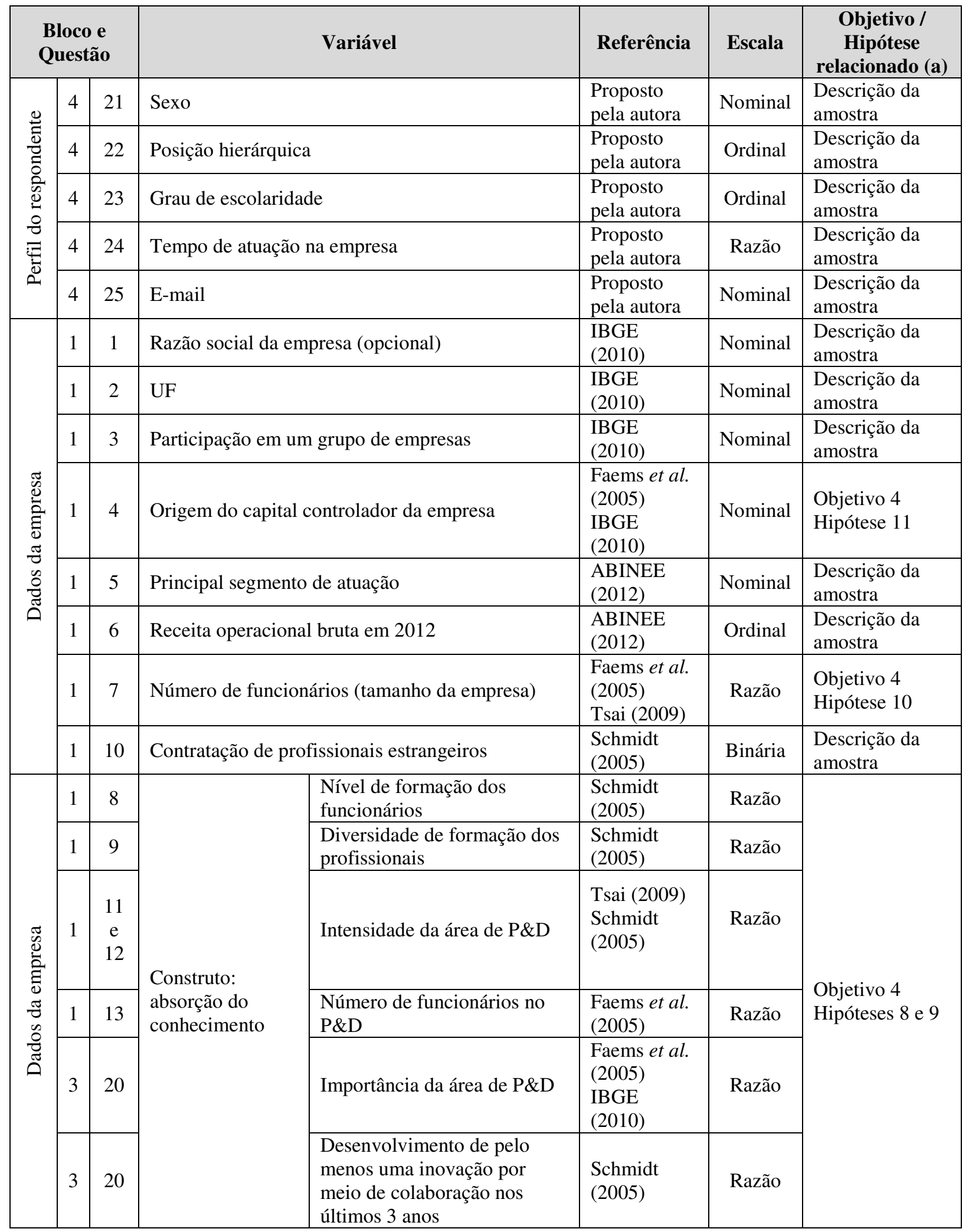

Fonte: Elaborado pela autora 
Quadro 14 - Variáveis e escalas de mensuração do instrumento de coleta de dados (cont.)

\begin{tabular}{|c|c|c|c|c|c|c|}
\hline \multicolumn{3}{|c|}{$\begin{array}{l}\text { Bloco e } \\
\text { Questão }\end{array}$} & Variável & Referência & Escala & $\begin{array}{c}\text { Objetivo / } \\
\text { Hipótese } \\
\text { relacionado }\end{array}$ \\
\hline \multirow{4}{*}{ 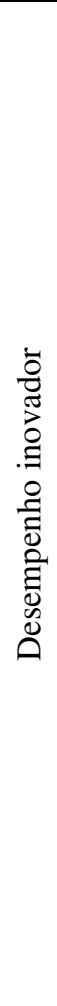 } & 2 & $\begin{array}{c}14 \\
\mathrm{e} \\
15\end{array}$ & Construto: inovação de produto & $\begin{array}{l}\text { Neely e Hii } \\
(1998) \\
\text { Faems } \text { et al. } \\
(2005) \text { OCDE } \\
(2005) \\
\text { Tsai (2009) } \\
\text { Carvalho (2010) } \\
\text { IBGE (2010) } \\
\text { Oliva } \text { et al. } \\
\text { (2011) }\end{array}$ & Razão & $\begin{array}{l}\text { Objetivos } 3 \text { e } \\
4 \\
\text { Hipóteses } 1 \text {, } \\
2,3,4,8,9 \text {, } \\
10 \text { e } 11\end{array}$ \\
\hline & 2 & $\begin{array}{c}14 \\
\mathrm{e} \\
15\end{array}$ & Construto: inovação de processo & $\begin{array}{l}\text { Neely e Hii } \\
(1998) \\
\text { OCDE (2005) } \\
\text { IBGE (2010) }\end{array}$ & Razão & $\begin{array}{l}\text { Objetivos } 3 \text { e } \\
4 \\
\text { Hipóteses } 1 \text {, } \\
2,3,4,8,9 \text {, } \\
10 \text { e } 11\end{array}$ \\
\hline & 2 & $\begin{array}{c}14 \\
\mathrm{e} \\
15\end{array}$ & Construto: inovação de marketing & $\begin{array}{l}\text { OCDE }(2005) \\
\text { IBGE }(2010)\end{array}$ & Razão & $\begin{array}{l}\text { Objetivos } 3 \text { e } \\
4 \\
\text { Hipóteses } 1 \text {, } \\
2,3,4,8,9 \text {, } \\
10 \text { e } 11\end{array}$ \\
\hline & 2 & $\begin{array}{c}14 \\
\mathrm{e} \\
15\end{array}$ & Construto: inovação organizacional & $\begin{array}{l}\text { OCDE }(2005) \\
\text { IBGE }(2010)\end{array}$ & Razão & $\begin{array}{l}\text { Objetivos } 3 \text { e } \\
4 \\
\text { Hipóteses } 1 \text {, } \\
2,3,4,8,9 \text {, } \\
10 \text { e } 11\end{array}$ \\
\hline \multirow{5}{*}{ 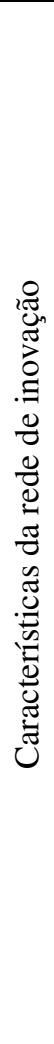 } & 3 & 16 & Responsável pelo desenvolvimento de inovações & IBGE (2010) & Nominal & $\begin{array}{l}\text { Descrição da } \\
\text { Amostra }\end{array}$ \\
\hline & 3 & 17 & $\begin{array}{l}\text { Existência de colaboração para inovação com } \\
\text { algum tipo de parceiro nos últimos } 3 \text { anos }\end{array}$ & $\begin{array}{l}\text { IBGE (2010) } \\
\text { Faems et al. } \\
(2005) \text { Tsai } \\
(2009)\end{array}$ & Binária & $\begin{array}{l}\text { Objetivo } 2 \\
\text { Hipóteses } 1 \text {, } \\
2,3,4,5,6 \text { e } \\
7\end{array}$ \\
\hline & 3 & 18 & Importância dos parceiros & $\begin{array}{l}\text { IBGE (2010) } \\
\text { Tsai (2009) }\end{array}$ & Razão & $\begin{array}{l}\text { Objetivo } 2 \\
\text { Hipóteses } 1 \text {, } \\
2,3,4,5,6 \text { e } \\
7\end{array}$ \\
\hline & 3 & 19 & Razões para o estabelecimento de redes & $\begin{array}{l}\text { Hagedoorn } \\
(2002) \\
\text { Küppers e Pyka } \\
(2002) \\
\text { Forfás (2004) } \\
\text { Camarinha- } \\
\text { Matos e Abreu } \\
\text { (2007) } \\
\text { Carvalho (2010) }\end{array}$ & Nominal & Objetivo 1 \\
\hline & 3 & 20 & $\begin{array}{l}\text { Construtos: estratégia de exploração e } \\
\text { explotação }\end{array}$ & $\begin{array}{l}\text { March (1991) } \\
\text { Dittrich e } \\
\text { Duysters (2003) } \\
\text { Faems } \text { et al. } \\
\text { (2005) } \\
\text { Westerlund e } \\
\text { Rajala (2010) }\end{array}$ & Razão & $\begin{array}{l}\text { Hipóteses } 5 a, \\
5 b \text { e } 5 c\end{array}$ \\
\hline
\end{tabular}

Fonte: Elaborado pela autora 
O instrumento de pesquisa foi desenvolvido com base nos indicadores e autores referenciados no Capítulo 2, tendo por base a pesquisa bibliográfica. As perguntas do questionário foram divididas em quatro blocos, levando-se em consideração o assunto abordado:

- Dados da empresa: visa fornecer informações acerca da empresa pesquisada, como, por exemplo, seu tamanho, sua capacidade de absorção de conhecimento, seu setor de atuação, dentre outros aspectos.

- Desempenho inovador: busca levantar dados sobre o desempenho da empresa em termos de inovação de produto, processo, de marketing e organizacional e seus possíveis efeitos.

- Características da rede de inovação: parte constituída por questões acerca das razões para formação da rede, dos tipos de parceiros estabelecidos e sua relevância para a organização, como também quanto à utilização da estratégia explotação ou exploração do conhecimento desenvolvida.

- Perfil do respondente: permite averiguar as características dos respondentes, como seu grau de escolaridade, posição hierárquica na empresa, idade e gênero.

No total, o questionário foi composto por 25 questões, de escalas de mensuração variadas: nominal, ordinal, razão e binária.

Visando obter uma mensuração em escala razão frente às afirmações utilizadas nas questões $14,15,18$ e 20 do questionário, foi utilizada uma tabela de referência, conforme expresso na Tabela 1.

Tabela 1 - Grau de concordância com relação às afirmações do questionário

\begin{tabular}{|c|c|c|c|c|c|c|c|c|c|c|c|c|c|c|c|c|c|c|c|c|c|c|c|c|}
\hline \multicolumn{5}{|c|}{ Grau muito baixo } & \multicolumn{5}{|c|}{ Grau baixo } & \multicolumn{5}{|c|}{ Grau regular } & \multicolumn{5}{|c|}{ Grau alto } & \multicolumn{5}{|c|}{ Grau muito alto } \\
\hline 0 & 0,5 & 1,0 & 1,5 & 2,0 & 2,1 & 2,5 & 3,0 & 3,5 & 4,0 & 4,1 & 4,5 & 5,0 & 5,5 & 6,0 & 6,1 & 6,5 & 7,0 & 7,5 & 8,0 & 8,1 & 8,5 & 9,0 & 9,5 & 10,0 \\
\hline
\end{tabular}

Fonte: VERÍSSIMO, 2011, p.78.

A utilização da escala razão visa permitir uma abordagem métrica às questões a serem analisadas por meio da Modelagem de Equações Estruturais (SEM). Ressalta-se que as escalas métricas possibilitam o uso de estatísticas, como média e desvio-padrão, sem as restrições relacionadas às escalas qualitativas e não métricas (FÁVERO et al., 2009). A partir desta escala, os respondentes puderam atribuir notas de 0 a 10, incluindo decimais, para 
expressar o seu grau de concordância frente às afirmações (nas questões 14, 15 e 20), como também o grau de importância dos parceiros estabelecidos pelas organizações (na questão 18).

Para uma melhor referência na atribuição dos graus de concordância e importância, as notas foram divididas em cinco grupos, variando desde 'grau muito baixo' (para notas de 0 a 2) até 'grau muito alto' (para notas de 8,1 a 10). Esta mesma escala foi utilizada por outros pesquisadores que também aplicaram a técnica de modelagem de equações estruturais para análise dos dados (VERÍSSIMO, 2011).

Ademais, com o objetivo de averiguar a validade do questionário e identificar possíveis pontos passíveis de melhora, foi realizado um pré-teste do instrumento de pesquisa com 8 respondentes.

De acordo com o Manual de Oslo (OCDE, 2005), algumas regras básicas devem ser seguidas quando da formulação do questionário para uma pesquisa sobre inovação, dentre elas a realização do pré-teste do instrumento de coleta de dados. O Manual estabelece que o préteste pode ser realizado por meio de entrevistas com especialistas a respeito de seu entendimento do questionário, como também por meio do envio do questionário a uma pequena amostra de unidades. Para Marconi e Lakatos (2006, p.32), o pré-teste consiste em “testar os instrumentos da pesquisa sobre uma pequena parte da população do 'universo' ou da amostra, antes de ser aplicado definitivamente, a fim de evitar que a pesquisa chegue a um resultado falso".

Em decorrência da realização do pré-teste, algumas melhorias foram incorporadas ao instrumento de coleta de dados, de modo a facilitar seu entendimento e torná-lo mais objetivo. Dentre as alterações realizadas, pode-se citar a simplificação das perguntas 14, 15 e 20; a reformulação de enunciados; o acréscimo de opções de respostas de forma a abranger todas as possibilidades; e a retirada de algumas questões que não contribuíam para a análise dos objetivos propostos no estudo. A versão final do questionário é apresentada no Apêndice 1, ao final deste trabalho.

A coleta de dados da pesquisa foi feita por meio da ferramenta on-line Survey Gizmo, que permite a elaboração e transmissão dos questionários por meio da internet, além de 
possibilitar a exportação dos resultados já tabulados para o programa Microsoft Office Excel e Statistical Package for the Social Sciences (SPSS Statistics).

O questionário foi distribuído via correio eletrônico, juntamente com um breve texto explicativo para conceituar os entrevistados acerca do tema e objetivo da pesquisa. De acordo com o Manual de Oslo (OCDE, 2005), a utilização de tecnologias on-line ou automatizadas para a coleta de dados apresenta certa vantagem em relação à coleta de dados em questionários em papel. Isso porque, em um questionário em papel, os respondentes podem ver todas as questões, fato que pode alterar ou influenciar sua resposta. No caso do questionário eletrônico, o pesquisador ainda pode personalizar as questões conforme o andamento da pesquisa.

O questionário foi direcionado aos responsáveis pela gestão da empresa ou gerentes intermediários, como gerentes de $\mathrm{P} \& \mathrm{D}$ ou de projetos, quando o cargo existia na empresa, ou até mesmo por funcionários por eles designados. Para a realização da abordagem dos respondentes, foi elaborada uma lista com os contatos dos profissionais-alvos da pesquisa. Além disso, foram acrescentadas cinco questões no questionário para qualificação do respondente, inclusive para averiguar sua posição hierárquica na empresa.

Segundo o Manual de Oslo (OCDE, 2005), a escolha do respondente mais apropriado é particularmente importante em pesquisas sobre inovação, uma vez que as questões neste tipo de estudo são muito especializadas. O Manual recomenda que, em empresas de pequeno porte, o questionário seja respondido por gerentes, enquanto, em empresas de grande porte, esse papel seja exercido por alguma das pessoas envolvidas com o tema a ser pesquisado.

\subsection{Técnicas utilizadas no tratamento e análise dos dados}

De acordo com Yin (2005, p. 137), a análise de dados consiste em "examinar, categorizar, classificar em tabelas ou, do contrário, recombinar as evidências qualitativas e quantitativas para tratar as proposições iniciais do estudo". Pereira (2007) apontou que a análise e interpretação é uma etapa posterior à coleta e tabulação dos dados, sendo realizadas para atender aos objetivos da pesquisa e para confrontar os dados colhidos com as hipóteses ou pressupostos da pesquisa. 
Marconi e Lakatos (1990, p.165) ainda afirmaram que a análise e a interpretação dos dados são coisas distintas, porém relacionadas, sendo a análise uma "tentativa de evidenciar as relações existentes entre o fenômeno estudado e outros fatores”. Para as autoras, a elaboração da análise pode ser dividida em três níveis: interpretação, explicação e especificação. A interpretação consiste na verificação de relação entre as variáveis dependentes e independentes, com o objetivo de ampliar os conhecimentos sobre o fenômeno. A explicação refere-se ao esclarecimento sobre a origem da variável dependente, enquanto a especificação refere-se à explicitação sobre a validade das relações entre as variáveis dependente e independente.

Segundo Sampieri et al. (2006), a escolha do tipo de análise a ser realizada depende do tipo de dado coletado, ou seja, se os dados coletados são quantitativos, a análise será quantitativa, o que não impede, no entanto, a realização de alguma análise qualitativa. No caso da análise quantitativa, o pesquisador pode utilizar a estatística descritiva, cálculos e raciocínios da estatística inferencial, testes paramétricos e não paramétricos, análises multivariadas, etc.

De acordo com Marconi e Lakatos (1990), para proceder a análise dos dados, é necessário considerar o planejamento da pesquisa e a complexidade ou simplicidade das hipóteses ou do problema de estudo, para que a abordagem na análise esteja adequada. Além disso, é preciso atentar que, mesmo que os dados da pesquisa sejam válidos, a eficácia da análise pode ser prejudicada por uma tabulação descuidada, pela utilização de procedimentos estatísticos inadequados, por erros de cálculo, pela parcialidade do investigador, pela incapacidade de reconhecimento das limitações da pesquisa, dentre outros aspectos, evidenciando assim a importância e as dificuldades de se realizar uma análise satisfatória.

Após o procedimento de coleta, os dados passaram por uma verificação, com o objetivo de detectar possíveis falhas ou erros no preenchimento do questionário, o que poderia prejudicar o resultado da pesquisa. Previamente à análise, foi feita uma revisão do banco de dados, que comprovou a ausência de missings. Para identificação de outliers de variáveis métricas, foi utilizada a distância de Mahalanobis que indicou, com um nível de significância de 1\%, a inexistência de valores atípicos.

As análises foram executadas por meio da utilização do software Statistical Package for the Social Sciences (SPSS Statistics) da IBM, vs. 21 e do AMOS vs. 21. De modo a facilitar a 
identificação das variáveis no software, foram utilizadas as abreviações expressas no Quadro 15.

Quadro 15 - Legenda das variáveis utilizadas

\begin{tabular}{|c|c|}
\hline Abreviações & Descrição da variável \\
\hline V1 & Razão Social da empresa \\
\hline $\mathrm{V} 2$ & Unidade Federativa (UF) da empresa \\
\hline V3 & Constituição da empresa \\
\hline V4 & Origem do capital controlador da empresa \\
\hline V5 & Principal segmento de atuação \\
\hline V6 & Receita operacional bruta anual (2012) \\
\hline V7 & Número de funcionários da empresa \\
\hline V8 & Percentual de funcionários pós-graduados na empresa \\
\hline V9 & Principais áreas de formação dos profissionais da empresa \\
\hline V10 & Contratação de profissionais estrangeiros \\
\hline V11 & Percentual da receita operacional bruta gasto com treinamento (2012) \\
\hline $\mathrm{V} 12$ & Percentual da receita operacional bruta gasto com P\&D (2012) \\
\hline V13 & Número de funcionários no departamento de P\&D \\
\hline V14 & Construto (inovação de produto, de marketing, de processo e organizacional) \\
\hline V15 & Construto (inovação de produto, de marketing, de processo e organizacional) \\
\hline V16 & Principal responsável pelo desenvolvimento de inovações \\
\hline V17 & Atores com os quais as empresas desenvolveram pelo menos uma inovação nos últimos 3 anos \\
\hline V18 & Importância relativa de cada ator visando o estabelecimento de relações para a inovação \\
\hline V19 & Razões para o estabelecimento de redes de inovação \\
\hline V20 & Construto (absorção do conhecimento, estratégia de exploração e estratégia de explotação) \\
\hline $\mathrm{V} 21$ & Gênero dos respondentes \\
\hline $\mathrm{V} 22$ & Posição hierárquica na empresa \\
\hline V23 & Grau de escolaridade \\
\hline V24 & Número de anos trabalhados na empresa \\
\hline PROD 1-6 & Variáveis do construto Inovação de Produto \\
\hline PROC 1-6 & Variáveis do construto Inovação de Processo \\
\hline MKT 1-5 & Variáveis do construto Inovação de Marketing \\
\hline ORG 1-6 & Variáveis do construto Inovação Organizacional \\
\hline ABS 1-6 & Variáveis do construto Absorção do Conhecimento \\
\hline EXPT 1-4 & Variáveis do construto Estratégia de Explotação \\
\hline EXPR 1-4 & Variáveis do construto Estratégia de Exploração \\
\hline CLIENT 1-2 & Variáveis do construto clientes e consumidores \\
\hline FORNEC 1-2 & Variáveis do construto fornecedores \\
\hline COMPET 1-2 & Variáveis do construto competidores \\
\hline UNIVER 1-2 & Variáveis do construto universidades e institutos de pesquisa \\
\hline
\end{tabular}

Fonte: Elaborado pela autora

Visando atingir aos objetivos propostos nesta pesquisa, optou-se pela realização de uma análise baseada na estatística descritiva. Posteriormente, os dados foram submetidos à análise estatística multivariada, por meio da aplicação da análise multivariada de variância (MANOVA), da análise fatorial confirmatória (CFA) e da modelagem de equações estruturais (SEM). O Quadro 16 apresenta o tipo de técnica utilizada para análise dos dados segundo os objetivos propostos. 
Quadro 16 - Objetivos versus técnicas de análise dos dados

\begin{tabular}{|l|l|}
\hline \multicolumn{1}{|c|}{ Objetivo geral } & \multicolumn{1}{|c|}{ Técnica de análise dos dados } \\
\hline $\begin{array}{l}\text { Verificar qual a contribuição dos parceiros estabelecidos em redes de } \\
\text { inovação para o desempenho inovador de empresas da Indústria } \\
\text { Elétrica Eletrônica. }\end{array}$ & $\begin{array}{l}\text { Análise fatorial confirmatória } \\
\text { (CFA) } \\
\text { Modelagem de equações } \\
\text { estruturais (SEM) }\end{array}$ \\
\hline \multicolumn{1}{|c|}{ Objetivos específicos } & \multicolumn{1}{|c|}{ Técnica de análise dos dados } \\
\hline $\begin{array}{l}\text { - Identificar as razões primordiais pelas quais as empresas } \\
\text { constituem redes de inovação }\end{array}$ & $\bullet \quad$ Estatística descritiva \\
\hline $\begin{array}{l}2-\text { Hierarquizar os principais parceiros estabelecidos nas redes, } \\
\text { segundo seu grau de importância }\end{array}$ & $\bullet \quad$ Estatística descritiva \\
\hline $\begin{array}{l}3-\text { Mensurar os resultados das empresas em termos de inovação de } \\
\text { produto, processo, marketing e organizacional }\end{array}$ & $\begin{array}{l}\text { Análise fatorial confirmatória } \\
\text { (CFA) } \\
\text { Modelagem de } \\
\text { estruturais (SEM) }\end{array}$ \\
\hline $\begin{array}{l}4 \text { - Verificar qual a influência das variáveis moderadoras (tamanho da } \\
\text { organização, gasto com P\&D e origem do capital controlador) no } \\
\text { desempenho inovador. }\end{array}$ & $\begin{array}{l}\text { Análise multivariada de variância } \\
\text { (MANOVA) }\end{array}$ \\
\hline
\end{tabular}

Fonte: Elaborado pela autora

No que se refere à análise descritiva, vale salientar que algumas das questões são de respostas múltiplas com escala nominal e ordinal e, para análise das questões em escala nominal, foram construídos gráficos de frequências absolutas ou relativas. Já para análise das questões ordinais, foram elaboradas tabelas com base nas frequências relativas, além da construção de tabelas bivariadas. Para as variáveis quantitativas foram obtidos a média, mediana, desvio padrão, máximo e mínimo.

Os itens subsequentes descrevem as técnicas multivariadas empregadas na análise dos dados da pesquisa.

\subsubsection{Análise multivariada de variância}

A análise multivariada de variância (MANOVA) foi empregada para avaliar o efeito das variáveis moderadoras no desempenho inovador das organizações. Segundo Fávero et al. (2009), a MANOVA é um teste utilizado para verificar diferenças entre grupos, comportando mais de uma variável dependente simultaneamente. Trata-se, portanto, de uma técnica de dependência utilizada na comparação das diferenças de médias para duas ou mais variáveis dependentes métricas, com base em um conjunto de variáveis independentes categóricas. A 
MANOVA pode ser entendida como uma extensão da Análise da Variância (ANOVA) por apresentar um caráter multivariado.

A hipótese nula da MANOVA testa a igualdade de medidas considerando-se $k$ tratamentos e $p$ variáveis, sendo dada por:

$$
H_{0}: \underset{\sim}{\mu_{1}}=\mu_{\sim}=\cdots=\mu_{\sim} \quad \text { ou } \quad H_{0}:\left[\begin{array}{l}
\mu_{11} \\
\mu_{12} \\
\cdots \\
\mu_{1 p}
\end{array}\right]=\left[\begin{array}{l}
\mu_{21} \\
\mu_{22} \\
\cdots \\
\mu_{2 p}
\end{array}\right]=\cdots=\left[\begin{array}{l}
\mu_{k 1} \\
\mu_{k 2} \\
\cdots \\
\mu_{k p}
\end{array}\right]
$$

$H_{a}$ : Pelo menos dois tratamentos têm vetores de médias diferentes.

Testa-se, portanto, a hipótese nula de que todos os grupos apresentam vetores de médias iguais, em contrapartida à hipótese alternativa de que pelo menos dois grupos apresentam vetores de médias diferentes. Na MANOVA, há vários testes aplicáveis, sendo os mais utilizados o lambda de Wilks, o Traço de Pillai, o Traço de Hotelling-Lawley e a Maior Raiz de Roy, que, com exceção do último, se aproximam da distribuição F (FÁVERO et al., 2009).

Quando a hipótese $\mathrm{H}_{0}$ é rejeitada, isto é, quando os vetores de médias não são iguais, torna-se necessário um teste de médias para verificar quais vetores são diferentes entre si. Neste caso, foram utilizadas as comparações de Bonferroni.

Quanto aos parâmetros mínimos para aplicação da MANOVA, Hair et al. (2009) recomendam que o tamanho amostral seja de, no mínimo, 20 observações por grupo analisado e de que a amostra em cada célula da análise seja maior do que o número de variáveis dependentes incluídas.

Ainda quanto à aplicação da MANOVA, Fávero et al. (2009) ressaltaram as seguintes premissas:

- Independência das observações: quando as observações não são independentes, uma pode influenciar o resultado da outra, fato que pode prejudicar a análise dos dados e alterar seu nível de significância. Embora este seja um pressuposto básico da técnica, muitas situações práticas violam esta premissa. Deve-se, portanto, analisar o impacto da observância desta premissa no erro tipo I do estudo. 
- Distribuição normal multivariada das variáveis dependentes: esta premissa indica que qualquer combinação linear das variáveis dependentes deve seguir uma distribuição normal e todo subconjunto de variáveis deve apresentar distribuição normal multivariada. De acordo com Hair et al. (2009), não existe um teste direto para verificar a normalidade multivariada. Por esse motivo, os pesquisadores tendem a testar a normalidade univariada para cada variável, fato que, no entanto, não garante a normalidade multivariada dos dados. Apesar disso, segundo os autores, as violações dessa suposição, desde que não sejam provenientes de observações atípicas, têm pouco impacto em amostras de tamanho moderado.

- Igualdade das matrizes de variância-covariância para as variáveis dependentes: esta premissa supõe que as observações de cada grupo de estudo sejam provenientes de populações com a mesma variância-covariância para as variáveis dependentes. Vale ressaltar que os testes para verificação da homogeneidade da variância, como o M de Box, também pressupõe normalidade multivariada. Segundo Hair et al. (2009), a violação da suposição de não igualdade das matrizes tem um baixo impacto na análise se os grupos tiverem aproximadamente a mesma dimensão, ou seja, se a dimensão do maior grupo dividido pela dimensão do menor grupo for menor do que 1,5. Se os tamanhos diferirem mais do que isso, então se deve testar e corrigir as variâncias desiguais, se possível. Se as variâncias desiguais persistirem após a transformação e os tamanhos dos grupos diferirem bastante, devem ser feitos ajustes para os efeitos.

- Linearidade e multicolinearidade: além da condição de linearidade, as variáveis dependentes não devem ter multicolinearidade elevada, o que indicaria a existência de medidas dependentes redundantes, diminuindo assim a eficiência estatística.

Quanto aos testes da MANOVA, observa-se em Hair et al. (2009) que tanto o critério de Pillai, quanto o lambda de Wilks, são mais imunes às violações das suposições. Sugere-se ainda que o critério de Pillai é mais robusto e deve ser utilizado se o tamanho da amostra diminui, se diferentes tamanhos das células surgem ou se a homogeneidade de covariâncias é violada.

Vale ressaltar que o nível de significância fixado para todos os testes foi de 5\%. Assim, pelo p-valor obtido em cada teste, rejeitou-se a hipótese de igualdade dos grupos para p-valores menores do que 0,05 . 


\subsubsection{Modelagem de equações estruturais (SEM)}

A modelagem de equações estruturais (SEM) pode ser entendida como uma extensão de outras técnicas multivariadas, como a regressão múltipla e a análise fatorial. Ela é aplicada no exame de uma série de relações de dependência de forma simultânea, fornecendo bases para o teste de modelos que envolvem inter-relações de variáveis expressas em uma série de equações (HAIR et al., 2009).

Segundo Hair et al. (2009, p. 549),

a SEM é a única técnica multivariada que permite a estimação simultânea de múltiplas equações. Essas equações representam a maneira como construtos se relacionam com itens de indicadores medidos, bem como o modo como construtos se relacionam entre si.

A SEM se distingue das outras técnicas multivariadas justamente por possibilitar a estimativa de relações múltiplas e independentes, além de poder representar variáveis latentes ${ }^{2}$ nessas relações, considerando os erros de mensuração no processo de estimativa (HAIR et al., 2009). Em outras palavras, a SEM possibilita a estimativa dos erros dos parâmetros e permite expressar relações entre variáveis independentes e dependentes, inclusive quando uma variável dependente se torna independente em relações subsequentes. Neste sentido, a técnica pode ser vista como uma extensão da regressão múltipla, por possibilitar a previsão de mais de uma variável dependente (LEMKE, 2005). Além disso, existem dois tipos de variáveis em um modelo de SEM: variáveis endógenas e variáveis exógenas. Esta distinção é similar à feita entre variáveis dependentes (endógenas) e independentes (exógenas) da análise de regressão.

De acordo com Hair et al. (2009), a SEM compartilha três suposições com outros métodos multivariados: as observações independentes, a amostragem aleatória de respondentes e a linearidade de todas as relações. Além disso, a técnica é mais sensível às características de distribuição dos dados, particularmente ao desvio de normalidade multivariada ou a uma forte curtose dos dados.

Para aplicação da SEM, é necessária uma série de definições prévias, tais como a elaboração dos construtos (com pelo menos 3 a 4 itens), a determinação de quais variáveis influenciam

\footnotetext{
2 "Uma variável latente é um conceito teorizado e não observado que pode ser representado por variáveis observáveis ou mensuráveis" (HAIR et al., 2009, p. 470).
} 
outras e qual a direção dessa relação. Essas especificações são realizadas com base no referencial teórico acerca do tema e refletem as hipóteses do pesquisador, compondo o modelo a ser avaliado. Segundo Hair et al. (2009), o modelo da pesquisa é uma representação de uma teoria que, por sua vez, consiste em um conjunto sistemático de relações que fornecem uma explicação sobre os fenômenos. O modelo de análise de SEM pode ser decomposto em duas partes: o modelo de mensuração e o modelo estrutural.

O modelo de mensuração se refere à união das variáveis medidas para representar os construtos. Trata-se da ligação entre os escores de um instrumento de medida (as variáveis indicadoras observadas) com o construto teórico em estudo que foram designados para medir (variáveis não observadas). A validação do modelo de mensuração é realizada principalmente por meio da análise fatorial confirmatória. O processo se inicia com a especificação de um modelo fundamentado na teoria acerca do tema. Baseando-se em uma amostra representativa, a análise fatorial é usada para estabelecer quais indicadores parecem medir as variáveis latentes correspondentes, representados pelos fatores. O pesquisador só prossegue na análise quando o modelo de medida for validado. A tarefa primária no procedimento de teste do modelo é determinar quão bom ele é, utilizando o teste de aderência do modelo (goodness of fit) aos dados amostrais. Como não há ajuste perfeito, existe uma diferença entre o modelo especificado hipoteticamente e os dados amostrais, chamada resíduo (LEMKE, 2005).

Já o modelo estrutural tem por objetivo mostrar como os construtos ou variáveis estão associados entre si. Ele especifica como determinada variável latente causa (direta ou indiretamente) mudanças em outras variáveis latentes (LEMKE, 2005). O ajuste do modelo estrutural é realizado principalmente por meio da análise do diagrama de caminhos.

Segundo Hair et al. (2009), a análise de caminhos permite calcular a intensidade das relações entre as variáveis, por meio da utilização de uma matriz de correlação ou covariância como entrada. A análise de caminho pode ser estendida para qualquer sistema de relações tornando possível a análise de um conjunto de relações de maneira simultânea.

Quanto à aplicação da Modelagem de Equações Estruturais, Hair et al. (2009, p. 560-582) apontaram alguns estágios principais para seu desenvolvimento, expressos na Ilustração 14: 


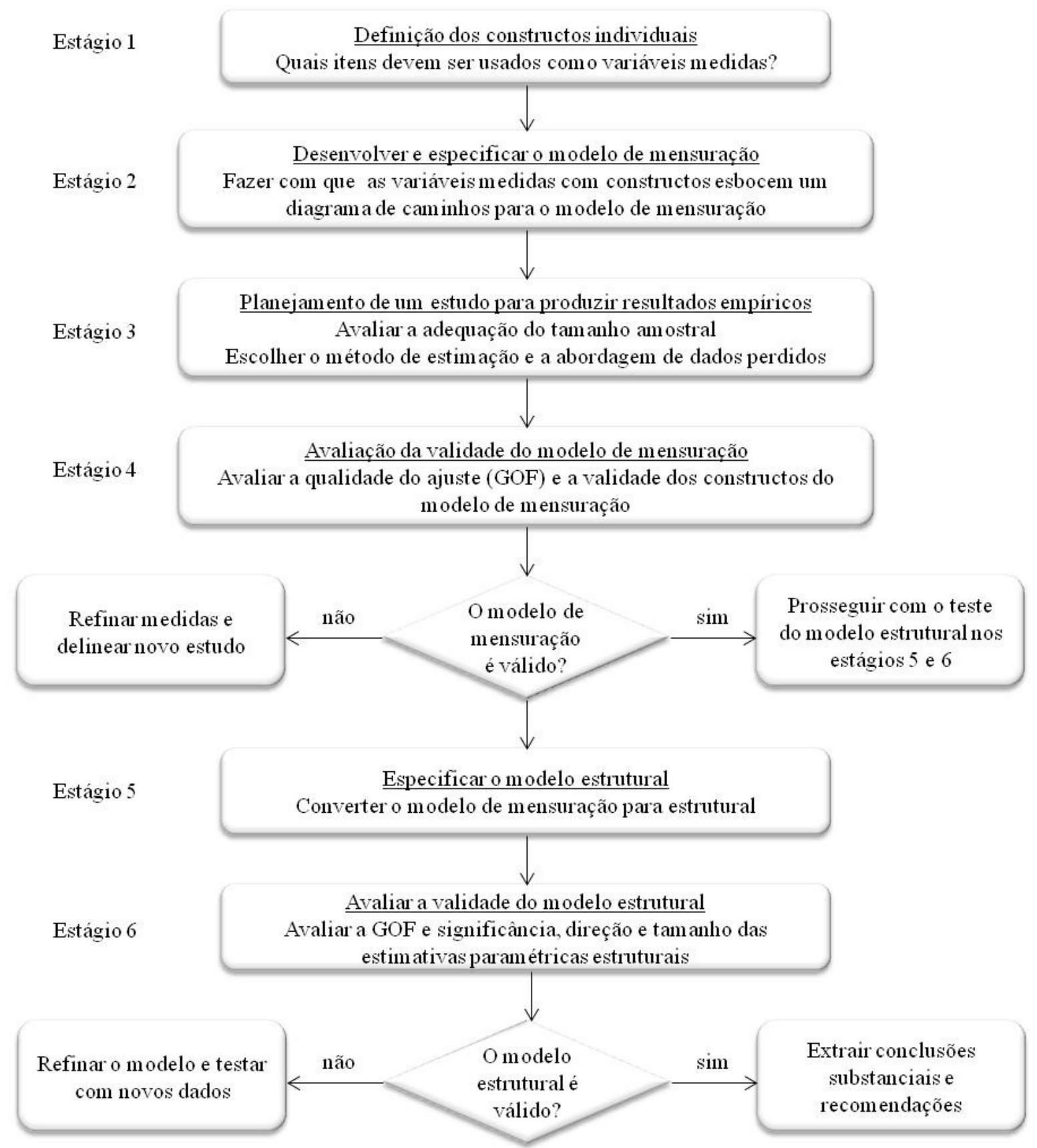

\section{Ilustração 14 - Processo de seis estágios para a Modelagem de Equações Estruturais Fonte: HAIR et al., 2009, p. 578.}

1. Definição de construtos individuais: trata-se da seleção dos itens para operacionalização dos construtos, por meio do referencial teórico. Esta etapa é bastante relevante, uma vez que serve de base para a fundamentação de todo o restante da análise SEM.

2. Desenvolvimento do modelo de mensuração geral: uma vez definidos os itens de escala, é necessário especificar o modelo de medição. Neste estágio, cada construto a 
ser incluído no modelo é identificado e as variáveis indicadoras medidas são designadas para construtos os latentes, geralmente por meio de um diagrama de caminhos.

3. Planejar um estudo para produzir resultados empíricos: esta etapa refere-se ao planejamento da pesquisa e da estimação do modelo.

a. No planejamento da pesquisa, são definidos os tipos de dados a serem analisados (covariâncias ou correlações), as decisões a serem tomadas com relação aos dados perdidos (missings) e o tamanho amostral. Uma questão importante na SEM refere-se à utilização da matriz de covariância ou da matriz de correlação. A utilização da matriz de covariância fornece comparações válidas entre diferentes populações e amostras, sendo indicada quando se pretende testar uma teoria. Já a matriz de correlação possibilita a realização de comparações diretas dos coeficientes dentro de um modelo. Seu uso é indicado quando o objetivo é apenas compreender o padrão de relações entre os construtos ao invés de procurar explicar a sua variância total. Quanto ao tratamento dos missings, Hair et al. (2009) afirmaram que, se os dados perdidos são aleatórios, representam menos de $10 \%$ das observações e as cargas fatoriais são relativamente elevadas $(0,7$ ou mais), bons resultados podem ser esperados por meio da abordagem de casos completos, da abordagem totalmente disponível e da atribuição baseada em modelos. No entanto, quando a quantia de dados perdidos representar mais de 25\% das observações, a SEM pode não ser adequada. Com relação ao tamanho amostral, geralmente a SEM requer uma amostra maior em comparação com outras técnicas multivariadas. Há cinco considerações que afetam o tamanho exigido para a amostra em SEM: a distribuição multivariada de dados, a técnica de estimação, a complexidade do modelo, a quantidade de dados perdidos e a quantia de variância média de erro entre os indicadores reflexivos. Hair et al. (2009) sugerem que modelos que contenham cinco construtos ou menos (cada um com mais de três itens) e com comunalidades elevadas ( 0,6 ou mais) podem ser estimados com amostras de 100 a 150 observações. Se as comunalidades forem entre $(0,45$ e 0,55$)$ ou se o modelo contiver construtos com menos de três itens, o tamanho exigido para a amostra é de 200 observações. Em outras condições, quando o número de fatores é maior do que seis e as comunalidades identificadas são baixas, as exigências de tamanho amostral podem exceder 500 observações. 
b. Para estimação do modelo, devem-se definir sua estrutura do modelo, as técnicas de estimação e o programa computacional a ser utilizado. A estrutura do modelo refere-se à determinação e à comunicação da estrutura do modelo para o programa a ser utilizado. Neste processo, emprega-se o diagrama de caminhos construído anteriormente e especificam-se os parâmetros a serem estimados. Uma vez estabelecido o modelo, o pesquisador deve escolher como o modelo será estimado, ou seja, qual algoritmo matemático será utilizado para identificar as estimativas para cada parâmetro livre. Dentre as diversas opções disponíveis, a estimação de máxima verossimilhança (MLE) é a técnica mais empregada em SEM, por ser mais eficiente e sem vieses na condição de normalidade multivariada. A técnica fornece resultados válidos com amostra de até 50 elementos, no entanto, Hair et al. (2009) recomendam uma amostra em torno de 200 observações. No entanto, a sensibilidade da técnica à não normalidade impulsionou o surgimento de outras técnicas de estimação alternativas, como os mínimos quadrados generalizados (GLS) e a estimação assintoticamente livre de distribuição (ADF). Quanto aos programas estatísticos disponíveis para executar a SEM, pode-se apontar para o LISREL (Linear Structural Relations) como o mais utilizado, além do EQS (abreviação de equações) e o AMOS (Análise de Estruturas de Momento). Por apresentar uma plataforma amigável e ser um módulo opcional do SPSS, o AMOS tem conquistado bastante popularidade ultimamente (HAIR et al., 2009).

4. Avaliar a validade do modelo de mensuração: este estágio consiste na avaliação da validade do modelo de mensuração que, por sua vez, depende da qualidade de ajuste para o mesmo. A qualidade do ajuste (GOF) indica o quão bem o modelo especificado reproduz a matriz de covariância/correlação entre os itens indicadores, ou seja, a similaridade entre as matrizes de covariância/correlação estimada e observada (HAIR et al., 2009). A avaliação do ajuste do modelo consiste em confrontar a teoria proposta pelo pesquisador com a realidade expressa pelos dados. Assim, se a teoria do pesquisador fosse perfeita, a matriz de covariância/correlação estimada e a matriz de covariância/correlação observada na amostra seriam iguais. Conclui-se, portanto, que, quanto mais próximos os valores dessas duas matrizes comparativamente, melhor é o ajuste do modelo. De acordo com Hair et al. (2009), o teste Qui-quadrado ( $\left.x^{2}\right)$ é a medida fundamental utilizada em SEM para quantificar as diferenças entre as matrizes de covariância/correlação observada e estimada. A hipótese nula do teste implica que 
as matrizes são iguais e, portanto, o modelo se ajusta perfeitamente. Assim, quanto menor o p-value, maior a chance de que as matrizes de covariância/correlação observadas na amostra e estimada por SEM não sejam iguais. Logo, almeja-se que o p-value no teste seja um número alto, fazendo com que a hipótese nula não seja rejeitada. Os autores ainda ressaltaram a existência de outras medidas alternativas ao GOF para avaliação da validade do modelo de mensuração, como índices absolutos (p.e. índice de qualidade de ajuste - GFI, raiz do resíduo quadrático médio padronizado - SRMR, raiz do erro quadrático médio de aproximação - RMSEA, etc); índices de ajuste incremental (p.e. índice de ajuste normado - NFI, índice de ajuste comparativo - CFI, índice de Tucker Lewis - TLI, etc); e índices de ajuste de parcimônia (p.e. índice de qualidade de ajuste de parcimônia - PGFI).

5. Especificar o modelo estrutural: este estágio refere-se à designação das relações de um construto com outro, representado no diagrama de caminhos com base no modelo teórico proposto. Em outras palavras, o desenvolvimento do modelo estrutural representa as hipóteses do modelo do pesquisador e tem por objetivo determinar as relações de dependência existentes entre as variáveis, seu tamanho e direção.

6. Avaliar a validade do modelo estrutural: o último estágio da SEM consiste no teste da validade do modelo estrutural, que só deve ser realizado após a validação do modelo de mensuração expresso no estágio 4. O ajuste do modelo estrutural pode ser avaliado usando os mesmos critérios do modelo de mensuração: por meio do teste Quiquadrado para o modelo estrutural, por outro índice absoluto (p.e. GFI, RMSEA), um índice incremental (p.e. CFI, TLI), um indicador de qualidade de ajuste (p.e. GFI, TLI) e um de má qualidade do ajuste (p.e. RMSEA). Para realização do teste, calculase uma nova matriz SEM de covariância/correlação estimada, diferente daquela do modelo de mensuração. Isso porque, no modelo de mensuração, assumem-se que todos os construtos são correlacionados entre si. No entanto, no modelo estrutural, as relações entre alguns construtos podem ser assumidas como sendo zero. Logo, para quase todos os modelos de SEM, a GOF de $x^{2}$ para o modelo de mensuração será menor do que a GOF de $x^{2}$ para o modelo estrutural. Hair et al. (2009) também ressaltaram a necessidade de exame das estimativas paramétricas individuais que representam cada hipótese específica. Dessa forma, um modelo teórico pode ser considerado válido quando as estimativas dos parâmetros forem estatisticamente significativas e na direção prevista, sendo também não triviais. É importante salientar que a qualidade do ajuste depende consideravelmente das características do modelo, 
incluindo sua complexidade e o tamanho amostral. Além disso, quando o ajuste não é satisfatório, Hair et al. (2009) ainda recomendaram que haja um refinamento no modelo, seja por meio de um delineamento de um novo estudo - no caso de invalidação do modelo de mensuração - ou da realização de testes com novos dados no caso de invalidação do modelo estrutural.

\subsubsection{Análise fatorial exploratória e confirmatória}

Considerando-se que a validação do modelo de mensuração, na modelagem de equações estruturais, é realizada principalmente por meio técnica de análise fatorial confirmatória, é importante definir suas características e pressupostos.

O principal objetivo da análise fatorial é explicar a covariância ou correlação entre muitas variáveis observadas por meio do relacionamento de poucas variáveis latentes subjacentes. A análise fatorial pode ser classificada como análise fatorial exploratória (EFA) e análise fatorial confirmatória (CFA).

A análise fatorial exploratória é uma técnica multivariada que identifica um número relativamente pequeno de fatores que podem ser usados para representar relações entre muitas variáveis que estão inter-relacionadas (HAIR et al., 2009). De acordo com Fávero et al. (2009, p. 235), a maior vantagem da EFA é permitir a simplificação de um grande número de dados, através da determinação das dimensões latentes, também conhecidos por fatores e, "como consequência, possibilitar ao pesquisador a criação de indicadores inicialmente não observáveis compostos do agrupamento de variáveis".

A característica que mais a distingue é a não exigência de especificação prévia de um modelo que relacione variáveis latentes às variáveis observadas. A EFA explora os dados e fornece ao pesquisador informação sobre quantos fatores são necessários para melhor representar os dados. Na EFA, todas as variáveis medidas são relacionadas com cada fator por uma estimativa de carga fatorial, ou seja, há uma carga para cada variável sobre cada fator. Os fatores são formados a partir dos resultados estatísticos, e não da teoria, fazendo com que a análise possa ser conduzida sem que se saiba quantos fatores realmente existem ou quais variáveis pertencem a quais construtos. Assim, os fatores somente podem ser nomeados 
depois que a análise fatorial é executada (HAIR et al., 2009). Em resumo, por meio da EFA, o pesquisador identifica variáveis ou fatores que explicam correlações dentro de um conjunto de variáveis. É um procedimento de redução da dimensão dos dados originais que visa identificar um pequeno número de fatores que explique a maior parte da variação observada de um número grande de variáveis (LEMKE, 2005).

Para que a utilização da análise fatorial exploratória seja adequada, é necessário que a matriz de correlações entre as variáveis apresente valores superiores a 0,30 e que a hipótese nula do teste de esfericidade de Bartlett, que indica que a matriz de correlação entre variáveis é igual à matriz identidade, seja rejeitada. Outra estatística importante para adequação da técnica é a de Kaiser-Meuer-Olkin (KMO), que deve ser maior do que 0,5, indicando que as correlações totais entre as variáveis são mais expressivas do que as correlações residuais. Semelhantemente à estatística do KMO, a Medida de Adequação da Amostra (MSA) fornece indícios sobre a necessidade de eliminação de determinada variável da análise. Assim, as variáveis que apresentarem valores de MSA inferiores a 0,5 devem ser excluídas do modelo (FÁVERO et al., 2009). Ressalta-se também que a porcentagem da variância de cada variável captada pelos fatores comuns (comunalidade) e a variância total explicada pelo modelo devem ser maiores do que 0,5. Com relação ao tamanho da amostra, Hair et al. (2009) indicaram a necessidade de pelo menos cinco vezes mais observações do que o número de variáveis a serem analisadas.

Já a análise fatorial confirmatória (CFA) "é utilizada para testar o quão bem as variáveis medidas representam um número menor de construtos" (HAIR et al., 2009, p.589). Diferentemente da EFA, na CFA, o pesquisador deve especificar o número de fatores que existem dentro de um conjunto de itens, uma vez que a técnica não designa variáveis a fatores. Segundo Lemke (2005), a CFA é apropriada quando já se possui alguma ideia sobre as variáveis latentes em estudo. Baseado no conhecimento teórico, resultados de pesquisas, ou até mesmo de ambos, o pesquisador postula as relações entre as variáveis medidas e os fatores, para então testar estatisticamente essa estrutura hipotética. Por meio do CFA, apenas as cargas que teoricamente conectam um item medido ao seu correspondente fator latente são calculadas, sendo que todas as demais são assumidas como nulas (HAIR et al., 2009). Sendo assim, a CFA é utilizada em SEM para testar o grau em que os fatores determinados pelo pesquisador representam os dados reais, sendo particularmente útil na validação de escalas de mensuração de construtos específicos. Assim, ao invés de permitir que o método estatístico 
determine o número de fatores e cargas, como em EFA, a estatística de CFA tem por objetivo avaliar o quão bem a especificação dos fatores combina com a realidade, fornecendo um teste confirmatório da teoria de mensuração. Segundo Hair et al. (2009), a habilidade para avaliar a validade de um construto de uma teoria de mensuração é uma das maiores vantagens de aplicação da CFA em SEM. Os autores entendem como 'validade de construto' o grau em que um conjunto de itens medidos realmente reflete o construto latente teórico que aqueles itens devem medir, ou seja, diz respeito ao fato de que ele está medindo o que se propôs a medir. A validade do construto na CFA é formada por quatro componentes importantes expressos no Quadro 17: a validade convergente (cargas fatoriais, variância extraída, confiabilidade); a validade discriminante; a validade nomológica e a validade de expressão.

\section{Quadro 17 - Validade do construto via CFA}

\begin{tabular}{|c|c|}
\hline Validade & Descrição \\
\hline \multirow{4}{*}{ Validade convergente } & $\begin{array}{l}\text { Os itens que são indicadores de um construto específico devem convergir ou } \\
\text { compartilhar uma elevada proporção de variância em comum. }\end{array}$ \\
\hline & $\begin{array}{l}\text { a. Cargas fatoriais: altas cargas indicam que elas convergem para algum ponto em } \\
\text { comum. O quadrado de uma carga fatorial padronizada representa o quanto da } \\
\text { variação é explicado por um fator latente. Assim, as estimativas de cargas } \\
\text { padronizadas devem ser de } 0,5 \text { ou mais e, idealmente, maiores ou iguais a } 0,7 \text {. }\end{array}$ \\
\hline & $\begin{array}{l}\text { b. Variância extraída (VE): é a carga fatorial quadrática média, que indica } \\
\text { convergência. A VE deve ser maior ou igual a 0,5 para sugerir uma validade } \\
\text { convergente adequada. Uma VE menor que } 0,5 \text { indica que, em média, mais erro } \\
\text { permanece nos itens do que a variância explicada pela estrutura fatorial latente } \\
\text { imposta sobre a medida. }\end{array}$ \\
\hline & $\begin{array}{l}\text { c. Confiabilidade: a elevada confiabilidade do construto indica a existência de } \\
\text { consistência interna, ou seja, que todas as medidas representam consistentemente o } \\
\text { mesmo construto latente. A confiabilidade do construto deve ser de igual ou maior } \\
\text { do que } 0,7 \text { para indicar uma convergência adequada ou a consistência interna. }\end{array}$ \\
\hline $\begin{array}{l}\text { Validade } \\
\text { discriminante }\end{array}$ & $\begin{array}{l}\text { É o grau em que um construto é verdadeiramente diferente dos demais. Logo, oferece } \\
\text { evidência de que um construto é único e captura alguns fenômenos que outras medidas } \\
\text { não conseguem. Para avaliar esta validade, comparam-se os percentuais de variância } \\
\text { extraída de dois construtos quaisquer com o quadrado da estimativa de correlação entre } \\
\text { tais construtos. As estimativas da variância extraída devem ser maiores do que a } \\
\text { estimativa quadrática de correlação. Esta avaliação está baseada na ideia de que um } \\
\text { construto latente deve explicar as medidas de seus itens melhor do que outro construto. } \\
\text { Em outras palavras, as estimativas da variância extraída para dois fatores também } \\
\text { devem ser maiores do que o quadrado da correlação entre os dois fatores, para fornecer } \\
\text { evidência de validade discriminante. }\end{array}$ \\
\hline Validade nomológica & Examina se as correlações entre os construtos na teoria de mensuração fazem sentido. \\
\hline Validade de expressão & $\begin{array}{l}\text { Refere-se a quanto o conteúdo dos itens é consistente com a definição do construto, } \\
\text { com base no julgamento do pesquisador, a partir da compreensão do mesmo sobre o } \\
\text { conteúdo analisado. }\end{array}$ \\
\hline
\end{tabular}

Fonte: Adaptado de Hair et al., 2009, p.591-608.

Vale ressaltar que, conforme exposto no Quadro 17, além da necessidade de análise da validade dos dados utilizados na SEM, é importante verificar sua confiabilidade, definida como a consistência da mensuração de um modelo. A análise da confiabilidade não garante 
que o modelo seja válido. Pelo contrário, a confiabilidade só pode ser aplicada se a validade dos indicadores for garantida. Dentre as várias formas de se estimar a confiabilidade das medidas, a mais utilizada e aceita é o Alpha de Cronbach.

\subsubsection{Considerações sobre a utilização da SEM neste trabalho}

Neste estudo, a técnica de modelagem de equação estruturais foi utilizada com o objetivo principal de descrever a relação entre o tipo de parceiro estabelecido na rede e os resultados da empresa em termos de inovação de produto, de processo, de marketing e organizacional, considerando-se também a capacidade de absorção do conhecimento das empresas e a estratégia de exploração ou explotação do conhecimento adotada por elas. A SEM admite o teste de todas as variáveis conjuntamente, de maneira a avaliar sua adequação ao modelo e permitir a confirmação ou rejeição das hipóteses propostas. Dessa forma, partindo da especificação de um modelo inicial, pretendeu-se, por meio da SEM, testá-lo e ajustá-lo da melhor maneira possível aos dados. Objetivou-se a construção de um modelo que não somente se ajustasse aos dados do ponto de vista estatístico, como também permitisse uma explicação lógica e aceitável sobre as relações detectadas.

Como não existiam missings (dados faltantes) no conjunto de dados utilizado na SEM, não foi necessária a realização de alterações nos dados.

Inicialmente, os construtos propostos no item 3.3 foram submetidos à Análise Fatorial Confirmatória (CFA) e também ao coeficiente Alfa de Cronbach para verificar sua consistência e a satisfação das condições da CFA.

Segundo Churchill Jr. (1999), o coeficiente Alfa de Cronbach deve ser a primeira medida a ser calculada para avaliar a qualidade do instrumento, dado que é a estatística básica para determinar a confiabilidade de uma medida baseada na consistência interna. 
O coeficiente alfa pode ser calculado por meio da seguinte fórmula,

$$
\alpha=\frac{k\left(\frac{\operatorname{cov}}{v a r}\right)}{1+(k-1)\left(\frac{\operatorname{cov}}{v a r}\right)}
$$

onde

$k=$ número de variáveis consideradas;

$c o v=$ média das covariâncias;

var = média das variâncias.

O valor assumido pelo Alfa de Cronbach está entre 0 e 1 e, quanto mais próximo de 1 estiver este valor, maior a fidedignidade das dimensões do construto.

Por meio dos resultados obtidos, verificou-se que alguns construtos apresentaram Alfa de Cronbach abaixo de 0,7 , indicando a necessidade de reavaliação dos mesmos. Para tanto, os dados foram submetidos à Análise Fatorial Exploratória (EFA) e, a partir da retirada de algumas variáveis e junção de outras, foi possível a determinação de novos construtos que atendiam aos pressupostos da técnica.

O Quadro 18 apresenta os novos construtos formados a partir da EFA e as abreviações utilizadas no software AMOS.

\section{Quadro 18 - Formação dos novos construtos}

\begin{tabular}{|l|l|}
\hline Novos construtos & Variáveis do construto \\
\hline Estratégia de explotação e exploração (EXPR_EXPT) & EXPR1, EXPR2, EXPT1, EXPT2 e EXPT3 \\
\hline Clientes e consumidores (CLIENT11) & CLIENT1*CLIENT2(1 - não, 2- sim) \\
\hline Fornecedores (FORNEC11) & FORNEC1*FORNEC2 $(1-$ não, $2-\operatorname{sim})$ \\
\hline Competidores (COMPET11) & COMPET1*COMPET2 $(1-$ não, $2-\operatorname{sim})$ \\
\hline Universidades e institutos de pesquisa (UNIVER11) & UNIVER1*UNIVER2(1 - não, 2 - sim) \\
\hline Inovação em produto e marketing (PROD_MKT) & $\begin{array}{l}\text { PROD1, PROD2, PROD5, PROD6, MKT1, MKT3 } \\
\text { e MKT5 }\end{array}$ \\
\hline Inovação em processo e organizacional (PROC_ORG) & $\begin{array}{l}\text { PROC1, PROC2, PROC3, PROC5, PROC6, } \\
\text { ORG1, ORG2, ORG3, ORG4, ORG5 e ORG6 }\end{array}$ \\
\hline Capacidade de absorção (ABS) & ABS1, ABS2, ABS3, ABS4, ABS5 e ABS6 \\
\hline
\end{tabular}


Por meio da aplicação da CFA, foi verificada a confiabilidade e a validade discriminante e convergente dos construtos. A confiabilidade indica se os itens utilizados medem um mesmo construto; a validade discriminante refere-se ao grau em que os fatores são distintos e não correlacionados, considerando-se que as variáveis devem se relacionar mais fortemente ao seu próprio fator do que a outro fator. Por fim, a validade convergente significa que as variáveis dentro de um único fator são altamente correlacionadas.

A confiabilidade foi verificada por meio do coeficiente Alfa de Cronbach e pelo coeficiente Composite Reliability (CR). Já a validade convergente foi verificada pelo Average Variance Extracted (AVE) e a validade discriminante por meio do AVE, Maximum Shared Squared Variance (MSV) e pelo Average Shared Squared Variance (ASV).

Vale ressaltar que os problemas de validade convergente indicam que as variáveis não se correlacionam bem umas com as outras dentro de um mesmo fator, ou seja, o fator latente não é bem explicado por suas variáveis observadas. Já os problemas de validade discriminante indicam que as variáveis se correlacionam mais fortemente com as variáveis fora do seu fator do que com as variáveis dentro, ou seja, o fator latente é mais bem explicado por outras variáveis (de um fator diferente), que por suas próprias variáveis observadas.

Considerando tais aspectos, Hair et al. (2009) sugerem os seguintes critérios para a validação do modelo:

a) Confiabilidade:

$$
\begin{aligned}
\text { i. } & \text { Alfa de Cronbach }>0,7 ; \\
\text { ii. } & C R>0,7 .
\end{aligned}
$$

b) Validade Convergente:

i. $\quad C R>(A V E)$;

ii. $\quad A V E>0,5$.

c) Validade Discriminante:

$$
\begin{aligned}
\text { i. } & M S V<A V E \\
\text { ii. } & A S V<A V E \\
\text { iii. } & \sqrt{A V E}>\text { Correlação entre o construto e os demais. }
\end{aligned}
$$


Com os fatores determinados e as condições descritas anteriormente satisfeitas, iniciou-se o processo de ajuste do modelo de equações estruturais (SEM). Para estimar os coeficientes, foi utilizado o método de máxima verossimilhança.

As relações entre os construtos foram avaliadas por meio de dois modelos. O primeiro envolve o desempenho inovador em produto e marketing e o segundo refere-se ao desempenho inovador em processo e organizacional. Essa separação foi realizada com o intuito de obter melhores ajustes do modelo. Sendo assim, as hipóteses testadas em cada um dos casos foram:

\section{Modelo 1 (PROD_MKT)}

- H1.1a A colaboração com clientes/consumidores está relacionada positivamente com o resultado em inovação de produto e marketing.

- H1.2a A colaboração com fornecedores está relacionada positivamente com o resultado em inovação de produto e marketing.

- H1.3a A colaboração com competidores está relacionada positivamente com o resultado em inovação de produto e marketing.

- H1.4a A colaboração com universidades e institutos de pesquisa está relacionada positivamente com o resultado em inovação de produto e marketing.

- H1.5a A utilização de estratégias de explotação e exploração do conhecimento está relacionada positivamente com o desenvolvimento de colaborações com clientes/consumidores.

- H1.6a A utilização de estratégias de explotação e exploração do conhecimento está relacionada positivamente com o desenvolvimento de colaborações com fornecedores.

- H1.7a A utilização de estratégias de exploração e explotação do conhecimento está relacionada positivamente com o desenvolvimento de colaborações com universidades e institutos pesquisa.

- H1.8a Quanto maior a capacidade de absorção do conhecimento apresentada pela empresa, maior seu resultado em inovação de produto e marketing.

Modelo 2 (PROC_ORG)

- H1.1b A colaboração com clientes/consumidores está relacionada positivamente com o resultado em inovação de processo e organizacional. 
- H1.2b A colaboração com fornecedores está relacionada positivamente com o resultado em inovação de processo e organizacional.

- H1.3b A colaboração com competidores está relacionada positivamente com o resultado em inovação de processo e organizacional.

- H1.4b A colaboração com universidades e institutos de pesquisa está relacionada positivamente com o resultado em inovação de processo e organizacional.

- H1.5b A utilização de estratégias de explotação e exploração do conhecimento está relacionada positivamente com o desenvolvimento de colaborações com clientes/consumidores.

- H1.6b A utilização de estratégias de explotação e exploração do conhecimento está relacionada positivamente com o desenvolvimento de colaborações com fornecedores.

- H1.7b A utilização de estratégias de exploração e explotação do conhecimento está relacionada positivamente com o desenvolvimento de colaborações com universidades e institutos pesquisa.

- H1.8b Quanto maior a capacidade de absorção do conhecimento apresentada pela empresa, maior seu resultado em inovação de processo e organizacional.

Para verificar os ajustes obtidos, foram utilizados alguns índices como: $\chi^{2} /$ d.f. (Cmin/d.f.), GFI, CFI, IFI, RMSEA e SRMR, expressos no Quadro 19.

Quadro 19 - Medidas de qualidade de ajuste e valores recomendados

\begin{tabular}{|l|l|}
\hline \multicolumn{1}{|c|}{ Medida } & \multicolumn{1}{c|}{ Valor aceitável } \\
\hline$\chi^{2} /$ d.f & Valores iguais ou menor a 5. \\
\hline Goodness of Fit Index (GFI) & $\begin{array}{l}\text { Varia de zero (ajuste nulo) a 1 (ajuste perfeito). } \\
>0,8 \text { ajuste marginal; }>0,9 \text { bom ajuste. }\end{array}$ \\
\hline $\begin{array}{l}\text { Root Mean Square Error of } \\
\text { Approximation (RMSEA) }\end{array}$ & Valores inferiores a $0,08$. \\
\hline $\begin{array}{l}\text { Standardized Root Mean Residuals } \\
\text { (SRMR) }\end{array}$ & Valores inferiores a 0,10. \\
\hline Comparative Fit Index (CFI) & $\begin{array}{l}\text { Varia de zero (ajuste nulo) a 1 (ajuste perfeito). } \\
>0,8 \text { ajuste marginal; }>0,9 \text { bom ajuste. }\end{array}$ \\
\hline Incremental Fit Index (IFI) & $\begin{array}{l}\text { Varia de zero (ajuste nulo) a 1 (ajuste perfeito). } \\
>0,8 \text { ajuste marginal; }>0,9 \text { bom ajuste. }\end{array}$ \\
\hline
\end{tabular}

Fonte: baseado em Hair et al. (2009) e Hu e Bentler (1999). 


\subsection{Limitações da pesquisa}

Uma das limitações da pesquisa reside na dificuldade de obtenção de respostas, uma vez que alguns dados perguntados no questionário podem ser considerados estratégicos, fazendo com que os respondentes fiquem receosos em revelá-los.

Outra dificuldade que pode representar limitações à pesquisa refere-se ao acesso do pesquisador às empresas selecionadas para coleta dos dados, fato que pode resultar em um alto índice de não-resposta.

Além disso, apesar do Manual de Oslo e outras fontes bibliográficas utilizadas neste estudo fornecerem um conjunto robusto de diretrizes que podem ser utilizadas na produção de indicadores significativos, a complexidade inerente ao processo de inovação em si dificulta o estabelecimento de métricas totalmente precisas.

Considerando-se que a inovação é um processo contínuo, o estabelecimento de um período de análise ideal para mensuração de seus resultados também é um fator limitador para o estudo. Isso porque, os efeitos decorrentes de ações voltadas para a inovação, como a constituição de redes, por exemplo, pode provocar resultados futuros, no longo prazo, ainda não identificados no período de análise da pesquisa. Visando minimizar essa limitação, as perguntas sobre as atividades inovativas das empresas contemplaram as ações nos últimos 3 anos, conforme o estabelecido pelo Manual de Oslo (OCDE, 2005).

Vale ressaltar que, apesar do estudo propor a elaboração de um modelo conceitual, a utilização da técnica de modelagem de equações estruturais não possibilita sua validação para posterior replicação. Dessa forma, o modelo elaborado teve como finalidade o alcance dos objetivos da pesquisa, não podendo ser replicado a outros setores e/ou conjunturas sem a realização de novos estudos.

Outra limitação se refere à realização de uma amostragem não probabilística que, apesar de facilitar os processos de coleta de dados, permitindo a obtenção de um número maior de observações para a execução de análises multivariadas, faz com que seus resultados não possam ser generalizados para a população de interesse. 
Finalmente, é necessário salientar que a pesquisa se baseia na opinião de executivos das empresas participantes quantos aos fatores relacionados à rede de inovação. Logo, tratam-se de percepções acerca da realidade da organização, que podem apresentar certo viés. Com o intuito de mitigar essa limitação, as perguntas no questionário foram elaboradas de forma bastante objetiva, contendo explicações claras, de forma a minimizar a incorporação desses vieses e evitar possíveis erros de interpretação / compreensão das questões. 


\section{APRESENTAÇÃO E ANÁLISE DOS RESULTADOS DA PESQUISA}

Este capítulo tem por objetivo apresentar os principais resultados provenientes da pesquisa de campo, bem como discuti-los à luz da teoria. Primeiramente, são feitas considerações acerca da Indústria Elétrica Eletrônica, baseadas em pesquisas de dados secundários e informativos do setor. Na sequência, a amostra da pesquisa é caracterizada e, por fim, são realizadas as análises descritivas e multivariadas dos dados primários, visando atingir aos objetivos estabelecidos na pesquisa.

\subsection{A Indústria Elétrica Eletrônica Brasileira}

A Indústria Elétrica Eletrônica ocupa um lugar proeminente na economia nacional, sendo um dos setores mais priorizados pela política de desenvolvimento industrial, que visa incentivar a modernização das empresas, de forma a propiciar a inovação e a melhoria da competitividade. Sua relevância se deve ao intenso efeito multiplicador sobre a economia, por condicionar as operações e a eficiência de outros setores (MACEDO et al., 2009).

A Indústria é composta pelos seguintes segmentos: automação industrial; comércio eletrônico; componentes elétricos e eletrônicos; equipamentos de segurança eletrônica; equipamentos industriais; geração, transmissão e distribuição de energia; informática; material elétrico de instalação; responsabilidade socioambiental; serviço de manufatura em eletrônica; telecomunicações e utilidades domésticas (ABINEE, 2012). Por abranger diversas atividades, esta indústria é de extrema importância para a economia brasileira.

A maioria das organizações do setor está concentrada na região Sudeste, sendo que 51,2\% destas empresas estão localizadas em São Paulo, 9,5\% em Minas Gerais, 4,3\% no Rio de Janeiro e 0,9\% no Espírito Santo [Gráfico 1]. Na região Sul destaca-se o Rio Grande do Sul com 8,6\%, seguido do Paraná com 7,6\% e Santa Catarina com 5,4\%. Na região Norte, o estado do Amazonas representa 3,6\% das empresas, na região Nordeste, os estados da Bahia e Pernambuco possuem $2,2 \%$ e $1,6 \%$ das organizações do setor, respectivamente, e na região Centro-Oeste destaca-se o estado de Goiás, com 1,1\%. Os demais estados concentram apenas $4,0 \%$ das empresas do setor. 


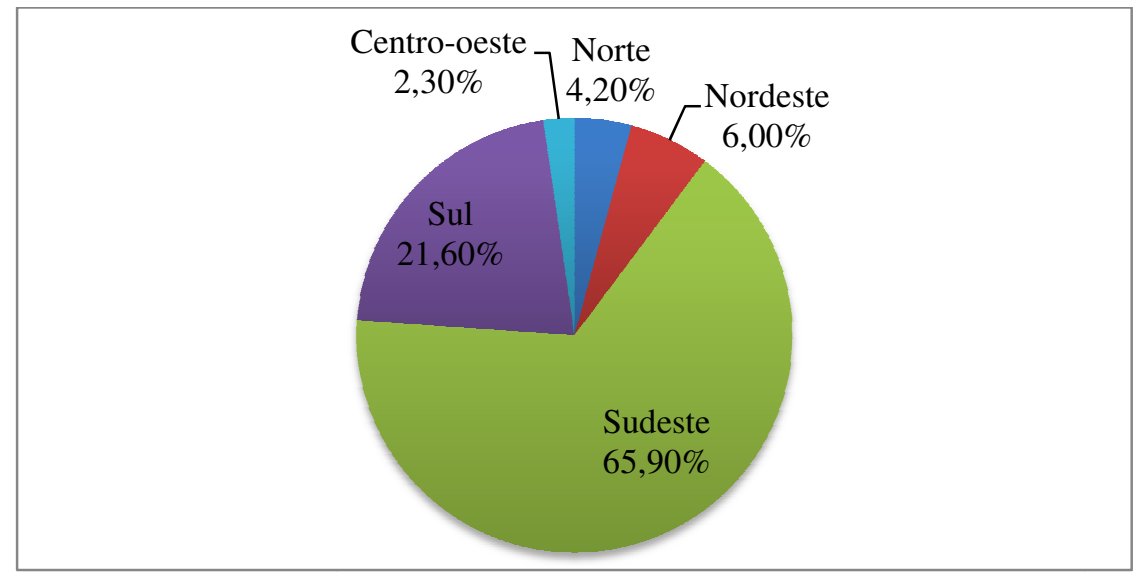

Gráfico 1 - Distribuição geográfica das organizações do Setor Elétrico Eletrônico Fonte: Elaborado pela autora com base na Pesquisa Industrial Anual (PIA) (IBGE, 2012).

A Indústria Elétrica Eletrônica vem experimentando forte dinamismo, representado por um faturamento de $\mathrm{R} \$ 145$ bilhões em 2012, o que significou um acréscimo de 5\% em relação a 2011. A Tabela 2 apresenta o faturamento total da indústria em 2012, a projeção para 2013e o percentual de variação, para os principais segmentos que a compõe (ABINEE, 2013).

Tabela 2 - Faturamento total por segmentos da Indústria Elétrica Eletrônica

\begin{tabular}{l|c|c|c}
\hline $\begin{array}{c}\text { Projeções para Faturamento Total por Área } \\
\text { (R\$ milhões a preços correntes) }\end{array}$ & $\mathbf{2 0 1 2}$ & $\mathbf{2 0 1 3}$ & $\mathbf{2 0 1 3} \times \mathbf{2 0 1 2}$ \\
\hline Automação Industrial & 4.024 & 4.507 & $12 \%$ \\
\hline Componentes Elétricos e Eletrônicos & 9.991 & 10.590 & $6 \%$ \\
\hline Equipamentos Industriais & 22.979 & 25.736 & $12 \%$ \\
\hline Geração, Transmissão e Distribuição & 15.454 & 16.999 & $10 \%$ \\
\hline Informática & 43.561 & 45.739 & $5 \%$ \\
\hline Material Elétrico de Instalação & 9.364 & 9.739 & $4 \%$ \\
\hline Telecomunicações & 22.687 & 24.275 & $7 \%$ \\
\hline Utilidades Domésticas Eletroeletrônicas & 17.390 & 19.129 & $10 \%$ \\
\hline \multicolumn{1}{c|}{ Total } & $\mathbf{1 4 5 . 4 5 0}$ & $\mathbf{1 5 6 . 7 1 4}$ & $\mathbf{8 \%}$ \\
\hline
\end{tabular}

* projeção

Fonte: ABINEE, 2013.

Apesar das boas perspectivas para o setor, é preciso frisar que uma parcela relevante do consumo doméstico dos produtos elétricos e eletrônicos é abastecida pela produção internacional. Segundo Macedo et al. (2009, p. 19),

a indústria e o consumo doméstico vêm crescendo baseados no aumento da importação de componentes e de bens finais, e na redução do valor agregado localmente. Com efeito, as importações de produtos elétricos e eletrônicos são muito elevadas, com destaque para o segmento de componentes, que se configura como uma lacuna sensível da malha produtiva doméstica. 
Tal fato faz com que o setor elétrico e eletrônico exiba um elevado déficit em sua balança comercial, o que ressalta a necessidade da internalização da produção de alguns segmentos de componentes, não apenas com o objetivo de reduzir o elevado déficit, como também para criar condições mais favoráveis para o avanço tecnológico da indústria brasileira e para ampliar e qualificar a inserção do país no mercado internacional.

A Tabela 3 apresenta os principais indicadores da Indústria Elétrica e Eletrônica nos últimos anos, dentre eles o déficit comercial setorial que, no ano de 2012, foi de 33,4 bilhões de dólares. Outro dado relevante, apresentado na Tabela 3, refere-se aos investimentos realizados no ano de 2012 no setor ( $\mathrm{R} \$ 4,1$ bilhões), que correspondem a 2,8\% de seu faturamento no ano, representando uma queda de 7\% em relação a 2011. Tal queda é justificada, segundo a ABINEE (2013), pelas apreensões em relação à crise internacional e pelas dificuldades competitivas do setor produtivo brasileiro, decorrentes do 'custo Brasil'.

Tabela 3 - Principais indicadores da Indústria Elétrica Eletrônica

\begin{tabular}{|c|c|c|c|c|c|c|}
\hline Principais Indicadores & 2010 & 2011 & 2012 & 2013* & $\frac{2012}{2011}$ & $\frac{2013 *}{2012}$ \\
\hline Faturamento ( $\mathrm{R} \$$ bilhões) & 124,4 & 138,1 & 145,5 & 156,7 & $5 \%$ & $8 \%$ \\
\hline Faturamento (US\$ bilhões) & 70,7 & 82,5 & 74,5 & 75,6 & $-10 \%$ & $1 \%$ \\
\hline Numero de Empregados (mil) & 174,7 & 180,3 & 183,0 & 187,0 & $1 \%$ & $2 \%$ \\
\hline Exportações (US\$ milhões) $(* *)$ & 7.723 & 8.198 & 7.780 & 8.100 & $-5 \%$ & $4 \%$ \\
\hline Importações (US\$ milhões) $(* *)$ & 35.836 & 40.742 & 41.200 & 43.600 & $1 \%$ & $6 \%$ \\
\hline Déficit Comercial Setorial (US\$ milhões) $(* *)$ & -28.113 & -32.544 & -33.420 & -35.500 & $3 \%$ & $6 \%$ \\
\hline Investimentos ( $\mathrm{R}$ \$ milhões) & 3.560 & 4.380 & 4.058 & 4.616 & $-7 \%$ & $14 \%$ \\
\hline Investimentos (\% do Faturamento) & $2,9 \%$ & $3,2 \%$ & $2,8 \%$ & $2,9 \%$ & - & - \\
\hline $\begin{array}{l}\text { Faturamento por Empregado } \\
(\mathrm{R} \$ \text { mil) }\end{array}$ & 712,0 & 766,2 & 794,8 & 838,0 & $4 \%$ & $5 \%$ \\
\hline $\begin{array}{l}\text { Correspondência do Faturamento em relação ao } \\
\text { PIB }(\%)\end{array}$ & 3,3 & 3,3 & 3,3 & 3,2 & $-1 \%$ & $-2 \%$ \\
\hline Participação das Exportações no faturamento (\%) & 10,9 & 9,9 & 10,4 & 10,7 & $5 \%$ & $3 \%$ \\
\hline $\begin{array}{l}\text { Participação das Exportações do Setor no Total das } \\
\text { Exportações do País (\%) }\end{array}$ & 3,8 & 3,2 & 3,2 & 3,1 & $0 \%$ & $-3 \%$ \\
\hline $\begin{array}{l}\text { Participação das Importações do Setor no Total das } \\
\text { Importações do País (\%) }\end{array}$ & 19,7 & 18,0 & 18,3 & 18,1 & $1 \%$ & $-1 \%$ \\
\hline
\end{tabular}

Fonte: ABINEE, 2013.

Além do alto déficit comercial e da diminuição dos investimentos, outros fatores também podem ser apontados como obstáculos ao desenvolvimento da indústria, tais como a insuficiência de mão de obra qualificada; a limitada disponibilidade e dificuldade de acesso 
aos financiamentos para empresas de menor porte; e a instabilidade do ambiente de negócios. Ademais, questões relacionadas à logística e à morosidade nos processos aduaneiros também comprometem o desenvolvimento da indústria local, por dificultar a atuação mais intensa no mercado internacional (ABINEE, 2012).

Apesar desses obstáculos, há importantes fatores capazes de conferir oportunidades de desenvolvimento à indústria nacional. $\mathrm{O}$ primeiro fator se refere ao tamanho, diversidade e potencial de crescimento do mercado brasileiro, fato que favorece a criação de novos produtos e a expansão dos mercados existentes. Aliados a esse fator, a expansão da renda, da produção, dos investimentos e da construção civil também deverão manter a demanda relativamente aquecida nos próximos anos. O segundo fator importante é a possibilidade de inovação tecnológica, com destaque para o processo de convergência tecnológica, que pode promover a integração de diversos equipamentos e provocar o crescimento da demanda, sobretudo por produtos eletrônicos. A crescente introdução da eletrônica nos aparelhos elétricos, que se modernizam acumulando funções, bem como o crescimento da eletrônica embarcada em diferentes setores industriais, em particular para a indústria automobilística, também podem ampliar a demanda por componentes, constituindo-se como estímulos importantes para o desenvolvimento do setor. Este fator, conjugado ao crescimento da importância dos softwares e à ampliação dos serviços, permitem maior diferenciação de produto e agregação de valor, e podem beneficiar todos os segmentos da indústria elétrica e eletrônica (ABINEE, 2012). Vale ressaltar também a instituição das Leis $n^{\circ} 10.176 / 01$ e 11.077/04, popularmente conhecidas como Lei da Informática, que propõe a diminuição do Imposto sobre Produtos Industrializados (IPI) pago pelas empresas desenvolvedoras de bens de informática e de equipamentos de telecomunicações, mediante o investimento de no mínimo $4 \%$ de seu faturamento em atividades de Pesquisa e Desenvolvimento de Produtos. Ademais, as políticas governamentais de fomento ao investimento, principalmente em infraestrutura, como o Plano de Aceleração do Crescimento (PAC) e o programa de Inclusão Digital, potencializam as oportunidades já geradas pelo tamanho, pela diversidade e pelo potencial de crescimento do mercado brasileiro (MACEDO et al., 2009).

Visando alcançar maior autonomia tecnológica e competitividade no mercado internacional, a Associação Brasileira da Indústria Elétrica e Eletrônica (ABINEE) encomendou um estudo, intitulado "O setor elétrico e eletrônico em 2020: uma estratégia de desenvolvimento" que, a 
partir de uma visão estrutural, desenvolveu planos estratégicos para nortear a construção da indústria desejável para os próximos anos. Dentre os objetivos estipulados estão:

- Alcançar uma indústria que, em 2020, será mais autônoma tecnologicamente - o que inclui sobretudo, mas não exclusivamente, o domínio da tecnologia de convergência digital;

- Consolidar o Brasil como um competidor efetivo no mercado externo, o que estará, em parte, relacionado à internalização de uma indústria de componentes adequada, em dimensão e em composição setorial, para prover competitividade global à indústria brasileira;

- Alavancar o faturamento das empresas instaladas no Brasil, para que alcance $7 \%$ do PIB em 2020 (MACEDO et al., 2009).

Para que essa trajetória seja alcançada, o segmento de componentes deve ser expandido, de forma a desacelerar as importações e dinamizar as exportações, movimentos que resultarão em taxas médias de crescimento da produção doméstica em torno de $15 \%$ a.a. até 2020 . No entanto, a maior dificuldade para o desenvolvimento do segmento de componentes está associada à grande intensidade tecnológica e de capital, o que demanda operação em larga escala. Isso porque a demanda local por componentes não confere escala produtiva suficiente e o mercado externo já possui uma concorrência bastante acirrada, baseada em empresas que operam na fronteira tecnológica. Portanto, para reverter esta situação, é necessário contemplar a instalação de uma indústria doméstica que esteja atualizada tecnologicamente e já disponha de uma capacidade competitiva forte. Tal fato exige coordenação de políticas entre a indústria, seus fornecedores e compradores em âmbito internacional, aliada a uma intensa estratégia de inovação das empresas (MACEDO et al., 2009).

Outro segmento-chave que deverá liderar o desenvolvimento da Indústria Elétrica e Eletrônica é o das Tecnologias da Informação e Comunicação (TICs). Segundo Marcedo et al. (2009), até 2020, o Brasil deverá dominar a tecnologia da convergência digital, o que permitirá que as inovações continuem sustentando o dinamismo do setor de TICs como um todo, evitando a saturação do mercado.

Para a área elétrica, a perspectiva também é de forte crescimento, intensificado principalmente pelo aumento da demanda interna e pelos planos de investimentos do governo, especialmente nas áreas de energia elétrica e construção civil, além dos investimentos nas 
atividades petrolíferas previstos para os próximos anos. Para Macedo et al. (2009), como a indústria local já dispõe de razoável competitividade global neste segmento, o Brasil apresentará condições de se consolidar como um importante player no mercado internacional. Nesse contexto, impulsionado tanto pela demanda interna quanto pela externa, a perspectiva é que a indústria elétrica local apresente crescimento a taxas também elevadas, entre $6 \%$ e $9 \%$ ao ano.

Como resultado do estudo realizado a pedido da ABINEE, foi desenvolvido um plano estratégico de desenvolvimento que envolve o aprimoramento das políticas de incentivos já existentes, bem como a utilização de novos instrumentos que devem ser criados com vistas a superar os principais obstáculos e aproveitar plenamente as oportunidades existentes no setor eletroeletrônico. Esses instrumentos abrangem políticas estruturantes, em seu eixo principal, e políticas complementares, apresentadas na Ilustração 15.

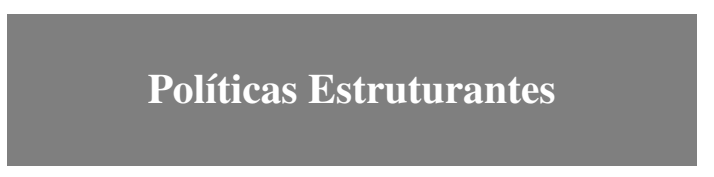

- Governança: postura estratégica do governo

-P\&D: Agenda de Estratégia de Inovação para a Indústria Elétrica e Eletrônica

-PADIC: desenvolvimento da indústria doméstica de componentes

• Consolidação no mercado internacional

\section{Políticas complementares}

-Logística: investimento em infra-estrutura

-Disponibilidade e acesso ao crédito para empresas de menor porte

-Aperfeiçoamento dos mecanismos tributários

- Flexibilização do marco regulatório

- Utilizar poder de compra do governo

\section{Ilustração 15 - Políticas estruturantes e complementares para a Indústria Elétrica Eletrônica} Fonte: MACEDO et al., 2009, p.14.

As políticas estruturantes constituem o núcleo prioritário de medidas necessárias para a construção de uma nova trajetória de desenvolvimento da Indústria Elétrica e Eletrônica até 2020. Dentre os principais aspectos a serem desenvolvidos pode-se citar a criação de uma nova estrutura de governança do setor público, para a coordenação e a elaboração de políticas estratégicas para o setor de forma a permitir a centralização da interlocução entre agentes privados e públicos para as questões relevantes da Indústria. Segundo Macedo et al. (2009, p. 15), dentre as ações e objetivos estaria incluída "a instituição de um programa nacional de 
capacitação e qualificação de recursos humanos para a atuação no setor", já que a carência de recursos humanos pode ser destacada como um problema de todos os segmentos da Indústria Elétrica e Eletrônica brasileira.

Outro fator crucial refere-se à disponibilidade de recursos para investimentos em $\mathrm{P} \& \mathrm{D}$, para que a Indústria nacional consiga dominar, sobretudo, as tecnologias de convergência digital. Mais do que a disponibilidade de recursos, contudo, é necessária a construção de uma Agenda Estratégica de Inovação, para eleição das prioridades no setor, bem como para direcionar a aplicação de recursos provenientes dos instrumentos de incentivos já existentes em $P \& D$ (MACEDO et al., 2009).

Além disso, a estruturação de uma indústria de componentes competitiva internacionalmente é imprescindível para uma maior autonomia tecnológica. Para atingir essa meta, o estudo propõe a instituição do Programa de Apoio ao Desenvolvimento Tecnológico da Indústria de Componentes (PADIC), responsável por criar condições favoráveis à produção local de componentes, em padrão competitivo internacionalmente, por meio da isenção do IPI, PIS, PASEP, COFINS, inclusive para importação de insumos e maquinário, obrigando as empresas a direcionarem $2 \%$ de seu faturamento para investimento em P\&D.

Por fim, outra medida importante para intensificar o desenvolvimento do setor refere-se à consolidação do Brasil como concorrente efetivo no mercado internacional por meio de ações como a melhoria do processo aduaneiro nos portos e aeroportos, a ampliação de acordos comerciais, a promoção do produto brasileiro nos mercados internacionais, dentre outras (MACEDO et al., 2009).

Para superar alguns obstáculos estratégicos para o crescimento do setor, Macedo et al. (2009) também ressaltaram a necessidade de execução de algumas políticas complementares, tais como:

- a melhoria da infraestrutura e condições logísticas;

- o aprimoramento da estrutura de financiamento do setor por meio, principalmente, do estabelecimento de condições de financiamento pelas entidades competentes, como o BNDES/FINAME, além da ampliação da disponibilidade e do acesso ao crédito, especialmente para as empresas de menor porte; 
- o aperfeiçoamento dos mecanismos tributários, destacando-se as medidas que impeçam o acúmulo de crédito de ICMS, que representa um problema especialmente para as empresas de bens de capital sob encomenda;

- a atualização do marco regulatório de telecomunicações, para viabilizar o aproveitamento das oportunidades abertas pela convergência tecnológica; e

- o direcionamento do poder de compra do governo para potencializar a demanda interna de todos os produtos que compõem a Indústria Elétrica e Eletrônica.

Segundo a ABINEE (2012), a implementação dessa estratégia de desenvolvimento da Indústria Elétrica e Eletrônica é crucial para o alcance de uma maior autonomia tecnológica e para o aumento do valor agregado pela indústria local, corroborando para a elevação de seu valor estratégico no desenvolvimento nacional.

A partir desta breve análise, pode-se inferir que a Indústria Elétrica e Eletrônica é de extrema importância para a economia nacional, servindo de base para o aprimoramento dos processos de produção e desenvolvimento de novos produtos em diversos segmentos. Em outras palavras, é possível dizer que o setor eletroeletrônico influencia as operações e a eficiência de outros segmentos da economia, além de gerar, diretamente, oportunidades de emprego para mão de obra qualificada.

Sendo assim, é necessário que esta Indústria não continue somente crescendo de forma intensa, mas também que desenvolva uma maior autonomia tecnológica, passando a competir internacionalmente. Para tanto, o governo deve canalizar recursos e esforços para implementar uma estratégia de desenvolvimento efetiva, fato que demanda elevada coordenação e cooperação entre diversos atores, de forma a promover a inovação e competitividade para as empresas do setor.

\subsubsection{Inovação na Indústria Elétrica Eletrônica}

Com relação às atividades inovativas na Indústria, alguns dados podem ser extraídos da Pesquisa de Inovação Tecnológica (PINTEC 2008), divulgada pelo IBGE em 2010. O estudo baseou-se em uma amostra de 106.863 empresas industriais de todo o Brasil, das quais 3.404 pertenciam ao setor eletroeletrônico. 
A análise dos dados destas 3.404 empresas mostra que 50,7\% implementaram algum tipo de inovação de produto e/ou processo no período de 2006 a 2008 (IBGE, 2010). Com relação às inovações organizacionais e de marketing, esse número cai para $24,9 \%$, conforme expresso na Tabela 4.

Tabela 4 - Proporção de empresas que implementaram inovações

\begin{tabular}{c|c|c}
\hline & $\mathrm{N}^{\circ}$ de empresas & Porcentagem do total \\
\hline Inovação de produto e/ou processo & 1727 & $50,7 \%$ \\
\hline Inovação organizacional e/ou de marketing & 849 & $24,9 \%$ \\
\hline
\end{tabular}

Fonte: Elaborado pela autora com base na PINTEC 2008 (IBGE, 2010).

Ainda segundo a PINTEC (IBGE, 2010), a média percentual da receita líquida despendida em atividades de P\&D no setor é de aproximadamente 3\%. Apesar de ser um investimento considerável, alguns setores apresentam percentuais superiores, como o de fabricação de equipamentos de transporte $(5,09 \%)$ e de produtos farmoquímicos e farmacêuticos $(4,20 \%)$.

Outro aspecto importante refere-se ao principal responsável pelo desenvolvimento de novos produtos. Conforme apresentado no Gráfico 2, a inovação em produto no setor Elétrico Eletrônico está concentrada, em sua maioria (87\%), na própria empresa.

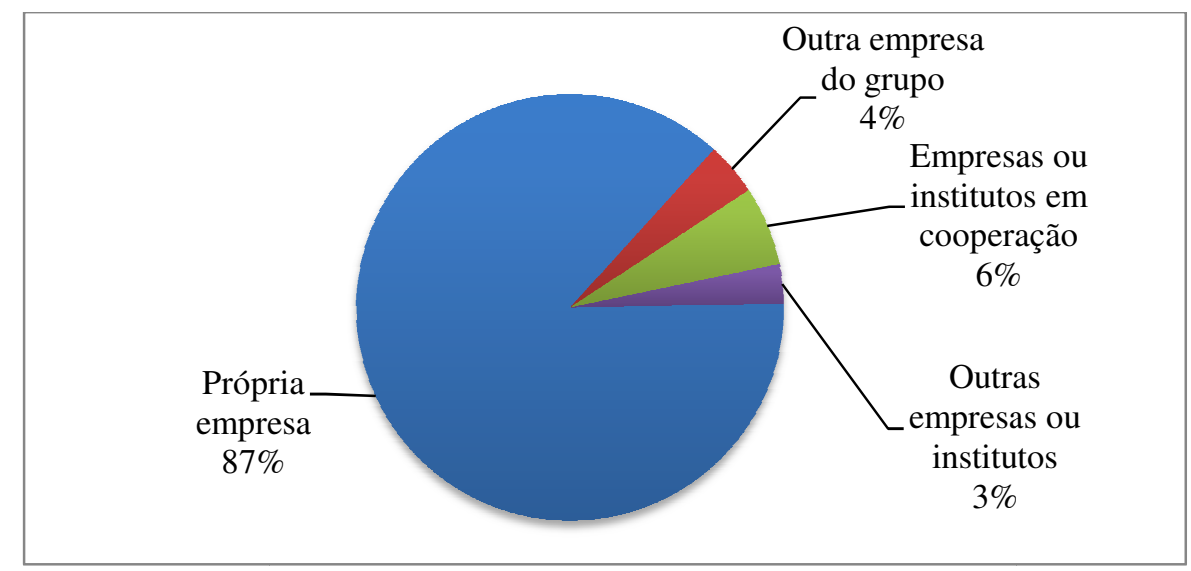

Gráfico 2 - Principal responsável pelo desenvolvimento de inovações em produto Fonte: Elaborado pela autora com base na PINTEC 2008 (IBGE, 2010).

A PINTEC (IBGE, 2010) também abordou a importância de diferentes atividades para o desenvolvimento das inovações, tais como: atividades internas de $\mathrm{P} \& \mathrm{D}$, aquisição externa de 
$\mathrm{P} \& \mathrm{D}$, aquisição de outros conhecimentos externos, aquisição de software, aquisição de máquinas e equipamentos, treinamento, introdução das inovações tecnológicas no mercado e projeto industrial e outras preparações técnicas. A importância de cada atividade foi avaliada por meio de uma escala composta pelos pesos 3 (grau alto), 2 (grau médio), 1 (grau baixo) e 0 (não realizou a atividade).

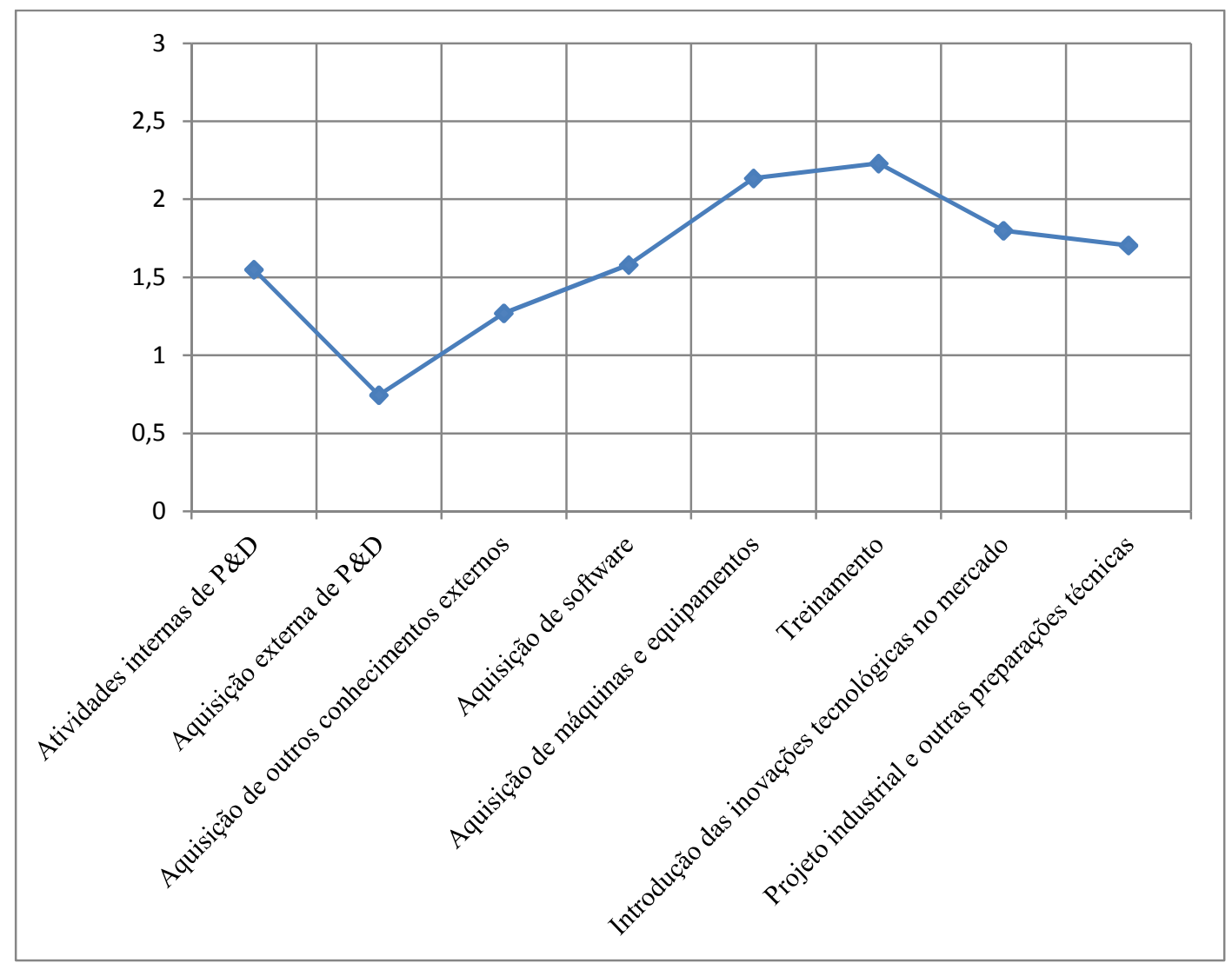

Gráfico 3 - Grau de importância das atividades no desenvolvimento de inovação Fonte: Elaborado pela autora com base na PINTEC 2008 (IBGE, 2010).

De acordo com o Gráfico 3, percebe-se que as principais atividades inovadoras desenvolvidas pelas empresas do setor eletroeletrônico, segundo o grau médio de importância atribuída, são o treinamento e a aquisição de máquinas e equipamentos.

Verificou-se também, a partir da pesquisa, o grau de importância referente ao impacto causado pela realização de inovações nas empresas [Gráfico 4]. Para tanto, foi utilizada a escala supracitada frente aos seguintes efeitos percebidos: melhoria na qualidade dos bens ou serviços, ampliação da gama de bens ou serviços ofertados, manutenção da participação da empresa no mercado, ampliação da participação da empresa no mercado, abertura de novos 
mercados, aumento da capacidade produtiva, aumento da flexibilidade da produção, redução dos custos de produção, redução dos custos do trabalho, redução do consumo de matériasprimas, redução do consumo de energia, redução do consumo de água, redução do impacto sobre o meio ambiente, ampliação do controle ligado à saúde e segurança e enquadramento em regulações e normas padrão.

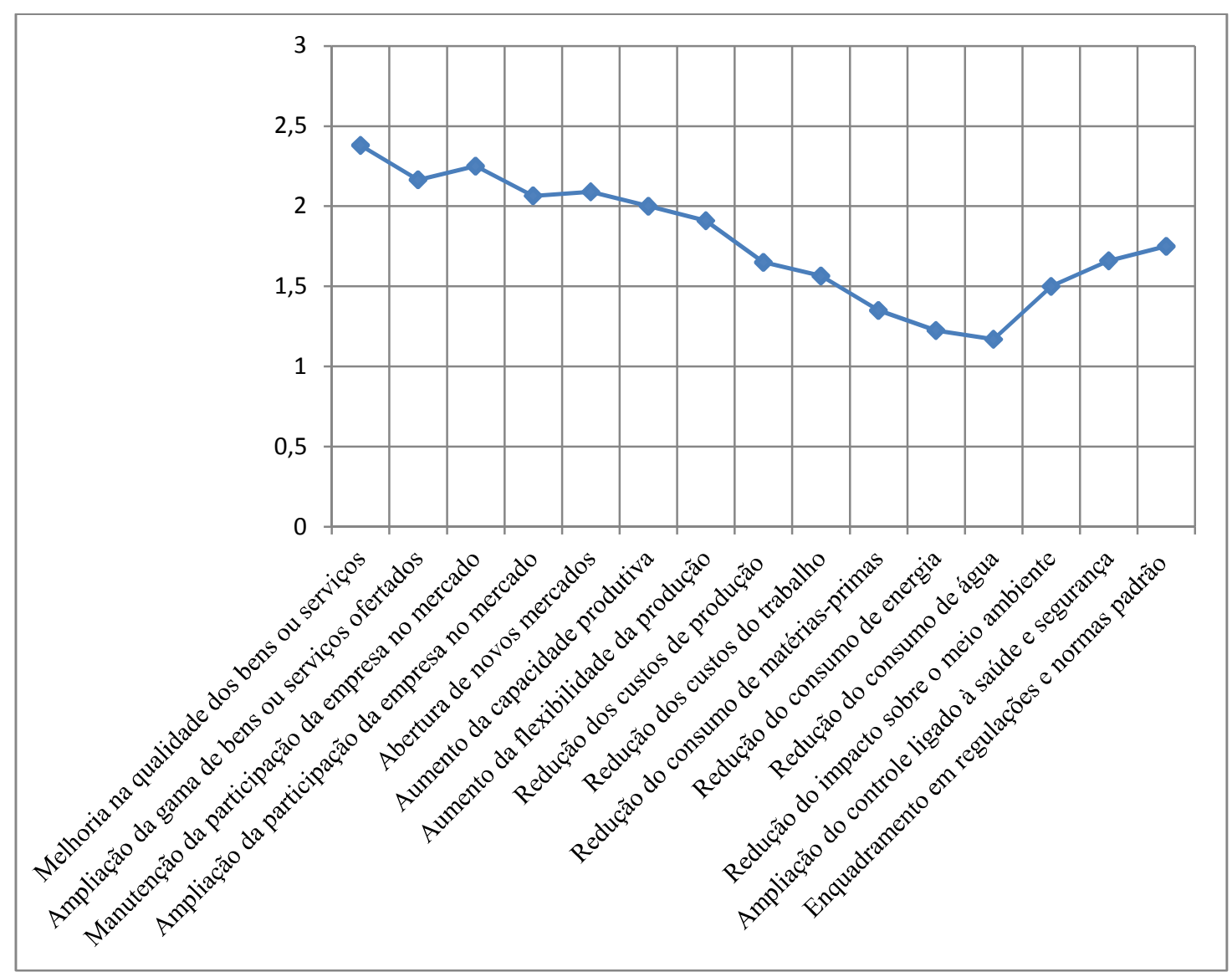

Gráfico 4 - Grau de importância do impacto causado pela inovação Fonte: Elaborado pela autora com base na PINTEC 2008 (IBGE, 2010).

Percebe-se, no Gráfico 4, que as empresas da Indústria em estudo consideram como efeitos relevantes, decorrentes da inovação, questões relacionadas ao produto e ao mercado, como a melhoria na qualidade dos bens ou serviços, a ampliação da gama de bens ou serviços ofertados e a manutenção da participação da empresa no mercado. No entanto, questões relacionadas à redução de custos e de consumo foram percebidas pelas empresas como sendo de baixa à média importância, como no caso da redução do consumo de energia e de água. 
Quanto aos obstáculos à inovação listados pelo IBGE (2010), as empresas apontaram os elevados riscos econômicos e os altos custos como principais barreiras, seguida pela falta de profissionais qualificados.

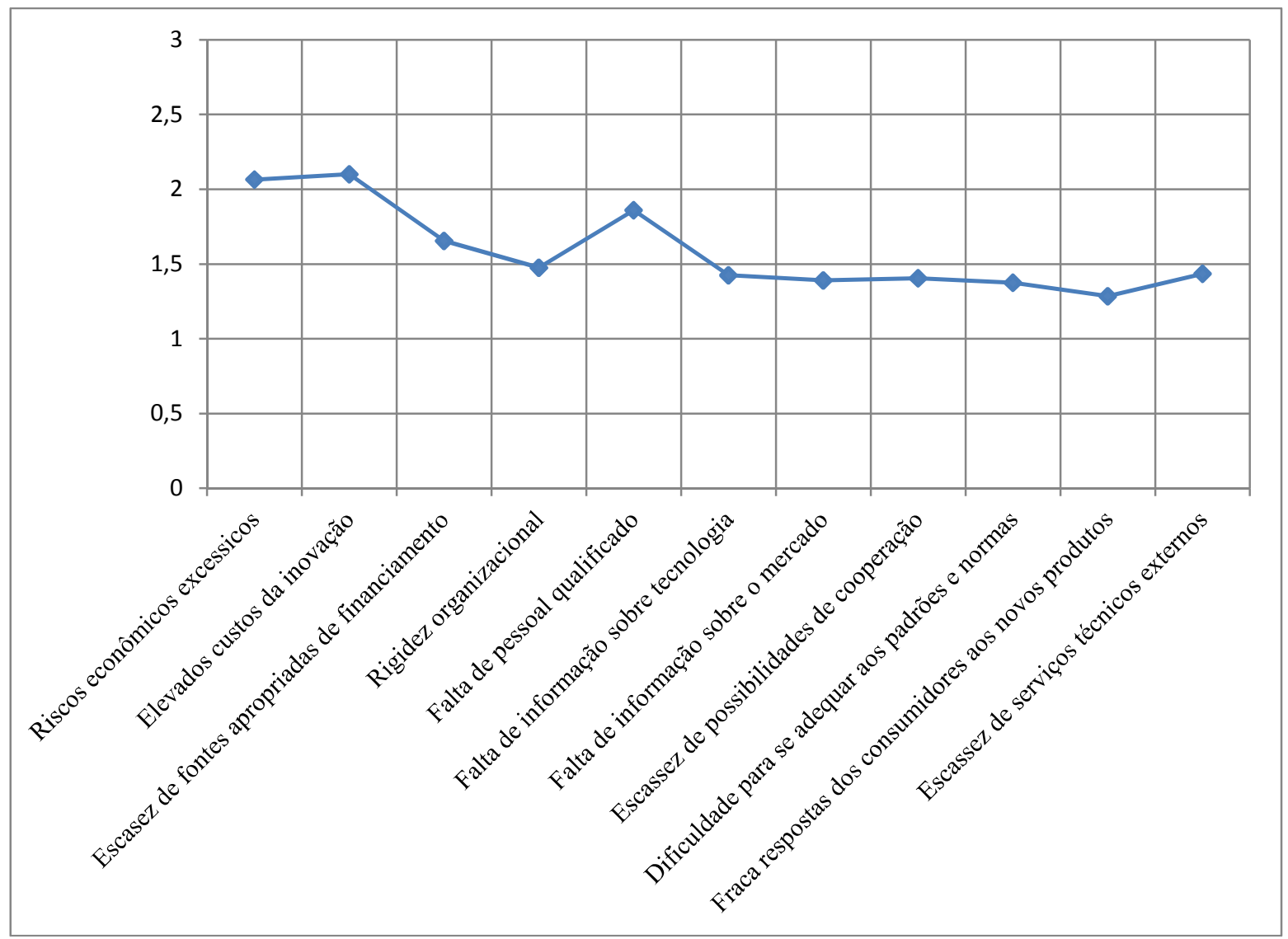

Gráfico 5 - Grau de importância atribuído aos obstáculos à inovação Fonte: Elaborado pela autora com base na PINTEC 2008 (IBGE, 2010).

Além disso, destaca-se, no Gráfico 5, a baixa importância atribuída à escassez de possibilidade de cooperação, indicando que a falta de parceiros para cooperação possui pouca influência na capacidade inovativa, de acordo com as empresas.

O questionário da PINTEC (IBGE, 2010) também abordou o grau de importância atribuído pelas empresas às fontes de informação para inovação, expressas no Gráfico 6. 


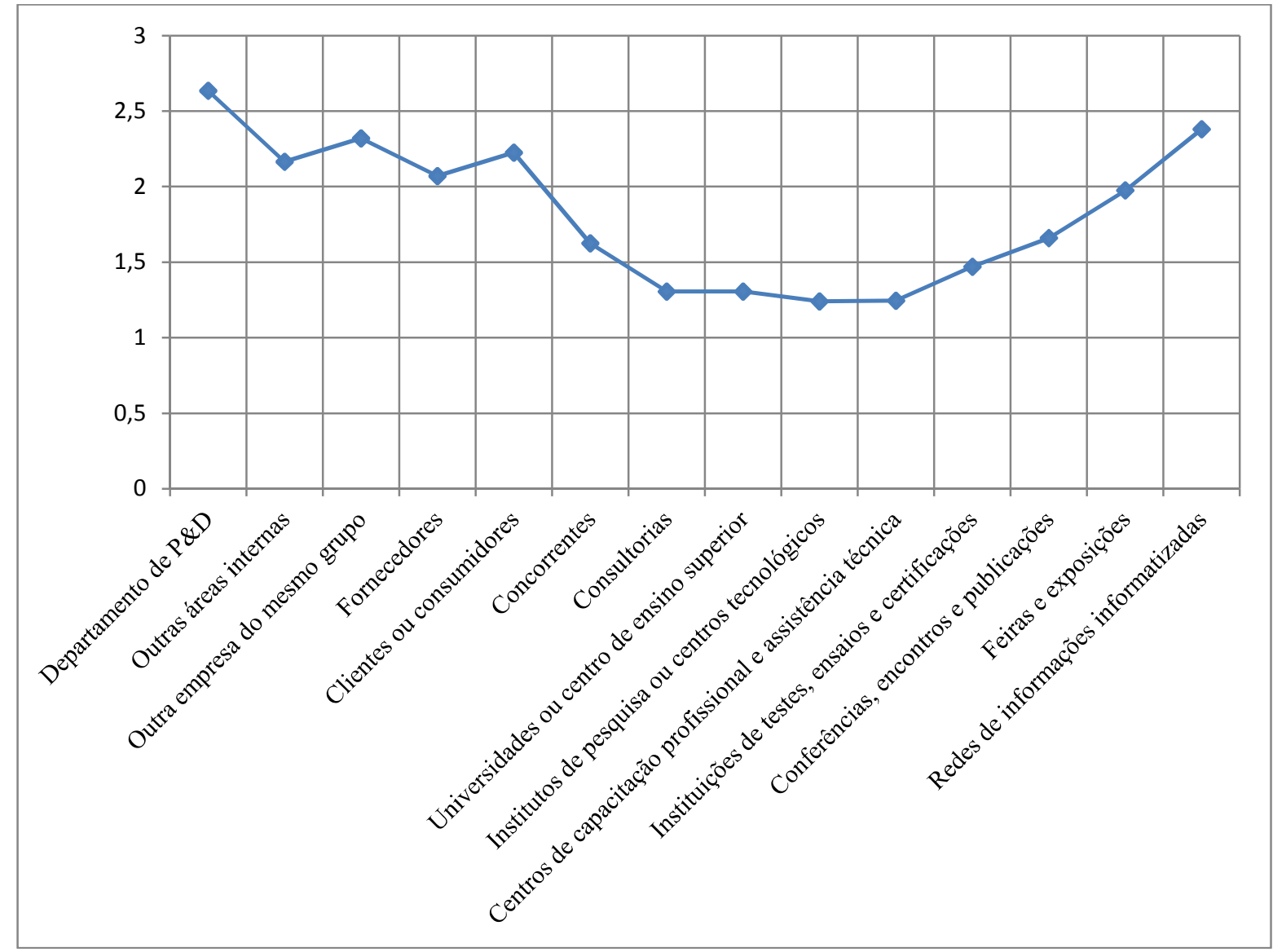

Gráfico 6 - Grau de importância atribuído às fontes de informação

Fonte: Elaborado pela autora com base na PINTEC 2008 (IBGE, 2010).

No Gráfico 6, as fontes de informação mais importantes para as atividades inovativas são o próprio departamento de $\mathrm{P} \& \mathrm{D}$, as redes de informações informatizadas, outras empresas do mesmo grupo e os clientes e consumidores. As empresas de consultoria, as universidades, os institutos de pesquisa e os centros de capacitação profissional e assistência técnica são, segundo a percepção das empresas pesquisadas, fontes de informação menos relevantes ao processo de inovação.

Esta opinião, no entanto, se altera quando as empresas são perguntadas acerca da importância atribuída às fontes de cooperação para o processo de inovação [Gráfico 7]. 


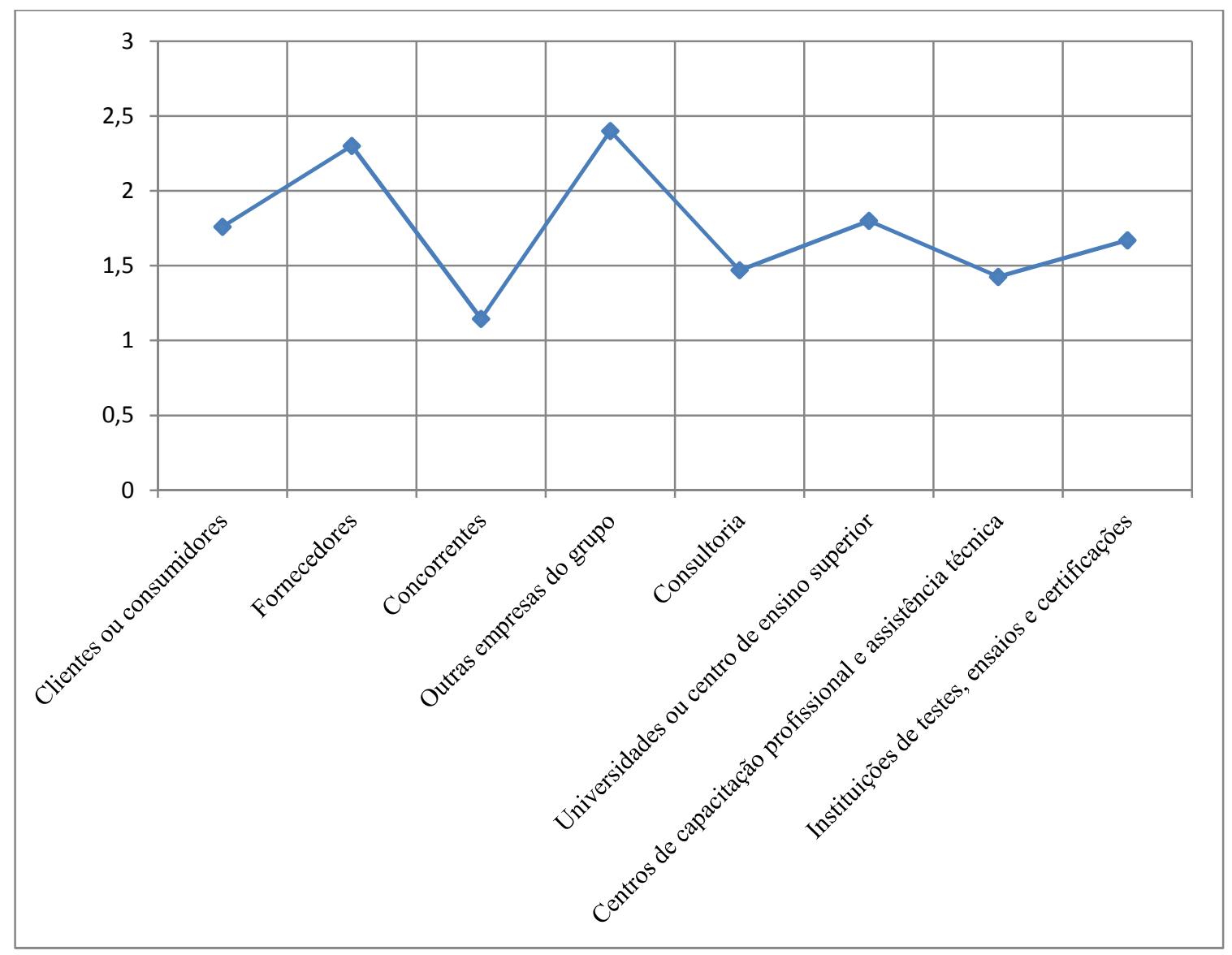

Gráfico 7 - Grau de importância atribuído às fontes de cooperação Fonte: Elaborado pela autora com base na PINTEC 2008 (IBGE, 2010).

Como pode ser visto no Gráfico 7, os fornecedores e outras empresas do grupo se destacam como importantes fontes de cooperação para a inovação, ao contrário dos concorrentes, que não são considerados parceiros relevantes pelas empresas da Indústria.

Em resumo, pode-se notar que as empresas do setor atribuem maior importância às atividades e parceiros internos e a outras empresas do grupo no que se refere ao desenvolvimento de inovações. Isso fica claro a partir da análise do Gráfico 2, que indica a centralização do processo de desenvolvimento de inovações de produto na própria empresa, como também quando se examina a importância conferida às fontes de informação [Gráfico 6] e aos parceiros de inovação [Gráfico 7].

No entanto, considerando os principais obstáculos ao processo de inovação citados pelas empresas - os riscos e custos elevados e a escassez de pessoal qualificado - percebe-se que estes podem ser amenizados por meio da colaboração com atores externos. Apesar disso, a 
PINTEC (IBGE, 2010) apontou que a importância atribuída às fontes de informação de fora da organização, como as universidades e centros de pesquisa, ainda é baixa em comparação a outras e, apesar das empresas considerarem os fornecedores e consumidores como importantes parceiros, ainda assim a cooperação com outras empresas do grupo se sobressai a outras fontes externas.

Visando discutir e aprofundar os resultados apresentados pela PINTEC, os subitens a seguir tratam da caracterização dos respondentes e da amostra fruto da presente pesquisa, bem como apresentam a análise dos dados coletados de forma primária acerca das redes de inovação e do desempenho inovador de empresas da Indústria Elétrica Eletrônica.

\subsection{Descrição dos respondentes}

Com relação aos respondentes, nota-se, no Gráfico 8, que a maioria é do sexo masculino (74,05\%), representada por 137 indivíduos.

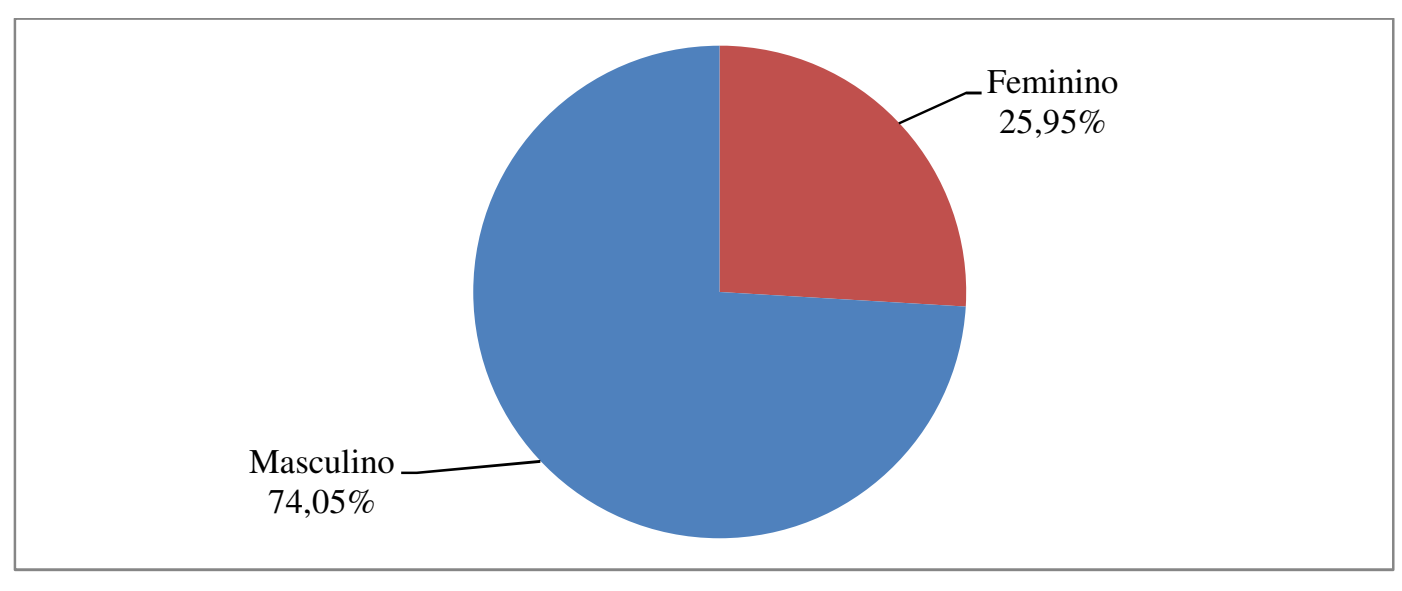

Gráfico 8 - Gênero dos respondentes

Fonte: Elaborado pela autora.

Quanto à sua posição hierárquica na empresa, grande parte dos respondentes possui cargo de diretor $(35,14 \%)$ ou de gerente da empresa $(30,81 \%)$, conforme expresso no Gráfico 9. A categoria 'outros', representada por $13,51 \%$ dos respondentes, refere-se principalmente a cargos como analistas, coordenadores, engenheiros e consultores. 
Vale salientar que o questionário foi direcionado aos responsáveis pela gestão da empresa ou gerentes intermediários, como gerentes de $\mathrm{P} \& \mathrm{D}$ ou de projetos, seguindo as recomendações expressas no Manual de Oslo (OCDE, 2005).

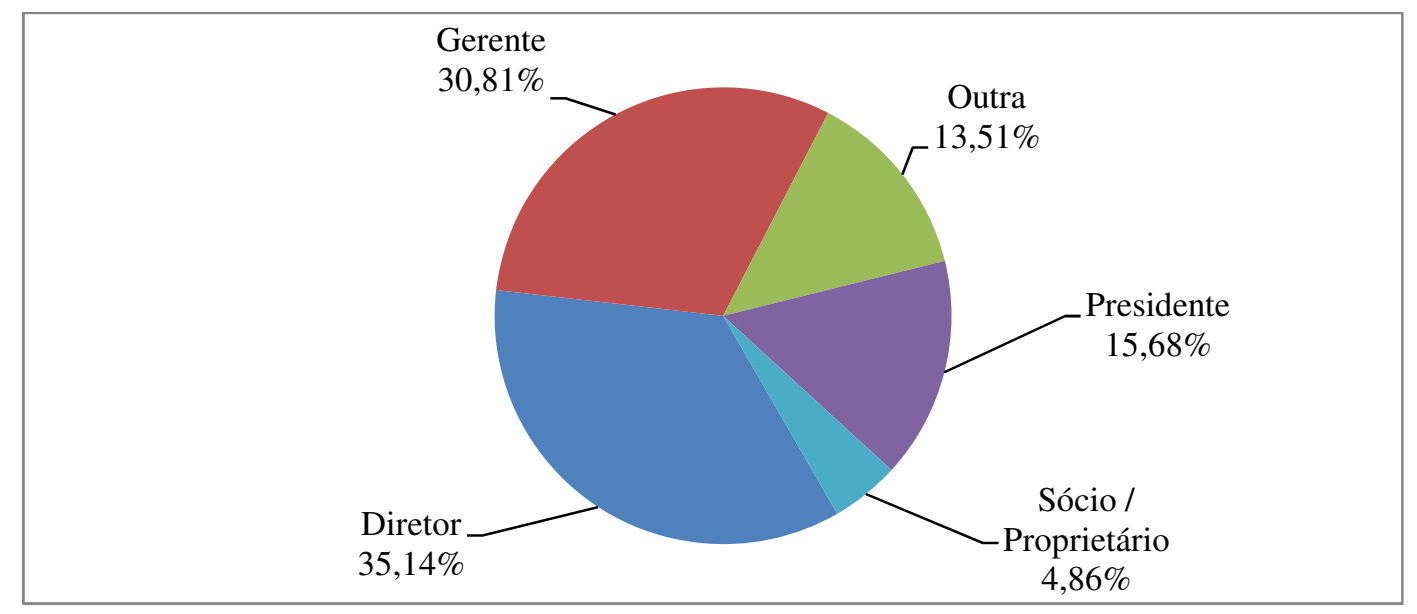

Gráfico 9 - Posição hierárquica na empresa Fonte: Elaborado pela autora.

No Gráfico 10 observa-se um alto grau de escolaridade dos respondentes. Do total, 50,27\% cursaram até o ensino superior e outros $36,22 \%$ possuem pós-graduação completa.

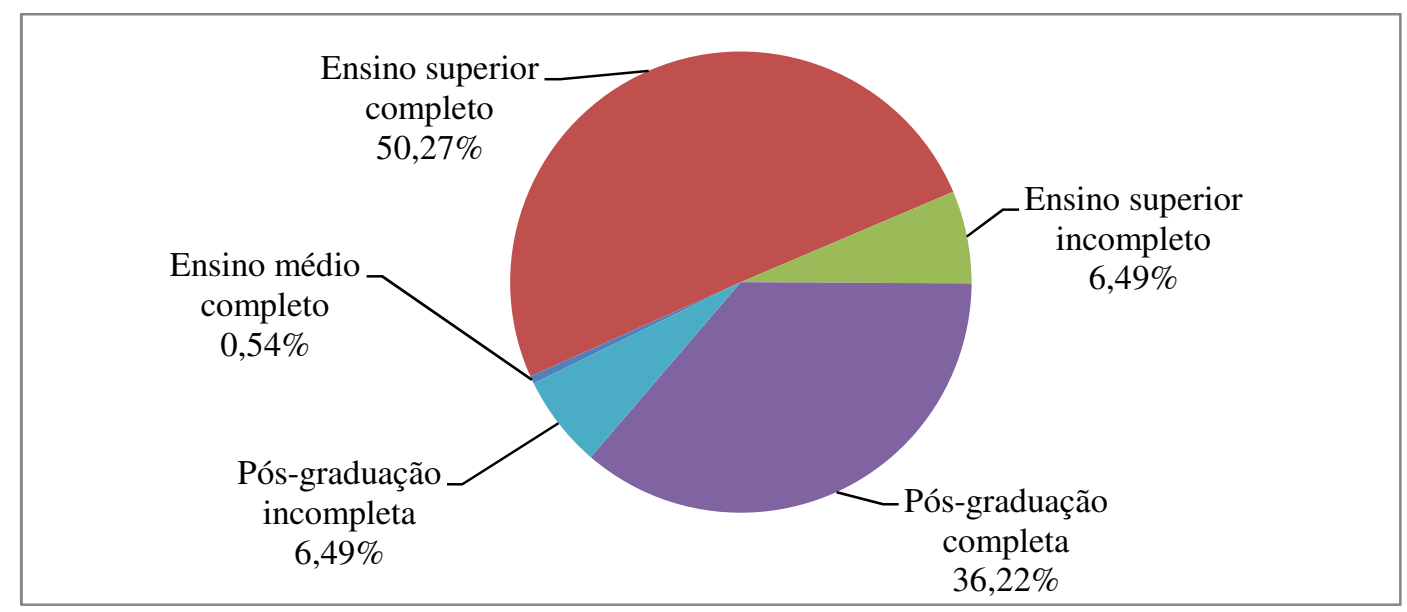

Gráfico 10 - Grau de escolaridade dos respondentes Fonte: Elaborado pela autora.

Quanto ao número de anos trabalhados na empresa, aponta-se, na Tabela 5 que, em média, os entrevistados trabalham há 11,09 anos na empresa, sendo que o mínimo observado foi de 1 ano e o máximo de 33 anos. 
Tabela 5 - Tempo de trabalho na empresa

\begin{tabular}{c|c|c|c|c|c}
\hline v.24 n & Média & Desvio Padrão & Mediana & Mínimo & Máximo \\
\hline 185 & 11,09 & 8,99 & 7 & 1 & 33 \\
\hline \multicolumn{5}{c}{ Fonte: Elaborado pela autora. }
\end{tabular}

\subsection{Descrição da amostra}

Com relação à descrição da amostra, o Gráfico 11 indica que a maioria das empresas está localizada no estado de São Paulo 57,3\%, seguida pelo Rio Grande do Sul $(9,2 \%)$ e pelo Paraná $(8,1 \%)$. A distribuição geográfica da amostra está razoavelmente congruente à apresentada pela PINTEC (IBGE, 2010), no Gráfico 1, no qual se destacam os estados da região Sudeste e Sul.

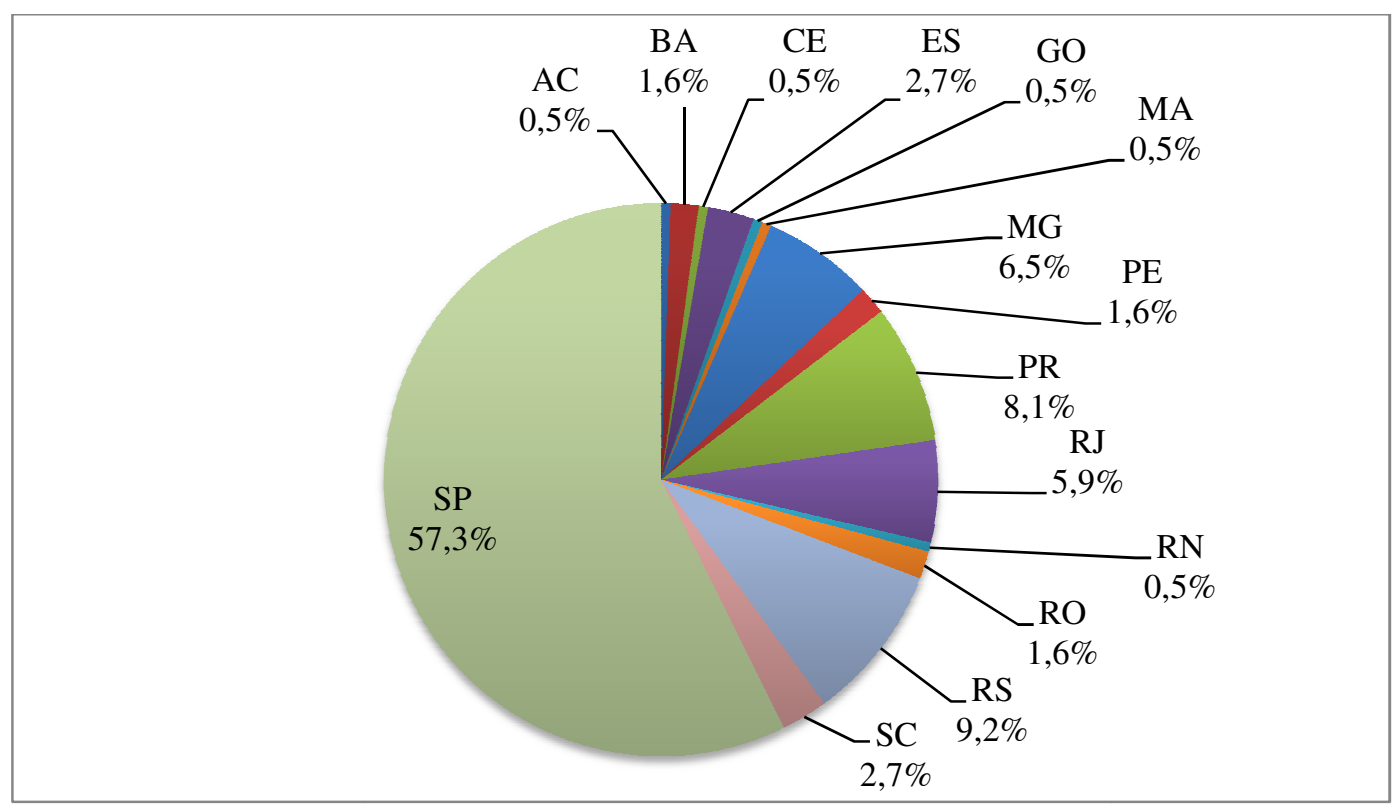

Gráfico 11 - Localização das empresas

Fonte: Elaborado pela autora.

Das 185 empresas que participaram do estudo, cerca de $85 \%$ são independentes, sendo que apenas 15\% fazem parte de grupos, conforme o Gráfico 12. 


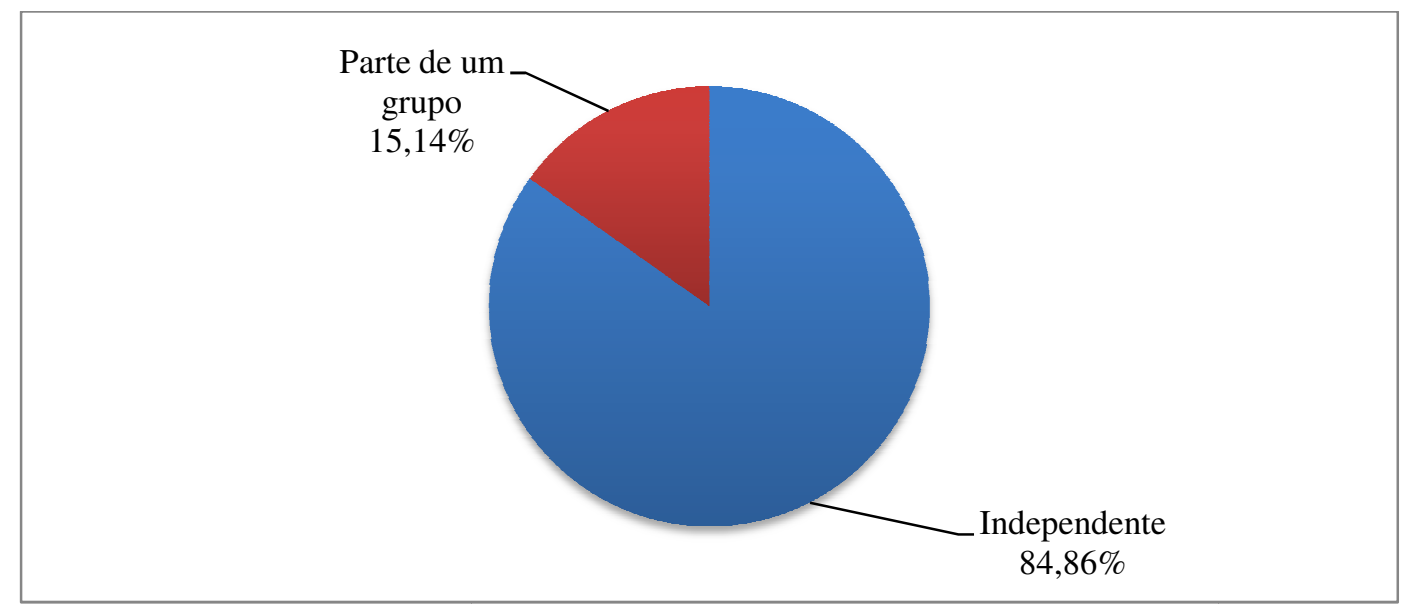

Gráfico 12 - Constituição das empresas

Fonte: Elaborado pela autora.

Além disso, aponta-se, no Gráfico 13, que a grande maioria possui capital controlador nacional $(88,65 \%)$, seguida por empresas de capital estrangeiro $(9,16 \%)$ e empresas com capital misto $(2,16 \%)$.

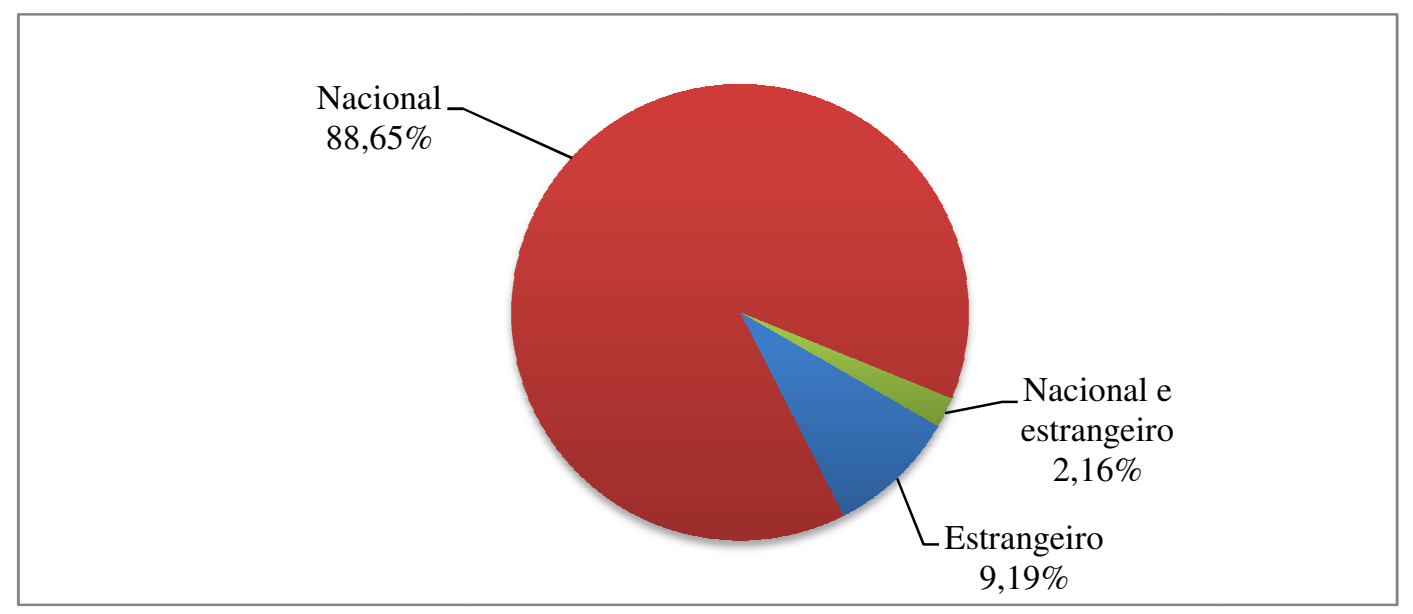

Gráfico 13 - Origem do capital controlador

Fonte: Elaborado pela autora.

Por meio do Gráfico 14 é possível verificar que o segmento de atuação que mais se destaca é o de Informática, com $28,11 \%$ dos casos, seguido por Automação Industrial $(12,43 \%)$ e Telecomunicações $(9,73 \%)$. O segmento 'Outros' também merece destaque, por representar $12,97 \%$ da amostra. Este item corresponde principalmente a empresas que atuam em comércio eletrônico, utilidades domésticas, meio ambiente e serviços para o Setor Eletroeletrônico, como instalações, manutenção, consultoria e sistemas de teste e medição. 


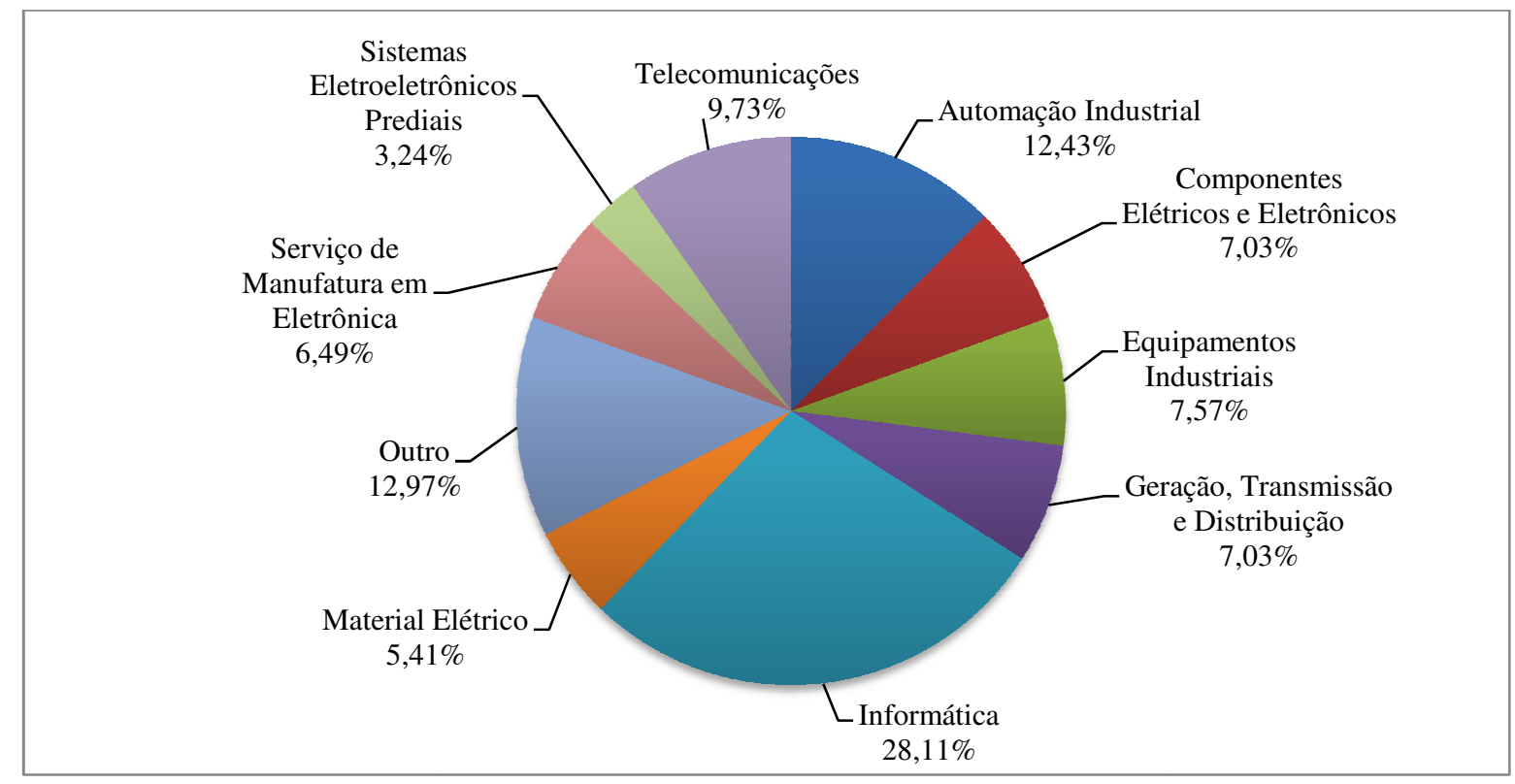

Gráfico 14 - Principal segmento de atuação

Fonte: Elaborado pela autora.

O Gráfico 15 mostra que, em 2012, a maior parte das empresas apresentou receita bruta de até $\mathrm{R} \$ 1,2$ milhão (37,30\%), seguida por empresas cuja receita bruta foi de $\mathrm{R} \$ 1,2$ milhão à $\mathrm{R} \$ 10,5$ milhões $(28,11 \%)$.

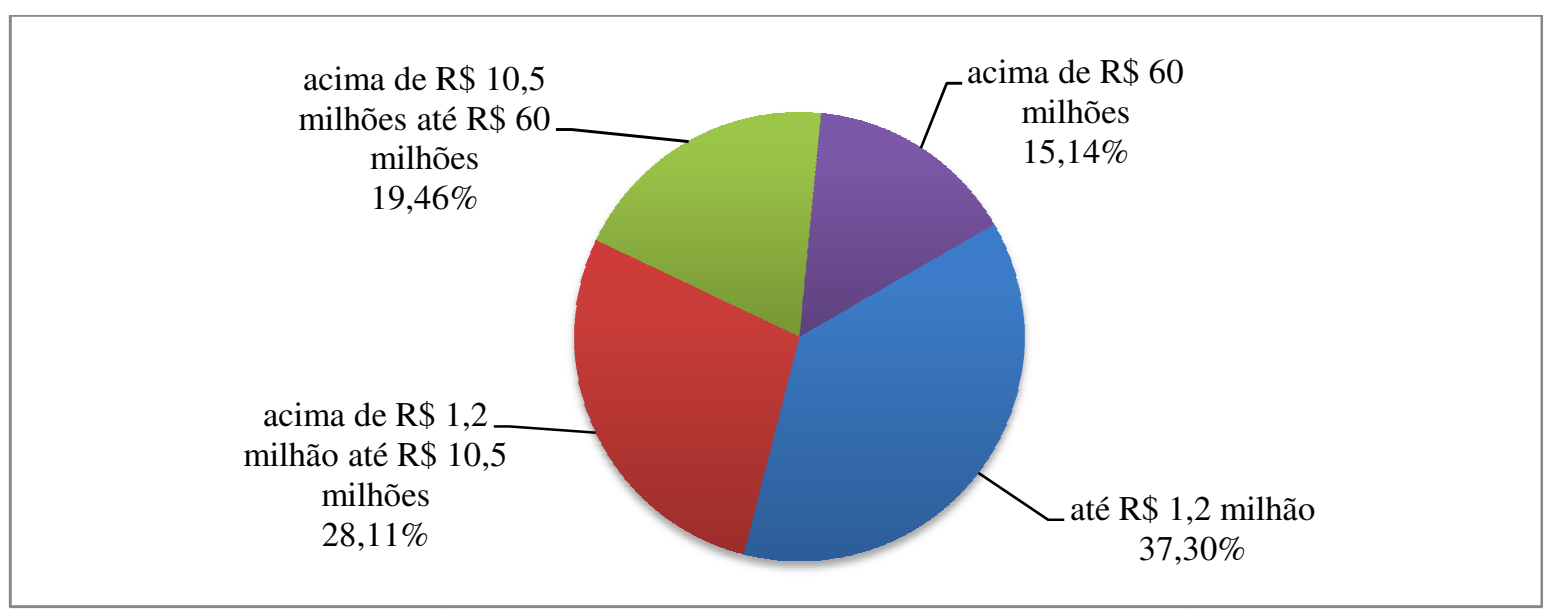

Gráfico 15 - Receita operacional bruta em 2012

Fonte: Elaborado pela autora.

As empresas possuem, em média, 357 funcionários, com um mínimo observado igual a 10 e máximo igual a 12.876. Vale ressaltar que, em cumprimento ao Manual de Oslo (OCDE, 2005), todas as empresas que apresentaram menos de dez funcionários foram desconsideradas 
da amostra da pesquisa. Utilizando a classificação do SEBRAE (2012), verifica-se no Gráfico 16 que a maior parte das empresas foi classificada como micro empresa $(44,86 \%)$.

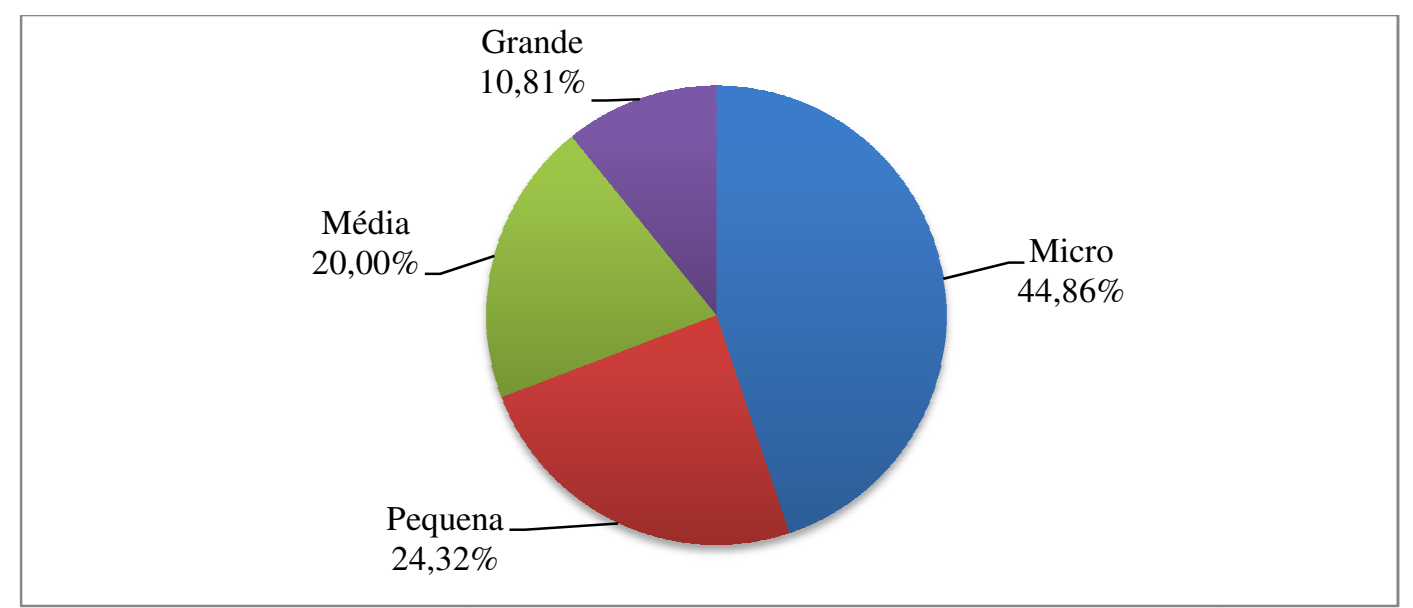

Gráfico 16 - Tamanho das empresas

Fonte: Elaborado pela autora.

O SEBRAE utiliza o critério por número de empregados do IBGE para classificação do porte das empresas. Para empresas industriais, especificamente, são consideradas micro empresas àquelas que apresentam até 19 empregados. Para serem classificadas como pequenas empresas, elas devem possuir de 20 a 99 empregados, já as médias empresas devem possuir de 100 a 499 empregados e, as grandes empresas, mais do que 500 empregados (SEBRAE, 2012).

Visando levantar alguns dados que possam corroborar com a avaliação da capacidade de absorção do conhecimento das empresas amostradas, foi perguntado o número de funcionários, em relação ao total, que possuía cursos de especialização, mestrado e doutorado. Analisando o Gráfico 17, observa-se que, em média, 20,31\% dos funcionários possuem especialização, $2,21 \%$ mestrado e $0,98 \%$ doutorado. 


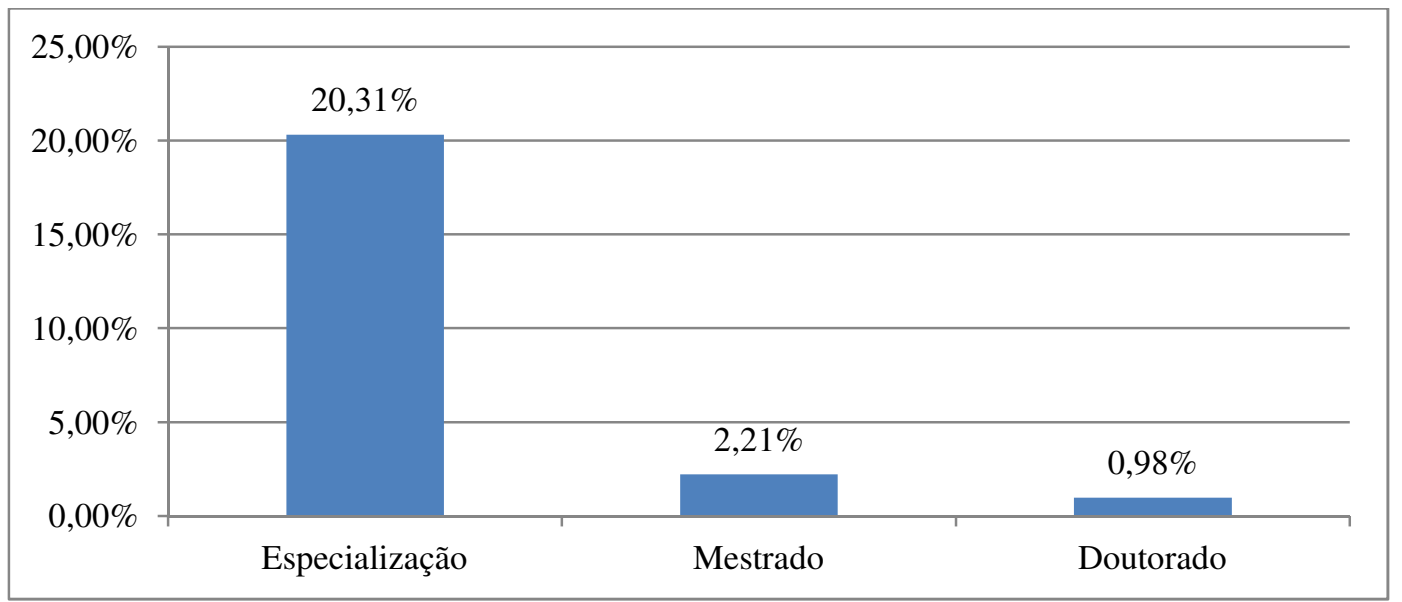

Gráfico 17 - Percentual médio de funcionários com cursos de Especialização, Mestrado e Doutorado Fonte: Elaborado pela autora.

No Gráfico 18, nota-se que as principais áreas de formação dos funcionários das empresas são engenharia, administração de empresas e tecnologia da informação. Dentre a categoria 'outros' observa-se também um alto número de cursos técnicos, que são bastante realizados pelos funcionários do setor. Vale ressaltar que esta era uma questão de múltipla escolha e que os resultados apresentados são condizentes com o perfil da Indústria Elétrica Eletrônica.

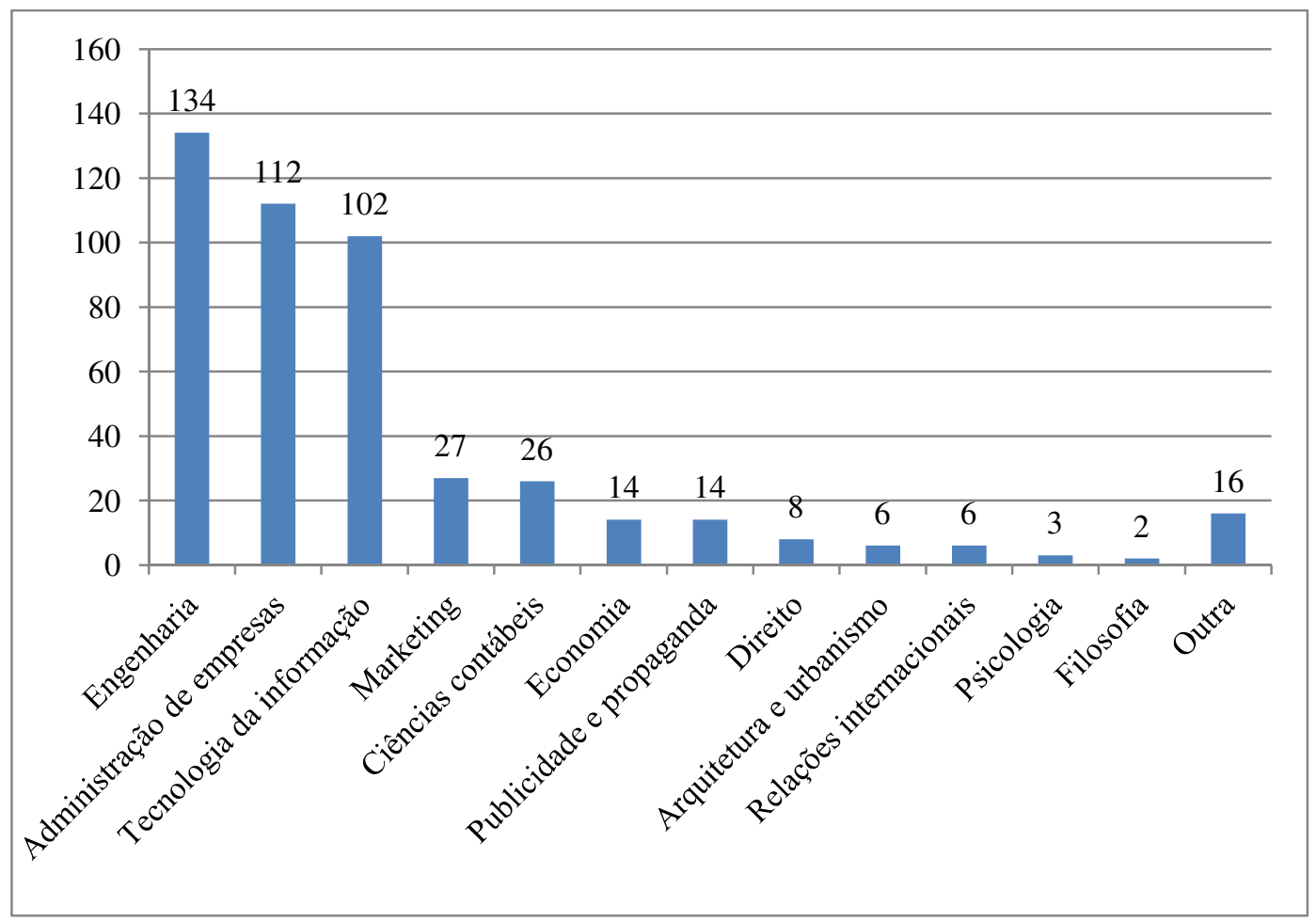

Gráfico 18 - Principais áreas de formação dos profissionais Fonte: Elaborado pela autora. 
A partir do Gráfico 19, verifica-se que, apesar da falta de mão de obra qualificada no Brasil ser um problema para as empresas da Indústria (IBGE, 2010; ABINEE, 2012), apenas 9,73\% delas contrataram profissionais de empresas estrangeiras. Tal fato pode ser explicado pela dificuldade de acesso ao mercado de trabalho externo ou aos custos inerentes a este processo, inviabilizando a contratação de profissionais estrangeiros, principalmente em empresas de micro, pequeno e médio porte. O baixo índice de contratação de profissionais estrangeiros também pode ser explicado pela pequena quantidade de empresas de controle estrangeiro presentes na pesquisa.

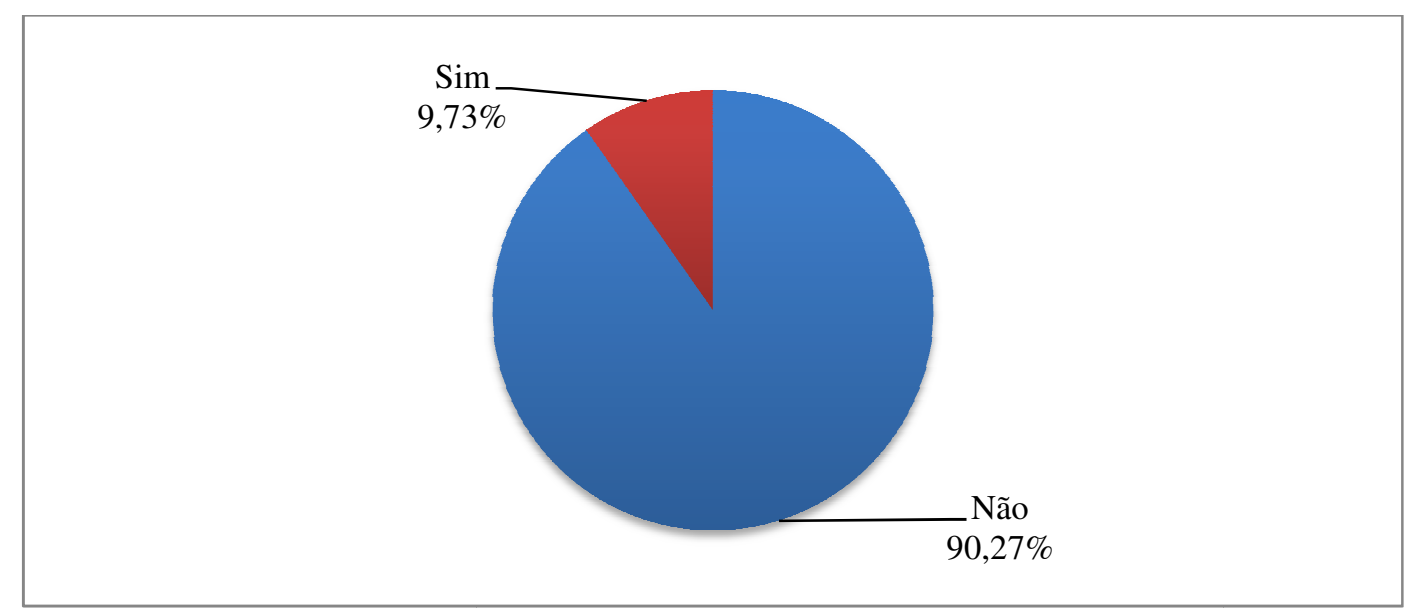

Gráfico 19 - Contratação de profissionais estrangeiros Fonte: Elaborado pela autora.

Em relação ao percentual da receita operacional bruta de 2012 gasto com atividades de treinamento e de $\mathrm{P} \& \mathrm{D}$, nota-se, nas tabelas 6 e 7, que, em média, as empresas investem 4,60\% de sua receita em atividades de treinamento e 6,51\% em atividades de P\&D.

Tabela 6 - Investimento em treinamento

\begin{tabular}{c|c|c|c|c|c|c}
\hline & $\mathbf{n}$ & Média & $\begin{array}{c}\text { Desvio } \\
\text { Padrão }\end{array}$ & Mediana & Mínimo & Máximo \\
\hline $\begin{array}{c}\text { V11 - Percentual da receita operacional bruta anual } \\
\text { gasto com atividades de treinamento em 2012 }\end{array}$ & 185 & 4,60 & 5,25 & 3 & 0 & 30 \\
\hline
\end{tabular}

Fonte: Elaborado pela autora.

Tabela 7 - Investimento em P\&D

\begin{tabular}{c|c|c|c|c|c|c}
\hline & $\mathbf{n}$ & Média & $\begin{array}{c}\text { Desvio } \\
\text { Padrão }\end{array}$ & Mediana & Mínimo & Máximo \\
\hline $\begin{array}{c}\text { V12 - Percentual da receita operacional bruta anual } \\
\text { gasto com P\&D em 2012 }\end{array}$ & 185 & 6,51 & 9,07 & 3 & 0 & 40 \\
\hline
\end{tabular}

Fonte: Elaborado pela autora. 
Este percentual, a priori, parece alto em comparação ao apontado pela PINTEC (IBGE, 2010). No entanto, deve-se ressaltar que a maior parte da amostra é composta por micro e pequenas empresas que, apesar de investirem nominalmente uma quantia menor em tais atividades, percentualmente este valor pode ser mais representativo de sua receita em comparação às grandes e médias empresas.

Para uma análise mais detalhada desta questão, foi realizado o cruzamento entre a receita operacional bruta das empresas e a porcentagem gasta com treinamento e P\&D. A Tabela 8 apresenta o percentil 25\%, a mediana e o percentil $75 \%$ para o percentual da receita operacional bruta gasto com treinamento e com P\&D. Esses valores foram utilizados para criação de faixas para as variáveis.

Tabela 8 - Percentis observados para o percentual da receita operacional bruta gasto com treinamento e P\&D

\begin{tabular}{c|c|c|c}
\hline & Percentil 25 & Mediana & Percentil 75 \\
\hline Treinamento & $1,00 \%$ & $3,00 \%$ & $5,00 \%$ \\
\hline P\&D &, $00 \%$ & $3,00 \%$ & $8,00 \%$ \\
\hline
\end{tabular}

Fonte: Elaborado pela autora.

De acordo com os valores apresentados, os percentuais da receita operacional bruta gastos com treinamento foram classificados da seguinte maneira:

- Até $1 \%$;

- Entre 1 e $3 \%$;

- $\quad$ Entre 3 e $5 \%$;

- Acima de 5\%.

Da mesma maneira, o percentual gasto com P\&D foi classificado da seguinte forma:

- $0 \%$

- Entre 0 e 3\%;

- $\quad$ Entre 3 e $8 \%$;

- Acima de 8\%.

Por meio da Tabela 9 é possível perceber que o percentual gasto com treinamento das empresas que apresentaram renda operacional bruta até $\mathrm{R} \$ 1,2$ milhão está dividido em até 1\% 
(20 empresas) e acima de 5\% (20 empresas). Para empresas com receita entre $\mathrm{R} \$ 1,2$ milhão até 10,5 milhões, nota-se que a maior parte gasta entre 1 e $3 \%$ da receita operacional bruta. Tanto as empresas com receita entre $\mathrm{R} \$ 10,5$ milhões até 60 milhões, quanto àquelas que possuem receita acima de $\mathrm{R} \$ 60$ milhões apresentaram gastos de até $1 \%$ com treinamento.

Tabela 9 - Cruzamento entre receita operacional bruta anual e porcentagem gasta com treinamento

\begin{tabular}{r|c|c|c|c|c|c|c|c}
\hline & \multicolumn{2}{|c|}{ Até 1\% } & \multicolumn{2}{c}{ Entre 1 e 3\% } & \multicolumn{2}{c}{ Entre 3 e 5\% } & \multicolumn{2}{c}{ Acima de 5\% } \\
\cline { 2 - 9 } & $\mathrm{n}$ & $\%$ & $\mathrm{n}$ & $\%$ & $\mathrm{n}$ & $\%$ & $\mathrm{n}$ & $\%$ \\
\hline Até R\$ 1,2 milhão & 20 & $28,99 \%$ & 11 & $15,94 \%$ & 18 & $26,09 \%$ & 20 & $28,99 \%$ \\
\hline Acima de R\$ 1,2 até R\$ 10,5 milhões & 13 & $25,00 \%$ & 19 & $36,54 \%$ & 13 & $25,00 \%$ & 7 & $13,46 \%$ \\
\hline Acima de R\$ 10,5 até R\$ 60 milhões & 18 & $50,00 \%$ & 4 & $11,11 \%$ & 7 & $19,44 \%$ & 7 & $19,44 \%$ \\
\hline Acima de R\$ 60 milhões & 11 & $39,29 \%$ & 6 & $21,43 \%$ & 4 & $14,29 \%$ & 7 & $25,00 \%$ \\
\hline Total & 62 & $33,51 \%$ & 40 & $21,62 \%$ & 42 & $22,70 \%$ & 41 & $22,16 \%$ \\
\hline
\end{tabular}

Fonte: Elaborado pela autora.

Na Tabela 10, observa-se que a maioria das empresas que apresentaram receita operacional bruta até $\mathrm{R} \$ 1,2$ milhão não investiu em $\mathrm{P} \& \mathrm{D}$ ou então investiu acima de $8 \%$ de sua receita. Para as empresas com receita entre $\mathrm{R} \$ 1,2$ milhão e 10,5 milhões e acima de $\mathrm{R} \$ 60$ milhões, a maior parte investiu entre 0 e $3 \%$ em $P \& D$, enquanto que para as empresas com receita entre $\mathrm{R} \$ 10,5$ milhões e 60 milhões, a maioria gastou entre 0 e $8 \%$ com P\&D.

Tabela 10 - Cruzamento entre receita operacional bruta anual e porcentagem gasta com P\&D

\begin{tabular}{r|c|c|c|c|c|c|c|c}
\hline & \multicolumn{2}{|c}{$\mathbf{0} \%$} & \multicolumn{2}{c|}{ Entre 0 e 3\% } & \multicolumn{2}{c}{ Entre 3 e 8\% } & \multicolumn{2}{c}{ Acima de 8\% } \\
\cline { 2 - 10 } & $\mathrm{n}$ & $\%$ & $\mathrm{n}$ & $\%$ & $\mathrm{n}$ & $\%$ & $\mathrm{n}$ & $\%$ \\
\hline Até R\$ 1,2 milhão & 27 & $39,13 \%$ & 6 & $8,70 \%$ & 15 & $21,74 \%$ & 21 & $30,43 \%$ \\
\hline Acima de R\$ 1,2 até R\$ 10,5 milhões & 14 & $26,92 \%$ & 16 & $30,77 \%$ & 9 & $17,31 \%$ & 13 & $25,00 \%$ \\
\hline Acima de R\$ 10,5 até R\$ 60 milhões & 4 & $11,11 \%$ & 12 & $33,33 \%$ & 12 & $33,33 \%$ & 8 & $22,22 \%$ \\
\hline Acima de R\$ 60 milhões & 3 & $10,71 \%$ & 12 & $42,86 \%$ & 9 & $32,14 \%$ & 4 & $14,29 \%$ \\
\hline Total & 48 & $25,95 \%$ & 46 & $24,86 \%$ & 45 & $24,32 \%$ & 46 & $24,86 \%$ \\
\hline
\end{tabular}

Fonte: Elaborado pela autora.

Por fim, na Tabela 11, nota-se que o número médio de funcionários no departamento de P\&D é igual a 9,86, com um mínimo de 0 e máximo de 230. A mediana observada para esse aspecto é igual a 2. 
Tabela 11 - Funcionários no departamento de P\&D

\begin{tabular}{c|c|c|c|c|c|c}
\hline & $\mathbf{n}$ & Média & Desvio Padrão & Mediana & Mínimo & Máximo \\
\hline V13 & 185 & 9,86 & 28,6 & 2 & 0 & 230 \\
\hline
\end{tabular}

Fonte: Elaborado pela autora.

\subsection{Descrição da atividade inovativa}

O desempenho em termos de inovação das empresas foi medido por meio de construtos elaborados com base na literatura e expressos no item 3.3 deste estudo. A avaliação dos respondentes se deu por meio de uma escala de 0 a 10 para medir o grau de concordância frente às afirmações e a análise descritiva foi feita com base nas médias de cada item. Assim, os itens que apresentassem média entre 0 e 2 indicariam grau muito baixo de concordância; entre 2,1 e 4, um grau baixo; entre 4,1 e 6 um grau regular; entre 6,1 e 8 um grau alto; e entre 8,1 e 10 um grau muito alto de concordância.

Com relação ao desempenho em inovação de produto, os respondentes apresentaram entre grau regular e grau alto de concordância frente às afirmações, conforme expresso na Tabela 12. A média da escala somada foi 5,70 , indicando que, de forma geral, as empresas têm introduzido inovações em produtos e/ou percebido os efeitos decorrentes deste tipo de inovação.

Tabela 12 - Inovação de produto

\begin{tabular}{|c|c|c|c|c|}
\hline & & Média & $\begin{array}{l}\text { Desvio } \\
\text { Padrão }\end{array}$ & $\mathrm{n}$ \\
\hline PROD1 & $\begin{array}{l}\text { A empresa introduziu pelo menos um produto (bem ou serviço) novo ou } \\
\text { significativamente melhorado no mercado. }\end{array}$ & 7,07 & 2,72 & 185 \\
\hline PROD2 & $\begin{array}{l}\text { Grande parte do percentual de vendas da empresa é proveniente de produtos } \\
\text { (bens ou serviços) novos ou significativamente melhorados. }\end{array}$ & 5,63 & 2,53 & 185 \\
\hline PROD3 & $\begin{array}{l}\text { A empresa participa frequentemente de congressos e feiras como } \\
\text { expositor/palestrante. }\end{array}$ & 4,31 & 2,76 & 185 \\
\hline PROD4 & A empresa possui poucos competidores por produto ou serviço prestado. & 4,64 & 2,66 & 185 \\
\hline PROD5 & Observou-se a melhoria na qualidade dos bens ou serviços da empresa. & 6,97 & 1,73 & 185 \\
\hline PROD6 & A empresa ampliou a gama de bens ou serviços ofertados. & 5,55 & 2,37 & 185 \\
\hline
\end{tabular}

Fonte: Elaborado pela autora.

A partir da análise da Tabela 13, parece que, quanto maior a receita operacional da empresa, maior o valor médio para PROD1 e PROD3, enquanto que, para PROD2, quanto menor a 
receita operacional bruta, maior o valor da média observada, revelando que as empresas de menor porte possuem maior parcela do percentual de vendas provenientes de produtos novos ou significativamente melhorados. Em relação à PROD4, PROD5 e PROD6, observou-se que as categorias de receita operacional bruta apresentaram valores próximos.

Tabela 13 - Média e desvio padrão das variáveis do construto inovação de produto de acordo com faixas da receita operacional bruta anual

\begin{tabular}{l|c|c|c|c|c|c|c|c}
\hline & \multicolumn{2}{|c|}{ Até R\$ 1,2 milhão } & \multicolumn{2}{c|}{$\begin{array}{c}\text { Acima de R\$ 1,2 } \\
\text { milhão até R\$ 10,5 } \\
\text { milhões }\end{array}$} & \multicolumn{2}{c|}{$\begin{array}{c}\text { Acima de R\$ 10,5 } \\
\text { milhões até R\$ 60 } \\
\text { milhões }\end{array}$} & \multicolumn{2}{c}{$\begin{array}{c}\text { Acima de R\$ 60 } \\
\text { milhões }\end{array}$} \\
\cline { 2 - 9 } & Média & $\begin{array}{c}\text { Desvio } \\
\text { Padrão }\end{array}$ & Média & $\begin{array}{c}\text { Desvio } \\
\text { Padrão }\end{array}$ & Média & $\begin{array}{c}\text { Desvio } \\
\text { Padrão }\end{array}$ & Média & $\begin{array}{c}\text { Desvio } \\
\text { Padrão }\end{array}$ \\
\hline PROD1 & 6,77 & 2,75 & 6,88 & 3,17 & 7,18 & 2,13 & 8,37 & 2,02 \\
\hline PROD2 & 6,08 & 2,63 & 5,59 & 2,67 & 5,57 & 2,33 & 4,66 & 2,06 \\
\hline PROD3 & 3,19 & 2,41 & 3,66 & 2,88 & 5,46 & 2,09 & 6,8 & 1,97 \\
\hline PROD4 & 4,78 & 2,77 & 4,92 & 2,75 & 3,81 & 2,46 & 4,82 & 2,37 \\
\hline PROD5 & 6,68 & 1,79 & 7,06 & 1,79 & 6,83 & 1,71 & 7,71 & 1,29 \\
\hline PROD6 & 5,32 & 2,67 & 5,79 & 2,33 & 5,88 & 2,01 & 5,24 & 2,1 \\
\hline
\end{tabular}

Fonte: Elaborado pela autora.

Quanto ao desempenho em inovação de processo, os respondentes apresentaram entre grau baixo e grau regular de concordância frente às afirmações, conforme expresso na Tabela 14. A média da escala somada foi 4,84 , indicando que, de forma geral, as empresas têm introduzido algumas inovações em processo e/ou percebido alguns efeitos decorrentes deste tipo de inovação. Nota-se, no entanto, que a média do construto referente à inovação de processo é inferior à de inovação de produto.

Tabela 14 - Inovação de processo

\begin{tabular}{|c|c|c|c|c|}
\hline & & Média & $\begin{array}{l}\text { Desvio } \\
\text { Padrão }\end{array}$ & $\mathrm{n}$ \\
\hline PROC1 & $\begin{array}{l}\text { A empresa introduziu pelo menos um novo método de fabricação de bens ou } \\
\text { serviços }\end{array}$ & 5,01 & 2,94 & 185 \\
\hline PROC2 & $\begin{array}{l}\text { A empresa introduziu pelo menos um sistema logístico ou método de entrega } \\
\text { para seus insumos, bens ou serviços }\end{array}$ & 3,64 & 2,67 & 185 \\
\hline PROC3 & $\begin{array}{l}\text { A empresa introduziu equipamentos, softwares e técnicas em atividades de } \\
\text { apoio à produção (como por exemplo: planejamento e controle da produção, } \\
\text { medição de desempenho, controle da qualidade, compra, manutenção ou } \\
\text { infraestrutura de TI) }\end{array}$ & 5,74 & 2,63 & 185 \\
\hline PROC4 & $\begin{array}{l}\text { Houve aumento da capacidade e flexibilidade de produção ou de prestação } \\
\text { de serviços. }\end{array}$ & 5,77 & 2,18 & 185 \\
\hline PROC5 & Observou-se uma redução de custos de produção/serviços prestados. & 5,23 & 2,53 & 185 \\
\hline PROC6 & Observou-se uma redução do consumo de matérias-primas e energia. & 3,66 & 2,52 & 185 \\
\hline
\end{tabular}


Observa-se ainda, na Tabela 15, que as empresas com receita operacional bruta acima de R\$60 milhões apresentaram as maiores médias para PROC1, PROC2, PROC3, PROC4, PROC5 e PROC6, podendo indicar que a realização de inovações de processo requer uma maior estrutura e recursos por parte da empresa.

Tabela 15 - Média e desvio padrão das variáveis do construto inovação de processo de acordo com faixas da receita operacional bruta anual

\begin{tabular}{l|c|c|c|c|c|c|c|c}
\hline & \multicolumn{2}{|c|}{ Até R\$ 1,2 milhão } & \multicolumn{2}{c|}{$\begin{array}{c}\text { Acima de R\$ 1,2 } \\
\text { milhão até R\$ 10,5 } \\
\text { milhões }\end{array}$} & \multicolumn{2}{c}{$\begin{array}{c}\text { Acima de R\$ 10,5 } \\
\text { milhões até R\$ 60 } \\
\text { milhões }\end{array}$} & \multicolumn{2}{c}{ Acima de R\$ 60 milhões } \\
\cline { 2 - 9 } & Média & $\begin{array}{c}\text { Desvio } \\
\text { Padrão }\end{array}$ & Média & $\begin{array}{c}\text { Desvio } \\
\text { Padrão }\end{array}$ & Média & $\begin{array}{c}\text { Desvio } \\
\text { Padrão }\end{array}$ & Média & $\begin{array}{c}\text { Desvio } \\
\text { Padrão }\end{array}$ \\
\hline PROC1 & 5,22 & 3,01 & 4,39 & 2,99 & 5,09 & 2,68 & 5,54 & 2,98 \\
\hline PROC2 & 3,17 & 2,69 & 3,52 & 2,75 & 4,07 & 2,37 & 4,45 & 2,69 \\
\hline PROC3 & 5,64 & 2,65 & 4,99 & 2,97 & 6,08 & 2,0 & 6,95 & 2,2 \\
\hline PROC4 & 5,62 & 2,17 & 5,68 & 2,17 & 5,7 & 2,21 & 6,39 & 2,21 \\
\hline PROC5 & 5,44 & 2,61 & 4,15 & 2,23 & 5,2 & 2,29 & 6,79 & 2,3 \\
\hline PROC6 & 3,4 & 2,53 & 3,1 & 2,36 & 3,97 & 2,44 & 4,97 & 2,52 \\
\hline
\end{tabular}

Fonte: Elaborado pela autora.

Com relação ao desempenho em inovação de marketing, os respondentes apresentaram entre grau regular e grau alto de concordância frente às afirmações, conforme expresso na Tabela 16. A média da escala somada foi 5,66, indicando que, de forma geral, as empresas têm introduzido inovações de marketing e/ou percebido os efeitos decorrentes deste tipo de inovação. O grau médio de concordância apresentado neste construto se aproxima do resultado apresentado pelas empresas com relação à inovação de produto. Isso é explicado, muito provavelmente, pela ligação direta entre esses dois tipos de inovação, já que as alterações em produtos podem gerar mudanças na forma como o marketing é executado, além de poder proporcionar efeitos similares, como a abertura de mercados e a adaptação às diferentes demandas dos clientes. 
Tabela 16 - Inovação de marketing

\begin{tabular}{|c|c|c|c|c|}
\hline & & Média & $\begin{array}{l}\text { Desvio } \\
\text { Padrão }\end{array}$ & $\mathrm{n}$ \\
\hline MKT1 & $\begin{array}{l}\text { A empresa implementou mudanças significativas nos conceitos/estratégias de } \\
\text { marketing (como por exemplo: novas mídias ou técnicas para a promoção de } \\
\text { produtos; novas formas para colocação de produtos no mercado ou canais de } \\
\text { venda; ou novos métodos de fixação de preços para a comercialização de bens e } \\
\text { serviços) }\end{array}$ & 4,85 & 2,49 & 185 \\
\hline MKT2 & $\begin{array}{l}\text { Foram implementadas grandes mudanças na estética ou desenho em pelo menos } \\
\text { um dos produtos }\end{array}$ & 5,69 & 3,05 & 185 \\
\hline MKT3 & Houve a abertura de novos mercados. & 5,64 & 2,48 & 185 \\
\hline MKT4 & Observou-se um aumento da visibilidade ou da exposição dos produtos. & 5,42 & 2,2 & 185 \\
\hline MKT5 & $\begin{array}{l}\text { Houve uma melhoria da capacidade de adaptação às diferentes demandas dos } \\
\text { clientes. }\end{array}$ & 6,69 & 1,93 & 185 \\
\hline
\end{tabular}

Fonte: Elaborado pela autora.

Vale ressaltar que as médias dos itens do construto inovação de marketing são relativamente próximas para todas as empresas, independentemente da faixa de receita bruta operacional, conforme indicado na Tabela 17.

Tabela 17 - Média e desvio padrão das variáveis do construto inovação de marketing de acordo com faixas da receita operacional bruta anual

\begin{tabular}{c|c|c|c|c|c|c|c|c}
\hline \multirow{2}{*}{} & \multicolumn{2}{|c|}{ Até R\$ 1,2 milhão } & \multicolumn{2}{c|}{$\begin{array}{c}\text { Acima de R\$ 1,2 } \\
\text { milhão até R\$ 10,5 } \\
\text { milhões }\end{array}$} & \multicolumn{2}{c|}{$\begin{array}{c}\text { Acima de R\$ 10,5 } \\
\text { milhões até R\$ 60 } \\
\text { milhões }\end{array}$} & \multicolumn{2}{c}{$\begin{array}{c}\text { Acima de R\$ 60 } \\
\text { milhões }\end{array}$} \\
\cline { 2 - 9 } & Média & $\begin{array}{c}\text { Desvio } \\
\text { Padrão }\end{array}$ & Média & $\begin{array}{c}\text { Desvio } \\
\text { Padrão }\end{array}$ & Média & $\begin{array}{c}\text { Desvio } \\
\text { Padrão }\end{array}$ & Média & $\begin{array}{c}\text { Desvio } \\
\text { Padrão }\end{array}$ \\
\hline MKT1 & 4,32 & 2,28 & 4,93 & 2,81 & 5,21 & 2,32 & 5,52 & 2,43 \\
\hline MKT2 & 6,03 & 2,9 & 5,08 & 3,0 & 6,06 & 3,07 & 5,5 & 3,46 \\
\hline MKT3 & 5,02 & 2,76 & 6,26 & 2,47 & 5,57 & 1,67 & 6,13 & 2,39 \\
\hline MKT4 & 5,21 & 2,04 & 5,8 & 2,36 & 5,28 & 2,29 & 5,43 & 2,18 \\
\hline MKT5 & 6,89 & 1,93 & 6,82 & 1,75 & 5,99 & 1,94 & 6,87 & 2,11 \\
\hline
\end{tabular}

Fonte: Elaborado pela autora.

Quanto ao desempenho em inovação organizacional, os respondentes apresentaram, em sua maioria, entre grau regular e grau alto de concordância frente às afirmações, conforme indicado na Tabela 18. O único item cujo grau de concordância é baixo refere-se à melhoria no compartilhamento e à transferência de conhecimentos com outras organizações, ou seja, as empresas não têm notado este efeito em suas atividades. Vale ressaltar que o compartilhamento do conhecimento é uma das tarefas primordiais para a realização de inovações. Neste sentido, a formação de redes de inovação pode ser apontada como uma 
alternativa para melhorar sua disseminação entre as organizações (MELO; AGOSTINHO, 2007).

A média da escala somada para o construto em questão foi de 4,82, indicando que, de forma geral, as empresas introduzem algumas inovações organizacionais e/ou têm percebido alguns efeitos decorrentes deste tipo de inovação, principalmente no que se refere à implementação novas técnicas de gestão para melhorar rotinas e práticas de trabalho, como também em relação ao enquadramento da empresa em regulações e normas acerca do mercado. Comparativamente, a média somada deste construto é inferior aos resultados apresentados pelos construtos de inovação de produto e de marketing, assemelhando-se à média obtida no construto inovação de processo.

Tabela 18 - Inovação organizacional

\begin{tabular}{|c|c|c|c|c|}
\hline & & Média & $\begin{array}{l}\text { Desvio } \\
\text { Padrão }\end{array}$ & $\mathrm{n}$ \\
\hline ORG1 & $\begin{array}{l}\text { A empresa implementou novas técnicas de gestão para melhorar rotinas e } \\
\text { práticas de trabalho [como por exemplo: reengenharia dos processos de } \\
\text { negócio, gestão do conhecimento, controle da qualidade total, sistemas de } \\
\text { formação/treinamento, SIG (sistemas de informações gerenciais) e ERP } \\
\text { (planejamento dos recursos do negócio)] }\end{array}$ & 6,36 & 2,48 & 185 \\
\hline ORG2 & $\begin{array}{l}\text { A empresa implementou novos métodos de organização do trabalho para } \\
\text { melhor distribuir responsabilidades e poder de decisão (como por exemplo o } \\
\text { estabelecimento do trabalho em equipe, a descentralização ou integração de } \\
\text { departamentos) }\end{array}$ & 4,97 & 2,45 & 185 \\
\hline ORG3 & $\begin{array}{l}\text { A empresa implementou mudanças nas relações com outras empresas ou } \\
\text { instituições públicas visando constituir uma novidade organizacional(tais como } \\
\text { o estabelecimento pela primeira vez de alianças, parcerias, terceirização ou } \\
\text { subcontratação de atividades) }\end{array}$ & 4,15 & 2,58 & 185 \\
\hline ORG4 & $\begin{array}{l}\text { Observou-se uma melhoria na comunicação e a interação entre as diferentes } \\
\text { áreas de negócios. }\end{array}$ & 4,80 & 2,13 & 185 \\
\hline ORG5 & $\begin{array}{l}\text { Observou-se uma melhoria no compartilhamento e a transferência de } \\
\text { conhecimentos com outras organizações. }\end{array}$ & 3,62 & 2,46 & 185 \\
\hline ORG6 & $\begin{array}{l}\text { Houve o enquadramento da empresa em regulações e normas relativas ao } \\
\text { mercado interno ou externo. }\end{array}$ & 5,03 & 2,89 & 185 \\
\hline
\end{tabular}

Fonte: Elaborado pela autora.

No caso da inovação organizacional, há indicações na Tabela 19 de que, para as variáveis ORG1, ORG2, ORG5 e ORG6, quanto maior a receita, maior o valor da média e, portanto, maior a concordância em relação às afirmações. No caso de ORG3 e ORG4 todas as empresas com receitas maiores do que $\mathrm{R} \$ 1,2$ milhão apresentaram média superior às empresas com receita de até $\mathrm{R} \$ 1,2$ milhão. 
Tabela 19 - Média e desvio padrão das variáveis do construto inovação organizacional de acordo com faixas da receita operacional bruta anual

\begin{tabular}{c|c|c|c|c|c|c|c|c}
\hline & \multicolumn{2}{|c|}{ Até R\$ 1,2 milhão } & \multicolumn{2}{c|}{$\begin{array}{c}\text { Acima de R\$ 1,2 } \\
\text { milhão até R\$ 10,5 } \\
\text { milhões }\end{array}$} & $\begin{array}{c}\text { Acima de R\$ 10,5 } \\
\text { milhões até R\$ 60 } \\
\text { milhões }\end{array}$ & \multicolumn{2}{c}{$\begin{array}{c}\text { Acima de R\$ 60 } \\
\text { milhões }\end{array}$} \\
\cline { 2 - 9 } & Média & $\begin{array}{c}\text { Desvio } \\
\text { Padrão }\end{array}$ & Média & $\begin{array}{c}\text { Desvio } \\
\text { Padrão }\end{array}$ & Média & $\begin{array}{c}\text { Desvio } \\
\text { Padrão }\end{array}$ & Média & $\begin{array}{c}\text { Desvio } \\
\text { Padrão }\end{array}$ \\
\hline ORG1 & 5,89 & 2,57 & 6,36 & 2,51 & 6,55 & 2,61 & 7,3 & 1,7 \\
\hline ORG2 & 4,31 & 2,35 & 4,77 & 2,54 & 5,77 & 2,49 & 5,93 & 1,92 \\
\hline ORG3 & 3,57 & 2,47 & 4,56 & 2,81 & 4,54 & 2,72 & 4,31 & 2,03 \\
\hline ORG4 & 4,04 & 1,88 & 5,2 & 2,29 & 5,09 & 2,2 & 5,54 & 1,82 \\
\hline ORG5 & 3,12 & 2,31 & 3,52 & 2,29 & 4,14 & 2,81 & 4,39 & 2,47 \\
\hline ORG6 & 3,89 & 2,76 & 5,28 & 2,91 & 5,81 & 2,3 & 6,38 & 2,95 \\
\hline
\end{tabular}

Fonte: Elaborado pela autora.

Uma vez levantados os dados acerca do desempenho inovador das empresas amostradas, a pesquisa buscou verificar as características das redes de inovação porventura existentes. Vale ressaltar que a definição de redes de inovação proposta neste estudo foi baseada no Manual de Oslo (OCDE, 2005) e na Forfás (2004). Dessa forma, sob o ponto de vista da empresa pesquisada, foram consideradas redes de inovação todo e qualquer conjunto de relações estabelecidas de modo colaborativo entre empresas e outras organizações, instituições e/ou indivíduos, nas quais os intervenientes assumem um papel ativo visando à realização de inovações. São incluídas nesta definição relações formais ou informais, de qualquer horizonte temporal, em qualquer localização geográfica, à exceção das relações estabelecidas por contratos de aquisição de conhecimento ou tecnologia.

Inicialmente, perguntou-se sobre o principal responsável pelo desenvolvimento de inovações, segundo a percepção da empresa. O Gráfico 20, mostra que a grande maioria das empresas declarou ser a principal responsável pelas inovações $(76,22 \%)$, seguida por $15,68 \%$ de empresas que afirmaram desenvolver as inovações em cooperação com outras empresas ou institutos. Para 4,86\% das empresas, a principal responsável pelo desenvolvimento de inovações é outra empresa do grupo, enquanto que, para 3,24\%, as inovações são desenvolvidas por outras empresas ou institutos. Esse resultado é próximo ao apontado pela PINTEC (IGBE, 2010) e por Carvalho (2010), indicando que o processo de desenvolvimento de inovações ainda está bastante centralizado na empresa. 


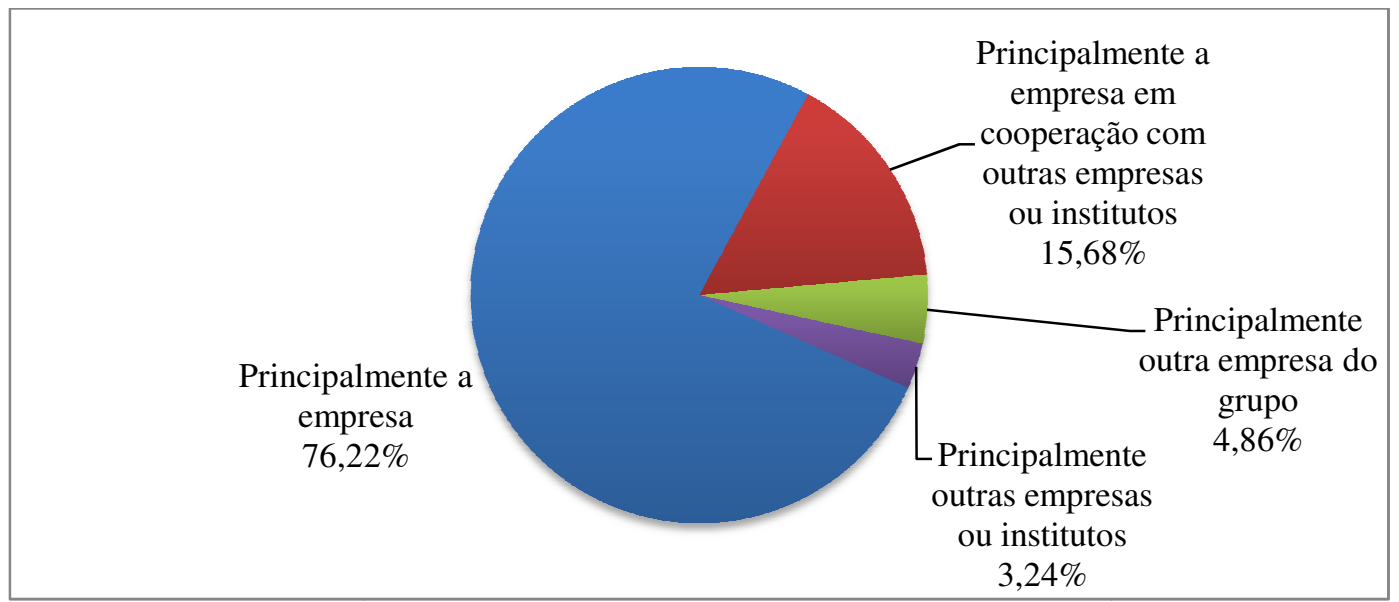

Gráfico 20 - Principal responsável pelo desenvolvimento de inovações Fonte: Elaborado pela autora.

Apesar disso, nota-se que a frequência observada para os atores com os quais as empresas desenvolveram pelo menos uma inovação nos últimos três anos é bastante significativa [Gráfico 21]. A pesquisa revelou que 79,46\% das empresas respondentes desenvolveu pelo menos uma inovação nos últimos três anos por meio da colaboração com clientes/consumidores; $62,70 \%$ a partir da colaboração com fornecedores; $23,24 \%$ com competidores e $39,46 \%$ com universidades e institutos de pesquisa.

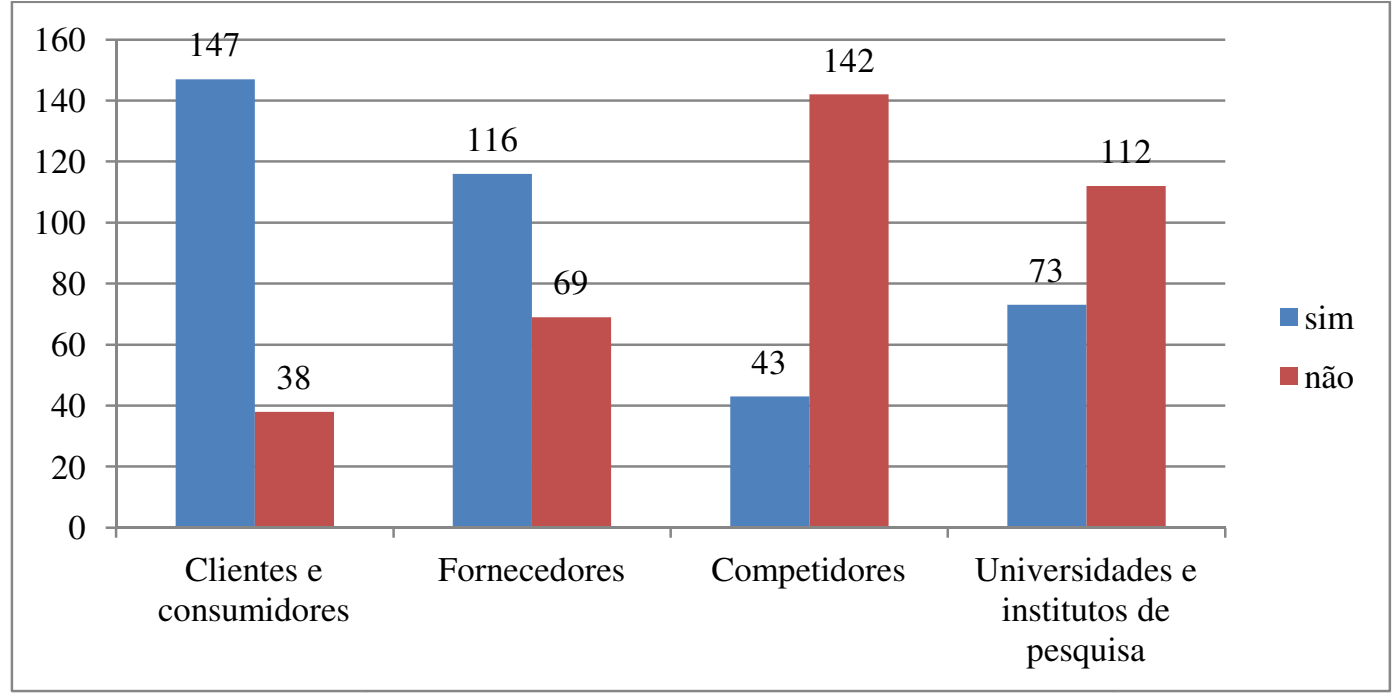

Gráfico 21 - Existência de colaboração

Fonte: Elaborado pela autora. 
Comparando-se os Gráficos 20 e 21 é possível afirmar que grande parte dos respondentes tem estabelecido relações com diferentes parceiros visando o desenvolvimento de inovações. No entanto, a participação destes parceiros na atividade inovativa da empresa como um todo ainda é pequena, considerando-se que a maioria das empresas declarou ser a principal responsável pelas inovações.

Além disso, apesar da pesquisa realizada pelo INSEAD (DOZ et al., 2006) ter revelado que os setores de eletrônicos e engenharia elétrica costumam apresentar níveis de colaboração com consumidores abaixo da média, estando mais inclinados à colaboração com os fornecedores, nota-se, no Gráfico 21, que o número de empresas que colaboram com clientes/consumidores (147 empresas) é superior àquelas que afirmam colaborar com fornecedores (116 empresas) para desenvolvimento de inovações.

De fato, os consumidores e fornecedores são os agentes mais citados na literatura acerca das redes de inovação (GEMÜDEN et al., 1996; TETHER, 2002; OCDE, 2005; CARVALHO, 2010; NDOU et al., 2011, CALDEIRA et al., 2012, FITJAR; RODRÍGUEZ-POSE, 2013). Isso é justificado, possivelmente, pela necessidade de criação de colaborações mais aprofundadas e de longo-prazo, que possibilite a sobrevivência das empresas e um ambiente de alto desenvolvimento tecnológico (DOZ et al., 2006).

Dando continuidade à análise, foi realizado um cruzamento de dados referentes aos parceiros estabelecidos nas redes de inovação segundo o tamanho da empresa. O Gráfico 22 indica a existência de um alto percentual de cooperação com clientes/consumidores em micro, pequenas e médias empresas, seguidos pelos fornecedores, citados por $73 \%$ das médias empresas. Destaca-se também o alto percentual de empresas grandes que afirmaram ter desenvolvido pelo menos uma inovação nos últimos três anos por meio da colaboração com universidades e institutos de pesquisa $(70 \%)$. 


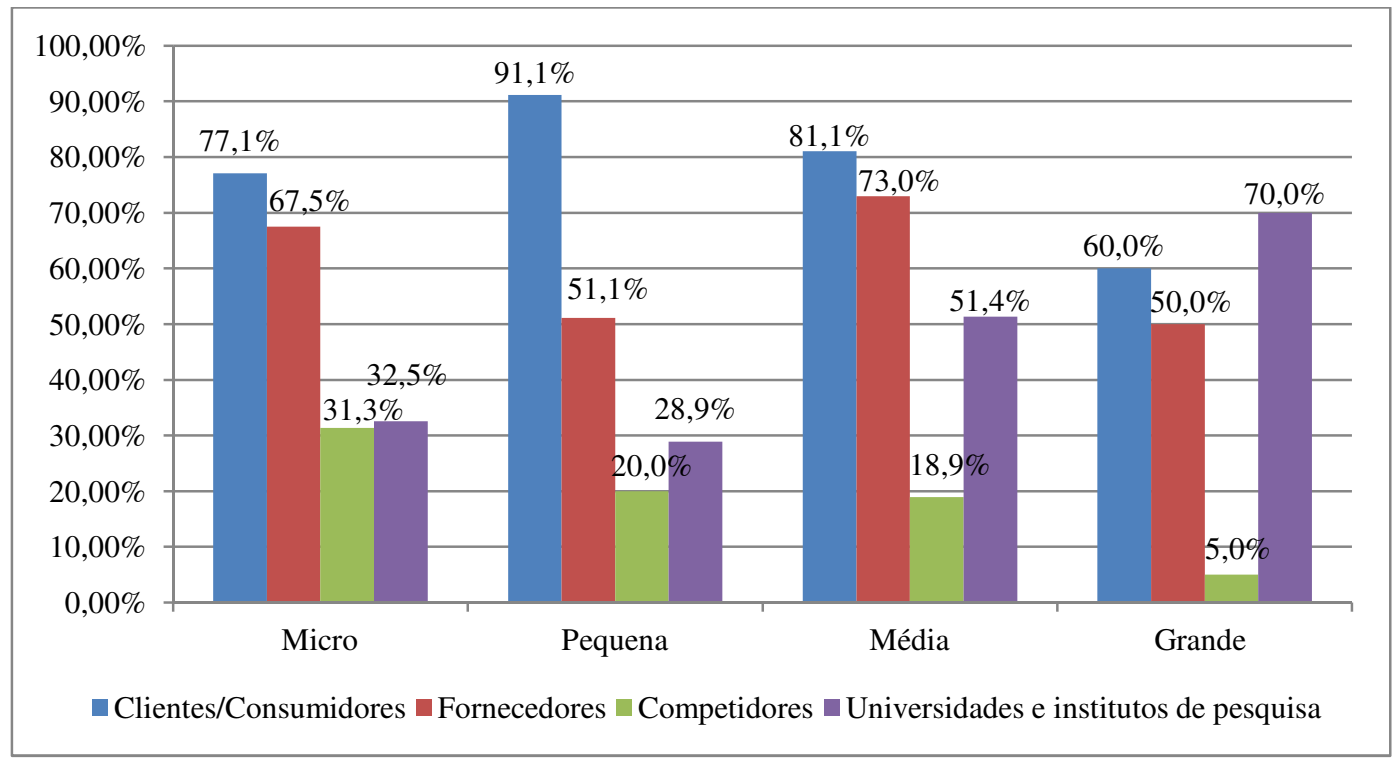

Gráfico 22 - Parceiros para inovação por tamanho da empresa Fonte: Elaborado pela autora.

Quanto ao grau de importância relativo atribuído a cada parceiro, observa-se, na Tabela 20, que os atores mais importantes para o estabelecimento de relações para a inovação são os clientes/consumidores e fornecedores. Os números em destaque na Tabela 20 foram obtidos por meio do cálculo da média do grau de importância atribuído a cada um dos parceiros de inovação. Este resultado é condizente tanto com os dados expressos no Gráfico 21, quanto com outros levantamentos (CARVALHO, 2010; NDOU et al., 2011).

Nota-se também, na Tabela 20, que a menor importância média foi dada aos competidores. Este fato também foi percebido na PINTEC (IBGE, 2010) e na pesquisa de Tsai (2009), que apontou que a colaboração com competidores é o tipo menos comum de parceria em redes de inovação.

Tabela 20 - Grau de importância dos parceiros de inovação

\begin{tabular}{l|c|c|c}
\hline & Média & $\begin{array}{c}\text { Desvio } \\
\text { Padrão }\end{array}$ & $\mathrm{n}$ \\
\hline Clientes e consumidores & 7,4 & 2,52 & 185 \\
\hline Fornecedores & 6,01 & 2,92 & 185 \\
\hline Universidades e institutos de pesquisa & 3,76 & 3,12 & 185 \\
\hline Competidores & 2,99 & 2,53 & 185 \\
\hline
\end{tabular}

Fonte: Elaborado pela autora. 
Dentre as razões para o estabelecimento de redes de inovação, observam-se no Gráfico 23 os destaques para o acesso a novos conhecimentos, citado por 51,89\% dos respondentes; e para a combinação de competências, referenciada por 48,68\% destes. O item "outras" foi apontado por 5,95\% dos respondentes que justificaram a formação de redes de inovação principalmente em decorrência de exigências do mercado e de incentivos provenientes da Lei da Informática. Vale salientar que, por ser uma questão de resposta múltipla, as organizações poderiam indicar mais do que um motivo para o estabelecimento das redes.

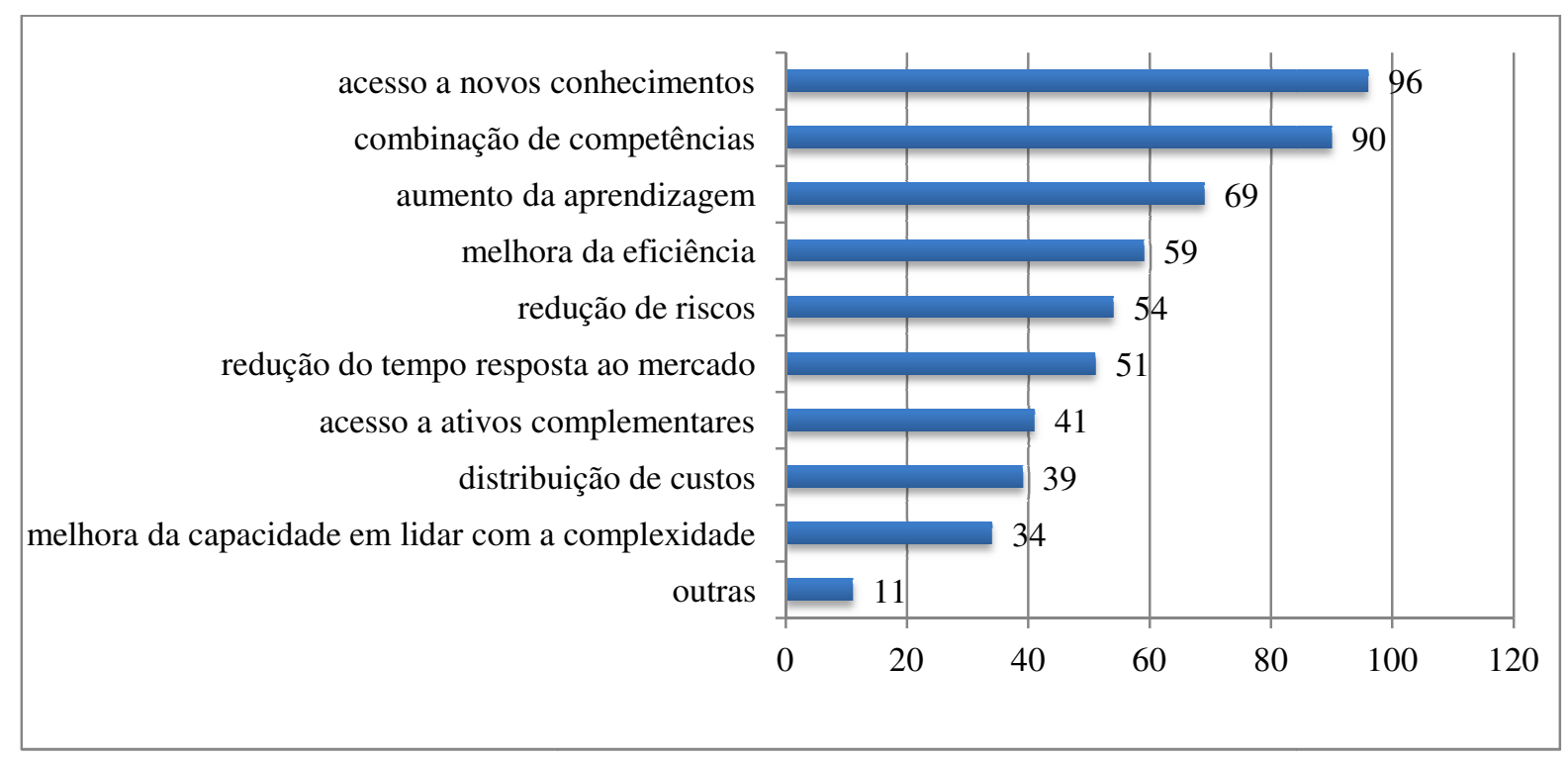

Gráfico 23 - Razões para o estabelecimento de redes de inovação Fonte: Elaborado pela autora.

Os dados expressos no Gráfico 23 enfatizam que grande parte das razões motivadoras para a formação de redes se refere a questões como a obtenção de conhecimento, competências e aprendizado. Estes resultados convergem com os estudos de Powell et al. (1996; 2005), Dyer e Nobeoka (2000), Chesbrough (2003), Powell e Grodal (2006), Cassiman e Veugelers (2006), Ndou et al. (2011), que salientaram a importância do compartilhamento de conhecimento e combinação de competências para os processos de inovação.

Tendo em vista que o conhecimento é considerado um fator-chave para a realização de inovações e, consequentemente, para a formação das redes, a pesquisa também teve como foco o levantamento de questões relacionadas à capacidade das empresas de absorção do conhecimento. $\mathrm{O}$ construto para avaliação dessa capacidade foi formado por seis itens que incluíam variáveis objetivas, como o número de funcionários de P\&D em relação ao total, 
como também variáveis de valor, como o grau de relevância da área de P\&D para o desenvolvimento de inovações segundo uma escala de 0 a 10.

A Tabela 21 expressa as médias obtidas para cada uma das variáveis, destacando-se, em média, o alto grau de concordância frente à afirmação de que a área de P\&D é bastante relevante para o desenvolvimento de inovações na empresa $(7,1)$ e o grau de concordância muito alto de que pelos menos uma inovação na empresa foi desenvolvida a partir de relações com clientes, fornecedores, competidores, universidades ou institutos de pesquisa nos últimos $3 \operatorname{anos}(8,1)$.

Tabela 21 - Absorção do conhecimento

\begin{tabular}{|c|c|c|c|c|}
\hline & & Média & $\begin{array}{l}\text { Desvio } \\
\text { Padrão }\end{array}$ & $\mathrm{n}$ \\
\hline ABS1 & $\begin{array}{l}\text { Intensidade da área de } \mathrm{P} \& \mathrm{D} \text { (porcentagem da receita operacional bruta gasta } \\
\text { com } \mathrm{P} \& \mathrm{D} \text { e treinamento em } 2012 \text { sobre o total de funcionários na empresa) }\end{array}$ & $0,48 \%$ & 0,82 & 185 \\
\hline ABS2 & Número de funcionários na área de P\&D em relação ao total & $6,92 \%$ & 9,11 & 185 \\
\hline ABS3 & $\begin{array}{l}\text { A área de P\&D é bastante relevante para o desenvolvimento de inovações na } \\
\text { empresa (importância da área de } P \& D \text { ) }\end{array}$ & 7,1 & 2,73 & 185 \\
\hline ABS4 & $\begin{array}{l}\text { Percentual de funcionários da empresa que possui cursos de Especialização, } \\
\text { Mestrado e Doutorado (média ponderada com os pesos: } 1 \text { - Esp; } 2 \text { - Mest.; } 3 \\
\text { - Dout.) }\end{array}$ & $4,61 \%$ & 5,41 & 185 \\
\hline ABS5 & $\begin{array}{l}\text { Diversidade de formações dos profissionais da empresa (quantidade de áreas } \\
\text { de formação detectada na empresa sobre o total de funcionários) }\end{array}$ & $53,66 \%$ & 43,75 & 185 \\
\hline ABS6 & $\begin{array}{l}\text { Pelos menos uma inovação na empresa foi desenvolvida a partir de relações } \\
\text { com clientes, fornecedores, competidores, universidades ou institutos de } \\
\text { pesquisa nos últimos } 3 \text { anos }\end{array}$ & 8,1 & 2,09 & 185 \\
\hline
\end{tabular}

Fonte: Elaborado pela autora.

Complementarmente, foram levantados dados acerca da estratégia de utilização do conhecimento, visando identificar a existência de alguma relação destas variáveis com os tipos de parceiros estabelecidos nas redes de inovação. A Tabela 22 apresenta as médias e os desvios padrão para cada uma das variáveis que formam os construtos estratégia de exploração e explotação.

Vale salientar que as estratégias de exploração estão relacionadas à inovação radical e à troca de informações novas para a empresa, enquanto a estratégia de explotação está relacionada à inovação incremental e à troca de informações complementares às da empresa. 
Para o construto exploração (EXPR), observou-se, em média, graus baixos, médios e altos de concordância frente às afirmações, sendo que a média somada deste construto foi de 5,36. Já para o construto explotação (EXPT), a pesquisa revelou graus médios e altos de concordância, resultando em uma média somada de 6,45. Pode-se verificar, por meio do exposto, que ambas as estratégias são utilizadas pelas organizações, parecendo haver uma leve vantagem para a estratégia de explotação.

A partir dos valores apresentados, nota-se que, dentre as variáveis que formam o construto estratégia de exploração, parece haver maior concordância média em EXPR2 e EXPR4, enquanto que, para a estratégia de explotação, houve maior concordância média em EXPT4.

Tabela 22 - Estratégia de exploração e explotação

\begin{tabular}{|c|c|c|c|c|}
\hline & & Média & $\begin{array}{l}\text { Desvio } \\
\text { Padrão }\end{array}$ & $\mathrm{n}$ \\
\hline EXPR1 & $\begin{array}{l}\text { A empresa desenvolve relações com parceiros que permitam a } \\
\text { implementação de inovações mais radicais. }\end{array}$ & 4,96 & 2,9 & 185 \\
\hline EXPR2 & $\begin{array}{l}\text { A empresa visa o desenvolvimento de relações que lhe proporcionem a } \\
\text { geração de novas ideias e conhecimentos organizacionais. }\end{array}$ & 6,32 & 2,45 & 185 \\
\hline EXPR3 & $\begin{array}{l}\text { O desenvolvimento de ligações mais fracas com os parceiros de inovação é } \\
\text { preferível, por possibilitar a difusão de novas informações. }\end{array}$ & 3,29 & 2,24 & 185 \\
\hline EXPR4 & $\begin{array}{l}\text { A empresa possui como foco o desenvolvimento de novos produtos, } \\
\text { processos e métodos. }\end{array}$ & 6,86 & 2,55 & 185 \\
\hline EXPT1 & $\begin{array}{l}\text { A empresa desenvolve relações com parceiros que permitam a realização de } \\
\text { inovações incrementais. }\end{array}$ & 5,93 & 2,76 & 185 \\
\hline EXPT2 & $\begin{array}{l}\text { A empresa visa o desenvolvimento de relações que lhe proporcionem o } \\
\text { reforço e aprimoramento dos conhecimentos organizacionais já estabelecidos. }\end{array}$ & 6,13 & 2,33 & 185 \\
\hline ЕXРТ3 & $\begin{array}{l}\text { O desenvolvimento de ligações fortes com os parceiros de inovação é } \\
\text { preferível, por estarem baseadas em interações regulares, fundamentadas na } \\
\text { confiança entre as organizações. }\end{array}$ & 6,13 & 2,48 & 185 \\
\hline EXPT4 & $\begin{array}{l}\text { A empresa possui como foco a melhoria dos produtos, métodos e processos } \\
\text { existentes. }\end{array}$ & 7,61 & 1,87 & 185 \\
\hline
\end{tabular}

Fonte: Elaborado pela autora.

\subsection{Análise das variáveis moderadoras}

A análise da influência das variáveis moderadoras no desempenho inovador foi feita com base na comparação de médias dos grupos, por meio da Análise Multivariada de Variância (MANOVA). Tal técnica consiste em comparar "k" grupos independentes segundo "m" variáveis. Para a presente análise, foram comparadas as seguintes variáveis: percentual gasto com P\&D, tamanho da empresa e origem do capital controlador, segundo as variáveis dos construtos estudados (inovação em produto, processo, marketing e organizacional). 


\subsubsection{Percentual gasto com P\&D}

Para analisar a influência do gasto com P\&D no resultado em inovação da empresa, foram criadas faixas com base no percentil, resultando em 4 categorias:

- Nenhum gasto com $P \& D(n=48)$;

- Gastos maiores do que zero e menores ou iguais a $3 \%$ da receita operacional bruta $(n=46)$;

- Gastos maiores do que $3 \%$ e menores ou iguais a $8 \%$ da receita operacional bruta $(n=45)$;

- Gastos maiores do que $8 \%$ da receita operacional bruta $(n=46)$.

Primeiramente, foi analisada a influência do percentual gasto com P\&D no desempenho em inovação de produto. A Tabela 23 mostra o teste de igualdade entre as matrizes de covariâncias dos grupos. Pelo p-valor apresentado, observa-se que a suposição de igualdade não é satisfeita. Entretanto, como os grupos apresentam tamanhos próximos, sabe-se que o impacto dessa violação não invalida a análise.

Tabela 23 - Teste M de Box para inovação de produto e gasto com P\&D

\begin{tabular}{c|c}
\hline M de Box & 135,401 \\
\hline F & 2,022 \\
\hline G.L. 1 & 63 \\
\hline G.L. 2 & 76470,814 \\
\hline P.Valor & 0,000 \\
\hline
\end{tabular}

Fonte: Elaborado pela autora.

Pela Tabela 24, pode-se observar que, tanto para o traço de Pillai, quanto para lambda de Wilks, existe significância ao nível de 5\% para a diferença entre os grupos.

Tabela 24 - MANOVA para inovação de produto e gasto com P\&D

\begin{tabular}{c|c|c|c|c|c}
\hline & Valor & F & $\begin{array}{c}\text { G.L. } \\
\text { Hipótese }\end{array}$ & $\begin{array}{c}\text { G.L. } \\
\text { Erro }\end{array}$ & P-Valor \\
\hline Traço de Pillai & 0,178 & 1,872 & 18 & 534 & 0,016 \\
\hline Lambda de Wilks & 0,831 & 1,875 & 18 & 498,288 & 0,016 \\
\hline Traço de Hotelling & 0,193 & 1,874 & 18 & 524 & 0,016 \\
\hline Maior Raiz de Roy & 0,102 & 3,028 & 6 & 178 & 0,008 \\
\hline
\end{tabular}

Fonte: Elaborado pela autora. 
Os testes de comparações múltiplas dispostos na Tabela 25 indicaram que há diferença entre os grupos apenas em PROD1 e PROD3. Para PROD1, a diferença ocorre entre empresas que gastam acima de $8 \%$ e empresas que não gastam $(0 \%)$ (p-valor $=0,018)$ e também entre empresas que gastam entre 3 e $8 \%$ e empresas que não gastam $(0 \%)(p$-valor $=0,001)$, sendo que os maiores valores da média para ambos os casos foram para empresas que gastam acima de $8 \%$ e entre 3 e $8 \%$. Para PROD3, a diferença foi encontrada entre grupos de empresas que investem entre 0 e $3 \%$ da receita (maior média) e empresas que não investem em P\&D (menor média).

Tabela 25 - Teste de comparações múltiplas entre o percentual gasto com P\&D e variáveis do construto inovação de produto

\begin{tabular}{|c|c|c|c|c|c|c|}
\hline \multirow[b]{2}{*}{ Variável } & \multirow{2}{*}{$\begin{array}{c}\text { (I) } \\
\text { V12 }\end{array}$} & \multirow[b]{2}{*}{ (J) V12 } & \multirow{2}{*}{$\begin{array}{c}\text { Dif. de Médias } \\
\text { (I-J) }\end{array}$} & \multirow{2}{*}{$\begin{array}{c}\text { P- } \\
\text { Valor }\end{array}$} & \multicolumn{2}{|c|}{ I.C. $95 \%$ de Confiança } \\
\hline & & & & & $\begin{array}{c}\text { Limite } \\
\text { Inferior }\end{array}$ & $\begin{array}{c}\text { Limite } \\
\text { Superior }\end{array}$ \\
\hline \multirow{3}{*}{ PROD1 } & \multirow{3}{*}{ Zero } & Acima de 8 & $-1,626$ &, 018 & $-3,071$ & $-0,182$ \\
\hline & & Entre 0 e 3 & $-0,859$ &, 687 & $-2,303$ &, 586 \\
\hline & & Entre 3 e 8 & $-2,041$ &, 001 & $-3,494$ & $-0,589$ \\
\hline \multirow{3}{*}{ PROD3 } & \multirow{3}{*}{ Zero } & Acima de 8 & $-0,587$ & 1,000 & $-2,079$ & ,906 \\
\hline & & Entre 0 e 3 & $-1,743$ &, 013 & $-3,236$ & $-0,251$ \\
\hline & & Entre 3 e 8 & $-0,765$ & 1,000 & $-2,266$ & ,736 \\
\hline
\end{tabular}

Fonte: Elaborado pela autora.

De forma geral, pode-se afirmar que o aumento na porcentagem gasta com P\&D, nos níveis de indicados, tende a proporcionar um maior potencial de introdução de pelo menos um produto novo ou significativamente melhorado no mercado (PROD1) e tornar mais frequente a participação da empresa em congressos e feiras como expositor/palestrante (PROD3).

Na sequência, a Tabela 26 mostra o teste de igualdade entre as matrizes de covariâncias dos grupos considerando o construto de inovação de processo. Pelo p-valor apresentado, observase novamente que a suposição de igualdade das matrizes de covariância não é satisfeita considerando um nível de significância de 5\%, mas é aceita para o nível de $1 \%$ de significância. Como os grupos apresentam tamanhos próximos, foi dado prosseguimento à análise. 
Tabela 26 - Teste M de Box para inovação de processo e gasto com P\&D

\begin{tabular}{c|c}
\hline M de Box & 90,219 \\
\hline F & 1,347 \\
\hline G.L. 1 & 63 \\
\hline G.L. 2 & 76470,814 \\
\hline P.Valor &, 035 \\
\hline
\end{tabular}

Fonte: Elaborado pela autora.

Pela Tabela 27, pode-se observar que tanto para o traço de Pillai, quanto para Lambda de Wilks, não existe diferença significativa das médias da população ao nível de significância de $5 \%$. Portanto, para as empresas pesquisadas, o percentual investido em atividades de P\&D parece não provocar alterações no desempenho em inovação de processo.

Tabela 27 - MANOVA para inovação de processo e gasto com P\&D

\begin{tabular}{c|c|c|c|c|c}
\hline & Valor & F & $\begin{array}{c}\text { G.L. } \\
\text { Hipótese }\end{array}$ & $\begin{array}{c}\text { G.L. } \\
\text { Erro }\end{array}$ & P-Valor \\
\hline Traço de Pillai & 0,108 & 1,105 & 18 & 534 & 0,343 \\
\hline Lambda de Wilks & 0,895 & 1,102 & 18 & 498,288 & 0,347 \\
\hline Traço de Hotelling & 0,113 & 1,098 & 18 & 524 & 0,35 \\
\hline Maior Raiz de Roy & 0,069 & 2,037 & 6 & 178 & 0,063 \\
\hline
\end{tabular}

Fonte: Elaborado pela autora.

Em relação à inovação de marketing, a Tabela 28 mostra que a suposição de igualdade entre as matrizes de covariâncias dos grupos é satisfeita ( $\mathrm{p}$-valor $=0,317$ ).

Tabela 28 - Teste M de Box para inovação de marketing e gasto com P\&D

\begin{tabular}{c|c}
\hline M de Box & 51,518 \\
\hline F & 1,088 \\
\hline G.L. 1 & 45 \\
\hline G.L. 2 & 80780,107 \\
\hline P.Valor & 0,317 \\
\hline
\end{tabular}

Fonte: Elaborado pela autora.

Analisando-se os p-valores apresentados na Tabela 29, verifica-se que não existe diferença significativa entre as médias populacionais dos grupos ao nível de 5\%. Sendo assim, para as empresas da população alvo modificada, o percentual investido em atividades de P\&D parece não provocar alterações no desempenho em inovação de marketing. 
Tabela 29 - MANOVA para inovação de marketing e gasto com P\&D

\begin{tabular}{c|c|c|c|c|c}
\hline & Valor & F & $\begin{array}{c}\text { G.L. } \\
\text { Hipótese }\end{array}$ & $\begin{array}{c}\text { G.L. } \\
\text { Erro }\end{array}$ & P-Valor \\
\hline Traço de Pillai & 0,06 & 0,731 & 15 & 537 & 0,753 \\
\hline Lambda de Wilks & 0,941 & 0,732 & 15 & 489,02 & 0,752 \\
\hline Traço de Hotelling & 0,063 & 0,733 & 15 & 527 & 0,751 \\
\hline Maior Raiz de Roy & 0,051 & 1,823 & 5 & 179 & 0,111 \\
\hline
\end{tabular}

Fonte: Elaborado pela autora.

Dando continuidade à análise, a Tabela 30 mostra o teste de igualdade entre as matrizes de covariâncias dos grupos em relação à inovação organizacional. Pelo p-valor apresentado, observa-se que a igualdade não é satisfeita. Novamente, considerou-se que, como os grupos apresentam tamanhos próximos, o impacto dessa violação é mínimo.

Tabela 30 - Teste M de Box para inovação organizacional e gasto com P\&D

\begin{tabular}{c|c}
\hline M de Box & 91,491 \\
\hline F & 1,366 \\
\hline G.L. 1 & 63 \\
\hline G.L. 2 & 76470,814 \\
\hline P.Valor & 0,029 \\
\hline
\end{tabular}

Fonte: Elaborado pela autora.

Pela Tabela 31 pode-se observar que, tanto para o traço de Pillai, quanto para lambda de Wilks, estatísticas mais adequadas para avaliar as diferenças de médias, não existe significância ao nível de 5\% para a diferença entre os grupos.

Tabela 31 - MANOVA para inovação organizacional e gasto com P\&D

\begin{tabular}{c|c|c|c|c|c}
\hline & Valor & F & $\begin{array}{c}\text { G.L. } \\
\text { Hipótese }\end{array}$ & $\begin{array}{c}\text { G.L. } \\
\text { Erro }\end{array}$ & P-Valor \\
\hline Traço de Pillai & 0,152 & 1,584 & 18 & 534 & 0,059 \\
\hline Lambda de Wilks & 0,854 & 1,584 & 18 & 498,288 & 0,06 \\
\hline Traço de Hotelling & 0,163 & 1,582 & 18 & 524 & 0,06 \\
\hline Maior Raiz de Roy & 0,085 & 2,528 & 6 & 178 & 0,023 \\
\hline
\end{tabular}

Fonte: Elaborado pela autora. 
Portanto, considera-se que o aumento ou diminuição do percentual da receita operacional bruta investido em atividades de $\mathrm{P} \& \mathrm{D}$ não provoca alterações nos resultados em inovações organizacionais nas empresas da população alvo modificada.

\subsubsection{Tamanho da empresa}

Para analisar a influência do tamanho da empresa no desempenho em inovação, foram considerados os seguintes grupos:

- Empresas grandes $(\mathrm{n}=20)$;

- Empresas médias $(\mathrm{n}=37)$;

- Empresas pequenas $(n=45)$;

- Micro empresas $(\mathrm{n}=83)$.

Primeiramente foram analisadas as variáveis do construto inovação em produto segundo o tamanho da empresa. A Tabela 32 mostra o teste de igualdade entre as matrizes de covariâncias dos grupos. Pode-se observar através do p-valor apresentado que a suposição de igualdade não foi satisfeita. Como o tamanho dos grupos é diferente e, observando-se o desvio padrão dos dados, percebeu-se que os maiores valores encontram-se nos maiores grupos. Nesse caso, deve-se considerar o Traço de Pillai como estatística do teste, por ser mais robusto à violação de igualdade entre as matrizes de covariâncias.

Tabela 32 - Teste M de Box para inovação de produto e tamanho da empresa

\begin{tabular}{c|c}
\hline M de Box & 108,281 \\
\hline F & 1,580 \\
\hline G.L. 1 & 63 \\
\hline G.L. 2 & 19907,785 \\
\hline P.Valor & 0,002 \\
\hline
\end{tabular}

Fonte: Elaborado pela autora.

Pela Tabela 33, observa-se que o p-valor apresentado para o traço de Pillai foi igual a 0,000, indicando diferença significativa das matrizes de covariâncias de diferentes grupos. 
Tabela 33 - MANOVA para inovação de produto e tamanho da empresa

\begin{tabular}{c|c|c|c|c|c}
\hline & Valor & F & $\begin{array}{c}\text { G.L. } \\
\text { Hipótese }\end{array}$ & $\begin{array}{c}\text { G.L. } \\
\text { Erro }\end{array}$ & P-Valor \\
\hline Traço de Pillai & 0,416 & 4,782 & 18 & 534 & 0,000 \\
\hline Lambda de Wilks & 0,612 & 5,253 & 18 & 498,288 & 0,000 \\
\hline Traço de Hotelling & 0,589 & 5,715 & 18 & 524 & 0,000 \\
\hline Maior Raiz de Roy & 0,501 & 14,852 & 6 & 178 & 0,000 \\
\hline
\end{tabular}

Fonte: Elaborado pela autora.

Para verificar onde se encontram as diferenças, foram realizados testes de comparações múltiplas. Observa-se, através dos p-valores na Tabela 34, que as empresas se diferem em PROD1, com diferença entre grande e micro $(p$-valor $=0,006)$ e entre grande e pequena $(p-$ valor $=0,049$ ), com maior valor para a empresa grande em ambos os casos. Em PROD2, a diferença foi significativa para a empresa grande e micro ( $p$-valor $=0,020)$, com maior valor para a micro empresa. As médias se diferem também em PROD3, com diferença entre grande e pequena $(p$-valor $=0,000)$, grande e micro $(p$-valor $=0,000)$ e média e micro $(p$-valor $=$ 0,000 ), sendo que quanto maior a empresa, maior o valor da média para todos esses casos.

Tabela 34 - Teste de comparações múltiplas entre o tamanho da empresa e variáveis do construto inovação de produto

\begin{tabular}{|c|c|c|c|c|c|c|}
\hline & \multirow[t]{2}{*}{ (I) $\mathrm{V7}$} & \multirow[t]{2}{*}{ (J) $\mathbf{V 7}$} & \multirow[t]{2}{*}{ Dif. de Médias (I-J) } & \multirow[t]{2}{*}{ P-Valor } & \multicolumn{2}{|c|}{ I.C. $95 \%$ de Confiança } \\
\hline & & & & & Limite Inferior & Limite Superior \\
\hline \multirow[t]{3}{*}{ PROD1 } & \multirow[t]{3}{*}{ Grande } & Média & 1,745 & 0,115 & $-0,223$ & 3,714 \\
\hline & & Pequena & 1,911 & 0,049 &, 004 & 3,817 \\
\hline & & Micro & 2,217 & 0,006 &, 450 & 3,984 \\
\hline \multirow[t]{3}{*}{ PROD2 } & \multirow[t]{3}{*}{ Grande } & Média & $-1,382$ & 0,281 & $-3,225$ &, 460 \\
\hline & & Pequena & $-1,119$ & 0,576 & $-2,903$ & 665 \\
\hline & & Micro & $-1,844$ & 0,020 & $-3,497$ & $-0,190$ \\
\hline \multirow[t]{6}{*}{ PROD3 } & \multirow[t]{3}{*}{ Grande } & Média & 1,301 & 0,379 & $-0,555$ & 3,156 \\
\hline & & Pequena & 2,776 & 0,000 & ,979 & 4,573 \\
\hline & & Micro & 3,518 & 0,000 & 1,852 & 5,183 \\
\hline & \multirow[t]{3}{*}{ Média } & Grande & $-1,301$ & 0,379 & $-3,156$ &, 555 \\
\hline & & Pequena & 1,475 & 0,052 & $-0,008$ & 2,959 \\
\hline & & Micro & 2,217 & 0,000 &, 895 & 3,539 \\
\hline
\end{tabular}

Fonte: Elaborado pela autora.

Pelo exposto, é possível afirmar que as empresas grandes se destacaram das micro e pequenas no que se refere à introdução de produtos novos ou significativamente melhorados no 
mercado (PROD1) e à frequência em congressos e feiras como expositor e palestrante (PROD3). As empresas médias também se destacaram das micro empresas neste último quesito. No entanto, as micro empresas possuem maior percentual de vendas proveniente de produtos novos ou significativamente melhorados (PROD2) se comparadas às grandes empresas.

Em relação à inovação de processo, observa-se, através do p-valor apresentado na Tabela 35, que a suposição de igualdade entre as matrizes de covariâncias dos grupos não foi satisfeita. Novamente, tendo em vista que o tamanho dos grupos é diferente e que, na maior parte dos casos os maiores desvios estão nos menores grupos, o Traço de Pillai foi considerado como estatística teste.

Tabela 35 - Teste M de Box para inovação de processo e tamanho da empresa

\begin{tabular}{c|c}
\hline M de Box & 136,773 \\
\hline F & 1,996 \\
\hline G.L. 1 & 63 \\
\hline G.L. 2 & 19907,785 \\
\hline P.Valor & 0,000 \\
\hline
\end{tabular}

Fonte: Elaborado pela autora.

Por meio da Tabela 36 verifica-se a existência de diferença significativa entre os grupos ao nível de $5 \%$.

Tabela 36 - MANOVA para inovação de processo e tamanho da empresa

\begin{tabular}{c|c|c|c|c|c}
\hline & Valor & F & $\begin{array}{c}\text { G.L. } \\
\text { Hipótese }\end{array}$ & $\begin{array}{c}\text { G.L. } \\
\text { Erro }\end{array}$ & P-Valor \\
\hline Traço de Pillai & 0,171 & 1,794 & 18 & 534 & 0,023 \\
\hline Lambda de Wilks & 0,836 & 1,81 & 18 & 498,288 & 0,022 \\
\hline Traço de Hotelling & 0,188 & 1,821 & 18 & 524 & 0,02 \\
\hline Maior Raiz de Roy & 0,114 & 3,379 & 6 & 178 & 0,004 \\
\hline
\end{tabular}

Fonte: Elaborado pela autora.

Na comparação dos grupos, nota-se, a partir da Tabela 37, que as empresas são diferentes em PROC2, PROC3, PROC5 e PROC6. Em PROC2, PROC3 e PROC6 as grandes empresas são diferentes das micro empresas ( $\mathrm{p}$-valor $=0,044 ; 0,027$ e 0,045 respectivamente), com maior valor da média para as grandes em todos os casos; em PROC5 as grandes e médias empresas 
se diferem da pequena ( $\mathrm{p}$-valor $=0,011$ e 0,026 respectivamente), com maior valor para as empresas maiores.

Tabela 37 - Teste de comparações múltiplas entre o tamanho da empresa e variáveis do construto inovação de processo

\begin{tabular}{|c|c|c|c|c|c|c|}
\hline & \multirow[t]{2}{*}{ (I) $\mathrm{V} 7$} & \multirow[t]{2}{*}{ (J) V7 } & \multirow{2}{*}{$\begin{array}{c}\text { Dif. de Médias (I- } \\
\text { J) }\end{array}$} & \multirow{2}{*}{$\begin{array}{c}\text { P- } \\
\text { Valor }\end{array}$} & \multicolumn{2}{|c|}{ I.C. $95 \%$ de Confiança } \\
\hline & & & & & $\begin{array}{c}\text { Limite } \\
\text { Inferior }\end{array}$ & $\begin{array}{c}\text { Limite } \\
\text { Superior }\end{array}$ \\
\hline \multirow[t]{3}{*}{ PROC2 } & \multirow[t]{3}{*}{ Grande } & Média & ,719 & 1,000 & $-1,221$ & 2,658 \\
\hline & & Pequena &, 924 & 1,000 & $-0,954$ & 2,802 \\
\hline & & Micro & 1,771 &, 044 &, 030 & 3,512 \\
\hline \multirow[t]{3}{*}{ PROC3 } & \multirow[t]{3}{*}{ Grande } & Média &, 725 & 1,000 & $-1,184$ & 2,633 \\
\hline & & Pequena & 1,299 &, 374 & $-0,549$ & 3,147 \\
\hline & & Micro & 1,845 &, 027 &, 133 & 3,558 \\
\hline \multirow[t]{3}{*}{ PROC5 } & \multirow[t]{3}{*}{ Pequena } & Grande & $-2,089$ &, 011 & $-3,847$ & $-0,331$ \\
\hline & & Média & $-1,571$ &, 026 & $-3,023$ & $-0,120$ \\
\hline & & Micro & $-0,675$ & ,832 & $-1,886$ &, 536 \\
\hline \multirow[t]{3}{*}{ PROC6 } & \multirow[t]{3}{*}{ Grande } & Média & ,664 & 1,000 & $-1,168$ & 2,495 \\
\hline & & Pequena & 1,528 &, 136 & $-0,245$ & 3,302 \\
\hline & & Micro & 1,664 &, 045 &, 021 & 3,308 \\
\hline
\end{tabular}

Fonte: Elaborado pela autora.

A partir desta análise, pode-se concluir que as empresas grandes apresentaram resultado superior às micro empresas com relação à introdução de pelo menos um sistema logístico ou método de entrega para seus insumos, bens ou serviços (PROC2), como também com relação à introdução de equipamentos, softwares e técnicas em atividades de apoio à produção, como por exemplo planejamento e controle da produção, medição de desempenho, controle da qualidade, compra, manutenção ou infraestrutura de TI (PROC3).

Também houve diferença nas médias referentes aos efeitos provenientes da inovação em processo. Segundo a comparação de médias, as empresas grandes notaram, nos últimos três anos, uma redução do consumo de matérias-primas e energia (PROC6) mais significativa do que as micro empresas. Além disso, as grandes e médias empresas também indicaram uma maior redução de custos de produção ou nos serviços prestados (PROC5) em comparação às pequenas empresas. 
Dando prosseguimento à análise, procurou-se testar a influência do tamanho das empresas no desempenho em inovação de marketing. Por meio das Tabelas 38 e 39, é possível perceber que o pressuposto de igualdade das matrizes de covariâncias é satisfeito (p-valor $=0,142$ ) e que, considerando as estatísticas do traço de Pillai e lambda de Wilks, não existe diferença significativa entre os grupos ao nível de 5\% de significância. É importante ressaltar que essas estatísticas são mais adequadas quando não se tem as condições de normalidade satisfeita.

Tabela 38 - Teste M de Box para inovação de marketing e tamanho da empresa

\begin{tabular}{c|c}
\hline M de Box & 59,186 \\
\hline F & 1,227 \\
\hline G.L. 1 & 45 \\
\hline G.L. 2 & 20774,019 \\
\hline P.Valor & 0,142 \\
\hline
\end{tabular}

Fonte: Elaborado pela autora.

Tabela 39 - MANOVA para inovação de marketing e tamanho da empresa

\begin{tabular}{c|c|c|c|c|c}
\hline & Valor & F & $\begin{array}{c}\text { G.L. } \\
\text { Hipótese }\end{array}$ & $\begin{array}{c}\text { G.L. } \\
\text { Erro }\end{array}$ & P-Valor \\
\hline Traço de Pillai & 0,133 & 1,655 & 15 & 537 & 0,056 \\
\hline Lambda de Wilks & 0,871 & 1,677 & 15 & 489,02 & 0,052 \\
\hline Traço de Hotelling & 0,145 & 1,695 & 15 & 527 & 0,048 \\
\hline Maior Raiz de Roy & 0,112 & 4,012 & 5 & 179 & 0,002 \\
\hline
\end{tabular}

Fonte: Elaborado pela autora.

Em relação à inovação organizacional, a Tabela 40 indica a rejeição da hipótese nula do teste de igualdade entre as matrizes de covariâncias, indicando que as elas são diferentes (p-value 0,00). Como o tamanho dos grupos difere e os maiores desvios estão principalmente nos maiores grupos, foi utilizado o traço de Pillai como estatística teste.

Tabela 40 - Teste M de Box para inovação organizacional e tamanho da empresa

\begin{tabular}{c|c}
\hline M de Box & 116,942 \\
\hline F & 1,706 \\
\hline G.L. 1 & 63 \\
\hline G.L. 2 & 19907,785 \\
\hline P.Valor & 0,000 \\
\hline
\end{tabular}

Fonte: Elaborado pela autora. 
Avaliando o p-valor apresentado na Tabela 41, verifica-se a existência de diferença significativa entre as médias dos grupos ao nível de $5 \%$.

Tabela 41 - MANOVA para inovação organizacional e tamanho da empresa

\begin{tabular}{c|c|c|c|c|c}
\hline & Valor & F & $\begin{array}{c}\text { G.L. } \\
\text { Hipótese }\end{array}$ & $\begin{array}{c}\text { G.L. } \\
\text { Erro }\end{array}$ & P-Valor \\
\hline Traço de Pillai & 0,179 & 1,886 & 18 & 534 & 0,015 \\
\hline Lambda de Wilks & 0,824 & 1,955 & 18 & 498,288 & 0,011 \\
\hline Traço de Hotelling & 0,208 & 2,021 & 18 & 524 & 0,008 \\
\hline Maior Raiz de Roy & 0,184 & 5,457 & 6 & 178 & 0,000 \\
\hline
\end{tabular}

Fonte: Elaborado pela autora.

Por meio dos testes de comparações múltiplas verifica-se, na Tabela 42, que as empresas médias se diferem das micro empresas em ORG1 e também ORG4 (p-valores iguais a 0,024 e 0,002 respectivamente), com maior valor para empresa de porte médio. Além disso, em ORG2 as grandes e médias empresas se diferem das micro empresas (p-valores iguais a 0,031 e 0,002 respectivamente), com maior valor para as maiores empresas. Por fim, em ORG6 as grandes e médias empresas se diferem das micro (p-valores iguais a 0,020 e 0,012), sendo que os maiores valores doas médias foram constatados nas maiores empresas.

Tabela 42 - Teste de comparações múltiplas entre o tamanho da empresa e variáveis do construto inovação organizacional

\begin{tabular}{|c|c|c|c|c|c|c|}
\hline & \multirow[t]{2}{*}{ (I) $\mathrm{V7}$} & \multirow[t]{2}{*}{ (J) V7 } & \multirow{2}{*}{$\begin{array}{c}\text { Dif. de } \\
\text { Médias (I-J) }\end{array}$} & \multirow[t]{2}{*}{ P-Valor } & \multicolumn{2}{|c|}{ I.C. $95 \%$ de Confiança } \\
\hline & & & & & $\begin{array}{c}\text { Limite } \\
\text { Inferior }\end{array}$ & $\begin{array}{c}\text { Limite } \\
\text { Superior }\end{array}$ \\
\hline \multirow{3}{*}{ ORG1 } & \multirow[t]{3}{*}{ Média } & Grande &, 082 & 1,000 & $-1,712$ & 1,877 \\
\hline & & Pequena & ,955 & ,466 & $-0,480$ & 2,390 \\
\hline & & Micro & 1,400 & 024 &, 122 & 2,678 \\
\hline \multirow[t]{3}{*}{ ORG2 } & \multirow[t]{3}{*}{ Micro } & Grande & $-1,661$ &, 031 & $-3,224$ & $-0,097$ \\
\hline & & Média & $-1,710$ &, 002 & $-2,951$ & $-0,469$ \\
\hline & & Pequena & $-0,963$ &, 170 & $-2,125$ & ,199 \\
\hline \multirow[t]{3}{*}{ ORG4 } & \multirow[t]{3}{*}{ Micro } & Grande & $-1,104$ &, 194 & $-2,470$ &, 261 \\
\hline & & Média & $-1,474$ &, 002 & $-2,557$ & $-0,390$ \\
\hline & & Pequena & $-0,963$ &, 073 & $-1,977$ &, 052 \\
\hline \multirow[t]{3}{*}{ ORG6 } & \multirow[t]{3}{*}{ Micro } & Grande & $-2,073$ &, 020 & $-3,931$ & $-0,214$ \\
\hline & & Média & $-1,738$ &, 012 & $-3,213$ & $-0,264$ \\
\hline & & Pequena & $-1,055$ &, 258 & $-2,436$ &, 326 \\
\hline
\end{tabular}

Fonte: Elaborado pela autora. 
Pelo exposto, pode-se afirmar que as empresas médias se destacam das micro empresas no que se refere à implementação de novas técnicas de gestão para melhorar as rotinas e práticas de trabalho, como por exemplo: reengenharia dos processos de negócio, gestão do conhecimento, controle da qualidade total, sistemas de formação/treinamento, SIG e ERP (ORG1). As empresas médias também identificaram, de forma mais pronunciada, uma melhoria na comunicação e na interação entre as diferentes áreas de negócios (ORG4) em relação às micro empresas.

Ademais, os resultados mostram que as grandes e médias empresas, se comparadas às micro, implementaram mais significativamente novos métodos de organização do trabalho para melhor distribuir responsabilidades e poder de decisão (ORG2), além de terem percebido um maior enquadramento em regulações e normas relativas ao mercado interno ou externo (ORG6).

\subsubsection{Origem do capital controlador}

Para analisar a influência da origem do capital controlador no desempenho em inovação, foram considerados os seguintes grupos:

- Empresas cujo capital controlador é estrangeiro ( $n=17)$;

- Empresas cujo capital controlador é nacional ( $\mathrm{n}=164)$.

Não foram consideradas as empresas cujo capital é misto, uma vez que este grupo era composto por apenas quatro elementos.

Baseando-se nas variáveis do construto de inovação em produto, a Tabela 43 indica a satisfação do pressuposto de igualdade entre as matrizes de covariâncias dos grupos (p-valor $=0,411)$.

Tabela 43 - Teste M de Box para inovação de produto e origem do capital

\begin{tabular}{c|c}
\hline M de Box & 25,387 \\
\hline F & 1,038 \\
\hline G.L. 1 & 21 \\
\hline G.L. 2 & 2792,995 \\
\hline P-Valor & 0,411 \\
\hline
\end{tabular}

Fonte: Elaborado pela autora. 
Pela Tabela 44, observa-se que tanto para o traço de Pillai, quanto para lambda de Wilks, há significância ao nível de 5\% para a diferença média entre os grupos.

Tabela 44 - MANOVA para inovação de produto e origem do capital

\begin{tabular}{c|c|c|c|c|c}
\hline & Valor & F & $\begin{array}{c}\text { G.L. } \\
\text { Hipótese }\end{array}$ & $\begin{array}{c}\text { G.L. } \\
\text { Erro }\end{array}$ & P-Valor \\
\hline Traço de Pillai & 0,105 & 3,414 & 6 & 174 & 0,003 \\
\hline Lambda de Wilks & 0,895 & 3,414 & 6 & 174 & 0,003 \\
\hline Traço de Hotelling & 0,118 & 3,414 & 6 & 174 & 0,003 \\
\hline Maior Raiz de Roy & 0,118 & 3,414 & 6 & 174 & 0,003 \\
\hline
\end{tabular}

Fonte: Elaborado pela autora.

Para verificar onde estão essas diferenças, foram realizados testes de comparações múltiplas dispostos na Tabela 45. Nota-se, através dos p-valores, que a diferença entre capital estrangeiro e nacional está em PROD3 (p-valor $=0,000$ ), com maior valor da média para capital estrangeiro.

Tabela 45 - Teste de comparações múltiplas entre a origem do capital e variáveis do construto inovação de produto

\begin{tabular}{|c|c|c|c|c|c|c|}
\hline & \multirow{2}{*}{ (I) $\mathrm{V4}$} & \multirow{2}{*}{ (J) V4 } & \multirow{2}{*}{$\begin{array}{c}\text { Dif. de } \\
\text { Médias } \\
\text { (I-J) }\end{array}$} & \multirow{2}{*}{ P-Valor } & \multicolumn{2}{|c|}{$\begin{array}{c}\text { I.C. } 95 \% \text { de } \\
\text { Confiança }\end{array}$} \\
\hline & & & & & $\begin{array}{c}\text { Limite } \\
\text { Inferior }\end{array}$ & $\begin{array}{c}\text { Limite } \\
\text { Superior }\end{array}$ \\
\hline PROD1 & Estrangeiro & Nacional & 0,719 & 0,305 & $-0,661$ & 2,1 \\
\hline PROD2 & Estrangeiro & Nacional & $-0,256$ & 0,692 & $-1,529$ & 1,017 \\
\hline PROD3 & Estrangeiro & Nacional & 2,490 & 0,000 & 1,154 & 3,826 \\
\hline PROD4 & Estrangeiro & Nacional & $-0,162$ & 0,812 & $-1,508$ & 1,183 \\
\hline PROD5 & Estrangeiro & Nacional & 0,333 & 0,456 & $-0,546$ & 1,212 \\
\hline PROD6 & Estrangeiro & Nacional & $-0,564$ & 0,352 & $-1,755$ & 0,627 \\
\hline
\end{tabular}

Fonte: Elaborado pela autora.

Conclui-se, portanto, que as empresas cujo capital controlador é estrangeiro têm maior participação em congressos e feiras como expositor/palestrante (PROD3), o que, possivelmente indica que estas empresas também detêm conhecimentos significativos à Indústria.

Em relação às variáveis do construto inovação em processo, a Tabela 46 mostra o teste de igualdade entre as matrizes de covariâncias dos grupos. Pelo p-valor apresentado nota-se que 
a hipótese não foi satisfeita para o nível de significância de 5\%. Como existe diferença entre o tamanho dos grupos e os maiores desvios estão no maior grupo, utilizou-se o traço de Pillai como estatística do teste.

Tabela 46 - Teste M de Box para inovação de processo e origem do capital

\begin{tabular}{c|c}
\hline M de Box & 43,160 \\
\hline F & 1,765 \\
\hline G.L. 1 & 21 \\
\hline G.L. 2 & 2792,995 \\
\hline P.Valor & 0,017 \\
\hline
\end{tabular}

Fonte: Elaborado pela autora.

Pela Tabela 47, nota-se a existência de significância ao nível de 5\% para diferença entre os grupos.

Tabela 47 - MANOVA para inovação de processo e origem do capital

\begin{tabular}{c|c|c|c|c|c}
\hline & Valor & F & $\begin{array}{c}\text { G.L. } \\
\text { Hipótese }\end{array}$ & $\begin{array}{c}\text { G.L. } \\
\text { Erro }\end{array}$ & P-Valor \\
\hline Traço de Pillai & 0,072 & 2,259 & 6 & 174 & 0,04 \\
\hline Lambda de Wilks & 0,928 & 2,259 & 6 & 174 & 0,04 \\
\hline Traço de Hotelling & 0,078 & 2,259 & 6 & 174 & 0,04 \\
\hline Maior Raiz de Roy & 0,078 & 2,259 & 6 & 174 & 0,04 \\
\hline
\end{tabular}

Fonte: Elaborado pela autora.

Os testes de comparações múltiplas dispostos na Tabela 48 indicam que os grupos diferem em PROC3 e PROC6 (p-valor igual a 0,002 e 0,019 respectivamente). Em ambos os casos, empresas com capital estrangeiro apresentaram maior valor para a média.

Tabela 48 - Teste de comparações múltiplas entre a origem do capital e variáveis do construto inovação de processo

\begin{tabular}{|c|c|c|c|c|c|c|}
\hline & \multirow{2}{*}{ (I) $\mathrm{V4}$} & \multirow{2}{*}{ (J) V4 } & \multirow{2}{*}{$\begin{array}{c}\text { Dif. de } \\
\text { Médias } \\
\text { (I-J) }\end{array}$} & \multirow{2}{*}{ P-Valor } & \multicolumn{2}{|c|}{$\begin{array}{l}\text { I.C. } 95 \% \text { de } \\
\text { Confiança }\end{array}$} \\
\hline & & & & & $\begin{array}{c}\text { Limite } \\
\text { Inferior }\end{array}$ & $\begin{array}{c}\text { Limite } \\
\text { Superior }\end{array}$ \\
\hline PROC1 & Estrangeiro & Nacional & 0,804 & 0,285 & $-0,677$ & 2,285 \\
\hline PROC2 & Estrangeiro & Nacional & 1,181 & 0,085 & $-0,163$ & 2,525 \\
\hline PROC3 & Estrangeiro & Nacional & 2,093 & 0,002 & 0,791 & 3,394 \\
\hline PROC4 & Estrangeiro & Nacional & 0,379 & 0,494 & $-0,711$ & 1,469 \\
\hline PROC5 & Estrangeiro & Nacional & 1,027 & 0,111 & $-0,24$ & 2,295 \\
\hline PROC6 & Estrangeiro & Nacional & 1,503 & 0,019 & 0,247 & 2,759 \\
\hline
\end{tabular}

Fonte: Elaborado pela autora. 
Tal resultado indica que as empresas cujo capital controlador é estrangeiro, se comparadas às empresas de controle nacional, introduziram mais expressivamente equipamentos, softwares e técnicas em atividades de apoio à produção (PROC3). Neste item são consideradas, por exemplo, ferramentas de planejamento e controle da produção, medição de desempenho, controle da qualidade, compra, manutenção e infraestrutura de TI.

Além disso, notou-se que os efeitos decorrentes das inovações de processo, como a redução do consumo de matérias-primas e energia (PROC6), foram mais evidentes em empresas de capital estrangeiro.

Na sequência, foram analisadas as variáveis do construto inovação de marketing. A Tabela 49 mostra o teste de igualdade entre as matrizes de covariâncias dos grupos, apontando para a satisfação do pressuposto da técnica (p-valor=0,156).

Tabela 49 - Teste M de Box para inovação de marketing e origem do capital

\begin{tabular}{c|c}
\hline M de Box & 23,182 \\
\hline F & 1,364 \\
\hline G.L. 1 & 15 \\
\hline G.L. 2 & 2984,608 \\
\hline P.Valor & 0,156 \\
\hline
\end{tabular}

Fonte: Elaborado pela autora.

No entanto, analisando-se os p-valores apresentados na Tabela 50, observa-se que não existe diferença significativa entre os grupos ao nível de 5\%. Sendo assim, a origem do capital controlador parece não influenciar o desempenho médio das empresas da população alvo modificada no que se refere à inovação de marketing.

Tabela 50 - MANOVA para inovação de marketing e origem do capital

\begin{tabular}{c|c|c|c|c|c}
\hline & Valor & F & $\begin{array}{c}\text { G.L. } \\
\text { Hipótese }\end{array}$ & $\begin{array}{c}\text { G.L. } \\
\text { Erro }\end{array}$ & P-Valor \\
\hline Traço de Pillai & 0,042 & 1,517 & 5 & 175 & 0,187 \\
\hline Lambda de Wilks & 0,958 & 1,517 & 5 & 175 & 0,187 \\
\hline Traço de Hotelling & 0,043 & 1,517 & 5 & 175 & 0,187 \\
\hline Maior Raiz de Roy & 0,043 & 1,517 & 5 & 175 & 0,187 \\
\hline
\end{tabular}

Fonte: Elaborado pela autora. 
Por fim, foi realizada a análise das variáveis do construto inovação organizacional de acordo com a origem do capital controlador. O teste das matrizes de covariâncias disposto na Tabela 51 confirma a igualdade ( $\mathrm{p}$-valor $=0,531)$. Já pelos testes de comparação entre os grupos, observa-se na, Tabela 52, que não existe diferença significativa ao nível de $5 \%$.

Tabela 51 - Teste M de Box para inovação organizacional e origem do capital

\begin{tabular}{c|c}
\hline M de Box & 23,105 \\
\hline F &, 945 \\
\hline G.L. 1 & 21 \\
\hline G.L. 2 & 2792,995 \\
\hline P.Valor & 0,531 \\
\hline
\end{tabular}

Fonte: Elaborado pela autora.

Tabela 52 - MANOVA para inovação organizacional e origem do capital

\begin{tabular}{c|c|c|c|c|c}
\hline & Valor & F & $\begin{array}{c}\text { G.L. } \\
\text { Hipótese }\end{array}$ & $\begin{array}{c}\text { G.L. } \\
\text { Erro }\end{array}$ & P-Valor \\
\hline Traço de Pillai & 0,06 & 1,837 & 6 & 174 & 0,094 \\
\hline Lambda de Wilks & 0,94 & 1,837 & 6 & 174 & 0,094 \\
\hline Traço de Hotelling & 0,063 & 1,837 & 6 & 174 & 0,094 \\
\hline Maior Raiz de Roy & 0,063 & 1,837 & 6 & 174 & 0,094 \\
\hline
\end{tabular}

Fonte: Elaborado pela autora.

A partir da análise, pode-se afirmar que a origem do capital controlador parece não influenciar o desempenho das empresas amostradas no que se refere à inovação organizacional.

\subsection{Análise do modelo proposto}

\subsubsection{Modelo inicial}

Inicialmente, procurou-se testar o modelo estabelecido no Item 3.3 deste trabalho, por meio da técnica de Modelagem de Equações Estruturais (SEM). A Tabela 53 mostra os valores para o alfa de Cronbach dos construtos sugeridos e a Tabela 54 mostra os critérios de validação da CFA. 
Tabela 53 - Alfa de Cronbach (variáveis padronizadas) para cada construto

\begin{tabular}{c|c|c}
\hline Construtos & Alfa de Cronbach & Itens \\
\hline EXPT & 0,7324 & 4 \\
\hline EXPR & 0,6507 & 4 \\
\hline PROD & 0,6176 & 6 \\
\hline PROC & 0,7611 & 6 \\
\hline MKT & 0,7307 & 5 \\
\hline ORG & 0,7803 & 6 \\
\hline ABS & 0,5240 & 6 \\
\hline \multicolumn{2}{|c}{ Fonte: Elaborado pela autora. }
\end{tabular}

Por meio do alfa de Cronbach, nota-se que os valores para os construtos EXPR, PROD e ABS não são suficientes (valor recomendado $>0,70$ ).

Tabela 54 - Validação dos construtos por meio da CFA

\begin{tabular}{l|l|l|l|l|l|l|l|l|l|l|l}
\hline & CR & AVE & MSV & ASV & EXPT & EXPR & ABS & PROD & PROC & MKT & ORG \\
\hline EXPT & 0,738 & 0,431 & 1,022 & 0,407 & $0,656^{*}$ & & & & & & \\
\hline EXPR & 0,684 & 0,383 & 1,022 & 0,395 & 1,011 & $0,619^{*}$ & & & & & \\
\hline ABS & 0,534 & 0,172 & 0,521 & 0,226 & 0,623 & 0,722 & $0,414^{*}$ & & & & \\
\hline PROD & 0,640 & 0,262 & 1,080 & 0,496 & 0,589 & 0,532 & 0,460 & $0,511^{*}$ & & & \\
\hline PROC & 0,767 & 0,356 & 0,753 & 0,376 & 0,418 & 0,369 & 0,287 & 0,734 & $0,597 *$ & & \\
\hline MKT & 0,747 & 0,383 & 1,080 & 0,500 & 0,525 & 0,473 & 0,374 & 1,039 & 0,755 & $0,619^{*}$ & \\
\hline ORG & 0,779 & 0,374 & 0,753 & 0,402 & 0,482 & 0,429 & 0,100 & 0,720 & 0,868 & 0,845 & $0,612^{*}$ \\
\hline
\end{tabular}

* Raiz quadrada de AVE.

Fonte: Elaborado pela autora.

Além disso, o ajuste da CFA indicou que a matriz de covariância não é positiva definida, dando indícios de que existe uma dependência linear ou inconsistência em algum conjunto de variáveis. A partir da Tabela 54 observam-se problemas como, por exemplo, confiabilidade em EXPR, ABS e PROD (CR < 0,70), problemas de validade convergente em todos os construtos $(\mathrm{AVE}<0,50)$ e problemas de validade discriminante $(\mathrm{MSV}>\mathrm{AVE})$.

Além disso, verificou-se que determinadas correlações entre os construtos foram estimadas como maior do que 1, indicando problemas na análise. 
Dessa forma, foi necessário o reagrupamento de algumas variáveis, resultando na criação dos seguintes construtos:

- Inovação em produto e marketing (PROD_MKT):

○ Variáveis: PROD1, PROD2, PROD5, PROD6, MKT1, MKT3 e MKT5.

- Inovação em processo e organizacional (PROC_ORG):

O Variáveis: PROC1, PROC2, PROC3, PROC5, PROC6 ORG1, ORG2, ORG3, ORG4, ORG5 e ORG6.

- Estratégia de explotação e exploração (EXPR_EXPT):

○ Variáveis: EXPR1, EXPR2, EXPT1, EXPT2 e EXPT3.

O construto denominado inovação de produto e marketing é composto por variáveis que dizem respeito à introdução de produtos novos ou significativamente melhorados no mercado (PROD1) e à implementação de mudanças significativas nos conceitos/estratégias de marketing (MKT1). Como efeitos decorrentes dessas inovações, o construto abrangeu variáveis relacionadas ao aumento do percentual de vendas de novos produtos (PROD2), à melhoria na qualidade (PROD5), à ampliação da gama de bens ou serviços ofertados (PROD6), à abertura de novos mercados (MKT3) e à melhoria da capacidade de adaptação à demanda dos clientes (MKT5). A análise dos dados das variáveis pertencentes ao construto mostra a existência de relação entre inovação em produto e inovação em marketing. Isso porque, apesar dos construtos tratarem de tipos de inovações distintos, a introdução de novos produtos no mercado pode proporcionar efeitos nas estratégias de marketing adotadas pela empresa. Além disso, efeitos como a abertura de novos mercados e a melhoria da capacidade de adaptação à demanda dos clientes podem ser decorrentes tanto de inovações em produto, quanto de inovações em marketing (VARIS, LITTUNEN, 2010). Sendo assim, este construto pode ser entendido como inovações direcionadas ao mercado.

O construto denominado inovação de processo e organizacional é formado por variáveis relacionadas à introdução de novos métodos de fabricação (PROC1), sistemas logísticos (PROC2), equipamentos e softwares de apoio à produção (PROC3), à implementação de novas técnicas de gestão (ORG1) e novos métodos de organização do trabalho (ORG2), além da realização de mudanças nas relações com outras organizações (ORG3). Como efeitos decorrentes dessas inovações, o construto abrangeu variáveis relacionadas à redução nos custos de produção (PROC5) e no consumo de matérias-primas e energia (PROC6), à 
melhoria na comunicação e na interação entre as diferentes áreas de negócios (ORG4), à melhoria no compartilhamento e transferência de conhecimentos com outras organizações e ao enquadramento em regulações e normas relativas ao mercado interno ou externo (ORG6). A análise dos dados das variáveis pertencentes a este construto mostra certa relação entre a inovação em processo e organizacional. Por relacionar questões como implementação de novas técnicas e métodos de trabalho, gestão e produção, este construto pode ser entendido como inovações direcionadas à empresa.

Por fim, o construto denominado estratégia de explotação e exploração é formado por variáveis relacionadas ao desenvolvimento de relações que permitam a realização tanto de inovações mais radicais (EXPR1) quanto de inovações incrementais (EXPT1) e que proporcionem tanto a geração de novas ideias e conhecimentos organizacionais (EXPR2), quanto o reforço e aprimoramento dos conhecimentos organizacionais já estabelecidos (EXPT2). O construto inclui também a variável EXPT3, que se refere à preferência das empresas pelo estabelecimento de ligações fortes com os parceiros, por estarem baseadas em interações regulares, fundamentadas na confiança entre as organizações. Este novo construto foi formado em decorrência da atribuição, por parte da empresa, de graus similares de concordância para os itens de ambos os construtos, conforme demonstrado na análise descritiva dos dados. Sendo assim, este construto pode ser entendido como a utilização de ambas as estratégias de explotação e exploração.

Vale ressaltar que, com intuito de obter melhores ajustes, o modelo proposto inicialmente foi dividido em dois, conforme expressam os subitens 4.6.2 e 4.6.3 deste trabalho.

\subsubsection{Modelo 1}

O Modelo 1 foi construído com o objetivo de analisar as possíveis relações existentes entre as estratégias de utilização do conhecimento adotadas pela empresa com o tipo de parceiro na rede, bem como entender se a colaboração com estes diferentes atores pode influenciar o desempenho da empresa em termos de inovação de produto e marketing. Considerou-se também, neste Modelo, a variável moderadora capacidade de absorção do conhecimento, visando verificar sua influência no desempenho inovador da empresa. 
Baseando-se nos novos construtos formados, pode-se observar, na Tabela 55, que os construtos latentes EXPR_EXPT e PROD_MKT apresentam valor para o Alfa de Cronbach maior do que 0,7 , indicando alto grau de confiabilidade dos mesmos. No entanto, o construto ABS apresentou valor abaixo do necessário, indicando baixa confiabilidade. Tal fato não pôde ser corrigido mesmo com a retirada de variáveis.

Tabela 55 - Alfa de Cronbach (variáveis padronizadas) para cada construto no Modelo 1

\begin{tabular}{c|c|c}
\hline $\begin{array}{c}\text { Novos } \\
\text { construtos }\end{array}$ & Alfa de Cronbach & Itens \\
\hline EXPT_EXPR & 0,8656 & 4 \\
\hline PROD_MKT & 0,8442 & 8 \\
\hline ABS & 0,5240 & 6 \\
\hline
\end{tabular}

Fonte: Elaborado pela autora.

A Tabela 56 mostra que, para os construtos EXPT_EXPR e PROD_MKT, todas as variáveis contribuem de maneira considerável, apresentando altas cargas fatoriais. Já para a o construto absorção do conhecimento, verificou-se que apenas ABS1, ABS2 e ABS5 contribuem de maneira satisfatória.

Tabela 56 - Cargas fatoriais apresentadas pelas variáveis de cada construto no Modelo 1

\begin{tabular}{c|c|c}
\hline Variável & Construto & $\begin{array}{c}\text { Carga } \\
\text { Fatorial }\end{array}$ \\
\hline ABS1 & ABS & 0,990 \\
\hline ABS2 & ABS & 0,435 \\
\hline ABS3 & ABS & 0,103 \\
\hline ABS4 & ABS & 0,161 \\
\hline ABS5 & ABS & 0,502 \\
\hline ABS6 & ABS & 0,070 \\
\hline EXPR1 & EXPT_EXPR & 0,721 \\
\hline EXPR2 & EXPT_EXPR & 0,846 \\
\hline EXPT1 & EXPT_EXPR & 0,794 \\
\hline EXPT2 & EXPT_EXPR & 0,815 \\
\hline EXPT3 & EXPT_EXPR & 0,579 \\
\hline MKT1 & PROD_MKT & 0,572 \\
\hline MKT3 & PROD_MKT & 0,797 \\
\hline MKT4 & PROD_MKT & 0,675 \\
\hline MKT5 & PROD_MKT & 0,621 \\
\hline PROD1 & PROD_MKT & 0,507 \\
\hline PROD2 & PROD_MKT & 0,549 \\
\hline PROD5 & PROD_MKT & 0,563 \\
\hline PROD6 & PROD_MKT & 0,799 \\
\hline
\end{tabular}

Fonte: Elaborado pela autora. 
A análise para validação dos construtos, expressa na Tabela 57, indicou a existência de um problema de validade convergente para PROD_MKT $($ AVE $<0,50)$, sugerindo que as variáveis desse construto não são muito correlacionadas entre si. Considerando que a análise é investigativa e que esse problema pode ter ocorrido devido à junção dos construtos inovação em produto e inovação em marketing, optou-se por prosseguir com o exame do modelo. Além disso, pelos outros valores apresentados, observa-se que as demais condições de validades e confiabilidades foram satisfeitas, indicando que esse construto está adequado.

Notou-se ainda que o construto ABS não satisfez a condição de confiabilidade $(C R<0,70)$ e de validade convergente (AVE $<0,50)$. Como as demais condições foram satisfeitas, optou-se por seguir com a análise.

Tabela 57 - Validação dos construtos do Modelo 1 por meio da CFA

\begin{tabular}{c|c|c|c|c|c|c|c}
\hline & CR & AVE & MSV & ASV & PROD_MKT & EXPT_EXPR & ABS \\
\hline PROD_MKT & 0,847 & 0,415 & 0,246 & 0,123 & $0,644^{*}$ & & \\
\hline EXPT_EXPR & 0,869 & 0,573 & 0,246 & 0,140 & 0,496 & $0,757^{*}$ & \\
\hline ABS & 0,530 & 0,244 & 0,034 & 0,017 & 0,010 & 0,185 & $0,494^{*}$ \\
\hline
\end{tabular}

* Raiz quadrada de AVE.

Fonte: Elaborado pela autora.

A Tabela 58 expressa os índices de qualidade de ajuste apresentados pelo Modelo 1 de equações estruturais. Verifica-se que, com a divisão do modelo inicial, os índices ficaram melhores ou próximos do mínimo necessário, indicando um ajuste considerável.

Tabela 58 - Medidas de qualidade do ajuste (SEM) do Modelo 1

\begin{tabular}{l|c}
\hline \multicolumn{1}{c|}{ Medida } & Valor observado \\
\hline $\boldsymbol{\chi}^{\mathbf{2}} / \mathbf{d . f}$ & 2,079 \\
\hline Goodness of Fit Index ( GFI) & 0,825 \\
\hline Root Mean Square Error of Approximation (RMSEA) & 0,077 \\
\hline Standardized Root Mean Residuals (SRMR) & 0,079 \\
\hline Comparative Fit Index (CFI) & 0,828 \\
\hline Incremental Fit Index (IFI) & 0,832 \\
\hline
\end{tabular}

Fonte: Elaborado pela autora.

Com relação às hipóteses testadas, verificou-se, a partir da Tabela 59, que apenas as hipóteses H1.5a (p-valor $=0,005)$ e H1.6a (p-valor < 0,001) foram significativas ao nível de 5\%. 
Tabela 59 - Testes de hipótese realizados (SEM) para o Modelo 1

\begin{tabular}{c|c|c|c|c|c|c}
\hline \multicolumn{2}{l}{} & Hipótese & Estimativa & $\boldsymbol{T}$ & P-Valor \\
\hline PROD_MKT & $<---$ & CLIENT11 & H1.1a & 0,017 & 1,188 & 0,235 \\
\hline PROD_MKT & $<---$ & FORNEC11 & H1.2a & 0,006 & 0,446 & 0,656 \\
\hline PROD_MKT & $<---$ & COMPET11 & H1.3a & $-0,033$ & $-1,705$ & 0,088 \\
\hline PROD_MKT & $<---$ & UNIVER11 & H1.4a & $-0,008$ & $-0,589$ & 0,556 \\
\hline CLIENT11 & $<---$ & EXPT_EXPR & H1.5a & 0,636 & 2,779 & 0,005 \\
\hline FORNEC11 & $<---$ & EXPT_EXPR & H1.6a & 0,833 & 3,403 & $*$ \\
\hline UNIVER11 & $<---$ & EXPT_EXPR & H1.7a & 0,288 & 1,205 & 0,228 \\
\hline PROD_MKT & $<---$ & ABS & H1.8a & 0,54 & 0,349 & 0,727 \\
\hline$*$ p-valor < 0,001. & & & &
\end{tabular}

Fonte: Elaborado pela autora.

A partir do exposto, pode-se concluir que a utilização de estratégias de exploração e explotação do conhecimento impactam positivamente no desenvolvimento de colaborações com clientes/consumidores e também com fornecedores.

Vale ressaltar que, conforme apontado por March (1991), as empresas devem procurar desenvolver um equilíbrio entre a estratégia de exploração e explotação. A estratégia de exploração está associada com a ampliação dos conhecimentos da empresa, sendo bastante relevante para o processo de inovação. As relações estabelecidas com base nesta estratégia tendem a ter um caráter mais oportunista, baseadas em ligações fracas (DITTRICH; DUYSTERS, 2003). Já a estratégia de explotação está relacionada com o refinamento dos conhecimentos organizacionais já estabelecidos. As relações baseadas nesta estratégia tendem a serem mais fortes, estabelecidas, geralmente, entre clientes e fornecedores (DITTRICH; DUYSTERS, 2003). Sendo assim, pode-se inferir, a partir dos resultados da pesquisa, que as empresas estabelecem relações com clientes/consumidores e fornecedores tanto para a aquisição de novos conhecimentos quanto para o refinamento e seleção das ideias já existentes. Tal fato indica que estes parceiros podem ser relevantes para o estabelecimento de relações fortes e fracas visando o desenvolvimento de inovações radicais e incrementais.

Observando-se as estimativas dos parâmetros, nota-se que o aumento de uma unidade em estratégia de exploração e explotação causa o aumento de 0,833 unidades em fornecedores e 0,636 unidades em clientes/consumidores. Dessa forma, quanto maior a utilização da estratégia de exploração e explotação, maior a importância relativa e a colaboração com clientes/consumidores e fornecedores. 
No entanto, não foram notadas, no Modelo 1, relações significativas entre os tipos de parceiros estabelecidos e o desempenho em inovação de produto e marketing da empresa. Este resultado está de acordo com o apontado por Monjon e Waelbroeck (2003), Belderbos et al. (2004), no que se refere à colaboração com clientes. Em relação à colaboração com fornecedores, os resultados apresentados são concernentes aos estudos de Sánchez e Pérez (2003), Freel (2003) Belderbos et al. (2004) e Ledwith e Coughlan (2005). Quanto à colaboração com competidores, Monjon e Waelbroeck (2003), Miotti e Sachwald (2003) e Belderbos et al. (2004) também constataram que a colaboração não impacta de forma significativa no desempenho em inovação, principalmente em produtos. No que se refere à relação de colaboração com universidades e institutos de pesquisa, os resultados da pesquisa são congruentes ao apontado Monjon e Waelbroeck (2003), Caloghirou et al. (2004), e Ledwith e Coughlan (2005). Além disso, a variável absorção do conhecimento também parece não afetar os resultados da empresa em relação à inovação de produto e marketing ao nível de significância de $5 \%$.

A Ilustração 16 apresenta o primeiro modelo obtido a partir a aplicação da técnica de modelagem de equações estruturais. 


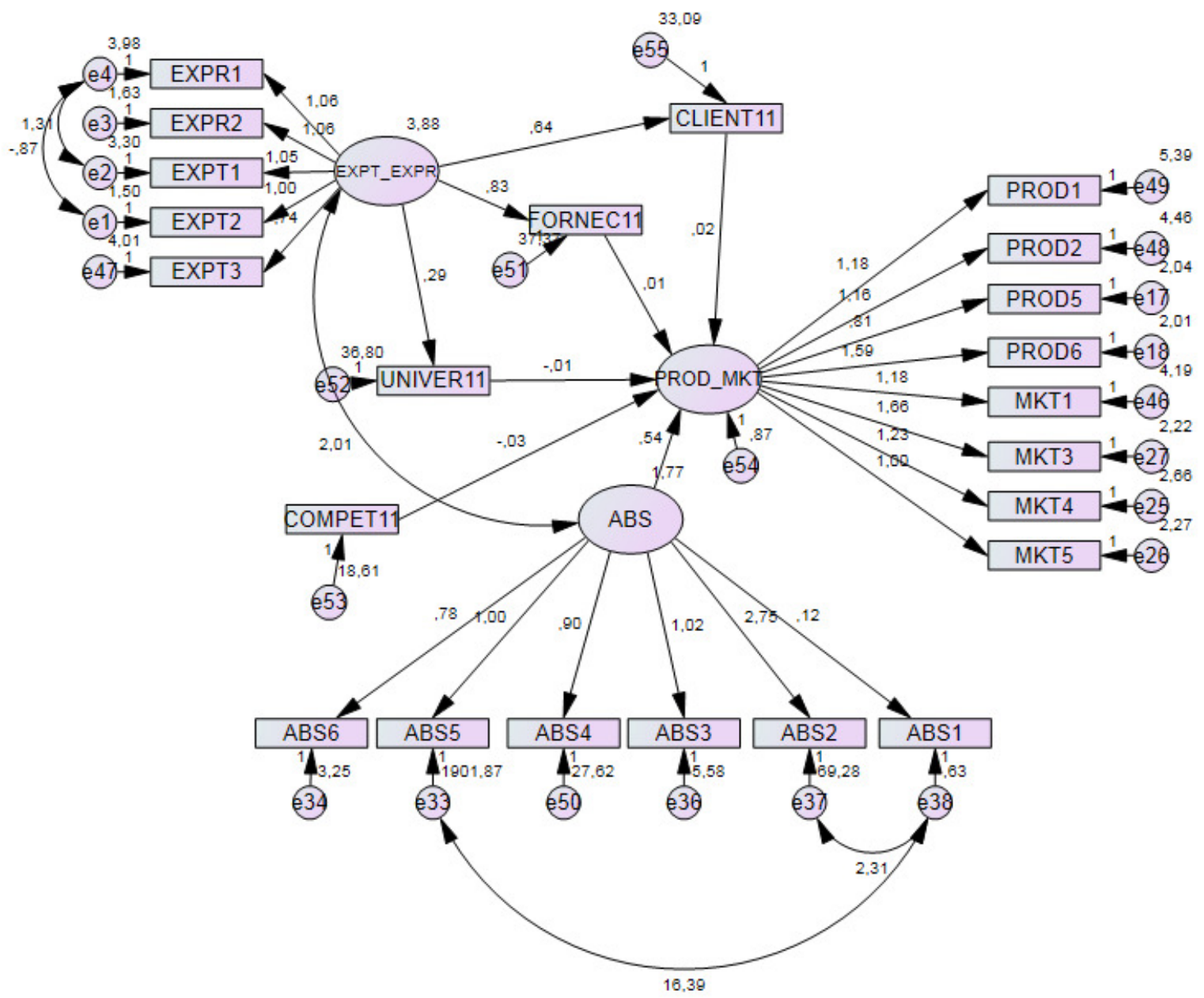

Ilustração 16 - Modelo de equações estruturais para inovação em produto e marketing Fonte: Elaborado pela autora.

\subsubsection{Modelo 2}

O Modelo 2 foi construído com o objetivo de analisar as possíveis relações existentes entre as estratégias de utilização do conhecimento adotadas pela empresa com o tipo de parceiro na rede, bem como entender se a colaboração com estes diferentes atores pode influenciar o desempenho da empresa em termos de inovação de processo e organizacional. Considerou-se também, neste modelo, a variável moderadora capacidade de absorção do conhecimento, visando verificar sua influência no desempenho inovador da empresa.

As estimativas para esse segundo modelo de equações estruturais são dadas a partir da Tabela 60. Por meio desses valores, nota-se que os construtos latentes EXPR_EXPT e PROC_ORG apresentam valor para o Alfa de Cronbach maior que 0,7, indicando alto grau de confiabilidade dos mesmos. No entanto, assim como no modelo anterior, o construto absorção 
do conhecimento apresentou valor abaixo do necessário, indicando baixa confiabilidade. Apesar disso, optou-se por mantê-lo apenas para verificar se há alguma influência dessas variáveis no desempenho inovador da organização.

Tabela 60 - Alfa de Cronbach (variáveis padronizadas) para cada construto no Modelo 2

\begin{tabular}{c|c|c}
\hline $\begin{array}{c}\text { Novos } \\
\text { construtos }\end{array}$ & Alfa de Cronbach & Itens \\
\hline EXPT_EXPR & 0,8656 & 4 \\
\hline PROC_ORG & 0,8595 & 12 \\
\hline ABS & 0,5240 & 6 \\
\hline
\end{tabular}

Fonte: Elaborado pela autora.

A partir das cargas fatoriais apresentas na Tabela 61, verificou-se que, para os construtos EXPT_EXPR e PROC_ORG, todas as variáveis contribuem de maneira considerável, apresentando cargas fatoriais altas. Para o construto ABS, observou-se que apenas ABS1, ABS2 e ABS5 contribuem de maneira satisfatória.

Tabela 61 - Cargas fatoriais apresentadas pelas variáveis de cada construto no Modelo 2

\begin{tabular}{c|c|c}
\hline Variável & Construto & $\begin{array}{c}\text { Carga } \\
\text { fatorial }\end{array}$ \\
\hline ABS1 & ABS & 0,892 \\
\hline ABS2 & ABS & 0,473 \\
\hline ABS3 & ABS & 0,137 \\
\hline ABS4 & ABS & 0,177 \\
\hline ABS5 & ABS & 0,535 \\
\hline ABS6 & ABS & 0,120 \\
\hline EXPR1 & EXPR_EXPT & 0,736 \\
\hline EXPR2 & EXPR_EXPT & 0,839 \\
\hline EXPT1 & EXPR_EXPT & 0,802 \\
\hline EXPT2 & EXPR_EXPT & 0,803 \\
\hline EXPT3 & EXPR_EXPT & 0,579 \\
\hline ORG1 & PROC_ORG & 0,716 \\
\hline ORG2 & PROC_ORG & 0,679 \\
\hline ORG3 & PROC_ORG & 0,571 \\
\hline ORG4 & PROC_ORG & 0,504 \\
\hline ORG5 & PROC_ORG & 0,563 \\
\hline ORG6 & PROC_ORG & 0,532 \\
\hline PROC1 & PROC_ORG & 0,603 \\
\hline PROC2 & PROC_ORG & 0,612 \\
\hline PROC3 & PROC_ORG & 0,610 \\
\hline PROC5 & PROC_ORG & 0,494 \\
\hline PROC6 & PROC_ORG & 0,59 \\
\hline & &
\end{tabular}

Fonte: Elaborado pela autora. 
A Tabela 62 mostra os valores apresentados na validação da CFA para o segundo modelo. Tais valores indicam problema de validade convergente para PROC_ORG $($ AVE $<0,50)$, sugerindo que as variáveis desse construto não são muito correlacionadas entre si. Assim como ocorreu com PROD_MKT, tal fato não é preocupante, pois essa característica pode ter ocorrido em decorrência da junção dos dois construtos. Além disso, as demais validades e confiabilidades indicam que esse construto está adequado.

Tabela 62 - Validação dos construtos no Modelo 2 por meio da CFA

\begin{tabular}{c|c|c|c|c|c|c|c}
\hline & CR & AVE & MSV & ASV & PROC_ORG & EXPR_EXPT & ABS \\
\hline PROC_ORG & 0,854 & 0,351 & 0,172 & 0,094 & $0,592^{*}$ & & \\
\hline EXPR_EXPT & 0,869 & 0,574 & 0,172 & 0,118 & 0,415 & $0,757^{*}$ & \\
\hline ABS & 0,541 & 0,228 & 0,063 & 0,039 & $-0,123$ & 0,251 & $0,478^{*}$ \\
\hline
\end{tabular}

* Raiz quadrada de AVE.

Fonte: Elaborado pela autora.

Novamente, observou-se que o construto ABS não satisfaz uma condição de confiabilidade $(\mathrm{CR}<0,70)$ e de validade convergente $(\mathrm{AVE}<0,50)$. Como as demais condições da validação foram satisfeitas, optou-se por prosseguir com a análise.

A Tabela 63 apresenta os índices de qualidade de ajuste para o segundo modelo de equações estruturais. Por meio desses valores, verifica-se que os índices ficaram melhores ou próximos do mínimo necessário, indicando um ajuste considerável.

Tabela 63 - Medidas de qualidade do ajuste (SEM) do Modelo 2

\begin{tabular}{l|c}
\hline \multicolumn{1}{c|}{ Medida } & Valor observado \\
\hline $\boldsymbol{\chi}^{\mathbf{2}} / \mathbf{d} . \mathbf{f}$ & 2,327 \\
\hline Goodness of Fit Index (GFI) & 0,785 \\
\hline Root Mean Square Error of Approximation (RMSEA) & 0,085 \\
\hline Standardized Root Mean Residuals (SRMR) & 0,128 \\
\hline Comparative Fit Index (CFI) & 0,751 \\
\hline Incremental Fit Index (IFI) & 0,756 \\
\hline
\end{tabular}

Fonte: Elaborado pela autora. 
A partir da análise da Tabela 64, verifica-se que as hipóteses H1.1b (p-valor = 0,004), H1.3b $(\mathrm{p}$-valor $=0,011), \mathrm{H} 1.4 \mathrm{~b}(\mathrm{p}$-valor $=0,005), \mathrm{H} 1.6 \mathrm{~b}(\mathrm{p}$-valor $<0,001)$ e H1.8b $(\mathrm{p}$-valor $=$ 0,045), foram significativas ao nível de $5 \%$.

Estes resultados indicam que o desenvolvimento de colaborações com clientes/consumidores, universidades e institutos de pesquisa e competidores está relacionado à inovação em processo e organizacional. Além disso, nota-se, no Modelo 2, que a utilização de estratégias de exploração e explotação do conhecimento está relacionada positivamente com o desenvolvimento de colaborações com fornecedores e que a capacidade de absorção do conhecimento está associada à inovação em processo e organizacional.

Tabela 64 - Testes de hipótese realizados (SEM) para o Modelo 2

\begin{tabular}{c|c|c|c|c|c|c}
\hline \multicolumn{2}{l}{} & Hipótese & Estimativa & T & P-Valor \\
\hline PROC_ORG & $<---$ & CLIENT11 & H1.1b & 0,063 & 2,858 & 0,004 \\
\hline PROC_ORG & $<---$ & FORNEC11 & H1.2b & 0,022 & 1,136 & 0,256 \\
\hline PROC_ORG & $<---$ & COMPET11 & H1.3b & 0,038 & 2,549 & 0,011 \\
\hline PROC_ORG & $<---$ & UNIVER11 & H1.4b & 0,060 & 2,827 & 0,005 \\
\hline CLIENT11 & $<---$ & EXPR_EXPT & H1.5b & 0,595 & 1,337 & 0,181 \\
\hline FORNEC11 & $<---$ & EXPR_EXPT & H1.6b & 0,843 & 3,384 & $*$ \\
\hline UNIVER11 & $<---$ & EXPR_EXPT & H1.7b & 0,215 & 0,882 & 0,378 \\
\hline PROC_ORG & $<---$ & ABS & H1.8b & $-0,012$ & $-2,008$ & 0,045 \\
\hline * & \multicolumn{7}{c}{ A-Valor $<0,001$}
\end{tabular}

Fonte: Elaborado pela autora.

Observando-se as estimativas dos parâmetros, nota-se que o aumento de uma unidade em estratégia de exploração e explotação causa o aumento de 0,843 unidades em fornecedores; o aumento de 1 unidade na colaboração com universidades e institutos de pesquisas causa o aumento de 0,06 unidades em inovação em processo e organizacional; o aumento de 1 unidade na colaboração clientes/consumidores causa o aumento de 0,063 unidades em inovação em processo e organizacional; o aumento de 1 unidade na colaboração com competidores causa o aumento de 0,038 unidades em inovação em processo e organizacional e o aumento em 1 unidade na capacidade de absorção causa o decréscimo de 0,012 unidades em inovação em processo e organizacional. 
Dessa forma, quanto maior a estratégia de exploração e explotação, maior a importância relativa e a colaboração com fornecedores, e quanto maior a colaboração com universidades e institutos de pesquisa, clientes/consumidores e competidores maior o resultado em inovação de processo e organizacional. Por fim, quanto maior a capacidade de absorção, menor a inovação em processo e organizacional.

Apesar da escassez de pesquisas que relacionem especificamente o tipo de parceiro na rede com o desempenho em inovação de processo e, principalmente, em inovação organizacional, os resultados apresentados no Modelo 2 parecem ser coerentes com o expresso por diversos autores.

Para Gemüden et al. (1996), por exemplo, a obtenção de sucesso em termos de inovação de processo é condicionada pelo desenvolvimento de cooperações em rede com múltiplos atores, seja por meio de uma interação intensa com universidades e consultores, seja por meio de interações de intensidade e padrões mais equilibrados entre outros agentes.

O mesmo resultado também foi constatado por Varis e Littunen (2010), que realizaram um dos poucos estudos dedicados à avaliação da influência das fontes de informação nas inovações organizacionais. Segundo os autores, as diferentes relações em rede estabelecidas pela empresa tendem a afetar significativamente o desempenho em inovação organizacional. De acordo com seus resultados, as empresas classificadas como inovadoras tem maior propensão a estabelecer relações com diferentes parceiros em rede, sendo as instituições de pesquisa e ensino uma valiosa fonte de informação.

Os clientes e consumidores também podem ser considerados como fontes importantes de inovação, conforme apontado por Gupta et al. (2000), Fritsch e Lukas (2001), Brockhoff (2003) e Prahalad e Ramaswamy (2004). Isso porque, os clientes podem fornecer informações valiosas acerca de suas necessidades e do mercado. Estas informações, se internalizadas, podem se refletir em mudanças significativas no modus operandi da organização, tanto em termos de processo, quanto em termos de gestão.

Com relação aos competidores, estudos propostos por Lawson e Samson (2001) apontaram que a aplicação do conhecimento deste parceiro permite a realização de benchmarking e a internalização das qualidades dos mesmos, por meio da imitação ou do aperfeiçoamento. De 
acordo com Tsai (2009), apesar de serem os agentes menos frequentes nas redes de inovação, a colaboração com competidores pode propiciar o compartilhamento de conhecimentos e habilidades, bem como a obtenção de um efeito sinérgico na resolução de problemas comuns fora da área de influência do concorrente. Além disso, a colaboração com os concorrentes permite às empresas conhecê-los melhor, favorecendo sua capacidade de diferenciação (LINN, 1994). Inkpen e Pien (2006) também sugerem que as empresas que colaboram com os concorrentes podem ter um melhor desempenho em inovação se comparadas à utilização de outras fontes de colaboração.

No que se refere à colaboração com universidades e institutos de pesquisa, Hemmert (2004), Caloghirou et al. (2004) e Clifton et al. (2010) apontaram para sua importância no que se refere à criação, disseminação e aquisição de novos conhecimentos científicos úteis ao processo de inovação. Segundo Ruef (2002), por permitirem o acesso à informações não redundantes, as universidades e institutos de pesquisa podem contribuir para a inovação organizacional.

Vale salientar que, assim como no Modelo 1, a utilização de estratégias de exploração e explotação do conhecimento está relacionada positivamente com o desenvolvimento de colaborações com fornecedores, indicando que estes podem ser parceiros relevantes para troca de conhecimentos novos e para o refinamento e seleção dos conhecimentos já existentes na empresa. No entanto, em contraponto aos estudos de Fitjar e Rodríguez-Pose (2013), a relação entre a colaboração com fornecedores e o desempenho em inovação de processo e organizacional não foi significativa na presente pesquisa ao nível de $5 \%$ de significância.

Por fim, o resultado referente à capacidade da empresa de absorver o conhecimento também merece destaque. A pesquisa apontou que a capacidade de absorção influi pouco, porém negativamente, na inovação em processo e organizacional. Tendo em vista que este resultado pode ter sido influenciado pelos problemas de confiabilidade e validade convergente no construto, sua interpretação sugere que as variáveis relacionadas à intensidade das atividades de P\&D na empresa e o nível de formação dos funcionários influem de forma negativa em inovações relacionadas ao processo e à gestão. Apesar de parecerem contraditórios, resultados próximos foram encontrados por Tsai (2009) no que se refere à relação entre a capacidade de absorção e o desempenho em inovação marginal em produtos, tomando como base as relações estabelecidas com clientes. 
Considerando-se os resultados apontados, a Ilustração 17 apresenta o segundo modelo obtido a partir a aplicação da técnica de modelagem de equações estruturais.

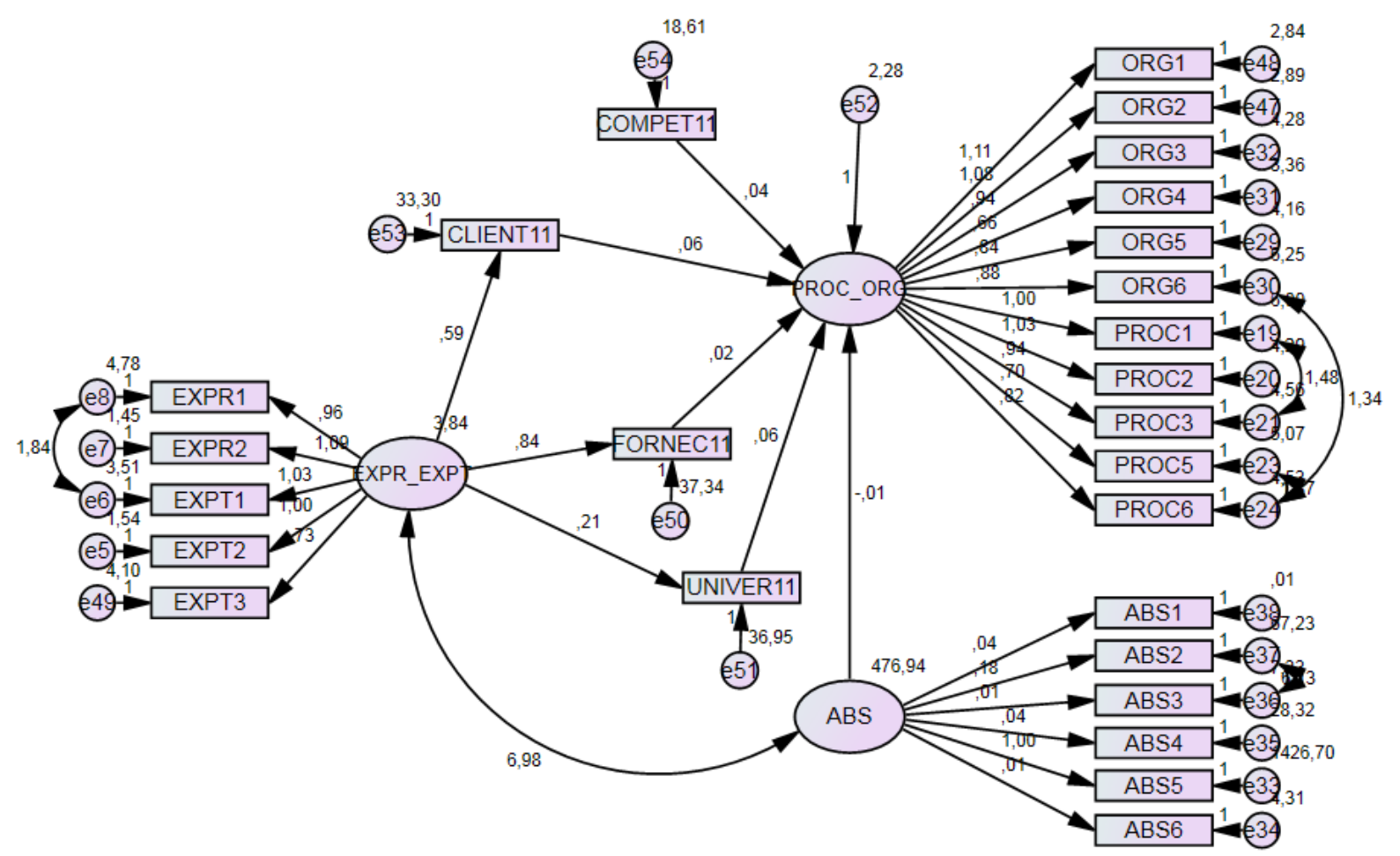

Ilustração 17 - Modelo de equações estruturais para inovação em processo e organizacional Fonte: Elaborado pela autora.

\subsection{Análise das hipóteses testadas e resumo dos resultados da pesquisa}

Tendo por base os resultados apresentados nos subcapítulos anteriores, o Quadro 20 apresenta, de forma sucinta, as considerações acerca de cada hipótese estabelecida no estudo. 
Quadro 20 - Síntese das hipóteses e resultados

\begin{tabular}{|c|c|}
\hline Hipóteses & $\begin{array}{c}\text { Síntese dos } \\
\text { resultados }\end{array}$ \\
\hline $\begin{array}{l}\text { H1.1 A colaboração com clientes/consumidores está relacionada positivamente com o } \\
\text { resultado em inovação da empresa. }\end{array}$ & $\begin{array}{l}\text { Comprovada } \\
\text { parcialmente }\end{array}$ \\
\hline $\begin{array}{l}\text { H1.2 A colaboração com fornecedores está relacionada positivamente com o resultado em } \\
\text { inovação da empresa. }\end{array}$ & Rejeitada \\
\hline $\begin{array}{l}\text { H1.3 A colaboração com competidores está relacionada positivamente com o resultado em } \\
\text { inovação da empresa. }\end{array}$ & $\begin{array}{l}\text { Comprovada } \\
\text { parcialmente }\end{array}$ \\
\hline $\begin{array}{l}\text { H1.4 A colaboração com universidades e institutos de pesquisa está relacionada } \\
\text { positivamente com o resultado em inovação da empresa. }\end{array}$ & $\begin{array}{l}\text { Comprovada } \\
\text { parcialmente }\end{array}$ \\
\hline $\begin{array}{l}\text { H1.5 A utilização de estratégias de explotação do conhecimento está relacionada } \\
\text { positivamente com o desenvolvimento de colaborações com clientes/consumidores. }\end{array}$ & $\begin{array}{l}\text { Comprovada } \\
\text { parcialmente }\end{array}$ \\
\hline $\begin{array}{l}\text { H1.6 A utilização de estratégias de explotação do conhecimento está relacionada } \\
\text { positivamente com o desenvolvimento de colaborações com fornecedores. }\end{array}$ & Comprovada \\
\hline $\begin{array}{l}\text { H1.7 A utilização de estratégias de exploração do conhecimento está relacionada } \\
\text { positivamente com o desenvolvimento de colaborações com universidades e institutos } \\
\text { pesquisa. }\end{array}$ & Rejeitada \\
\hline $\begin{array}{l}\text { H1.8 Quanto maior a capacidade de absorção do conhecimento apresentada pela empresa, } \\
\text { maior seu resultado em inovação. }\end{array}$ & Rejeitada \\
\hline H1.9 Quanto maior o gasto com P\&D na empresa, maior seu resultado em inovação. & $\begin{array}{l}\text { Comprovada } \\
\text { parcialmente }\end{array}$ \\
\hline H1.10 Quanto maior o tamanho da empresa, maior seu resultado em inovação. & $\begin{array}{l}\text { Comprovada } \\
\text { parcialmente }\end{array}$ \\
\hline $\begin{array}{l}\text { H1.11 As empresas cuja origem do capital controlador é estrangeira apresentam um maior } \\
\text { resultado em inovação. }\end{array}$ & $\begin{array}{l}\text { Comprovada } \\
\text { parcialmente }\end{array}$ \\
\hline
\end{tabular}

Fonte: Elaborado pela autora.

As conclusões apresentadas no Quadro 20 estão descritas na sequência:

- H1.1 A colaboração com clientes/consumidores está relacionada positivamente com o resultado em inovação da empresa.

Considerando-se que a colaboração com clientes e consumidores foi significativa apenas no Modelo 2, esta hipótese foi comprovada parcialmente. Sendo assim, pode-se afirmar que os clientes e consumidores estão relacionados positivamente com os resultados em inovação de processo e organizacional, porém não foram identificadas associações entre estes parceiros na rede com o desempenho em inovação de produto e marketing.

- H1.2 A colaboração com fornecedores está relacionada positivamente com o resultado em inovação da empresa. 
Esta hipótese foi rejeitada em ambos os modelos. Portanto, analisando o estabelecimento de relações de colaboração com fornecedores e seu grau de importância, não houve associação deste parceiro com o desempenho inovador da empresa, ao nível de significância de $5 \%$.

- H1.3 A colaboração com competidores está relacionada positivamente com o resultado em inovação da empresa.

A colaboração com competidores foi significativa apenas no Modelo 2. Sendo assim, pode-se afirmar que os competidores podem corroborar com os resultados em inovação de processo e organizacional. Como não foram identificadas associações entre estes parceiros e o desempenho em inovação de produto e marketing, esta hipótese foi parcialmente comprovada.

- H1.4 A colaboração com universidades e institutos de pesquisa está relacionada positivamente com o resultado em inovação da empresa.

Considerando-se que a colaboração com universidades e institutos de pesquisa foi significativa apenas no Modelo 2, esta hipótese também foi parcialmente comprovada. Sendo assim, pode-se afirmar que as universidades e institutos de pesquisa contribuem positivamente para os resultados em inovação de processo e organizacional. Não foram identificadas, ao nível de 5\% de significância, associações entre estes parceiros na rede e o desempenho em inovação de produto e marketing.

- H1.5 A utilização de estratégias de explotação do conhecimento está relacionada positivamente com o desenvolvimento de colaborações com clientes/consumidores.

Esta hipótese foi confirmada parcialmente, por ter sido significativa apenas no Modelo 1. Vale ressaltar que esta confirmação foi válida tanto para a estratégia de explotação quanto para a estratégia de exploração, uma vez que as variáveis dos construtos foram associadas em um mesmo construto a partir da análise fatorial. Dessa forma, quanto maior a utilização da estratégia de exploração e explotação, maior a colaboração/importância relativa dos clientes e consumidores, considerando-se o desenvolvimento de inovações de produto e marketing.

- H1.6 A utilização de estratégias de explotação do conhecimento está relacionada positivamente com o desenvolvimento de colaborações com fornecedores. 
Esta hipótese foi confirmada em ambos os modelos. Ressalta-se, novamente, que esta confirmação foi válida tanto para a estratégia de explotação quanto para a estratégia de exploração, uma vez que as variáveis dos construtos foram associadas por estarem bastante correlacionadas. Dessa forma, quanto maior a utilização da estratégia de exploração e explotação, maior a colaboração/importância relativa dos fornecedores, considerando-se o desenvolvimento de inovações de produto, processo, marketing e organizacional.

- H1.7 A utilização de estratégias de exploração do conhecimento está relacionada positivamente com o desenvolvimento de colaborações com universidades e institutos pesquisa.

Esta hipótese foi rejeitada nos dois modelos. Portanto, a utilização de estratégias de exploração, como também de explotação, não está relacionada ao estabelecimento de colaborações com as universidades e institutos de pesquisa.

- H1.8 Quanto maior a capacidade de absorção do conhecimento apresentada pela empresa, maior seu resultado em inovação.

Esta hipótese não foi significativa no Modelo 1 e, no Modelo 2, a capacidade de absorção do conhecimento foi associada negativamente, porém de forma fraca, à inovação em processo e organizacional. Sendo assim, rejeitou-se a hipótese estabelecida.

A Ilustração 18 expressa, de forma sintetizada, as principais relações encontradas nos Modelos 1 e 2 da pesquisa, por meio da aplicação da SEM. 
Variáveis exógenas

Variáveis endógenas

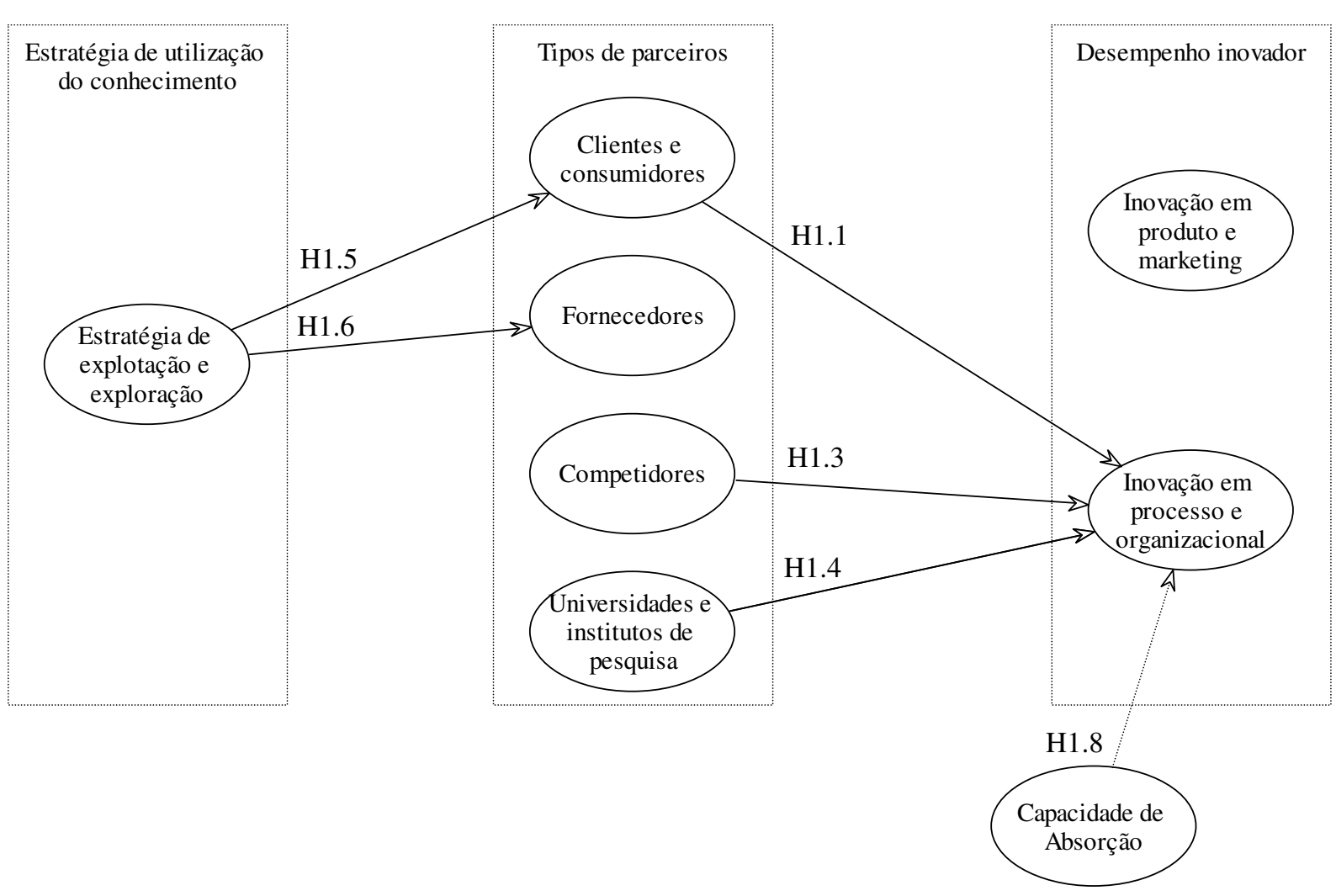

Ilustração 18 - Modelo final da pesquisa

Fonte: Elaborado pela autora

- H1.9 Quanto maior o gasto com P\&D na empresa, maior seu resultado em inovação.

Verificou-se, por meio da aplicação da MANOVA, que o aumento na porcentagem gasta com P\&D tende a proporcionar um maior potencial de introdução de inovações de produto. Sendo assim, esta hipótese foi parcialmente confirmada, já que não foram encontradas diferenças significativas nos resultados em inovação de processo, marketing e organizacional decorrentes dos níveis de investimento em P\&D.

- H1.10 Quanto maior o tamanho da empresa, maior seu resultado em inovação.

Por meio da MANOVA, foi possível identificar que, em grande parte dos casos, as empresas grandes se destacaram das menores no que se refere à inovação em produto, processo e organizacional. Como não houve diferenças nas médias relacionadas à inovação em marketing, esta hipótese também foi comprovada parcialmente. 
- H1.11 As empresas cuja origem do capital controlador é estrangeira apresentam um maior resultado em inovação.

A origem do capital controlador possui influência em algumas variáveis relativas à inovação de produto e processo. Notou-se, a partir da MANOVA, que as empresas cujo capital controlador é estrangeiro apresentam as maiores médias, no entanto, não foram notadas diferenças significativas em relação à inovação de marketing e organizacional. Portanto, esta hipótese foi comprovada parcialmente.

A Ilustração 19 apresenta um resumo dos principais resultados obtidos nos testes das variáveis moderadoras da pesquisa.

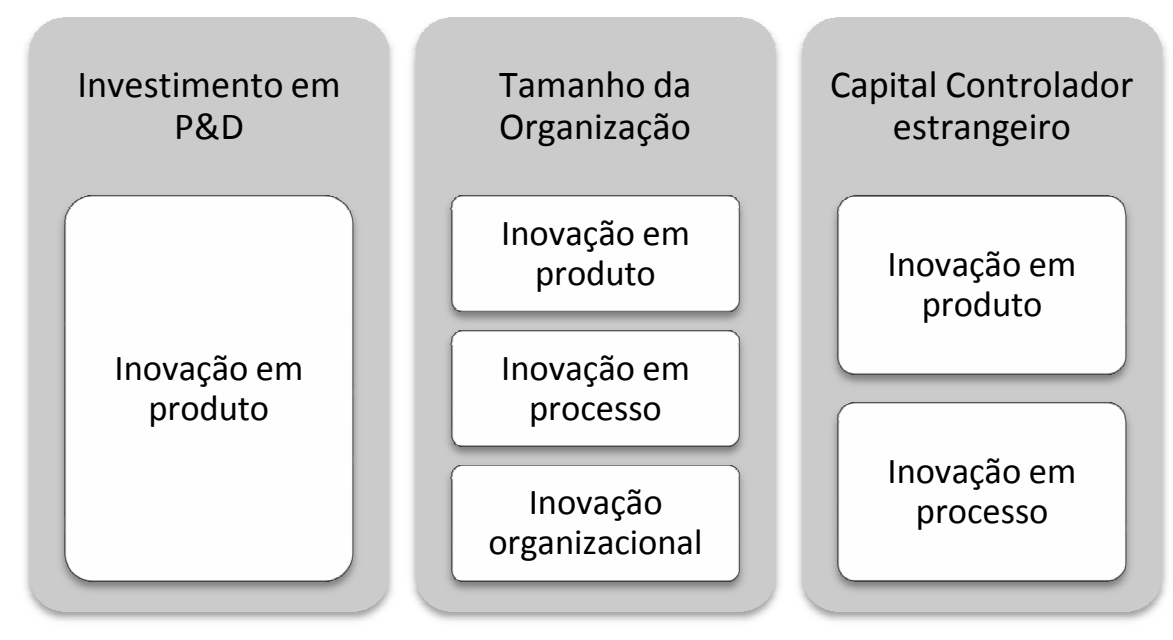

Ilustração 19 - Resumo dos resultados para as variáveis moderadoras

Fonte: Elaborado pela autora 


\section{CONSIDERAÇÕES FINAIS}

Este capítulo apresenta as conclusões provenientes dos resultados da pesquisa de campo a respeito da contribuição das parcerias estabelecidas em redes de inovação, trazendo reflexões e discussões acerca da temática. Além disso, são apresentadas as limitações da pesquisa e sugestões para futuros estudos provenientes das lacunas identificadas neste trabalho.

Em um ambiente marcado pela crescente necessidade de inovação, tanto como elemento fundamental para a competitividade, quanto para a sobrevivência das organizações, a formação de redes de inovação tem sido apontada como forma de complementar as capacidades inovadoras internas da empresa a partir da colaboração com outros agentes.

Visando buscar comprovações empíricas para tal assertiva, a presente pesquisa apresentou como objetivo principal verificar qual a contribuição dos parceiros estabelecidos em redes de inovação para o desempenho inovador de empresas da Indústria Elétrica Eletrônica. Para tanto, foram estabelecidos os seguintes objetivos específicos: (1) identificar as razões primordiais pelas quais as empresas constituem redes de inovação; (2) hierarquizar os principais parceiros estabelecidos nas redes, segundo seu grau de importância; (3) mensurar os resultados das empresas em termos de inovação de produto, processo, marketing e organizacional; e (4) verificar qual a influência das variáveis moderadoras (tamanho da organização, gasto com P\&D e origem do capital controlador) no desempenho inovador.

A pesquisa, de caráter exploratório e descritivo, resultou em um levantamento de dados quantitativos referentes a 185 empresas da Indústria Elétrica Eletrônica, que foram analisados por meio da Modelagem de Equações Estruturais (SEM) e da Análise Multivariada de Variância (MANOVA).

Com relação às razões primordiais apontadas pelas empresas para constituição de redes de inovação [objetivo 1], destacam-se o acesso a novos conhecimentos, a combinação de competências e o aumento da aprendizagem. Este resultado sugere a importância da transferência de conhecimentos e da aprendizagem para o processo de inovação, constatações que também foram identificadas em outros estudos sobre o tema. Vale salientar, no entanto, que a distribuição de custos e redução dos riscos, tidos como barreiras à inovação na 
literatura, não foram os fatores motivadores mais citados para o desenvolvimento das relações interorganizacionais em questão.

Foram identificados, na pesquisa, que os principais parceiros estabelecidos nas redes de inovação [objetivo 2] são os clientes e consumidores, seguidos pelos fornecedores, universidades e institutos de pesquisa e, por último, os competidores. Este resultado foi percebido analisando-se tanto a frequência de estabelecimento de relações visando à inovação, quanto o grau de importância atribuída a cada parceiro, segundo a percepção da empresa.

O estudo também revelou que as empresas estabelecem relações com clientes e fornecedores tanto para a aquisição de novos conhecimentos, quanto para o refinamento e seleção das ideias já existentes, uma vez que foram encontrados indícios significativos da utilização de estratégias de explotação e exploração do conhecimento com ambos os parceiros. Tal fato indica que estes atores são procurados para o estabelecimento de relações fortes e fracas visando o desenvolvimento tanto de inovações radicais, quanto incrementais.

É importante ressaltar que a grande maioria das empresas amostradas afirmou ter desenvolvido pelo menos uma inovação, nos últimos três anos, por meio da colaboração com clientes e consumidores. No entanto, a participação destes e de outros atores na atividade inovativa da empresa, como um todo, ainda é pequena. Isso porque, grande parte das empresas afirmou ser a principal responsável pelo desenvolvimento de inovações, contra uma pequena parcela que afirmou desenvolver suas inovações principalmente em cooperação com outros parceiros.

Outro ponto a ser enfatizado refere-se ao padrão de colaboração estabelecido pelas empresas segundo o seu porte. Foi notado um padrão semelhante de colaboração entre as micro e pequenas empresas, com destaque para os clientes/consumidores e fornecedores. Uma colaboração significativa com estes parceiros também foi notada em empresas de porte médio e grande. Porém, nas grandes empresas, a colaboração com universidades e institutos de pesquisa é bastante proeminente em comparação aos outros atores na rede. No caso dos competidores, o padrão de colaboração decai com o aumento do porte da empresa, indicando que as de menor porte têm maior propensão a estabelecer relações com este tipo de parceiro. 
Este estudo também apresentou como objetivo específico a mensuração do desempenho da empresa em termos de inovação de produto, processo, marketing e organizacional [objetivo 3], visando cruzar estes dados com as informações relativas às redes.

Com relação aos resultados em inovação de produto, observou-se que, de forma geral, as empresas têm introduzido novos bens ou serviços no mercado e/ou percebido os efeitos decorrentes deste tipo de inovação na organização. Resultados bastante semelhantes também foram encontrados na análise referente ao desempenho em inovação de marketing. Quanto ao desempenho em inovação de processo, foi notado um resultado inferior em comparação às inovações de produto e marketing, indicando que, de forma geral, as empresas têm introduzido apenas algumas inovações em processo. Estes resultados também foram percebidos na análise referente ao desempenho em inovação organizacional.

Sendo assim, pode-se concluir que, as empresas da Indústria Elétrica Eletrônica apresentaram melhores resultados relacionados às inovações voltadas ao mercado (produto e marketing) e resultados um pouco inferiores no que se refere às inovações direcionadas à empresa (processo e organizacional).

O exame da influência do gasto com $\mathrm{P} \& \mathrm{D}$, do tamanho e da origem do capital controlador no desempenho inovador das empresas [objetivo 4] mostrou que o aumento do investimento em $\mathrm{P} \& \mathrm{D}$ tende a proporcionar um maior potencial apenas na introdução de inovações de produto. Além disso, foi possível identificar que, em grande parte dos casos, as empresas grandes se destacaram das menores no que se refere à inovação de produto, processo e organizacional. Por fim, a origem do capital controlador parece influenciar apenas algumas variáveis relativas à inovação de produto e processo, com vantagem para as empresas de capital controlador estrangeiro.

Segundo o apontado na literatura, outra variável que parece afetar o desempenho inovador das empresas se refere à capacidade de absorção do conhecimento. No entanto, os resultados encontrados no estudo demonstraram uma associação fraca e negativa deste construto às inovações em processo e organizacional, e uma relação insignificante para as inovações em produto e marketing. Este resultado pode evidenciar a necessidade de novos estudos que forneçam escalas válidas para medição e análise da capacidade de absorção do conhecimento da empresa e sua influência nas relações interorganizacionais. 
A apreciação dos dados relativos à colaboração em rede, frente aos resultados em inovação da empresa, possibilitou o alcance do objetivo central deste estudo. Foi observado que o estabelecimento de relações de colaboração com clientes/consumidores, competidores e universidades e institutos de pesquisa pode corroborar com os resultados em inovação de processo e organizacional.

Embora alguns estudos afirmem que o fornecedor possa ser considerado uma fonte importante de informações para a atividade inovativa, não foi percebida uma associação deste parceiro com o desempenho inovador da empresa. Além disso, não foi observada a existência de relações significativas entre a colaboração com clientes/consumidores, fornecedores, competidores e universidades e institutos de pesquisa com o desempenho das empresas no que se refere à inovação de produto e marketing. Este resultado permite supor que, apesar das relações estabelecidas, as inovações direcionadas ao mercado ainda estão sob controle interno da empresa, sendo a colaboração externa pouco representativa para esta atividade.

Em resumo, pode-se afirmar que, apesar de alguns resultados significativos acerca da contribuição de diferentes parceiros na rede terem sido encontrados, as empresas da Indústria Elétrica Eletrônica ainda atribuem maior importância às atividades internas para desenvolvimento de suas inovações. Em outras palavras, ainda que o presente estudo tenha detectado um alto número de relações de colaboração com clientes, consumidores e fornecedores, ainda se nota uma centralização do processo de desenvolvimento de inovações.

No entanto, considerando-se os níveis moderados de inovação detectados no setor, aliados aos problemas de escassez de pessoal qualificado e à dificuldade de obtenção de recursos, principalmente financeiros, percebe-se que a colaboração por meio de redes poderia ser mais bem explorada, principalmente no que se refere às relações com universidades, institutos de pesquisa e competidores.

A centralização do processo de inovação nas empresas pode sugerir a existência de possíveis barreiras que afetam a formação e o desenvolvimento das redes, como a falta de consciência por parte da comunidade empresarial quanto aos benefícios propiciados pelas redes de inovação; a relutância, especialmente por parte das pequenas e médias empresas, em dedicar tempo e recursos para um processo que não é bem compreendido, ou cujos resultados não são claros; a relutância por parte das empresas em compartilhar informações e conhecimentos 
com outras organizações, especialmente concorrentes; a dificuldade das empresas em identificar os parceiros e oportunidades para formação de redes, uma vez que sua base de conhecimento e de informações pode estar limitada aos seus próprios contatos; a falta de habilidades e recursos para facilitar ou coordenar a implementação da rede, fazendo com que seus membros não consigam desenvolver relações de cooperação; dentre outros fatores.

Ainda acerca das barreiras para o desenvolvimento de relações de colaboração voltadas para a inovação, é possível propor algumas medidas que podem ser tomadas para superá-las, como a definição clara dos objetivos e necessidades dos atores na rede, o estabelecimento de mecanismos de coordenação e a conquista de confiança mútua entre os parceiros.

Além disso, é importante ressaltar a importância das cooperações voltadas para a inovação, visando a conversão do conhecimento puro em uma aplicação produtiva. Neste sentido, os governos podem atuar como intermediador no processo de formação das redes de inovação, de forma a facilitar a colaboração entre empresas por meio da sensibilização dos potenciais benefícios de tais parcerias, da prestação de informação a empresas locais, bem como por meio de apoio financeiro e técnico quando necessário.

Diante deste contexto, o trabalho visou ampliar o entendimento acerca das contribuições relativas a cada um dos principais parceiros estabelecidos nas redes de inovação para o desempenho inovador das empresas da Indústria Elétrica Eletrônica. Por meio do estudo, foi possível evidenciar a importância de algumas fontes externas para a inovação, que ainda são pouco exploradas. Outra contribuição importante refere-se à mensuração do resultado das empresas em termos de inovação de marketing e organizacional, que ainda são incipientes na maioria dos estudos acerca do tema.

Os resultados deste estudo têm implicações importantes para a gestão prática das empresas do setor. Considerando a intensa competição do mercado e a necessidade de realização de inovações, este estudo é relevante por mostrar que diferentes tipos de parceiros colaborativos podem ajudar a atingir diferentes tipos de desempenho em inovação. Ressalta-se, portanto, que os gestores devem estar cientes da importância da adequação do parceiro como forma de complementar e alavancar suas capacidades inovativas. 


\subsection{Limitações do estudo e recomendações para futuras pesquisas}

Embora este estudo revele qual a contribuição dos diferentes tipos de parceiros para o desempenho inovação das empresas pesquisadas, algumas limitações podem ser apontadas. Em primeiro lugar, a utilização da técnica de modelagem de equações estruturais não possibilita a validação do modelo encontrado para posterior replicação a outros setores e/ou conjunturas, sendo necessária a realização de novos estudos que possam comprová-lo.

Em segundo lugar, o levantamento dos dados foi feito com base em uma amostragem não probabilística. Cabe ressaltar, que, apesar de fornecer informações valiosas, os dados obtidos por meio dessa amostra não podem ser generalizados para a população de interesse original. Além disso, as implicações apresentadas neste estudo podem ser descritas como provisórias, considerando-se as limitações do estudo transversal e que os resultados decorrentes das colaborações para a inovação podem ser gerados em longo prazo.

Vale ressaltar que o estudo examinou a rede de inovação sob a perspectiva do ator principal (nível micro), a partir de sua percepção e resultados. Visando o aprofundamento do tema, sugere-se o desenvolvimento de novos estudos qualitativos e longitudinais, que possam investigar questões mais complexas e abrangentes, sob o ponto de vista de todos os atores das redes.

Indica-se também a introdução de novas variáveis no estudo que abordem as características das relações estabelecidas e seus objetivos, a dinâmica da rede, os mecanismos de coordenação, a estrutura da rede, a divisão de poderes e o grau de interdependência entre os atores. Além disso, sugere-se o estabelecimento de construtos que possam mensurar adequadamente alguns fatores influentes na relação entre os agentes na rede, como a capacidade da empresa de absorção dos conhecimentos. Isso porque, apesar de embasado na literatura, o construto sugerido neste trabalho para tal avaliação apresentou problemas de confiabilidade e validade convergente. Ademais, pesquisas futuras podem contemplar a representatividade de uma determinada população fazendo uso de uma amostra probabilística.

A ampliação das pesquisas sobre redes de inovação fornecerá bases para o desenvolvimento de novos estudos acerca do tema que, além poderem indicar meios para a melhoria do 
desempenho em inovação das empresas, podem tratar de questões igualmente pertinentes, como a governança da rede, que desponta como um tópico relevante de estudo na área. 


\section{REFERÊNCIAS BIBLIOGRÁFICAS}

ABERNATHY, W.; CLARK, K. B. Mapping the winds of creative destruction. Research Policy, v.14, n.1, p.3-22, feb.1985.

Academy of Management Journal. v. 47, n.6, 2004.

AHUJA, G. Collaboration Networks, Structural Holes, and Innovation: a longitudinal study. Administrative Science Quarterly, v. 45, n.3, p. 425-455, 2000.

AHUJA, G.; LAMPERT, C. M. Entrepreneurship in the large corporation: a longitudinal study of how established firms create breakthrough inventions. Strategic Management Journal, v. 22, n. 6/7, p. 521-543, 2001.

AMATO NETO, J. Redes de Cooperação Produtiva e Clusters Regionais. São Paulo: Atlas, 2000.

ASSOCIAÇÃO BRASILEIRA DA INDÚSTRIA ELÉTRICA E ELETRÔNICA (ABINEE). A indústria elétrica eletrônica em 2020: uma estratégia de desenvolvimento - Detalhamento e Atualização de Propostas. São Paulo, 2010. Disponível em <http://www.abinee.org.br/programas/imagens/2020.pdf>, acesso em 05 de agosto de 2012.

ASSOCIAÇÃO BRASILEIRA DA INDÚSTRIA ELÉTRICA E ELETRÔNICA (ABINEE). São Paulo, 2012. Disponível em <http://www.abinee.org.br/>, acesso em 20 de junho de 2012.

Desempenho setorial. São Paulo, 2013. Disponível em <http://www.abinee.org.br/abinee/decon/decon15.htm>, acesso em 12 de fevereiro de 2013.

ATUAHENE-GIMA, K.; SLATER, S. F.; OLSON, E. M. The contingent value of responsive and proactive market orientations for new product program performance. Journal of Product Innovation Management, v. 22, n. 6, p. 464-482, 2005.

BALESTRIN, A.; VERSCHOORE, J. R.; REYES JR., E. O campo de estudo sobre redes de cooperação interorganizacional no Brasil. Revista de Administração Contemporânea, Curitiba, v. 14, n. 3, art. 4, p. 458-477, 2010.

BANCO MUNDIAL. Conhecimento e inovação para a competitividade. Tradução: Confederação Nacional da Indústria. Brasília: CNI, 2008. Disponível em $<$ http://siteresources.worldbank.org/BRAZILINPOREXTN/Resources/3817166-

$1220382779545 /$ ConhecimentoeInovacaolivrocompletoPortugues.pdf $>$, acesso em 05 de agosto de 2012.

BARBIERI, J. C.; ÁLVARES, A. C. T. Inovações nas organizações empresariais. In BARBIERI, J. C. (org.). Organizações inovadoras: estudos e casos brasileiros. Rio de Janeiro: FGV Editora, 2003, p.41-64.

BAUM, J. A. C.; CALABRESE, T.; SILVERMAN, B. S. Don't go it alone: alliance network composition and startups' performance in Canadian biotechnology. Strategic Management Journal, v. 21, n. 3, p. 267-294, 2000. 
BAUMOL, W. J. The free-market innovation machine. Princeton: Princeton University Press, 2002.

BAUTZER, D. Inovação: repensando as organizações. São Paulo: Atlas, 2009.

BECKMAN, C. M.; HAUNSCHILD, P. R. Network Learning: The Effects of Partners' Heterogeneity of Experience on Corporate Acquisitions. Administrative Science Quarterly, v. 47 , p. $92-124, \operatorname{mar} / 2002$.

BELDERBOS, R.; CARREE, M.; LOKSHIN, B. Cooperative R\&D and firm performance. Research Policy, v. 33, n. 10, p.1477-1492, 2004.

BELL, J.; DEN OLDEN, B; ZIGGER, G.W. Dynamics of cooperation: at brick irreverence. Journal of Management Studies, v.43, n.7, 2006.

BOVET, D.; MARTHA, J. Value nets: reinventing the rusty supply chain for competitive advantage. Strategy \& Leadership, v. 28, n.4, p. 21-26, 2000.

BROCKHOFF, K. Customers' perspectives of involvement in new product development. International Journal of Technology Management, v. 26, n.5/6, p. 464-481, 2003.

BURT, R. S. Structural holes: the social structure of competition. Cambridge, MA: Harvard University Press, 1992.

CAIRNARCA, G.; COLOMBO, M.; MARIOTTI, S. Agreements between firms and the technological life cycle model: evidence from information technologies. Research Policy, v. 21, n. 1, p. 45-62, 1992.

CALDEIRA, A.; SANTOS; A. P. M; BARBOSA, B. F. A.; PIRES; M. L.; PALMA, T. R.; CINTRA, F. R. Estratégias de cooperação para a inovação: um estudo exploratório. In: XXXVI Encontro da ANPAD, 2012. Anais... Rio de Janeiro: ANPAD, 2012.

CALOGHIROU, Y.; KASTELLI, I.; TSAKANIKAS, A. Internal capability and external knowledge sources: complements or substitutes for innovative performance? Technovation, v. 24, n. 1, p. 29-39, 2004.

CAMARINHA-MATOS, L. M.; ABREU, A. Performance indicators for collaborative networks based on collaboration benefits. Production Planning \& Control: The Management of Operations, v. 18, n. 7, p. 592-609, 2007.

CARVALHO, F. P. Cooperação e alianças para a inovação e o desempenho das empresas brasileiras. In: SALERNO, M. S.; NEGRI, J. A.; TURCHI, L. M.; MORAIS, J. M. (orgs). Inovação: estudos de jovens pesquisadores brasileiros, vol. 1. São Paulo : Editora Papagaio, 2010.

CASSIMAN, B.; VEUGELERS, R. In search of complementarity in innovation strategy: Internal $R \& D$, cooperation in $R \& D$ and external technology acquisition. Management Science, v. 52, n. 1, p. 68-82, 2006.

CASTELLS, M. A sociedade em rede. São Paulo: Paz e Terra, 1999. 
CERVO, A. L.; BERVIAN, P. A.; DA SILVA, R. Metodologia Científica. 6. ed. São Paulo: Pearson Prentice Hall, 2007.

CHESBROUGH, H. W. Open Innovation: The New Imperative for Creating and Profiting from Technology. Cambridge: Harvard Business School Publishing, 2003.

Bookman, 2012.

Inovação Aberta: como criar e lucrar com a tecnologia. São Paulo:

CHRISTENSEN, C. M. The Innovator's Dilemma: When New Technologies Cause Great Firms to Fail. Boston: Harvard Business School Press, 1997.

CHRISTENSEN, C. M.; OVERDORF, M. Meeting the challenge of disruptive change. Harvard Business Review, v. 78, n. 2, p. 66-76, 2000.

CHURCHIL JR., G. A. Marketing research: methodological foundations. 7a. ed. New York: Inter. Thomson Publishing, 1999.

CINCERA, M. Firms' productivity growth and R\&D spillovers: an analysis of alternative technological proximity measures. Economics of Innovation and New Technology, v. 14, n. 8, p. 657-682, 2005.

CLIFTON, N.; KEAST, R.; PICKERNELL, D.; SENIOR, M. Network structure, knowledge governance and firm performance: evidence from innovation networks and SMEs in the UK. Growth and Change, v. 41, n.3, p. 337-373, 2010.

COHEN, W. M.; LEVINTHAL, D. A. Absorptive capacity: a new perspective on learning and innovation. Administrative Science Quarterly, v. 35, n. 1, p. 128-152, 1990.

CORTES, M. R.; PINHO, M.; FERNANDES, A. C.; SMOLKA, R. B.; BARRETO, A. L. C. M. Cooperação em empresas de base tecnológica: uma primeira avaliação baseada numa pesquisa abrangente. São Paulo em Perspectiva, v.19, n.1, p. 85-94, 2005. Disponível em <http://dx.doi.org/10.1590/S0102-88392005000100007>, acesso em 15 de março de 2012.

CRESWELL, J. W. Projeto de pesquisa: métodos qualitativo, quantitativo e misto. 2.ed. Porto Alegre: Artmed, 2007.

DAS, T. K.; TENG, B-S. A resource-based theory of strategic alliances. Journal of Management, v. 26, n. 1, p. 31-60, 2000.

DITTRICH, K.; DUYSTERS, G. M. The role of innovation networks in a changing competitive environment: the case of IBM. Banff, Canada: IASTED International Conference on Alliances, Mergers and Acquisitions, 2003.

DODGSON, M. Technological collaboration in industry: strategy, policy and internationalization in innovation. London: Routledge, 1993.

DOZ, Y; WILSON, K.; VELDHOEN, S.; GOLDBRUNNER, T.; ALTMA, G. Innovation: Is Global the Way Forward? Fontainebleau: INSEAD, 2006. 
DRUCKER, P. F. Prática de administração de empresas. Rio de Janeiro: Fundo de Cultura, 1962.

As Fronteiras da Administração: onde as decisões do amanhã estão sendo determinadas hoje. São Paulo: Pioneira, 1989.

Innovation imperative. Executive excellence. Provo, v. 13, n. 12, p. 7, dec.

1996.

DYER, J. H.; NOBEOKA, K. Creating and managing a high-performance knowledge sharing network: The Toyota case. Strategic Management Journal, v. 21, p. 345-367, 2000.

EISENHARDT, K. M.; SCHOONHOVEN, C. B. Resource-based view of strategic alliance formation: strategic and social effects in entrepreneurial firms. Organization Science, v. 7, n. 2, p. 136-150, 1996.

EISENHARDT, K. M., TABRIZI, B. N. Accelerating adaptive processes: product innovation in the global computer industry. Administrative Science Quarterly, v.40 n.1, p. 84-110, 1995.

FAEMS, D.; LOOY, B. V; DEBACKERE, K. Interorganizational collaboration and innovation: toward a portfolio approach. The Journal of Product Innovation Management, v.22, p. 238-250, 2005.

FÁVERO, L. P.; BELFIORE P.; SILVA, F. L.; CHAN, B. L. Análise de Dados: modelagem multivariada para tomada de decisões. Rio de Janeiro: Campus, 2009.

FITJAR, R. D.; RODRÍGUEZ-POSE, A. Firm collaboration and modes of innovation in Norway. Research Policy, v. 42, n.1, p. 128-138, 2013.

FOMBRUN, C. J. Strategies for network research in organizations. Academy of Management Review, v. 7, p. 280-291, 1997.

FORFÁS. Innovation Networks. Dublin: Forfás, 2004. Disponível em <www.forfas.ie $>$, acesso em 22 de maio de 2012.

FREEL, M. S. Sectoral patterns of small firm innovation, networking and proximity. Research Policy, v. 32, n. 4, p. 751-770, 2003.

FREEL, M. S.; HARRISON, R. T. Innovation and cooperation in the small firm sector: evidence from "Northern Britain". Regional Studies, v.40, n.4, p. 289-305, 2006.

FRITSCH, M.; LUKAS, R. Who cooperates on R\&D? Research Policy, v. 30, n. 2, p. 297312, 2001.

GEMÜDEN, H. G.; RITTER, T.; HEYDEBRECK, P. Network configuration and innovation success: an empirical analysis in German high-tech industries. International Journal of Research in Marketing. v.13, n. 5, p. 449-462, 1996.

GERWIN, D.; KUMAR, V.; PAL, S. Transfer of advanced manufacturing technology from Canadian universities to industry. The Journal of Technology Transfer, v. 17, n. 2-3, p. 5767, 1992. 
GIL, A. C. Como elaborar projetos de pesquisa. São Paulo. Atlas, 1996

Métodos e técnicas em pesquisa social. São Paulo: Atlas, 1999.

GRABHER, G; POWELL, W. W. Introduction. In: Critical Studies in Economic Institutions: Networks. London: Edward Elgar, 2004.

GRANDORI, A.; SODA, G. Inter-firm networks: antecedents, mechanisms and forms. Organization Studies, v. 16, n. 2, 1995.

GRANOVETTER, M. The strength of weak ties. American Journal of Sociology, v. 78, p. 1360-1380, 1973.

GRANT, R. M. Knowledge and Organization. In: NONAKA, I.; TEECE, D. (Eds.). Managing Industrial Knowledge: creation, transfer and utilization. London: Sage, 2001.

GUARAU, C. Innovation networks in the biopharmaceutical sector: a study of UK small and medium sized enterprises. International Journal of Entrepreneurship and Innovation Management, v.5, n. 1/2, 2005.

GULATI, R. Alliances and networks. Strategic Management Journal, v. 19, n. 4, p.293317, 1998.

GUPTA, A. K.; WILEMON, D.; ATUAHENE-GIMA, K. Excelling in R\&D. Research Technology Management, v. 43, n. 3, p. 52-59, 2000.

HAGEDOORN, J. Understanding the rationale of strategic technology partnering: interorganizational modes of cooperation and Industry differences. Strategic Management Journal, v. 14, n. 5, p. 371-385, 1993.

Inter-firm R\&D partnerships: an overview of major trends and patterns since 1960. Research Policy, v.31, n.4, p. 477-492, 2002.

HAIR, J. F., ANDERSON, R. E. TATHAM, R. L., BLACK, W. C. Análise Multivariada de Dados. 5. ed. Porto Alegre: Bookman, 2009.

HALLIKAS J.; VARIS J.; SISSONEN H.; VIROLAINEN V. M. The evolution of the network structure in the ICT sector. International Journal of Production Economics, v.115, n. 2, p. 296-304, 2008.

HALLIKAS, J.; KARKKAINEN, H.; LAMPELA, H. Learning in networks: an exploration from innovation perspective. International Journal of Technology Management, v.45, n.34, p. 229-243, 2009.

HAMEL, G. Competition for competence and inter-partner learning within international strategic alliances. Strategic Management Journal, v. 12, issue S1, p.83-103, 1991.

HEMMERT, M. The influence of institutional factors on the technology acquisition performance of high-tech firms: survey results from Germany and Japan. Research Policy, v. 33, n. 6/7, p. 1019-1040, 2004. 
HENDERSON, R.; CLARK, K. B. Architectural innovation: the reconfiguration of existing product technologies and the failure of established firms. Administrative Science Quarterly, v. 35, p. 9-30, 1990.

HILL, C. W. L.; ROTHAERMEL, F. T. The performance of incumbent firms in the face of radical technological innovation. Academy of Management Review, v. 28, n.2, p. 257-274, 2003.

HOFFMANN, V. E.; MOLINA-MORALES, F. X.; MARTINEZ-FERNANDEZ, M. T. Redes de empresas: proposta de uma tipologia para classificação aplicada na indústria de cerâmica de revestimento. Revista de Administração Contemporânea, v. 11, n. 1, 2007. Disponível em <http://www.scielo.br/scielo.php?script=sci_arttext\&pid=S1415-65552007000500006>, acesso em 25 de abril de 2012.

HU, L., BENTLER, P. M. Cutoff criteria for fit indexes in covariance structure analysis: conventional criteria versus new alternatives. Structural Equation Modeling, v.6, n.1, p. 1$55,1999$.

IACOB, M. E.; FIELT, E.; SMIT, A.; JANSSEN, W. Analysis of networked enterprises. Telematica Instituut, 2001. Disponível em <https://doc.novay.nl/dsweb/Get/Rendition30711/Analysis\%20of\%20Networked\%20Enterprises.doc>, acesso em 25 de maio de 2013.

INKPEN, A. C.; PIEN, W. An examination of collaboration and knowledge transfer: ChinaSingapore Suzhou industrial park. Journal of Management Studies, v. 43, n. 4, p. 779-811, 2006.

INSEAD; WORLD INTELLECTUAL PROPERTY ORGANIZATION (WIPO). The Global Innovation Index 2012: Stronger Innovation Linkages for Global Growth. Disponível em $<$ http://www.globalinnovationindex.org/gii/main/fullreport/index.html>, acesso em $08 \mathrm{de}$ agosto de 2012.

INSTITUTO BRASILEIRO DE GEOGRAFIA E ESTATÍSTICA - IBGE. Pintec: Pesquisa de Inovação Tecnológica 2008. Rio de Janeiro, 2010.

INSTITUTO BRASILEIRO DE GEOGRAFIA E ESTATÍSTICA - IBGE. Pesquisa Industrial 2010 (PIA), v. 29, n. $1, \quad 2012, \quad 179 \quad$ p. Disponível em $<\mathrm{ftp}$ ://ftp.ibge.gov.br/Industrias_Extrativas_e_de_Transformacao/Pesquisa_Industrial_Anual Empresa2010/piaempresa2010.pdf>, acesso em 05 de maio de 2013.

JARILLO, J. C. On strategic networks. Strategic Management Journal, v. 9, p. 31-41, 1988.

Journal of International Management. v.13, n.4, 2007.

KESSLER, E., CHAKRABATRI, A. Innovation speed: a conceptual model of context, antecedents, and outcome. Academy of Management Review, v. 21, n.4, p.1143-1191, 1996.

KIM, C.; SONG, J. Creating new technology through alliances: an empirical investigation of joint patients. Technovation, v. 27, n. 8, p. 461-470, 2007. 
KIM, L., Crisis construction and organizational learning: capability building in Catching up at Hyundai Motor. Organization Science, v. 9, n. 4, p. 506-521, 1998.

.The dynamics of technological learning in industrialization. International Social Science Journal, v. 53, n. 168, p. 297-308, 2001.

KUNIYOSHI, M. S. Institucionalização da gestão do conhecimento: um estudo das práticas gerenciais e suas contribuições para o poder de competição das empresas do setor elétrico-eletrônico. São Paulo, 2008. Tese (Doutorado em Administração) - Programa de PósGraduação em Administração, Departamento de Administração, Faculdade de Economia, Administração e Contabilidade da Universidade de São Paulo.

KÜPPERS, G.; PYKA, A. The self-organization of innovation networks: introductory remarks in innovation networks. Theory and practice. Cheltenham: Edward Elgar, 2002.

LANE, P. J.; LUBATKIN, M. L. Relative absorptive capacity and interorganizational learning. Strategic Management Journal, v. 19, n. 5, p. 461-477, 1998.

LANE, P. J.; SLAK, J. E.; LYLES, M. A. Absorptive capacity, learning, and performance in international joint ventures. Strategic Management Journal, v. 22, n. 10, p. 1139-1161, 2001 .

LAWSON, B; SAMSON, D. Developing innovation capability in organisations: a dynamic capabilities approach. International Journal of Innovation Management, v. 5, n. 3, p. 377400, 2001.

LEDWITH, A., COUGHLAN, P. Splendid isolation: does networking really increase new product success? Creativity and Innovation Management, v.14, n. 4, p. 366-373, 2005.

LEMKE, C. Modelos de Equações Estruturais com ênfase em Análise Fatorial Confirmatória no software AMOS. Porto Alegre, 2005. Monografia, Departamento de Estatística, Instituto de Matemática da Universidade Federal do Rio Grande do Sul.

LINN, T. A. Learning from the competition. Journal of Accountancy, v. 177, n. 2, p. 43-46, 1994.

MACEDO, B. G.; ALMEIDA, S. F.; FERREIRA, F. F.; MENTONE, F. O setor elétrico e eletrônico em 2020: uma estratégia de desenvolvimento. São Paulo: ABINEE, 2009.

MARCH, J. G. Exploration and Exploitation in Organizational Learning. Organization Science February, v. 2, n. 1, p.71-87, 1991.

MARCON, M.; MOINET, N. La stratégie-réseau. Paris: Éditions Zéro Heure, 2000.

MARCONI, M. A.; LAKATOS, E. M. Fundamentos de metodologia científica. 2. ed. São Paulo: Atlas, 1990.

Técnicas de Pesquisa. 6. ed. São Paulo: Atlas, 2006.

Metodologia Científica. 5. ed. São Paulo: Atlas, 2010. 
MARTINS, G. A.; THEÓPHILO, C. R. Metodologia da investigação científica para ciências sociais aplicadas. 2.ed. São Paulo: Atlas, 2009.

MATTAR, F. Pesquisa de marketing. São Paulo: Atlas, 1996.

MElO, M. A. C.; AGOSTINHO, M. C. E. Gestão Adaptativa: uma proposta para o gerenciamento de redes de inovação. Revista de Administração Contemporânea, v.11, n.2, p. 93-111, 2007.

MERCY, E. L. Avaliação de redes de inovação em nanotecnologia: a proposta de um modelo. São Paulo, 2008. Tese (Doutorado em Administração) - Programa de Pós-Graduação em Administração, Departamento de Administração, Faculdade de Economia, Administração e Contabilidade da Universidade de São Paulo.

MIOTTI, L.; SACHWALD, F. Cooperative R\&D: why, and with whom? An integrated framework of analysis. Research Policy, v. 32, n. 8, p.1481-1499, 2003.

MONJON, S.; WAELBROECK, P. Assessing spillovers from universities to firms: evidence from French firm level data. International Journal of Industrial Organization, v. 21, n. 9, p. 1255-1270, 2003.

NDOU, V.; DEL VECCHIO, P.; SCHINA, L. Open Innovation Networks: the role oof innovative marketplaces for small and medium enterprises' value creation. International Journal of Innovation and Technology Management, v. 8, n. 3, p. 437-453, 2011.

NEELY, A.; HII, J. Innovation and business performance: a literature review. University of Cambridge: The Judge Institute of Management Studies, 1998.

NIETO, M. J., SANTAMARÍA, L. The importance of diverse collaborative networks for the novelty of product innovation. Technovation, v. 27, n. 3, p. 367-377, 2007.

NOHRIA, N.; GARCIA-PONT, C. Global strategic linkages and industry structure. Strategic Management Journal, v. 12, n. S1, p. 105-124, 1991.

NONAKA, I.; KONNO, N.; TOYAMA, R. Emergence of Ba: a conceptual framework for the continuous and self- transcending process of knowledge creation. In: NONAKA, I.; NISHIGUCHI, T. (org.) Knowledge Emergence: social, technical and evolutionary dimensions of knowledge creation. New York: Oxford University Press, 2001, p. 13-29.

NONAKA, I; TAKEUCHI, H. Criação do conhecimento na empresa: como as empresas japonesas geram a dinâmica da inovação. Rio de Janeiro: Campus, 1997.

O'DOHERTY, D. Networking in Ireland: Policy responses, in Sustaining Competitive Advantage, Proceedings of National Economic and Social Council (NESC) Seminar, Dublin: NESC Research Series, 1998.

OLIVA, F. L.; SOBRAL, M. C.; SANTOS, S. A; ALMEIDA, M. I. R.; GRISI, C. C. H. Measuring the probability of innovation in technology-based companies. Journal of Manufacturing Technology Management, v. 22 , n. 3, p. 365-383, 2011.

OLIVER, C. Determinants of inter-organizational relationships: integration and future directions. Academy of Management Review, v. 15, n. 2, p. 241-265, 1990. 
ORGANIZAÇÃO PARA A COOPERAÇÃO E O DESENVOLVIMENTO ECONÔMICO (OCDE). Manual de Oslo: Proposta de Diretrizes para a Coleta e Interpretação de dados sobre Inovação Tecnológica. 3 ed., 2005.

Organization Studies. v. 19, n.4, 1998.

PELLEGRIN, I.; BALESTRO, M. V; ANTUNES JUNIOR, J. A. V.; CAULLIRAUX, H. M. Redes de inovação: construção e gestão da cooperação pró-inovação. Revista de Administração, São Paulo, v.42, n.3, p.313-325, jul./ago./set. 2007.

PEREIRA, J. M. Manual de metodologia da pesquisa científica. São Paulo: Atlas, 2007.

PLISSON, J.; LJUBIC, P.; MOZETIC, I.; LAVRAC, N. An Ontology for Virtual Organization Breeding Environments, IEEE transactions on systems, man, and cybernetics - part c: applications and reviews, v. 37, n. 6, p.1327-1341, 2007.

PORTER, M. E. Clusters and the new economics competition. Harvard Business Review, v.76, n.6, 1998.

Campus, 1999.

Competição: estratégias competitivas essenciais. Rio de Janeiro:

POWELL, W. W. Hybrid organizational arrangements: new form or transitional development? California Management Review, v. 30, n. 1, p. 67-87, 1987.

POWELL, W. W.; GRODAL, S. Networks of innovators. In: JAN FAGERBERG, J.; MOWERY, D. C.; NELSON, R. R. (orgs.). The Oxford Handbook of Innovation. New York: Oxford University Press, 2006, p.56-85.

POWELL, W. W.; KOPUT, K. W.; SMITH-DOERR, L. Interorganizational collaboration and the locus of innovation: networks of learning in biotechnology. Administrative Science Quarterly, v.41, p.116-145, 1996.

POWELL, W. W.; WHITE, D. R.; KOPUT, K. W. Network Dynamics and Field Evolution: The Growth of Interorganizational Collaboration in the Life Sciences. American Journal of Sociology, v. 110, n.4, p. 1132-1205, jan/2005.

PRAHALAD, C. K.; RAMASWAMY, V. O futuro da competição: como desenvolver diferenciais inovadores em parcerias com clientes. Rio de Janeiro: Elsevier, 2004.

PROVAN, K.G.; FISH, A.; SYDOW, J. Interorganizational networks at the network level: a review of the empirical literature on whole networks. Journal of Management, v. 33, n.3, p. 479-516, 2007.

QUINN, J. B. Managing innovation: controlled chaos. Harvard Business Review, v. 63, n.3, p. 73-84, May/June, 1985.

RADEMAKERS, M. F. L. Corporate universities: driving force of knowledge innovation. Journal of Workplace Learning. v.17, n. 1/2, p. 130-136, 2005.

RITTER, T.; GERMUNDEN, G. H. Interorganizational relationships and networks: an overview. Journal of Business Research, v. 56, n. 9, p. 691-697, 2003. 
ROBERTS, E. B.; BERRY, C. A. Entering new businesses: selecting strategies for success. Sloan Management Review, v. 26, n. 3, 1985.

ROSENFELD, S. A. Industrial-Strength Strategies: Regional Business Clusters and Public Policy. Washington DC: The Aspen Institute, 1995.

ROTHAERMEL, F. T. Incumbent's advantage through exploiting complementary assets via interfirm cooperation. Strategic Management Journal, v. 22, n. 6-7, p. 687-699, 2001.

ROTHWELL, R.. Towards the Fifth-generation Innovation Process. International Marketing Review, v. 11, n. 1, p.7-31, 1994.

RUEF, M. Strong ties, weak ties and islands: structural and cultural predictors of organizational innovation. Industral and Corporate Change, v.11, n.3, p.427-449, 2002.

SAMPIERI, R. H.; COLLADO, C. F.; LUCIO, P. B. Metodologia de Pesquisa. 3.ed. São Paulo: McGraw-Hill, 2006.

SÁNCHEZ, A. M.; PÉREZ, M. P. Cooperation and the ability to minimize the time and cost of new product development within the Spanish automotive supplier industry. Journal of Product Innovation Management , v. 20, n. 1, p. 57-69, 2003.

SCHMIDT, T. What determines absorptive capacity? In: Dynamics of Industry and Innovation: Organizations, Networks and Systems, 2005, Copenhagen. Anais...Copenhagen: DRUID Tenth Anniversary Summer Conference. Disponível em: $<$ http://www.druid.dk/conferences/summer2005/papers/ds2005-433.pdf $>$, acesso em $25 \mathrm{de}$ maio, 2012.

SCHUMPETER, J. A. Business cycles: a theoretical, historical and statistical analysis of the capitalist process. New York: Mcgraw-Hill, 1939.

SEBRAE. Critérios de Classificação de Empresas: EI - ME - EPP. 2012. Disponível em < http://www.sebrae-sc.com.br/leis/default.asp?vcdtexto=4154>, acesso em 21 de agosto de 2012.

SHAN, W.; WALKER, G.; KOGUT, B. Interfirm cooperation and startup innovation in the biotechnology industry. Strategic Management Journal, v. 15, n. 5, p. 387-394, 1994.

SHAW, B. User/Supplier links and innovation. In: DODGSON, M.; ROTHWELL, R. (eds.). The handbook of industrial innovation. Brookfield: Edward Elgar, 1994.

SMITH-DOERR, L.; POWELL, W. Networks and Economic Life. In: SMELSER, Neil J.; SWEDBERG, Richard (Eds.). The Handbook of Economic Sociology. 2. ed. Princeton e Oxford: Princeton University Press, 2005.

SUROWIECKI, J. A sabedoria das multidões. Rio de Janeiro: Record, 2006.

TAPSCOTT, D.; WILLIAMS, A. D. Wikinomics: como a colaboração em massa pode mudar o seu negócio. Rio de Janeiro: Nova Fronteira, 2007. 
TEECE, D. J. Profiting from technological innovation: Implications for integration, collaboration, licensing and public policy. Research Policy, v. 15, n. 6, p. 285-305, 1986.

Strategies for managing knowledge assets: the role of firm structure and industrial context. Long Range Planning, v. 33, n. 1, p. 35-54, 2000.

TETHER, B. Who cooperate for innovation, and why: an empirical analysis. Research Policy, v. 31, n. 6, p. 947-967, 2002.

TIDD, J.; BESSANT, J; PAVITT, K. Learning through alliances. In: MAYLE, D. (eds.) Managing Innovation and Change. 2.ed. London: SAGE, 2002.

Managing Innovation: Integrating technological, market and organizational change. 3 ed. Chichester: Wiley, 2005.

Gestão da Inovação. 3 ed., Porto Alegre: Bookman, 2008.

TODOROVA, G.; DURISIN, B. Absorptive capacity: valuing a reconceptualization. Academy of Management Review, v. 32, n. 3, p. 774-786, 2007.

TSAI, K. H. Collaborative networks and product innovation performance: toward a contingency perspective. Research Policy, v.38, p. 765-778, 2009.

VARIS, M.; LITTUNEN, H. Types of innovation, sources of information and performance in entrepreneurial SMEs. European Journal of Innovation, v.13, n.2, p.128-154, 2010.

VERÍSSIMO, H. U. D. S. Segmentação de mercado aplicada ao varejo online. São Paulo, 2011. Dissertação (Mestrado em Administração) - Programa de Pós-Graduação em Administração, Departamento de Administração, Faculdade de Economia, Administração e Contabilidade da Universidade de São Paulo.

VEUGELERS, R. Collaboration in R\&D: an assessment of theoretical and empirical findings. De Economist, v. 149, n. 3, p. 419-443, 1998.

VON HIPPEL, E. The sources of innovation. New York: Oxford University Press, 1988.

Economics of Product Development by Users: The Impact of 'Sticky' Local Information. Management Science, v. 44, p. 629-44, 1998.

VON HIPPEL, E.; THOMKE, S.; SONNACK, M. Creating breakthroughs at 3M. Harvard Business Review, v. 77, n. 5, p. 47-57, 1999.

WESTERLUND, M.; RAJALA, R. Learning and innovation in inter-organizational network collaboration. Journal of Business \& Industrial Marketing, v. 25, n. 6, p.435-442, 2010.

WHEELWRIGHT, S. C.; CLARK, K. B. Revolutionizing product development: quantum leaps in speed, efficiency and quality. New York: The Free Press, 1992.

WITZEMAN， S.; SLOWINSKI， G.; DIRKX， R.; GOLLOB， L.; TAO， J.; WARD, S.; MIRAGLIA, S.. Harnessing External Technology for Innovation. Research-Technology Management, v. 49, n. 3, p. 19-27, may/june 2006. 
YIN, R. K. Estudo de Caso: planejamento e métodos. 3. ed. Porto Alegre: Bookman, 2005.

ZOUAIN, D. M. Pesquisa Quantitativa em Administração. São Paulo: Atlas, 2006. 


\title{
APÊNDICE
}

\section{APÊNDICE 1 - INSTRUMENTO DE COLETA DE DADOS}

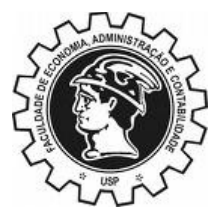

\author{
Programa de Pós-Graduação em Administração \\ Pesquisa sobre Redes de inovação \\ FEA-USP 2013
}

Prezado(a) Senhor(a),

Estamos realizando uma pesquisa que tem por objetivo verificar se a formação de redes de inovação pode contribuir para o desempenho inovador das empresas da Indústria Elétrica Eletrônica.

A pesquisa visa contribuir para a elaboração de uma dissertação de mestrado e está sendo conduzida pela mestranda Silvye Ane Massaini, sob a orientação do Prof. Dr. Fábio Lotti Oliva, da Faculdade de Economia, Administração e Contabilidade da Universidade de São Paulo (FEA-USP), com o apoio do Instituto de Pesquisa e Desenvolvimento Tecnológico do Complexo Eletroeletrônico e Tecnologia da Informação (IPD Eletron), organização parceira da Associação Brasileira da Indústria Elétrica Eletrônica (ABINEE).

As informações obtidas por meio deste questionário serão utilizadas unicamente para fins acadêmicos e os dados da pesquisa serão divulgados de forma agregada. Os resultados finais deste estudo serão disponibilizados às empresas respondentes interessadas.

O período de coleta de dados da pesquisa ocorrerá de 18/02/2013 até 14/04/2013.

O tempo estimado para resposta deste questionário é de aproximadamente 20 minutos.

Solicitamos gentilmente que as perguntas sejam respondidas pelo gestor da empresa (ou por alguém por ele designado).

Agradecemos antecipadamente pela colaboração e colocamo-nos à disposição para quaisquer esclarecimentos.

Atenciosamente,

Silvye Ane Massaini

Mestranda da FEA-USP

Professora da Faculdade de Administração da FAAP

E-mail: $\underline{\text { samassaini@usp.br }}$

Prof. Dr. Fábio Lotti Oliva

Professor da FEA-USP

Coordenador da Fundação Instituto de Administração - FIA.

E-mail: fabiousp@usp.br 
Data: $/ 2013$

No questionário:

PARTE 1 - DADOS DA EMPRESA

1. Razão social da empresa:

2. UF:

3. Sua empresa é:

( ) Independente

( ) Parte de um grupo

Capital controlador: participação no capital social que assegura a maioria dos votos e que, portanto, possui direitos permanentes de eleger os administradores e de preponderar nas deliberações sociais.

Origem do capital: o capital é nacional quando está sob a titularidade direta ou indireta de pessoas físicas ou jurídicas residentes e domiciliadas no país. É estrangeiro quando está sob titularidade direta ou indireta de pessoas físicas ou jurídicas fora do país.

4. Origem do capital controlador da empresa:

( ) Nacional

( ) Estrangeiro

( ) Nacional e estrangeiro

5. Principal segmento de atuação da empresa:
( ) Automação Industrial
( ) Comércio Eletrônico
( ) Componentes Elétricos e Eletrônicos
( ) Equipamentos Industriais
( ) Geração, Transmissão e Distribuição
( ) Informática
( ) Material Elétrico
( ) Meio Ambiente
( ) Serviço de Manufatura em Eletrônica
( ) Sistemas Eletroeletrônicos Prediais
( ) Telecomunicações
( ) Utilidades Domésticas
( ) Outro:

6. Receita operacional bruta anual em 2012:
( ) até $\mathrm{R} \$ 1,2$ milhão
( ) acima de $\mathrm{R} \$ 1,2$ milhão até $\mathrm{R} \$ 10,5$ milhões
( ) acima de $\mathrm{R} \$ 10,5$ milhões até $\mathrm{R} \$ 60$ milhões
( ) acima de $\mathrm{R} \$ 60$ milhões

7. Número de funcionários da empresa: (número)

8. Percentual de funcionários da empresa (em relação ao total) que possui cursos de Especialização, Mestrado e Doutorado:

\begin{tabular}{lr} 
Especialização & $\%$ \\
Mestrado & $\%$ \\
Doutorado & $\mathbf{\%}$ \\
\hline
\end{tabular} 
9. Assinale as principais áreas de formação dos profissionais que trabalham na empresa (resposta múltipla):

( ) Administração de empresas

( ) Arquitetura e urbanismo

( ) Ciências contábeis

( ) Direito

( ) Economia

( ) Engenharia

( ) Filosofia

( ) Marketing

( ) Psicologia

( ) Publicidade e propaganda

( ) Relações internacionais

( ) Tecnologia da informação

( ) Outra:

10. A empresa realizou, nos últimos 3 anos, a contratação de profissionais de empresas estrangeiras?

( ) Sim

( ) Não

11. Percentual da receita operacional bruta anual gasto com atividades de treinamento em 2012: número (\%)

12. Percentual da receita operacional bruta anual gasto com Pesquisa e Desenvolvimento (P\&D) em 2012: número (\%)

13. Número de funcionários no departamento de P\&D: (número) 


\section{PARTE 2 - DESEMPENHO INOVADOR}

Uma inovação refere-se à implementação de um produto (bem ou serviço), um processo, um método de marketing e/ou um método organizacional novo ou significativamente melhorado por parte da organização. O requisito mínimo para se definir uma inovação é que o produto, o processo, o método de marketing ou organizacional sejam novos (ou significativamente melhorados) para a empresa, não sendo necessariamente novos para o mercado. Isso inclui produtos, processos e métodos que as empresas são as pioneiras a desenvolver e aqueles que foram adotados de outras empresas ou organizações

14. Com base em informações dos últimos três anos da sua empresa, indique o grau de concordância em relação às afirmações abaixo.

Atribua valores de 0 a 10, conforme expresso na escala a seguir:

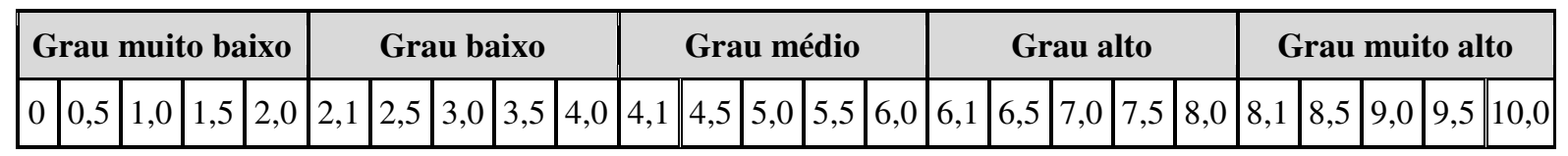

\begin{tabular}{|c|c|c|}
\hline & & $\begin{array}{c}\text { Grau de } \\
\text { concordância }\end{array}$ \\
\hline PROD1 & $\begin{array}{l}\text { A empresa introduziu pelo menos um produto (bem ou serviço) novo ou } \\
\text { significativamente melhorado no mercado. }\end{array}$ & \\
\hline MKT2 & $\begin{array}{l}\text { Foram implementadas grandes mudanças na estética ou desenho em pelo menos um dos } \\
\text { produtos }\end{array}$ & \\
\hline ORG1 & $\begin{array}{l}\text { A empresa implementou novas técnicas de gestão para melhorar rotinas e práticas de } \\
\text { trabalho } \\
\text { (como por exemplo: reengenharia dos processos de negócio, gestão do conhecimento, } \\
\text { controle da qualidade total, sistemas de formação/treinamento, SIG e ERP) }\end{array}$ & \\
\hline ORG3 & $\begin{array}{l}\text { A empresa implementou mudanças nas relações com outras empresas ou instituições } \\
\text { públicas visando constituir uma novidade organizacional } \\
\text { (tais como o estabelecimento pela primeira vez de alianças, parcerias, terceirização ou } \\
\text { subcontratação de atividades) }\end{array}$ & \\
\hline $\mathrm{PROC} 3$ & $\begin{array}{l}\text { A empresa introduziu equipamentos, softwares e técnicas em atividades de apoio à } \\
\text { produção } \\
\text { (como por exemplo: planejamento e controle da produção, medição de desempenho, } \\
\text { controle da qualidade, compra, manutenção ou infraestrutura de TI) }\end{array}$ & \\
\hline MKT1 & $\begin{array}{l}\text { A empresa implementou mudanças significativas nos conceitos/estratégias de marketing } \\
\text { (como por exemplo novas mídias, técnicas para a promoção de produtos; novas formas } \\
\text { para colocação de produtos no mercado; ou novos métodos de fixação de preços) }\end{array}$ & \\
\hline $\mathrm{PROC} 2$ & $\begin{array}{l}\text { A empresa introduziu pelo menos um sistema logístico ou método de entrega para seus } \\
\text { insumos, bens ou serviços }\end{array}$ & \\
\hline PROC1 & A empresa introduziu pelo menos um novo método de fabricação de bens ou serviços & \\
\hline PROD2 & $\begin{array}{l}\text { Grande parte do percentual de vendas da empresa é proveniente de produtos (bens ou } \\
\text { serviços) novos ou significativamente melhorados. }\end{array}$ & \\
\hline PROD3 & A empresa participa frequentemente de congressos e feiras como expositor/palestrante. & \\
\hline ORG2 & $\begin{array}{l}\text { A empresa implementou novos métodos de organização do trabalho para melhor distribuir } \\
\text { responsabilidades e poder de decisão } \\
\text { (como por exemplo o estabelecimento do trabalho em equipe, a descentralização ou } \\
\text { integração de departamentos) }\end{array}$ & \\
\hline PROD4 & A empresa possui poucos competidores por produto ou serviço oferecido. & \\
\hline
\end{tabular}


15. Indique a intensidade dos efeitos citados a seguir, decorrentes da implementação de inovações na sua organização, nos últimos três anos.

Atribua valores de 0 a 10, conforme expresso na escala abaixo:

\begin{tabular}{|c|c|c|c|c|c|c|c|c|c|c|c|c|c|c|c|c|c|c|c|c|c|c|c|c|}
\hline \multicolumn{5}{|c|}{$\begin{array}{c}\text { Intensidade muito } \\
\text { baixa }\end{array}$} & \multicolumn{5}{|c|}{ Intensidade baixa } & \multicolumn{5}{|c|}{ Intensidade média } & \multicolumn{5}{|c|}{ Intensidade alta } & \multicolumn{5}{|c|}{$\begin{array}{c}\text { Intensidade muito } \\
\text { alta }\end{array}$} \\
\hline 0 & 0,5 & 1,0 & 1,5 & 2,0 & 2,1 & 2,5 & 3,0 & 3,5 & 4,0 & 4,1 & 4,5 & 5,0 & 5,5 & 6,0 & 6,1 & 6,5 & 7,0 & 7,5 & 8,0 & 8,1 & 8,5 & 9,0 & 9,5 & 10,0 \\
\hline
\end{tabular}

\begin{tabular}{|c|l|c|}
\hline \multicolumn{2}{|l}{} & Intensidade \\
\hline PROC6 & Redução do consumo de matérias-primas e energia & \\
ORG6 & Enquadramento em regulações e normas relativas ao mercado interno ou externo. & \\
\hline PROD5 & Melhoria na qualidade dos bens ou serviços da empresa. & \\
\hline MKT3 & Abertura de novos mercados. & \\
\hline PROC4 & Aumento da capacidade e flexibilidade de produção ou de prestação de serviços. & \\
\hline ORG4 & Melhoria na comunicação e a interação entre as diferentes áreas de negócios. & \\
\hline PROD6 & Ampliação da gama de bens ou serviços ofertados pela empresa. & \\
\hline MKT4 & Aumento da visibilidade ou da exposição dos produtos. & \\
\hline PROC5 & Redução de custos de produção/serviços prestados. & \\
\hline ORG5 & Melhoria no compartilhamento e a transferência de conhecimentos com outras organizações. & \\
\hline MKT5 & Melhoria da capacidade de adaptação às diferentes demandas dos clientes. & \\
\hline
\end{tabular}




\section{PARTE 3 - CARACTERÍSTICAS DA REDE DE INOVAÇÃO}

Relações para a inovação: referem-se à participação ativa em relações cujo objetivo seja o desenvolvimento de inovações com outra organização (empresa ou instituição). Isto não implica, necessariamente, que as partes envolvidas obtenham benefícios comerciais imediatos. A simples contratação de serviços de outra organização, sem a sua colaboração ativa, não deve ser considerada.

16. Quem geralmente desenvolve as inovações?

( ) Principalmente a empresa

( ) Principalmente outra empresa do grupo

( ) Principalmente a empresa em cooperação com outras empresas ou institutos

( ) Principalmente outras empresas ou institutos

17. Nos últimos três anos, pelo menos uma inovação foi desenvolvida a partir da colaboração com:

\begin{tabular}{|l|l|l|}
\hline & Sim & Não \\
\hline Clientes / consumidores & & \\
\hline Fornecedores & & \\
\hline Competidores & & \\
\hline Universidades e institutos de pesquisa & & \\
\hline
\end{tabular}

18. Tendo em vista o estabelecimento de relações com outras organizações visando o desenvolvimento de inovações, indique a importância de cada parceiro.

Atribua valores de 0 a 10, conforme expresso na escala a seguir:

\begin{tabular}{|c|c|c|c|c|c|c|c|c|c|c|c|c|c|c|c|c|c|c|c|c|c|c|c|c|}
\hline \multicolumn{5}{|c|}{ Grau muito baixo } & \multicolumn{5}{|c|}{ Grau baixo } & \multicolumn{5}{|c|}{ Grau médio } & \multicolumn{5}{|c|}{ Grau alto } & \multicolumn{5}{|c|}{ Grau muito alto } \\
\hline 0 & 0,5 & 1,0 & 1,5 & 2,0 & 2,1 & 2,5 & 3,0 & 3,5 & 4,0 & 4,1 & 4,5 & 5,0 & 5,5 & 6,0 & 6,1 & 6,5 & 7,0 & 7,5 & 8,0 & 8,1 & 8,5 & 9,0 & 9,5 & 10,0 \\
\hline
\end{tabular}

\begin{tabular}{|l|c|}
\cline { 2 - 2 } \multicolumn{1}{l|}{} & \multicolumn{1}{c|}{$\begin{array}{c}\text { Grau de } \\
\text { importância }\end{array}$} \\
\hline Clientes / consumidores & \\
\hline Fornecedores & \\
\hline Competidores & \\
\hline Universidades e institutos de pesquisa & \\
\hline
\end{tabular}

19. Quais as principais razões para o estabelecimento de relações visando o desenvolvimento de inovações com outras organizações? (resposta múltipla)
( ) acesso a ativos complementares
( ) distribuição de custos
( ) redução de riscos
( ) combinação de competências
( ) acesso a novos conhecimentos
( ) redução do tempo resposta ao mercado
( ) melhora da capacidade em lidar com a complexidade
( ) aumento da aprendizagem
( ) melhora da eficiência
( ) outras: 
20. Com relação às afirmações acerca da empresa em que trabalha, por favor indique o seu grau de concordância.

Atribua valores de 0 a 10, conforme expresso na escala a seguir:

\begin{tabular}{|c|c|c|c|c|c|c|c|c|c|c|c|c|c|c|c|c|c|c|c|c|c|c|c|c|c|}
\hline \multicolumn{5}{|c|}{ Grau muito baixo } & \multicolumn{5}{|c|}{ Grau baixo } & \multicolumn{6}{|c|}{ Grau médio } & \multicolumn{5}{|c|}{ Grau alto } & \multicolumn{5}{|c|}{ Grau muito alto } \\
\hline 0 & 0,5 & 1,0 & 1,5 & 2,0 & 2,1 & 2,5 & 3,0 & 3 & 4, & 4, & 4,5 & 5,0 & 5 , & & 5,0 & 6,1 & 6,5 & 7,0 & 7,5 & 8,0 & 8,1 & 8,5 & 9,0 & 9,5 & 10,0 \\
\hline
\end{tabular}

\begin{tabular}{|c|c|c|}
\hline & & $\begin{array}{c}\text { Grau de } \\
\text { concordância }\end{array}$ \\
\hline $\mathrm{ABS} 3$ & A área de P\&D é bastante relevante para o desenvolvimento de inovações na empresa. & \\
\hline ABS7 & $\begin{array}{l}\text { Pelos menos uma inovação na empresa foi desenvolvida a partir de relações com } \\
\text { clientes, fornecedores, competidores, universidades ou institutos de pesquisa nos } \\
\text { últimos } 3 \text { anos. }\end{array}$ & \\
\hline EXPR1 & $\begin{array}{l}\text { A empresa desenvolve relações com parceiros que permitam a implementação de } \\
\text { inovações mais radicais. }\end{array}$ & \\
\hline EXPT1 & $\begin{array}{l}\text { A empresa desenvolve relações com parceiros que permitam a realização de inovações } \\
\text { incrementais. }\end{array}$ & \\
\hline EXPR2 & $\begin{array}{l}\text { A empresa visa o desenvolvimento de relações que lhe proporcionem a geração de } \\
\text { novas ideias e conhecimentos organizacionais. }\end{array}$ & \\
\hline EXPT2 & $\begin{array}{l}\text { A empresa visa o desenvolvimento de relações que lhe proporcionem o reforço e } \\
\text { aprimoramento dos conhecimentos organizacionais já estabelecidos. }\end{array}$ & \\
\hline EXPR3 & $\begin{array}{l}\text { O desenvolvimento de ligações mais fracas com os parceiros de inovação é preferível, } \\
\text { por possibilitar a difusão de novas informações. }\end{array}$ & \\
\hline EXPT3 & $\begin{array}{l}\text { O desenvolvimento de ligações fortes com os parceiros de inovação é preferível, por } \\
\text { estarem baseadas em interações regulares, fundamentadas na confiança entre as } \\
\text { organizações. }\end{array}$ & \\
\hline EXPR4 & $\begin{array}{l}\text { A empresa possui como foco o desenvolvimento de novos produtos, processos e } \\
\text { métodos. }\end{array}$ & \\
\hline EXPT4 & $\begin{array}{l}\text { A empresa possui como foco a melhoria dos produtos, métodos e processos } \\
\text { existentes. }\end{array}$ & \\
\hline
\end{tabular}


PARTE 4 - PERFIL DO RESPONDENTE

21. Gênero:

( ) Masculino

( ) Feminino

22. Qual a sua posição hierárquica na empresa?

( ) Sócio / Proprietário

( ) Presidente

( ) Diretor

( ) Gerente

( ) Outro:

23. Qual o seu grau de escolaridade?

( ) Ensino fundamental incompleto

( ) Ensino fundamental completo

( ) Ensino médio incompleto

( ) Ensino médio completo

( ) Ensino superior incompleto

( ) Ensino superior completo

( ) Pós-graduação incompleta

( ) Pós-graduação completa

24. Há quantos anos trabalha na empresa? (número)

25. E-mail:

(Caso tenha interesse em receber os resultados finais da pesquisa, por favor preencha este campo com seu e-mail) 


\section{APÊNDICE 2 - SOLICITAÇÃO DE APOIO À PESQUISA}

São Paulo, 01 de março de 2013.

Ao Instituto de Gestão de Pesquisa, Desenvolvimento e Inovação para a Indústria Elétrica e Eletrônica, organização parceira da Associação Brasileira da Indústria Elétrica e Eletrônica (ABINEE)

\section{At.: Ilmo. Sr. Fabián Yaksic}

Prezado Senhor,

Venho, por meio desta, solicitar o apoio do Instituto de Gestão de Pesquisa, Desenvolvimento e Inovação para a Indústria Elétrica Eletrônica (IPD Eletron), organização parceira da Associação Brasileira da Indústria Elétrica e Eletrônica (ABINEE), para repasse do questionário da pesquisa intitulada "Estudo da contribuição dos parceiros estabelecidos em redes de inovação para o desempenho inovador de empresas da Indústria Elétrica Eletrônica" aos seus associados, visando a elaboração de uma dissertação de mestrado na Faculdade de Economia, Administração e Contabilidade da Universidade de São Paulo (FEA-USP).

Ressalto que os dados serão coletados por meio de uma ferramenta on-line por mim disponibilizada e que as análises e resultados finais serão divulgados aos participantes da pesquisa e à ABINEE.

Grata pela colaboração,

\section{Silvye Ane Massaini}

No USP: 7544177

Mestranda da FEA-USP

Professora da Faculdade de Administração da FAAP

E-mail: samassaini@usp.br 


\section{APÊNDICE 3 - COMUNICADO AOS ASSOCIADOS DA ABINEE}

Prezados Associados,

A Faculdade de Economia, Administração e Contabilidade (FEA) da Universidade de São Paulo (USP) está realizando uma pesquisa, com o apoio da ABINEE e do IPD Eletron, sobre as possíveis contribuições decorrentes da formação de redes de inovação para a Indústria Elétrica e Eletrônica.

Os dados fornecidos serão utilizados para elaboração de uma dissertação de Mestrado (FEA-USP), e os resultados serão divulgados de forma agregada, mantendo o sigilo das informações e o anonimato das empresas.

Com a finalidade de contribuirmos para essa pesquisa, solicitamos a gentileza de responder ao questionário on line, com acesso pelo link:

http://edu.surveygizmo.comls3/1157612/Pesquisa-Redes-de-Inova-o

Reiteramos que sua participação é essencial para essa pesquisa, pois permitirá a compreensão de um tema bastante relevante à Indústria.

Os pesquisadores responsáveis pela pesquisa ficam à disposição para mais esclarecimentos, pelos contatos abaixo:

- Silvye Ane Massaini Mestranda da FEA-USP

Professora da Faculdade de Administração da FAAP

E-mail: samassaini@usp.br

- Prof. Dr. Fábio Lotti Oliva

Professor da FEA-USP

Coordenador da Fundação Instituto de Administração - FIA

E-mail: fabiousp@usp.br

Certo de contar com a sua especial atenção e colaboração.

Atenciosamente,

Eng ${ }^{\circ}$. Fabián Yaksic fabian@abinee.org.br

Gerente do Departamento de Tecnologia e Política Industrial - DETEPI

ABINEE - Associação Brasileira da Indústria Elétrica e Eletrônica www.abinee.org.br

Tel. 551121750040 Fax 551121750090

Realização:

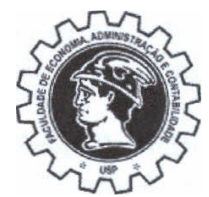

Apoio:

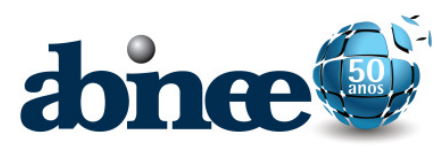

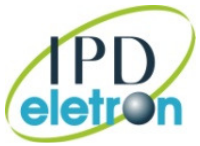

